TESE DE DOUTORADO

RESTAURAÇÃO DE IMAGENS SUBAQUÁTICAS USANDO ALGORITMOS DE ENXAMES E MÉTRICAS ESPECÍFICAS

CAMILO SÁNCHEZ FERREIRA

UNIVERSIDADE DE BRASÍLIA 


\section{UNIVERSIDADE DE BRASÍLIA}

FACULDADE DE TECNOLOGIA

DEPARTAMENTO DE ENGENHARIA MECÂNICA

\section{RESTAURAÇÃO DE IMAGENS SUBAQUÁTICAS USANDO ALGORITMOS DE ENXAMES E MÉTRICAS ESPECÍFICAS}

CAMILO SÁNCHEZ FERREIRA

Orientador: Prof. Dr. Carlos H. Llanos Quintero

Coorientador: Prof. Dr. Leandro dos Santos Coelho - PUCPR

TESE DE DOUTORADO

Publicação: ENM.DM-12/2016

Brasília, 14 de Dezembro de 2016 
UNIVERSIDADE DE BRASÍLIA

Faculdade de Tecnologia

TESE DE DOUTORADO

\section{RESTAURAÇÃO DE IMAGENS SUBAQUÁTICAS USANDO ALGORITMOS DE ENXAMES E MÉTRICAS ESPECÍFICAS}

\section{CAMILO SÁNCHEZ FERREIRA}

Tese de doutorado apresentada ao Programa de Pós-Graduação em Sistemas Mecatrônicos do Departamento de Engenharia Mecânica da

Universidade de Brasília como parte dos requisitos necessários para a obtenção do grau de Doutor em Sistemas Mecatrônicos

\section{Banca Examinadora}

Prof. Dr. Carlos H. Llanos Quintero, Dep. ENM/UnB Orientador

Prof. Dr. José Maurício Santos Torres da Motta, Dep. ENM/UnB Examinador interno

Prof. Dr. Li Weigang, Dep. CIC/UnB

Examinador interno

Profa. Dra. Mylène Christine Queiroz de Farias, Dep. ENE/UnB Examinadora externa

Eng. Dr. Helon Vicente Hultmann Ayala Examinador externo 


\section{FICHA CATALOGRÁFICA}

SÁNCHEZ FERREIRA., CAMILO

RESTAURAÇÃO DE IMAGENS SUBAQUÁTICAS USANDO ALGORITMOS DE ENXAMES E MÉTRICAS ESPECÍFICAS [Distrito Federal] 2016.

xxii, 180p. $210 \times 297 \mathrm{~mm}(\mathrm{ENM} / \mathrm{FT} / \mathrm{UnB}$, Doutor, Sistemas Mecatrônicos, 2016). Tese de Doutorado - Universidade de Brasília. Faculdade de Tecnologia.

Departamento de Engenharia Mecânica.

1. Restauração de Imagens Subaquáticas

2. Otimização Bio-inspirada

3. Processamento de Imagens

4. Avaliação Objetiva de Imagens

I. $\mathrm{ENM} / \mathrm{FT} / \mathrm{UnB}$

II. Título (série)

\section{REFERÊNCIA BIBLIOGRÁFICA}

SÁNCHEZ-FERREIRA, CAMILO. (2016). Restauração de Imagens Subaquáticas Usando Algoritmos de Enxames e Métricas Espeíficas. Tese de Doutorado em Sistemas Mecatrônicos, Publicação ENM.DM-12/2016, Departamento de Engenharia Mecânica, Universidade de Brasília, Brasília, DF, 180p.

\section{CESSÃO DE DIREITOS}

AUTOR: Camilo Sánchez Ferreira.

TÍTULO: Restauração de Imagens Subaquáticas Usando Algoritmos de Enxames e Métricas Espeíficas.

GRAU: Doutor

ANO: 2016

É concedida à Universidade de Brasília permissão para reproduzir cópias desta dissertação de mestrado e para emprestar ou vender tais cópias somente para propósitos acadêmicos e científicos. O autor reserva outros direitos de publicação e nenhuma parte dessa dissertação de mestrado pode ser reproduzida sem autorização por escrito do autor.

Camilo Sánchez Ferreira 


\section{Dedicatória}

Este trabalho está dedicado à minha família: meus pais Alirio (Q.E.P.D) e María Gabriela, meu irmão Santiago e meu sobrinho Sebastián pelo apoio incondicional na minha vida e nos meus estudos.

CAMILO SÁNCHEZ FERREIRA 


\section{Agradecimentos}

Agradeço primeiramente a minha família, já que eles foram meu leme e minha inspiração para continuar sempre lutando e alcançar as minhas metas. Porque, sentindo muita saudade deles, sei que estão comigo de coração, me acompanhando em cada passo, em cada sorriso e em cada problema que possa aparecer. Porque devo para eles tudo o que eu sou hoje, tudo o que tenho alcançado e tudo o que alcançarei na vida.

Agradeço especialmente a Gloria Liliana pelo indispensável e incondicional apoio, companhia e pela força que meu transmitiu nesta etapa da minha vida.

A minha segunda família, Cristabel, Margarita, Daniel, Alejo, Naty, Marcela e Miller por ter sido uma valiosa companhia nos momentos difíceis desta caminhada.

A todos meus amigos que foram um apoio constante desde o começo, e que, em pouco tempo passaram a formar parte importante da minha vida.

Aos meus amigos e colegas do LEIA: Jones, Helon, Sergio, Daniel, Janier, André e Renato por ser minha mão direita e pela amizade, deles aprendi muito e espero continuar aprendendo.

Um agradecimento muito especial para meu orientador, o Professor Carlos Humberto Llanos pela amizade, apoio, confiança, dedicação e paciência. Pelo seu tempo nas longas reuniões e por ter me permitido trabalhar do seu lado, aprendendo mais um pouco dele cada dia.

À Professora Mylène e ao Professor Leandro Coelho pelo valioso tempo investido neste trabalho. Seu apoio foi parte fundamental desta pesquisa.

Ao Programa de Formação em Recursos Humanos PRH-PB223 da Petrobrás e à Coordenação de Aperfeiçoamento de Pessoal de Nivel Superior (CAPES) pelo apoio financeiro deste trabalho.

Ao Grupo de Automação e Controle (GRACO) e todos os meus professores pelo suporte e formação acadêmica. 
RESUMO

\title{
RESTAURAÇÃO DE IMAGENS SUBAQUÁTICAS USANDO ALGORITMOS DE ENXAMES E MÉTRICAS ESPECÍFICAS
}

\author{
Autor: Camilo Sánchez-Ferreira \\ Orientador: Carlos Humberto Llanos \\ Programa de Pós-Graduação em Sistemas Mecatrônicos \\ Brasília, Dezembro 2016
}

Este trabalho apresenta um abordagem para restauração automática de imagens degradadas por um meio subaquático. Neste cenário, a restauração objetiva facilitar a aplicação de etapas posteriores baseadas em algoritmos de processamento de imagens e visão computacional. A estratégia de restauração apresentada neste trabalho requer uma imagem degradada como única entrada, produzindo uma imagem onde as degradações devidas ao meio subaquático são atenuadas. Neste trabalho são apresentados dois tipos de testes de restauração: (a) restauração para imagens degradadas artificialmente e (b) restauração para imagens reais. Em ambos os tipos de testes, a estratégia de restauração foi baseada na inversão de um modelo de formação de imagens (em um meio subaquático), e guiada por algoritmos de otimização bio-inspirados que visam estimar os parâmetros do modelo com a finalidade de minimizar funções objetivo que descrevem o nível de degradação da imagem. Nos primeiros testes de restauração (utilizando imagens com degradações artificiais), foi utilizado o modelo de formação de imagens proposto por Trucco e Olmos-Antillon para imagens em níveis de cinza, que apresenta uma simplificação do efeito de back-scattering. Por outro lado, foi realizado um estudo de desempenho de diferentes métricas de avaliação de qualidade de imagens com o objetivo de encontrar uma função objetivo adequada para guiar o processo de otimização. Neste estudo, a métrica NIQE (Natural Image Quality Evaluator) mostrou um melhor desempenho em comparação às demais métricas e foi utilizada como função objetivo. Posteriormente, foi implementada uma estratégia PSO monoobjetivo utilizando a métrica supracitada como função objetivo. Os resultados obtidos a partir de esta estratégia foram comparados com os resultados gerados por dois algoritmos exatos de otimização disponíveis na Toolbox de otimização do MATLAB. Os resultados do algoritmo PSO mostraram ser muito melhores que os apresentados pelos algoritmos exatos, mesmo assim, a imagem resultante apresentou problemas de contraste devido às limitações da métrica neste tipo de degradação. Por esta razão foi testado uma abordagem multi-objetivo baseada no algoritmo de evolução diferencial, onde foi implementada uma segunda métrica baseada na Distribuição de Contraste Local para cobrir a deficiência da métrica NIQE. Os resultados destes testes mostraram 
melhoras significativas no contraste das imagens restauradas. Nos segundos testes de restauração (usando imagens com degradações subaquáticas reais), foi escolhido o modelo de formação de imagens proposto por Wagner, que considera os dois tipos de degradações: forward-scattering e back-scattering. Neste caso, este modelo foi implementado para a restauração de imagens coloridas, pelo qual foi desenvolvida uma etapa de pré-processamento na qual são estimados um conjunto de parâmetros para compensação cromática. Esta estratégia de restauração foi testada utilizando 5 algoritmos de otimização bio-inspirada (chamados OPSO, RAPSO, ABC, OABC e DE), utilizando como única função objetivo a métrica NIQE. As imagens resultantes (assim como posteriores testes estatísticos) mostraram que os algoritmos OPSO e ABC apresentam o melhor desempenho. Adicionalmente, no contexto deste trabalho também foram desenvolvidas duas ferramentas para o estudo e a implementação de algoritmos de restauração de imagens em meios subaquáticos. A primeira ferramenta consiste na implementação de três modelos simplificados de degradação expostos na literatura, permitindo simular as degradações geradas pela água em qualquer imagem. A segunda ferramenta é o banco UID-LEIA (LEIA Underwater Image Database), que consta de 135 imagens degradadas com um índice de qualidade MOS obtido a partir de experimentos subjetivos. Este banco de imagens foi utilizado para realizar o estudo de desempenho das métricas implementadas no contexto deste trabalho, analisando à capacidade de avaliar a qualidade em imagens com degradações subaquáticas reais. 
ABSTRACT

UNDERWATER IMAGE RESTORATION USING SWARM-BASED ALGORITHMS AND SPECIFIC MÉTRICS

Author: Camilo Sánchez-Ferreira

Advisor: Carlos Humberto Llanos

Programa de Pós-Graduação em Sistemas Mecatrônicos

Brasília, December 2016

This work presents an approach for automatic restoration of images degraded by an underwater environment. In this scenery the image restoration aims to make possible the application of subsequent steps based on both image processing and computer vision algorithms. The restoration strategy presented in this work requires a degraded image as the only input, yielding an image where degradations due to the underwater environment are attenuated. In this work two types of restoration experiments are presented: (a) restoration for artificially degraded images and (b) restoration for real images. In both types of experiments, the restoration strategy was based on the inversion of a propagation model (in an underwater environment), guided by bio-inspired optimization algorithms for estimating the model parameters, in order to minimize objective functions that describe the degradation level of the image. In the first restoration experiment (using images with artificial degradations), the propagation model proposed by Trucco and Olmos-Antillon for gray-scale images has been used, which presents a simplification of the back-scattering effect. On the other hand, a performance study of different image quality assessment metrics was performed in order to find out an adequate objective function to guide the optimization process. In this study, the NIQE (Natural Image Quality Estimator) metric showed a better performance in comparison to the other metrics and was used as an objective function. Subsequently, a mono-objective PSO strategy was implemented using the aforementioned metric as an objective function. The results obtained from this strategy were compared with the results generated by two exact optimization algorithms available in the MATLAB Optimization Toolbox. The results of the PSO algorithm shown to be much better than those presented by the exact algorithms, although the resulting image presented contrast problems due to the limitations of the metric in this type of degradation. For this reason, a multi-objective approach based on the differential evolution algorithm was tested, where a second metric based on the Local Contrast Distribution was implemented to cover the deficiency of the NIQE metric. The results of these tests showed significant improvements in the contrast of restored images. In the second restoration experiment (using images with real underwater degradations) the propagation model 
proposed by Wagner was chosen, which considers both degradations: the forward-scattering and the back-scattering effects. In this case, this model was implemented for the restoration of colour images, whereby a preprocessing stage was developed, in which a set of parameters for colour compensation are estimated. This restoration strategy was tested by using five bio-inspired optimization algorithms (namely, OPSO, RAPSO, ABC, OABC and DE), using the NIQE metric as an unique objective function. The resulting images (as well as subsequent statistical tests) have pointed out that both OPSO and $\mathrm{ABC}$ algorithms present the best performance. Additionally, in the context of this work two tools have also been developed for the study and implementation of image restoration algorithms in underwater environments. The first tool consists of the implementation of three simplified degradation models presented in the literature, allowing the simulation of degradations generated by water in any image. The second one is the UID-LEIA database (LEIA Underwater Image Database), which comprises 135 degraded images with a MOS quality index obtained from subjective experiments. This image database was used to perform a performance study of the metrics implemented in the context of this work, analysing the ability to assess quality in images with real underwater degradations. 


\section{SUMÁRIO}

Lista de Figuras..$\ldots \ldots \ldots \ldots \ldots \ldots \ldots \ldots \ldots \ldots \ldots \ldots \ldots \ldots \ldots \ldots \ldots \ldots \ldots \ldots \ldots$

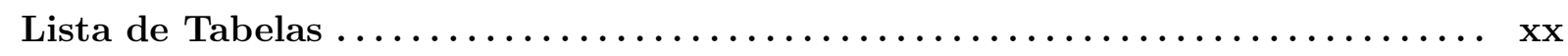

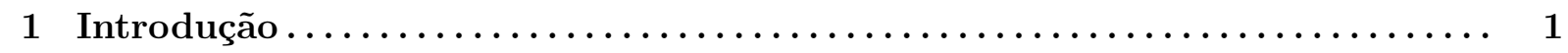

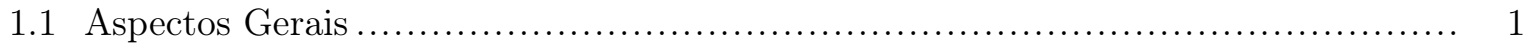

1.1.1 Processamento de Imagens e Visão Computacional ............................... 1

1.1.2 Áreas de Aplicação dos Sistemas de Visão Computacional ........................ 2

1.1 .3 Restauração de Imagens Subaquáticas ............................................. 4

1.1.4 Algoritmos de Otimização Aplicados ao Problema de

Restauração de Imagens ............................................................. 5

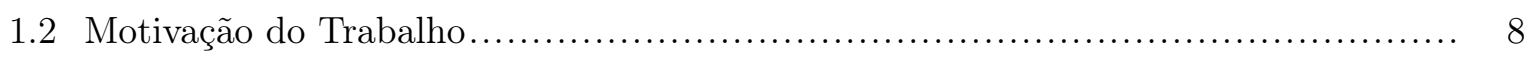

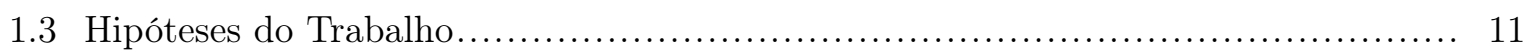

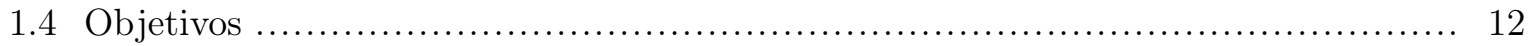

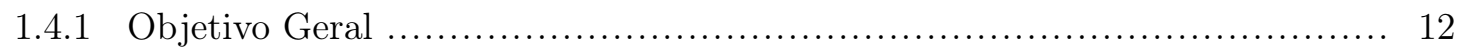

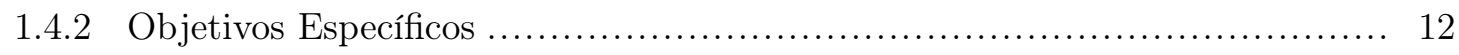

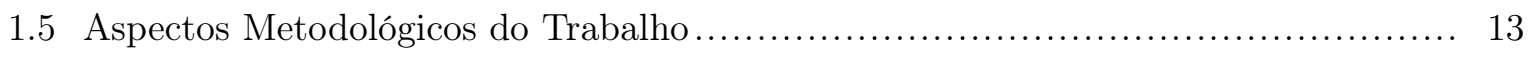

1.6 Contribuições do Trabalho ............................................................. 14

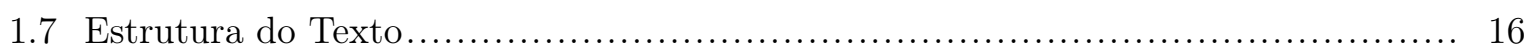

2 Modelos de Formação e Restauração de

Imagens em Meios Participativos..$\ldots \ldots \ldots \ldots \ldots \ldots \ldots \ldots \ldots \ldots \ldots \ldots \ldots \ldots$

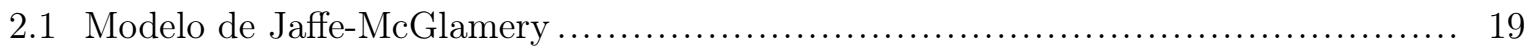

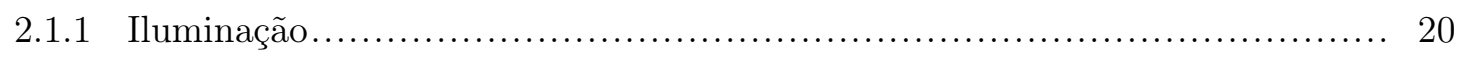

2.1 .2 Reflectância do Objeto ............................................................... 22

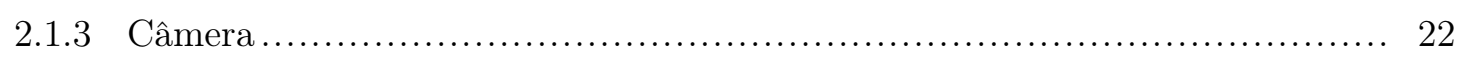

2.1 .4 Descrição Final do Modelo Jaffe-McGlamery ..................................... 23

2.2 Modelo Simplificado de Schechner ........................................................... 24

2.3 Modelo Simplificado Proposto por Trucco e

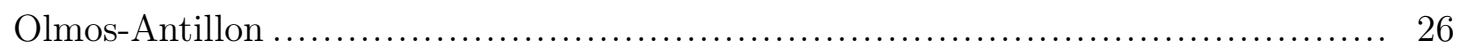




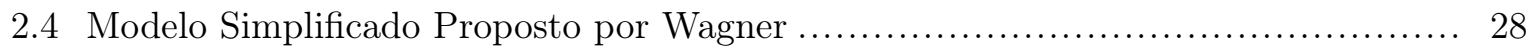

2.5 Restauração de Imagens Subaquáticas por Inversão do Modelo ........................ 30

2.6 Análise Comparativa dos Modelos de Formação de Imagens em Meios Participativos........................................... 31

2.7 Considerações Finais do Capítulo ............................................... 33

3 Algoritmos de Otimização Bio-inspirados $\ldots \ldots \ldots \ldots \ldots \ldots \ldots \ldots \ldots \ldots \ldots . \quad 34$

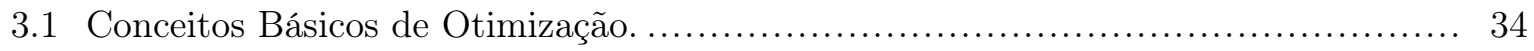

$3.1 .1 \quad$ Elementos de um Modelo de Otimização. .................................... 35

3.1 .2 Classificação dos Métodos de Otimização .................................... 36

3.1 .3 Algoritmos de Otimização Bio-inspirados ................................. 37

3.2 Otimização por Enxame de Partículas (PSO) ....................................... 38

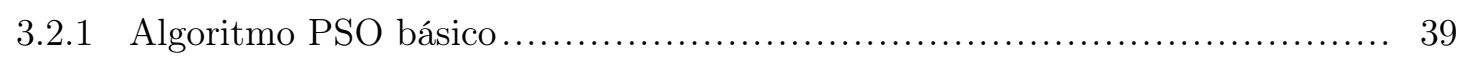

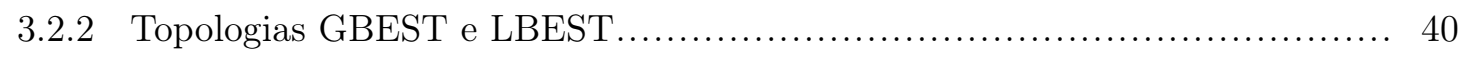

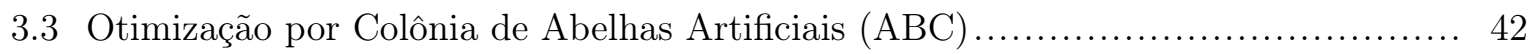

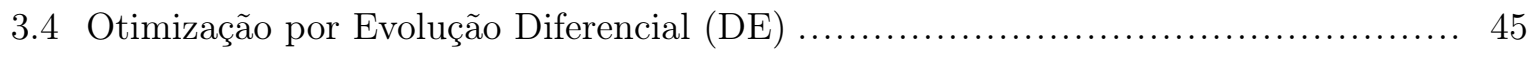

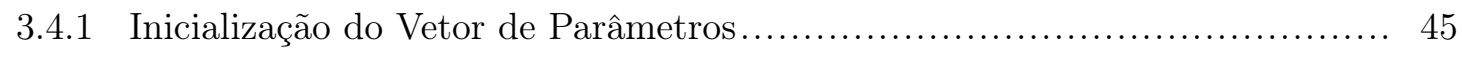

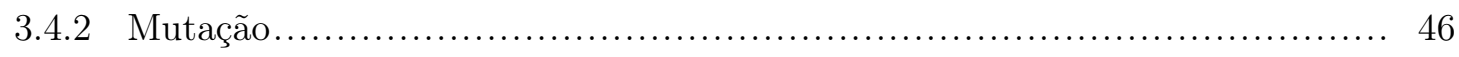

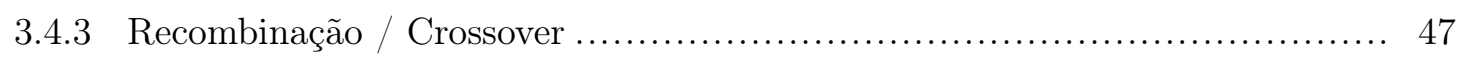

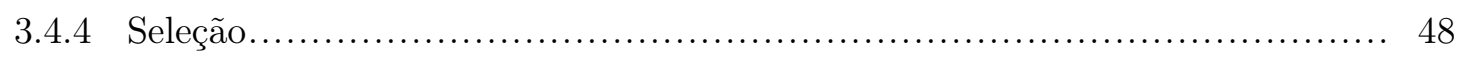

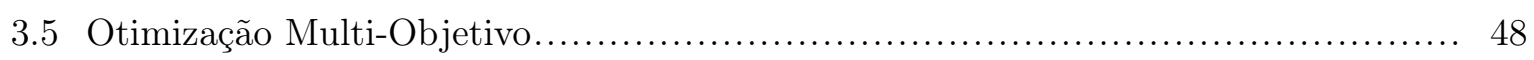

3.5 .1 Otimização Multi-objetivo por Evolução Diferencial (MODE) …............. 52

3.6 Métodos de Adição de Diversidade Artificial .......................................... 53

$3.6 .1 \quad$ O Método Atrativo-Repulsivo .............................................. 55

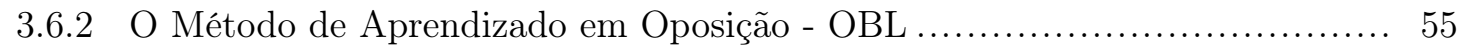

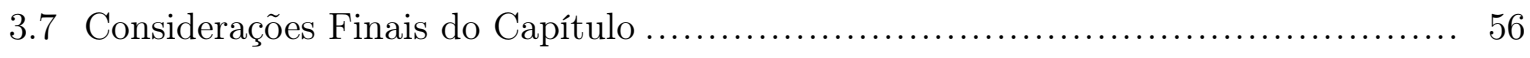

4 Avaliação de Qualidade em Imagens Digitais $. \ldots \ldots \ldots \ldots \ldots \ldots \ldots \ldots \ldots . . \ldots 8$

4.1 Métricas de Qualidade com Referência Completa

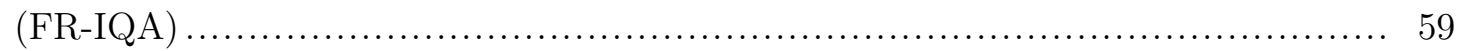

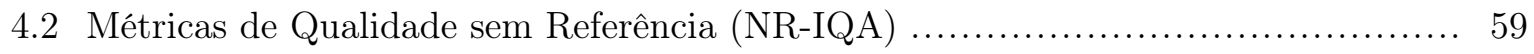

$4.2 .1 \quad$ Métrica Baseada em Ruído e Borramento (BN-IQA) ........................ 60

$4.2 .2 \quad$ Métrica de Qualidade de Imagens Naturais (NIQE) . ........................ 63

4.2 .3 Métrica de Distribuição de Contraste Local ................................. 67

4.2 .4 Avaliação de Cor em Imagens Subaquáticas (UCIQE) .......................... 68

$4.2 .5 \quad$ Qualidade Média de Imagens Subaquáticas Baseada em

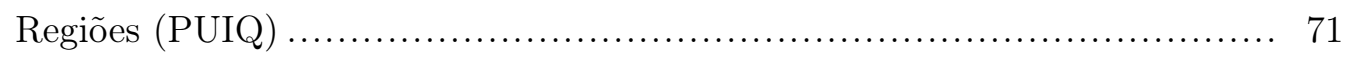


4.2.6 Discussão Sobre as Métricas de Avaliação Objetiva Sem

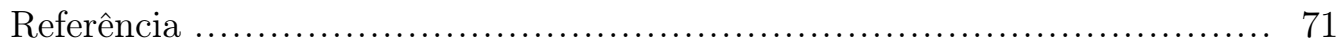

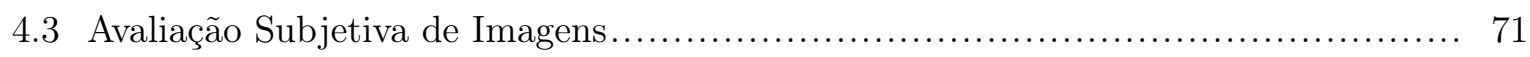

4.4 Bancos de Imagens e Análise de Correlação ....................................... 75

$4.4 .1 \quad$ Bancos de Imagens para Avaliação de Qualidade. ............................. 75

4.4 .2 Análise de Correlação ..................................................... 78

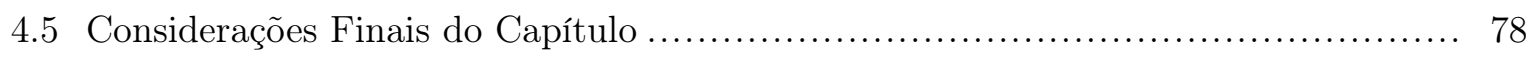

5 Desenvolvimento das Ferramentas para

Análise das Métricas e Testes de Restauração $\ldots \ldots \ldots \ldots \ldots \ldots \ldots \ldots . \quad 80$

5.1 Implementação dos Modelos de Formação de Imagens em Meios Participativos...... 81

5.1 .1 Implementação do Modelo de Trucco e Olmos-Antillon ........................ 81

5.1 .2 Implementação do Modelo de Schechner .................................. 83

5.1 .3 Implementação do Modelo de Wagner ................................... 86

5.1 .4 Ferramenta de Degradação de Imagens em Meios

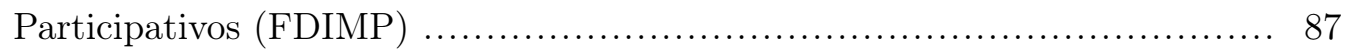

5.2 Análise de Desempenho das Métricas de Avaliação para Imagens com Degradações Artificiais ......................................................................... 90

5.3 Criação de um Banco de Imagens Subaquáticas...................................... 93

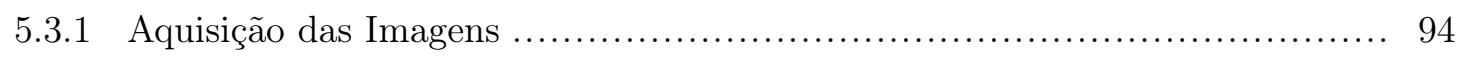

5.3 .2 Avaliação Subjetiva do Banco UID-LEIA ................................... 95

5.4 Análise de Desempenho das Métricas de Avaliação para Imagens do Banco UID-LEIA 97

5.5 Considerações Finais do Capítulo .................................................. 100

\section{Testes de Restauração para Degradações}

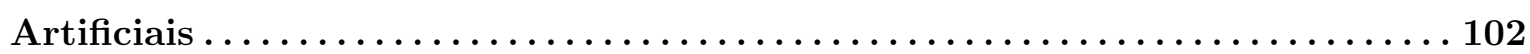

6.1 Inversão do Modelo de Trucco-Olmos ................................................. 102

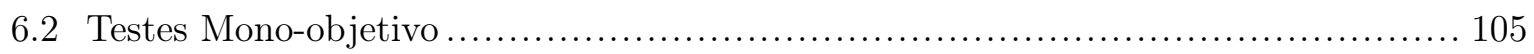

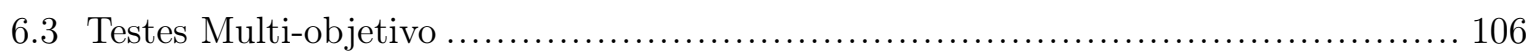

6.4 Considerações Finais do Capítulo ................................................ 111

7 Testes de Restauração para Degradações Reais $\ldots \ldots \ldots \ldots \ldots \ldots \ldots \ldots \ldots$

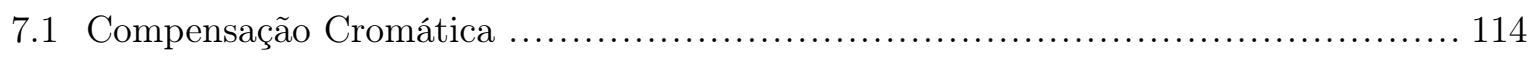

7.2 Estratégia de Restauração . ...................................................... 116

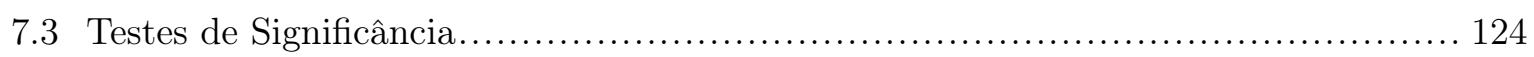

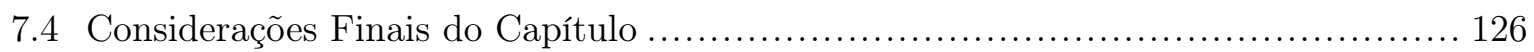

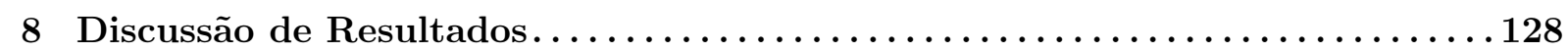

8.1 Implementação dos Modelos de Formação de Imagens em Meios Participativos....... 128 
8.2 Implementação e Análise das Métricas de Avaliação para Imagens com Degradações

Artificiais .

8.3 Testes de Restauração para Imagens com

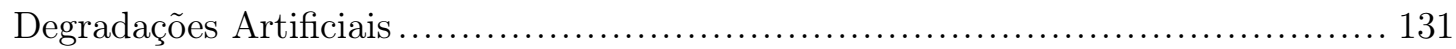

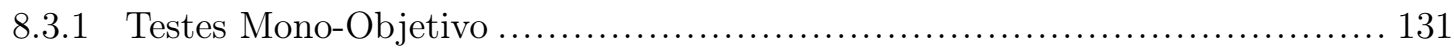

8.3 .2 Testes Multi-Objetivo ................................................... 132

8.4 Criação e Análise Subjetiva do UID-LEIA .......................................... 133

8.5 Análise das Métricas de Avaliação para Imagens com Degradações Reais .............. 134

8.6 Testes de Restauração para Imagens com

Degradações Reais.

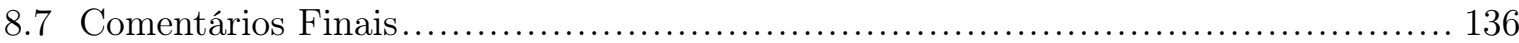

9 Conclusões e Perspectivas de Trabalhos

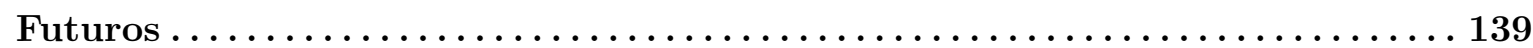

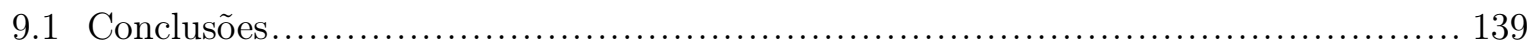

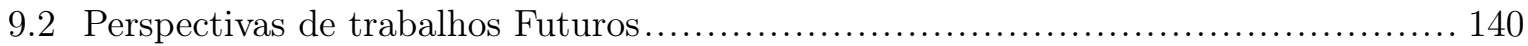

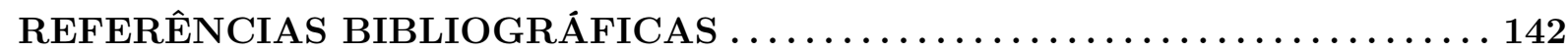

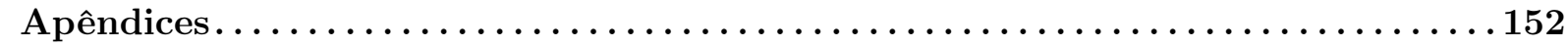

A Outros Experimentos de Restauração $\ldots \ldots \ldots \ldots \ldots \ldots \ldots \ldots \ldots \ldots \ldots \ldots \ldots$

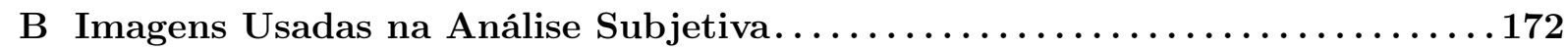




\section{LISTA DE FIGURAS}

1.1 Aplicação dos algoritmos de otimização bio-inspirada à restauração de imagens. ... 7

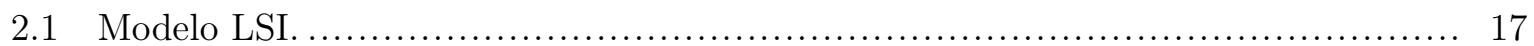

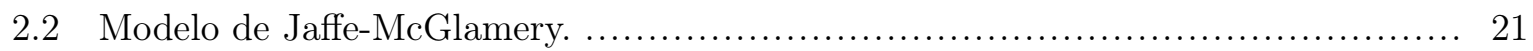

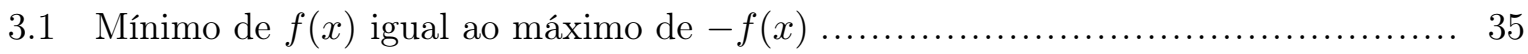

3.2 Classificação dos algoritmos bio-inspirados baseados em populações. ................. 38

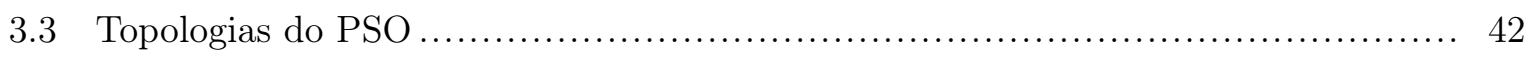

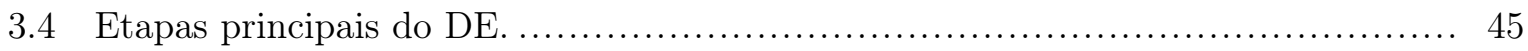

3.5 Exemplo do operador de mutação do algoritmo DE para um problema de duas variáveis. .................................................................... 47

3.6 Fronteira de Pareto de um conjunto de soluções para um problema de minimização

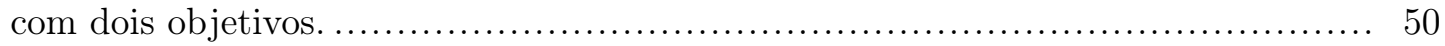

3.7 Exemplo de Fronteira de Pareto para um problema de minimização com destaque

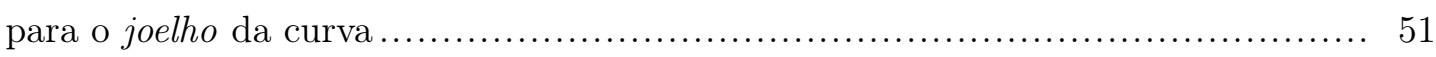

3.8 Exemplos com três conjuntos de soluções que ilustram relações entre convergência

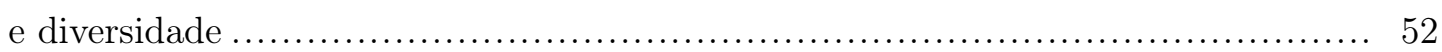

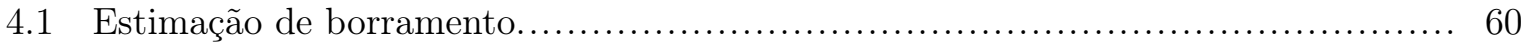

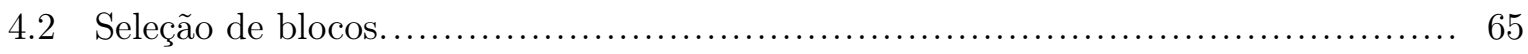

4.3 Exemplo de funcionamento da métrica de distribuição de contraste. . ................. 69

$5.1 \quad$ Exemplo de filtro no domínio da frequência para o modelo de Trucco-Olmos ........ 82

5.2 Exemplo de degradação de uma imagem utilizando o modelo de Trucco-Olmos. .... 83

5.3 Exemplo de degradação de uma imagem utilizando o modelo de Schechner.......... 86

5.4 Exemplo de degradação de uma imagem utilizando o modelo de Schechner. ......... 86

5.5 Exemplo de degradação de uma imagem utilizando o modelo de Wagner............. 87

5.6 Ferramenta de Degradação de Imagens em Meios Participativos - FDIMP (Interface). 89

5.7 Ferramenta de Degradação de Imagens em Meios Participativos - FDIMP (Opção

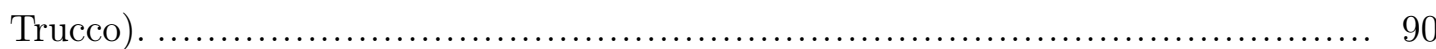


5.8 Ferramenta de Degradação de Imagens em Meios Participativos - FDIMP (Opção

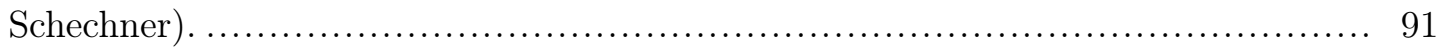

5.9 Ferramenta de Degradação de Imagens em Meios Participativos - FDIMP (Opção

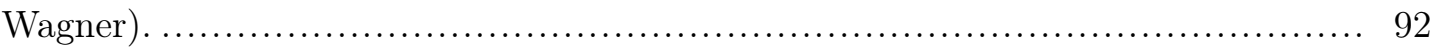

5.10 Montagem experimental para adquisição do banco de imagens. ....................... 94

5.11 Imagens de referência adquiridas para o banco de imagens. .......................... 95

5.12 Imagens degradadas adquiridas para o banco de imagens. ............................ 95

5.13 Escala de degradação utilizada nas etapas de treinamento e avaliação do experimento.

6.1 Degradação da imagem para testes de restauração. ...................................... 105

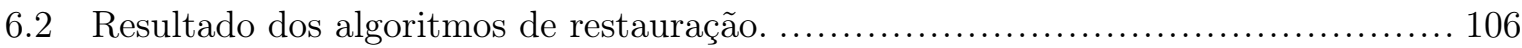

6.3 Variação do índice NIQE em relação aos parâmetros $c$ e $K$. ........................... 107

6.4 Imagem em níveis de cinza degradada utilizando o modelo de Trucco e Olmos-

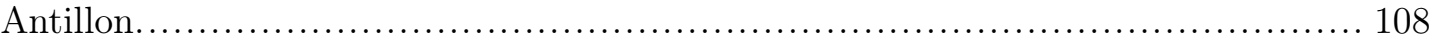

6.5 Fronteira de Pareto obtida pelo algoritmos DEMO/Parent e PDEA após 10 exe-

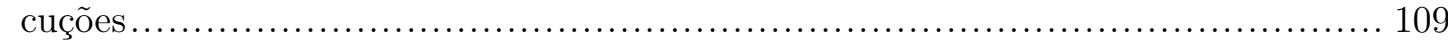

6.6 Resultados do processo de restauração da imagem. ................................... 110

6.7 Resultados da restauração de imagens com o algoritmo MODE. ........................ 111

7.1 Fluxograma do algoritmo de restauração de imagens reais.

7.2 Teste de restauração em imagens reais utilizando a métrica NIQE. .................... 120

7.3 Teste de restauração em imagens reais utilizando a métrica NIQE. .................... 122

7.4 Teste de restauração em imagens reais utilizando a métrica NIQE. .................... 122

A.1 Teste de restauração para imagem do UID-LEIA. ................................... 154

A.2 Teste de restauração para imagem do UID-LEIA. ................................... 155

A.3 Teste de restauração para imagem do UID-LEIA. .................................. 156

A.4 Teste de restauração para imagem do UID-LEIA. ................................... 157

A.5 Teste de restauração para imagem do UID-LEIA. ....................................... 158

A.6 Teste de restauração para imagem do UID-LEIA. ..................................... 159

A.7 Teste de restauração para imagem do UID-LEIA. ..................................... 160

A.8 Teste de restauração para imagem do UID-LEIA. ................................... 161

A.9 Teste de restauração para imagem do UID-LEIA. .................................. 162

A.10 Teste de restauração para imagem do UID-LEIA. .................................... 163

A.11 Teste de restauração para imagem do UID-LEIA. ................................... 164

A.12 Teste de restauração para imagem do UID-LEIA. ....................................... 165

A.13 Teste de restauração para imagem do UID-LEIA. .................................. 166 


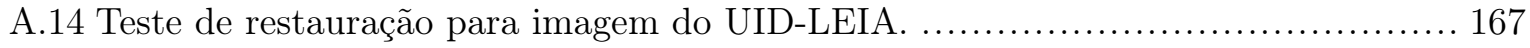

A.15 Teste de restauração para imagem do UID-LEIA. ................................... 168

A.16 Teste de restauração para imagem do UID-LEIA. . ................................... 169

A.17 Teste de restauração para imagem do UID-LEIA. ................................ 170 


\section{Lista DE TABELAS}

2.1 Análise comparativa dos modelos de formação de imagens em meios participativos 32

2.2 Parâmetros a serem estimados pelo processo de otimização $\ldots \ldots \ldots \ldots \ldots \ldots \ldots \ldots \ldots \ldots \ldots \ldots \ldots$

4.1 Métricas de avaliação objetiva de imagens sem referência (NR-IQA). . ................ 72

$4.2 \quad$ Bancos de Imagens para Análise Subjetiva. ....................................... 77

5.1 Coeficientes de correlação SRCC obtidos para cada uma das métricas. .............. 93

5.2 Informações sobre o experimento de avaliação subjetiva. . .......................... 96

5.3 Valores estimados no treinamento da métrica UCIQE. .............................. 98

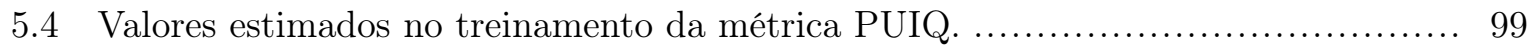

5.5 Valores estimados no treinamento da métrica BN-IQA. ............................ 100

5.6 Desempenho das métricas de avaliação objetivas implementadas no contexto deste

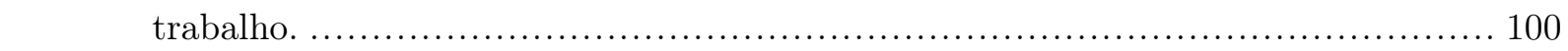

6.1 Parâmetros encontrados pelos algoritmos de restauração para restauração da ima-

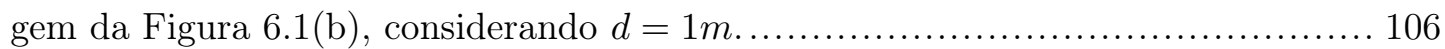

6.2 Resultados para a métrica de espaceamento dos algoritmos DEMO/Parent e PDEA $(10$ execuções) [111]. .............................................................. 109

6.3 Resultados para a métrica de hiper-volume dos algoritmos DEMO/Parent e PDEA

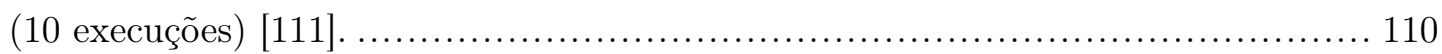

7.1 Valores das variáveis de decisão encontrados pelos algoritmos de otimização bioinspirada aplicados à restauração da imagem mostrada na Figura $\mid 7.2[\mid \ldots \ldots \ldots \ldots \ldots \ldots 120$

7.2 Valores das variáveis de decisão encontrados pelos algoritmos de otimização bioinspirada aplicados à restauração da imagem mostrada na Figura $\mid 7.3[\mid . . . . . . . . . . . . .121$

7.3 Valores das variáveis de decisão encontrados pelos algoritmos de otimização bioinspirada aplicados à restauração da imagem mostrada na Figura |7.4]............... 121

7.4 Estatísticas dos algoritmos de otimização bio-inspirada aplicados à restauração da

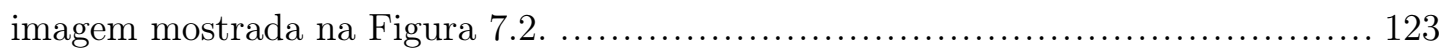

7.5 Estatísticas dos algoritmos de otimização bio-inspirada aplicados à restauração da imagem mostrada na Figura 7.3 ... 
7.6 Estatísticas dos algoritmos de otimização bio-inspirada aplicados à restauração da imagem mostrada na Figura|7.4].

7.7 Testes de significância para os algoritmos de otimização bio-inspirados aplicados ao problema de restauração apresentado na Figura |7.2.].

7.8 Valores das medianas para os testes de significância dos algoritmos de otimização aplicados ao problema de restauração mostrado na Figura $|7.2|] \ldots \ldots \ldots \ldots \ldots \ldots \ldots . \ldots \ldots$

A.1 Valores das variáveis de decisão encontrados pelos algoritmos de otimização bioinspirada aplicados à restauração da imagem mostrada na Figura $\mid$ A.1].

A.2 Estatísticas dos algoritmos de otimização bio-inspirada aplicados à restauração da imagem mostrada na Figura|A.1. $\mid$.....

A.3 Valores das variáveis de decisão encontrados pelos algoritmos de otimização bioinspirada aplicados à restauração da imagem mostrada na Figura $\mid$ A.2 $\mid$............... 156

A.4 Estatísticas dos algoritmos de otimização bio-inspirada aplicados à restauração da imagem mostrada na Figura|A.2||.

A.5 Valores das variáveis de decisão encontrados pelos algoritmos de otimização bioinspirada aplicados à restauração da imagem mostrada na Figura $\mid$ A.3| ............... 157

A.6 Estatísticas dos algoritmos de otimização bio-inspirada aplicados à restauração da

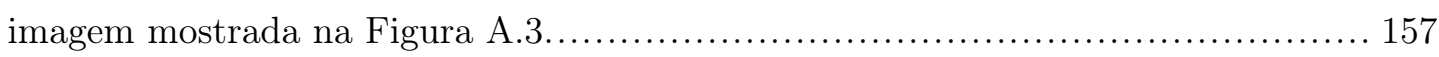

A.7 Valores das variáveis de decisão encontrados pelos algoritmos de otimização bioinspirada aplicados à restauração da imagem mostrada na Figura|A.4 |............... 158

A.8 Estatísticas dos algoritmos de otimização bio-inspirada aplicados à restauração da

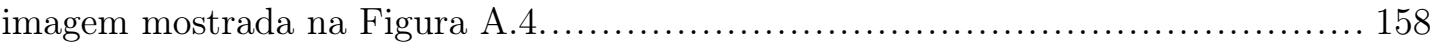

A.9 Valores das variáveis de decisão encontrados pelos algoritmos de otimização bioinspirada aplicados à restauração da imagem mostrada na Figura $\mid$ A.5 $\mid$................ 159

A.10 Estatísticas dos algoritmos de otimização bio-inspirada aplicados à restauração da imagem mostrada na Figura|A.5| ................................................. 159

A.11 Valores das variáveis de decisão encontrados pelos algoritmos de otimização bio-

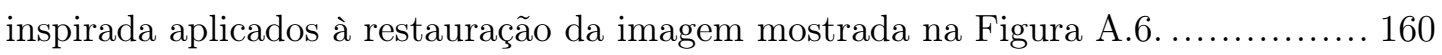

A.12 Estatísticas dos algoritmos de otimização bio-inspirada aplicados à restauração da

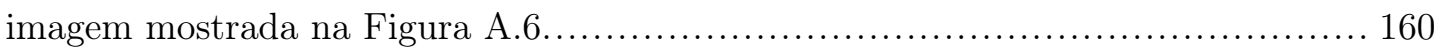

A.13 Valores das variáveis de decisão encontrados pelos algoritmos de otimização bioinspirada aplicados à restauração da imagem mostrada na Figura $\mid$ A.7. $\ldots . . . \ldots \ldots \ldots \ldots 161$

A.14 Estatísticas dos algoritmos de otimização bio-inspirada aplicados à restauração da

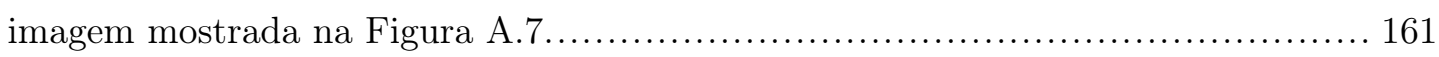

A.15 Valores das variáveis de decisão encontrados pelos algoritmos de otimização bioinspirada aplicados à restauração da imagem mostrada na Figura $\mid$ A.8|............ .162 
A.16 Estatísticas dos algoritmos de otimização bio-inspirada aplicados à restauração da imagem mostrada na Figura|A.8|.

A.17 Valores das variáveis de decisão encontrados pelos algoritmos de otimização bioinspirada aplicados à restauração da imagem mostrada na Figura $|A .9| \mid \ldots . . . . . . . . . . .163$

A.18 Estatísticas dos algoritmos de otimização bio-inspirada aplicados à restauração da imagem mostrada na Figura|A.9| ............................................. 163

A.19 Valores das variáveis de decisão encontrados pelos algoritmos de otimização bioinspirada aplicados à restauração da imagem mostrada na Figura|A.10|, .............. 164

A.20 Estatísticas dos algoritmos de otimização bio-inspirada aplicados à restauração da imagem mostrada na Figura|A.10| .............................................. 164

A.21 Valores das variáveis de decisão encontrados pelos algoritmos de otimização bioinspirada aplicados à restauração da imagem mostrada na Figura|A.11. . ............. 165

A.22 Estatísticas dos algoritmos de otimização bio-inspirada aplicados à restauração da imagem mostrada na Figura $\mid$ A.11] .............................................. 165

A.23 Valores das variáveis de decisão encontrados pelos algoritmos de otimização bioinspirada aplicados à restauração da imagem mostrada na Figura $\mid$ A.12, . ............. 166

A.24 Estatísticas dos algoritmos de otimização bio-inspirada aplicados à restauração da

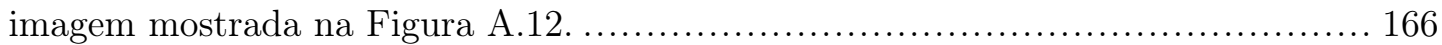

A.25 Valores das variáveis de decisão encontrados pelos algoritmos de otimização bio\begin{tabular}{ll|l|l|}
\hline inspirada aplicados à restauração da imagem mostrada na Figura & A.13.
\end{tabular}

A.26 Estatísticas dos algoritmos de otimização bio-inspirada aplicados à restauração da

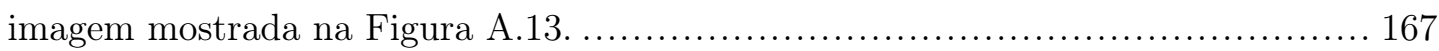

A.27 Valores das variáveis de decisão encontrados pelos algoritmos de otimização bioinspirada aplicados à restauração da imagem mostrada na Figura $\mid$ A.14. ............. 168

A.28 Estatísticas dos algoritmos de otimização bio-inspirada aplicados à restauração da

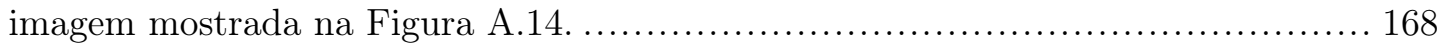

A.29 Valores das variáveis de decisão encontrados pelos algoritmos de otimização bioinspirada aplicados à restauração da imagem mostrada na Figura|A.15.] ............. 169

A.30 Estatísticas dos algoritmos de otimização bio-inspirada aplicados à restauração da imagem mostrada na Figura|A.15|] ............................................... 169

A.31 Valores das variáveis de decisão encontrados pelos algoritmos de otimização bioinspirada aplicados à restauração da imagem mostrada na Figura|A.16, ............. 170

A.32 Estatísticas dos algoritmos de otimização bio-inspirada aplicados à restauração da

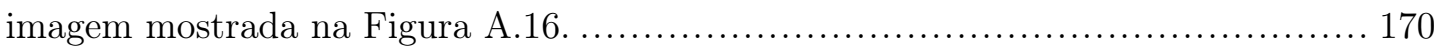

A.33 Valores das variáveis de decisão encontrados pelos algoritmos de otimização bioinspirada aplicados à restauração da imagem mostrada na Figura $\mid$ A.17. . 
A.34 Estatísticas dos algoritmos de otimização bio-inspirada aplicados à restauração da imagem mostrada na Figura|A.17] 171

B.1 Imagens usadas como referência no experimento de avaliação subjetiva................ 172

B.2 Imagens usadas para treinamento dos avaliadores no experimento de avaliação

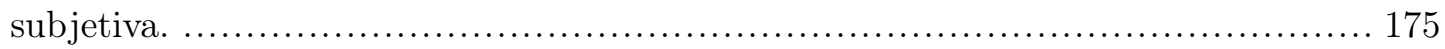

B.3 Imagens avaliadas no experimento de avaliação subjetiva. ............................ 175 


\title{
LISTA DE SÍMBOLOS
}

\author{
ABC Artificial Bee Colony \\ AC Ant Colony \\ AGGD Asymmetric Generalized Gaussian Distribution \\ ANOVA Analysis of Variance \\ AUV Autonomous Underwater Vehicle \\ BN-IQA Blur and Noise Image Quality Assessment \\ CL Contraste Local \\ DE Diferential Evolution \\ DM Decision Maker \\ DMOS Difference Mean Opinion Score \\ FDIMP Ferramenta de Degradação de Imagens em Meios Participativos \\ FPGA Field Programmable Gate Array \\ FR-IQA Full Reference Image Quality Assessment \\ GA Genetic Algorithms \\ GBEST Global Best \\ GGD Generalized Gaussian Distribution \\ HSV Hue, Saturation and Value \\ IQA Image Quality Assessment \\ LBEST Local Best \\ LEIA Laboratory of Embbedded Systems and Integrated Circuits Applications \\ LIVE Laboratory for Image and Video \\ LSI Linear Shift-Invariant \\ MGV Multivariate Gaussian \\ MODE Multi-objective Diferential Evolution \\ MOS Mean Opinion Score \\ MSE Mean Square Error \\ MTF Modulation Transfer Function \\ NIQE Natural Image Quality Evaluator
}


NR-IQA No-Reference Image Quality Assessment

NSS Natural Scene Statistic

OABC Opposition Based Artificial Bee Colony

OPSO Opposition Based Particle Swarm Optimization

OTF Optical Transfer Function

PDEA Pareto Differential Evolution Algorithm

PLCC Pearson's Linear Correlation Coefficient

PSO Particle Swarm Optimization

PSF Point Spread Function

PSNR Peak Signal-to-Noise Ratio

PTF Phase Transfer Function

PUIQ Patch-Based Mean Underwater Image Quality

RAPSO Repulsive-Attractive Particle Swarm Optimization

RGB Red, Green, Blue

ROV Remotely Operated Vehicle

SLAM Simultaneous Localization and Mapping

SRCC Spearman's rank correlation coefficient

TDF Transformada Discreta de Fourier

TIF Transformada Inversa de Fourier

UCIQE Underwater Colour Image Quality Evaluation

UID-LEIA LEIA Underwater Image Database 


\section{INTRODUÇÃO}

\subsection{Aspectos Gerais}

\subsubsection{Processamento de Imagens e Visão Computacional}

A capacidade humana para captar, processar e interpretar grandes quantidades de informação de natureza visual estimula o desenvolvimento de técnicas e dispositivos cada vez mais complexos e sofisticados. Visando o desenvolvimento e aprimoramento das técnicas para a análise automática ou semi-automática de informações extraídas de uma imagem ou cena, com auxilio de um computador e/ou processador, é de grande importância a compreensão do funcionamento do sistema visual humano, sua capacidade de aprendizagem e sua habilidade em realizar inferências e ações baseadas em estímulos visuais [1].

As áreas de processamento e análise de imagens têm evoluído significativamente nas últimas décadas. Esse crescimento pode ser observado pelo interesse de cientistas e profissionais em diversos domínios do conhecimento, tais como medicina, biologia, automação industrial, sensoreamento remoto, robótica, microscopia, entre outros [1]. O desenvolvimento de sistemas autônomos que sejam capazes de reagir a estímulos visuais de forma adequada à área especifica sob investigação continua sendo um grande desafio [1]. Assim, o interesse no processamento e análise de imagens digitais é derivado de duas áreas de aplicação específica: (1) melhorar a informação contida na imagem para interpretação humana; e (2) o processamento dos dados da imagem para serem transmitidos, armazenados, e representados por um sistema de visão autônomo [2].

Além disso, as técnicas de visão computacional pretendem auxiliar a resolução de problemas altamente complexos, buscando assim reproduzir as habilidades e conhecimentos usados pelos seres humanos para tomar decisões se baseando em informações contidas em uma imagem [1]. Objetivando simplificar o estudo das tarefas envolvidas em visão computacional, são normalmente estabelecidos dois níveis de abstração: (1) processamento de imagens (baixo nível) e (2) análise de imagens (alto nível). É importante salientar que a análise de imagens está estreitamente vinculada com o tema da visão computacional, onde o processamento da imagem é só uma ferramenta utilizada, assumindo, desta maneira, que o tema do "processamento" está resolvido. 
O processamento digital de imagens se ocupa das propriedades da imagem e de transformações de imagem-para-imagem. A maioria dos sistemas de visão computacional precisam de uma etapa preliminar de processamento de imagens, que objetiva extrair e identificar informações e melhorar a qualidade visual de certos aspectos estruturais, fazendo mais fácil a percepção humana e/ou a interpretação automática por meio de um computador [1]. Exemplos de processamento de imagens podem incluir: (a) operações de restauração, que consiste em eliminar o efeito de degradações conhecidas, geralmente geradas pelo meio de transmissão da imagem; (b) (melhoramento), que objetiva encontrar uma imagem com melhor qualidade que a imagem original; (c) compressão que trata da elaboração de representações mais compactas para imagens, geralmente objetivando simplificar processos de transmissão ou armazenamento; e (d) filtragem que procura "eliminar" o ruído presente em uma imagem [3].

A análise de imagens é baseada, geralmente, em características dos objetos contidos na cena tais como a forma, textura, as cores da imagem, etc. A razão principal pela qual a análise de imagens é uma tarefa complexa reside em seu caráter multidisciplinar, em que, tipicamente, são necessários diversos domínios de conhecimento para solucionar satisfatoriamente o problema [1. Os métodos de alto nível envolvem tarefas como segmentação da imagem em regiões ou objetos de interesse, descrição desses objetos em representações mais simples ou apropriadas e o reconhecimento ou classificação desses objetos. Características comuns para descrever objetos incluem contornos, dimensões do objeto, cores, texturas, entre muitas outras [1].

Assim, o processamento digital de imagens tende a ser parte fundamental em todo sistema de visão, já que permite uma etapa de análise das imagens com melhores resultados. Além disso, e como será discutido mais para frente, as imagens subaquáticas estão submetidas a degradações que limitam a qualidade da imagem e a análise posterior da mesma. A restauração de imagens degradadas está contida dentro da área de processamento de imagens, já que o objetivo principal é eliminar degradações presentes na imagem e, assim, facilitar uma etapa de analise posterior. É esta uma das razões pela qual este trabalho vai abordar a área de processamento de imagens, mais especificamente, na forma de restauração de imagens subaquáticas.

\subsection{2 Áreas de Aplicação dos Sistemas de Visão Computacional}

A utilização de técnicas de processamento de imagens na resolução de problemas, por meio da análise de informações visuais, já envolve inúmeras áreas de aplicação, principalmente devido ao grande avanço tecnológico na área de computação ao longo das últimas três décadas. Dentre as áreas de aplicação mais comuns, podemos citar, entre outras: a área militar, automação industrial, medicina, sensoriamento remoto, segurança e multimídia [1].

Na área militar, são encontradas aplicações como rastreamento de alvos móveis, auxílio à 
navegação de veículos não-tripulados, os quais podem ser terrestres, aéreos ou subaquáticos, assim como a identificação de cenas e alvos em imagens captadas por uma câmera colocada em dito veículo.

Na área de automação industrial são muito comuns equipamentos de inspeção visual de produtos, rótulos e embalagens, com o intuito de efetuar o descarte de produtos com não-conformidades. Outra utilização é na localização de objetos para manipulação por robôs e na monitorização de processos de fabricação em tempo real, para realimentação de controladores.

Na medicina, os sistemas de auxílio a diagnósticos permitem aos médicos uma maior segurança quando da análise de imagens oriundas de tomógrafos, aparelhos de raios X, ultrasonografia e ressonância magnética. Atualmente não só técnicas mais simples como ajustes de contraste e brilho são utilizadas, mas também equipamentos mais sofisticados que oferecem, com base na imagem e em um banco de dados, listagens de possíveis males do paciente.

No campo de ciência e engenharia de materiais, imagens de microscópios são muito utilizadas em análises metalográficas e cristalográficas, permitindo a identificação de estruturas e padrões de formação em materiais, auxiliando tanto na melhoria de processos de fabricação como na busca de novas aplicações e materiais.

O sensoriamento remoto permite a análise e interpretação não só de imagens no espectro visual, mas também imagens oriundas de diversos tipos de sensores, como infravermelhos e magnéticos, permitindo a identificação de zonas de mineração, correntes marítimas, focos de incêndios, desmatamento e crescimento urbano, permitindo um melhor planejamento por parte do governo e empresas, no sentido de aproveitar os recursos naturais e planejar estradas, rodovias e zoneamentos territoriais.

Sistemas de controle de acesso já utilizam desde a leitura de digitais até a identificação de padrões na íris, retina ou ainda o reconhecimento de faces. O reconhecimento óptico de caracteres pode identificar automaticamente uma assinatura, permitindo a autenticação de cheques ou ainda a conversão de imagens em textos.

Já no campo do entretenimento, novas aplicações surgem a todo momento. Videogames extremamente realistas utilizam tecnologias muito avançadas de computação gráfica, bem como algoritmos otimizados, principalmente de renderização de imagens. Câmeras fotográficas já são capazes de efetuar um disparo automático pela detecção de um sorriso, e as altas resoluções dos sensores comuns em aparelhos celulares exigem que existam algoritmos de compressão e descompressão de imagens e vídeos, sendo embarcados em dispositivos cada vez menores. Houve ainda, no início do século XXI, a consolidação dos sistemas de televisão digital, com recursos avançados, como interatividade e alta definição de imagens. A Internet já é utilizada como meio de transmissão de vídeos até mesmo em tempo real, dependendo de aquisição e processamento 
eficientes, bem como de algoritmos de compressão e descompressão de dados extremamente sofisticados, a fim de permitir maiores resoluções em canais de transmissão com largura de banda limitada.

No caso das imagens subaquáticas, estas são amplamente usadas em pesquisa científica e tecnologia. Os sistemas de visão computacional para imagens submarinas têm sido utilizados em varias aplicações tais como detecção de minas, inspeção de cabos de alimentação elétrica e de telecomunicações, tubulações [4], reatores nucleares e colunas de perfuração em plataformas offshore [5]. A visão computacional submarina é comercialmente usada em piscinas para auxiliar salva-vidas. Assim como nos sistemas de visão convencionais, os algoritmos são utilizados para navegação e controle de robôs submarinos para tarefas de localização, SLAM (Simultaneous Localization and Mapping), medição de distâncias, entre outras. Além disso, as imagens subaquáticas são usadas para pesquisa em biologia marinha, arqueologia e mapeamento. Além disso, a fotografia subaquática está se tornando mais acessível para o público em geral [5].

\subsubsection{Restauração de Imagens Subaquáticas}

No processo de geração, armazenamento e transmissão, a imagem observada geralmente aparece como uma versão degradada da imagem original devido a imperfeições nos sistemas de adquisição, condições climáticas, intensidade da luz e outras condições não ideais [2], [6], [7]. Essa degradação dificulta a análise posterior das imagens. Assim, a necessidade da restauração de imagens é obrigatória em varias aplicações. O desafio geral da restauração de imagens é remover o borramento em uma imagem em presença de ruído [8]. A restauração de uma imagem a partir da sua versão degradada tem sido um problema de longa data no processamento de imagens, e um grande número de métodos para restauração têm sido propostos. Um dos mais clássicos é o método de filtragem inversa com filtro de Wiener [2], 7].

Além disso, o meio no qual se encontra a cena tem um papel importante nas características da imagem. Geralmente, considera-se que o meio não interferirá no processo de formação da imagem. Contudo, essa consideração não se aplica em ambientes com neblina, com poluição ou em um ambiente subaquático, onde o meio exerce forte influência na propagação da luz, tais meios são chamados de meios participativos [9]. As propriedades físicas do meio aquático causam efeitos de degradação que não estão presentes em imagens tomadas no ar ou no vácuo. A imagens submarinas estão caracterizadas pela baixa visibilidade devido a luz ser atenuada enquanto se propaga na água e as imagens adquiridas costumam ser borradas e de baixo contraste.

Por exemplo, a atenuação da luz limita a distância visível em torno de vinte metros na água limpa e menos de cinco metros na água turva [10]. O efeito de atenuação da luz é gerado, principalmente, por dois processos físicos: (1) absorção e (2) dispersão (scattering). No processo 
de absorção, a energia lumínica é transformada em outros tipos de energia a longo do trajeto percorrido pela luz devido a interações com a matéria. Este processo gera um perda significativa no brilho dos objetos. Além disso, o processo de dispersão consiste em uma mudança na direção de propagação da luz devido a que os fótons colidem com as partículas em suspensão no meio. Neste caso, existem dois tipos de dispersão: (1) Back-scattering na qual uma fração de luz refletida pelas partículas de água é captada pela câmera antes de atingir os objetos da cena limitando o contraste da imagem; e (2) Forward-scattering na qual a luz é desviada aleatoriamente no caminho entre o objeto e a câmera, causando o borramento da imagem [10]. Estes processos físicos responsáveis da degradação de imagens em meios participativos serão discutidos com maior detalhe no Capítulo 2.

No caso do processamento das imagens, o próprio processamento pode der abordado desde dois pontos de vista diferentes: (1) como uma técnica de restauração de imagens ou (2) como um método de melhoramento. A restauração de imagens busca recuperar uma imagem degradada utilizando um modelo de degradação, cuja inversão permitiria encontrar uma imagem com degradações mínimas. A restauração de imagens é um dos tópicos mais importantes no processamento digital de imagens, e é um passo crucial para detectar com sucesso padrões ou características importantes dos objetos [11]. Esses métodos são complexos devido a que requerem muitos parâmetros (como coeficientes de atenuação e dispersão que definem as características físicas da água), os quais são extremamente variáveis. Outro parâmetro importante requerido é a estimativa de profundidade dos objetos na cena.

Além disso, o melhoramento de imagens usa critérios subjetivos para produzir imagens mais fáceis de serem visualizadas e não é utilizado nenhum modelo físico de formação da imagem, baseando-se simplesmente em transformações de imagem-para-imagem. Esses métodos realizam uma abstração total do processo de formação de imagens, e não precisam de nenhum conhecimento a priori (não utilizam coeficientes de atenuação e dispersão do meio, por exemplo). Os métodos de melhoramento são usualmente mais simples e mais rápidos que os algoritmos de restauração de imagens, porém carecem de generalidade e diferentes imagens podem precisar filtros diferentes, mesmo sendo capturadas no mesmo meio [10].

\subsubsection{Algoritmos de Otimização Aplicados ao Problema de Restauração de Imagens}

A otimização, no seu sentido mais amplo, pode ser aplicada com o intuito de resolver problemas de engenharia. Algumas aplicações típicas em diferentes disciplinas da engenharia apresentam o amplo alcance do tema. Na engenharia podem se destacar aplicações como o projeto de aeronaves e estruturas espaciais, projeto de sistemas de controle e planejamento de trajetória, 
visão computacional, etc. Além disso, a implementação de técnicas de otimização é de grande importância em outras áreas como física, química, administração, economia, entre outras. A otimização objetiva a solução de problemas visando encontrar uma resposta que proporcione o melhor resultado entre um conjunto de alternativas disponíveis, permitindo assim, encontrar maiores ganhos, maior produção e menor custo. Frequentemente, esses problemas envolvem a utilização mais eficiente de recursos de tempo, dinheiro, maquinaria e pessoal [12], [13].

Existem muitos algoritmos para otimização, porém, eles podem ser divididos em três tipos: (1) exatos, (2) heurísticos e (3) meta-heurísticos. Os métodos exatos de otimização geralmente utilizam algoritmos determinísticos para realizar uma busca exaustiva do espaço de soluções no intuito de encontrar uma solução ótima do problema. Técnicas de programação matemática como o algoritmo Simplex para programação linear, métodos baseados em derivadas para programação não linear ou algoritmos de programação dinâmica fazem parte dos métodos exatos. Os métodos heurísticos de otimização utilizam uma ou mais informações referentes ao problema para guiar o processo de busca de uma solução ótima. A principal desvantagem dos métodos heurísticos é que são desenvolvidos para resolver classes específicas de problemas, carecendo de generalidade [13]. Por último, os métodos meta-heurísticos de otimização permitem resolver diversos tipos de problemas sem precisar grandes mudanças nos algoritmos. Estes métodos geralmente utilizam estatísticas que permitem resolver uma ampla gama de problemas, sendo comum a utilização de modelos baseados em fenômenos naturais ou processos físicos.

Entre as técnicas de otimização meta-heurísticas mais utilizadas podem-se mencionar algoritmos bio-inspirados tais como os algoritmos genéticos (GA) ou técnicas baseadas em populações, como otimização por colônia de formigas (AC), otimização por colônia de abelhas (ABC), otimização por enxame de partículas (PSO), entre outros. Essas técnicas baseadas em populações têm sido acolhidas pela comunidade científica devido à facilidade de implementação e à qualidade das soluções obtidas, as quais são bastante próximas do valor ótimo, principalmente quando aplicados a problemas complexos que envolvem não linearidades e interações entre as variáveis de projeto, em que as soluções exatas são impraticáveis [14], [15]. Os métodos de otimização meta-heurísticos baseados em populações são o foco do presente trabalho.

Além disso, a Figura 1.1 apresenta um diagrama de fluxo que explica o momento em que os algoritmos bio-inspirados para otimização podem ser usados para resolver o problema da restauração de imagens.

Como já mencionado, podem-se usar duas técnicas para obter imagens de melhor qualidade: (1) melhoramento e (2) restauração (vide Figura 1.1). Sendo que o melhoramento utiliza somente critérios qualitativos para tal fim. Estas técnicas podem incluir correções no fator gama da imagem, funções de transformação e/ou um conjunto de filtros que permitam obter uma imagem de melhor qualidade. Neste caso, os algoritmos de otimização bio-inspirados podem ser utilizados 


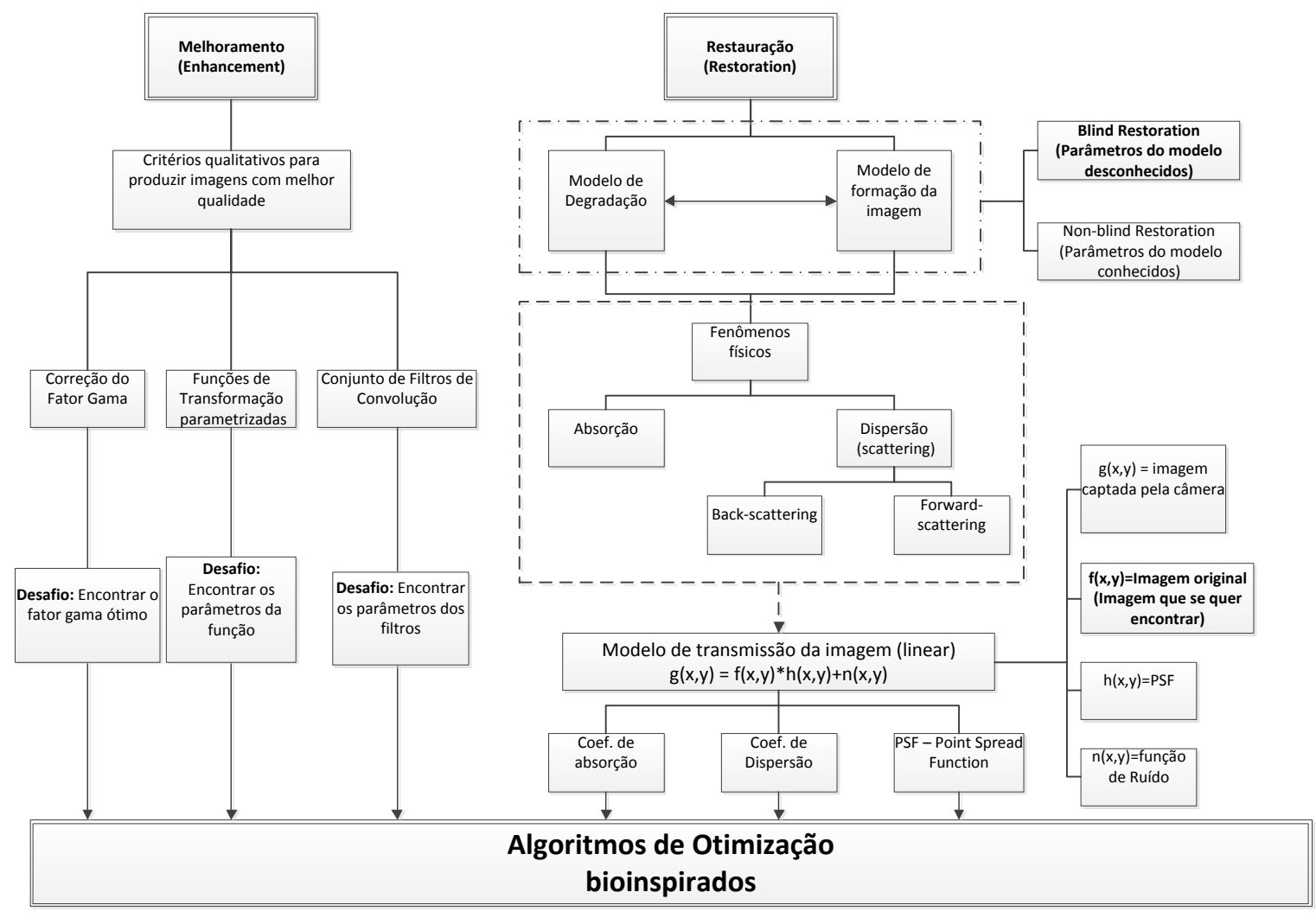

Figura 1.1. Aplicação dos algoritmos de otimização bio-inspirada à restauração de imagens.

para determinar parâmetros que permitam corrigir a imagem de forma adequada. Além disso, os algoritmos de restauração utilizam um modelo físico de degradação e/ou formação de imagens (vide Figura 1.1). Estes modelos representam os fenômenos físicos que interagem com a luz, degradando a imagem como resultado dessas interações. Estes também incluem parâmetros tais como o coeficiente de absorção do meio, o coeficiente de dispersão, a função de espalhamento pontual, entre outros. Existem casos em que estes parâmetros são conhecidos (restauração nãocega), porém, na maioria de aplicações, não se tem posse desses parâmetros (restauração cega). O problema de restauração de imagens subaquáticas é um claro exemplo de restauração cega, devido a que geralmente não se tem posse de uma imagem de referência ou dos parâmetros de degradação da imagem. Assim, neste último caso, os parâmetros do modelo podem ser encontrados mediante a implementação de algoritmos de otimização.

O uso de meta-heurísticas para processos de otimização é justificável no caso em que a função custo seja multidimensional (possuindo mais de uma variável de decisão) e/ou multimodal (com múltiplos máximos/mínimos locais) [13. Como será discutido no Capítulo 2, no contexto dos processos de restauração de imagens em meios participativos, deve-se estimar o valor ótimo de parâmetros, tais como o coeficiente de atenuação, o ganho da PSF, entre outros parâmetros 
que pertencem ao modelo de formação de imagens. E neste sentido, a qualidade da imagem restaurada depende diretamente da correta estimação destes parâmetros. Assim, pode-se afirmar que a restauração de imagens em meios participativos, como o subaquático, é um problema de otimização multidimensional. Além disso, as métricas de avaliação de qualidade de imagens, que serão discutidas no Capítulo 4, são não lineares e apresentam um comportamento multimodal. Por estas razões, a utilização de algoritmos exatos, baseados em gradientes, não é adequada para este tipo de problema. Assim, propõe-se utilizar algoritmos de otimização baseados em meta-heurísticas.

\subsection{Motivação do Trabalho}

Aproximadamente $71 \%$ do globo terrestre é formado pela superfície abaixo do oceano. Porém, a grande parte dessa área ainda corresponde a terrenos inexplorados e praticamente desconhecidos [9]. Na maioria das vezes, estas áreas cobertas por água não permitem um fácil acesso aos seres humanos, devido fatores como as altas pressões, baixa visibilidade, entre outros. Isto impossibilita que sejam desenvolvidas uma grande quantidade de pesquisas e/ou operações marítimas (por exemplo, inspeção e/ou manutenção de tubulações, cabos para alimentação elétrica, linhas de fibra ótica, etc.).

Nos últimos anos tem-se investido muito no desenvolvimento de robôs móveis submarinos, os quais podem ser autônomos (AUV - Autonomous Underwater Vehicle) ou remotamente operados (ROV - Remotely operated vehicle), e que seriam uma excelente solução para suprir a incursão de um operário humano em áreas hostis [16]. Na maioria das vezes, esse tipo de robôs conta com uma câmera que fornece informação visual para um operário remoto, no caso do ROV, ou para ser processada a fim de encontrar uma informação específica, no caso do AUV. Porém, além das degradações sofridas pela imagem devido aos processos de transmissão e/ou armazenamento, somam-se as degradações geradas pelo meio, neste caso, a água.

Como já mencionado, todo meio participativo tem uma grande influência no processo de formação das imagens, já que a luz está submetida a vários processos físicos tais como absorção, dispersão e as distorções geradas pela ótica da câmera. Os processos de dispersão e absorção geram uma perda significativa no contraste e no brilho da imagem, causando também borramento. Além disso, a faixa de visibilidade pode ser aumentada com iluminação artificial, porém estas fontes não somente sofrem as mesmas dificuldades mencionadas antes (absorção e dispersão), mas também tendem a iluminar a cena de uma forma não uniforme, produzindo um ponto brilhante no centro da imagem com uma área pouco iluminada no redor. Em resumo, as imagens subaquáticas podem sofrer mais de um dos seguintes problemas: (a) a faixa de visibilidade limitado, (b) baixo contraste, (c) iluminação não uniforme, (d) borramento, (e) artefatos luminosos, (f) diminuição 
de cor (aparição da cor azul ou verde) e (g) ruído [10].

Inúmeras áreas poderiam se beneficiar com a melhoria da qualidade visual de imagens subaquáticas, dentre elas: (a) o reconhecimento e a preservação de espécies aquáticas; a navegação autônoma em ambientes submersos; (b) a exploração de minerais em solo subaquático; (c) a inspeção visual de estruturas submersas ou embarcações naufragadas; (d) o auxílio a tarefas de prospecção submarina envolvendo a extração de gás e/ou petróleo, entre outras [9].

Além disso, a restauração de imagens é amplamente utilizada na maioria das áreas técnicas que envolvem imagens; astronomia, sensoreamento remoto, microscopia, imagens medicas, fotografia, segurança, e sistemas de TV de alta definição (HDTV) são somente umas poucas. Por exemplo, as placas dos carros podem aparecer ilegíveis devido ao borramento causado pelo movimento (motion blur); fotografias capturadas sob condições de baixa iluminação são suscetíveis ao ruído; fotografias fora de foco aparecem borradas; os sinais de TV padrão podem não ser suficientemente fortes para equipamentos de alta definição; distorções atmosféricas podem degradar a qualidade das imagens em sensoreamento remoto. Nesses exemplos e em muitos outros cenários, a importância da restauração de imagens varia de benéfica para essencial [17]. Outro dos cenários em que a restauração de imagens torna-se uma tarefa obrigatória é o já mencionado caso das imagens subaquáticas. Lembrando que o objetivo da restauração de imagens é recuperar uma versão não degradada da cena, e que o meio exerce uma grande influencia nessa degradação, é necessário um modelo de formação de imagens que permita representar, de forma aproximada, as interações entre a luz e o meio.

Diversos modelos têm sido propostos na literatura, os mais conhecidos são os apresentados por Jaffe (1990) e McGlamery (1979) [18],[19], Trucco e Olmos-Antillon (2006) [20], e o modelo proposto por Schechner e Karpel (2004) [5]. Esses modelos simplificados apresentam uma boa aproximação à realidade, porém, eles estão restritos a determinadas condições de operação (por exemplo, profundidade da cena). Existem também outros modelos, que não são tão utilizados, cada um deles com suas próprias características e limitações. Todos estes modelos têm que ser invertidos para encontrar uma imagem que se aproxime à imagem "original" e, na maioria das vezes, os parâmetros do modelo não são conhecidos. Esses parâmetros correspondem aos coeficientes de absorção, dispersão, atenuação, etc. Os processos de restauração nos quais não se tem posse dos parâmetros são denominados de restauração cega (blind restoration). Assim, os algoritmos de restauração cega baseados nos modelos de formação de imagens em meios participativos precisam de parâmetros ótimos que permitam a melhor restauração possível da imagem degradada.

Além disso, os algoritmos de otimização baseados em populações brindam uma ferramenta para estimar parâmetros ótimos presentes em um modelo de formação de imagens. A utilização dos algoritmos bio-inspirados (baseados em meta-heurísticas) justifica-se tendo em conta que, 
visando restaurar a imagem degradada, devem-se inverter os modelos de formação de imagens mencionados acima, assim como estimar o valor de vários parâmetros objetivando melhorar uma função objetivo, geralmente de carácter não linear e/ou multimodal que, portanto, não é adequada para ser tratada com algoritmos exatos. Nessa ordem de ideias, deve-se definir uma função objetivo que, no caso da restauração de imagens, corresponderia a uma métrica de avaliação de qualidade de imagens (IQA - Image Quality Assessment). Esses algoritmos de otimização têm sido muito utilizados na restauração e melhoramento de imagens fora do contexto subaquático. Y. Zhang (2008) [1] apresenta um sistema de restauração baseado em redes neurais artificiais que implementa o algoritmo PSO para melhorar o desempenho da rede neural. R. Dash (2009) [8] e Z. Sun [21] (2011) realizam a restauração das imagens pelo método de regularização, utilizando o algoritmo PSO para encontrar o parâmetro de regularização ótimo. J. P. Papa (2010) [22] apresenta a técnica de restauração baseada em Projeção em Conjuntos Convexos e utiliza o algoritmo PSO para encontrar o parâmetro de relaxamento ótimo. Além disso, N. Li [7] mistura algoritmos genéticos e o algoritmo PSO para encontrar os parâmetros do filtro que permitem restaurar corretamente a imagem. Embora esses trabalhos têm obtido resultados excelentes, poucos têm sido implementados em ambientes subaquáticos.

Finalmente, esta pesquisa foi desenvolvida no contexto do Programa de Formação de Recursos Humanos em Automação Offshore PRH-PB223 financiado pela Petrobras, que objetiva o desenvolvimento de tecnologias para serem aplicadas à industria de petróleo e gás. No presente trabalho foi desenvolvido um sistema capaz de restaurar imagens subaquáticas que podem auxiliar tarefas como, por exemplo, inspeção visual e/ou manutenção de plataformas offshore, tubulações, linhas de comunicação ou de potência, entre outras.

Tendo em vista os problemas mencionados acima, a importância e o amplo campo de aplicação que apresenta a restauração de imagens subaquáticas, decidiu-se desenvolver um sistema que permita restaurar imagens, sem a utilização de equipamentos de captura externos senão a câmera tradicional.

O sistema proposto está no âmbito dos métodos de restauração cega, devido a que não se tem conhecimento dos valores dos parâmetros físicos do modelo de formação de imagens e que são responsáveis pelas degradações inseridas pelo meio aquático. A fim de atingir este objetivo, implementaram-se diferentes algoritmos de otimização baseados em populações objetivando encontrar o melhor resultado possível. No processo de otimização, a definição da métrica de qualidade de imagens é de grande importância, pelo que será criado um banco de imagens subaquáticas que permita analisar diferentes métricas, escolhendo aquelas que apresentem melhor valor de correlação se comparadas com um estudo subjetivo feito por avaliadores humanos. Estas métricas foram utilizadas para avaliar a qualidade da imagem restaurada e guiar o processo de otimização. 
Deve ser salientado o fato de não existirem bancos de dados de imagens subaquáticas que apresentem uma análise subjetiva e permitam a análise de desempenho de novas métricas objetivas mediante uma análise de correlação. A criação e análise de novas métricas, ou de métricas já existentes, é de grande importância no estudo de novas estrategias de restauração de imagens subaquáticas, já que ditas métricas podem ser usadas para avaliar tarefas de restauração ou, de forma mais geral, da área de processamento de imagens subaquáticas.

\subsection{Hipóteses do Trabalho}

No contexto deste trabalho tem-se percebido uma lacuna no que corresponde a trabalhos de restauração de imagens subaquáticas, especificamente no campo de estimação dos parâmetros físicos do modelo, assim como na área de métricas de qualidade de imagem, que possam orientar este tipo de restauração. Portanto, as hipóteses que poderiam ser formuladas no contexto deste trabalho estão listadas a seguir:

- É possível abordar o processo de restauração de imagens como um problema de otimização. A caracterização do tipo de otimização mais apropriado é um importante foco de pesquisa, como demostrado no Capítulo 4 .

- O uso de algoritmos bio-inspirados é promissor dentro da área de restauração de imagens subaquáticas, tendo em conta que os modelos de formação de imagens em meios participativos, discutidos no Capítulo2, representam um problema multidimensional. Adicionalmente, as métricas para avaliação das imagens, apresentadas no Capítulo 4, são não lineares e multimodais, não sendo adequadas para algoritmos de otimização exatos como aqueles baseados em gradiente.

- Tendo em conta a dificuldade do processo de restauração de imagens, o qual envolve a estimação de parâmetros do modelo físico de degradação de imagens, é possível tratar o problema em tarefas pertinentes onde possam ser inseridos algoritmos de otimização específicos, por exemplo aqueles apropriados para funções custo multimodais e não lineares (como é o caso de algoritmos populacionais ou de enxames).

- Dentro do processo de otimização podem ser detectados problemas que envolvem a necessidade de abordar uma otimização multi-objetivo. Um estudo neste sentido pode provar em que casos isto pode ser aplicado para a restauração de imagens.

- Dentro dos aspecto de otimização é necessário pesquisar e implementar métricas apropriadas para o caso de imagens subaquáticas. Neste sentido, a pesquisa bibliográfica correspondente aponta a uma carência de métricas adequadas para avaliar a qualidade da 
restauração de imagens subaquáticas. Neste contexto, é factível encontrar uma ou mais métricas que servirão como função custo e, a sua vez, guiem satisfatoriamente este processo de restauração.

- Devido à versatilidade dos algoritmos de otimização bio-inspirados, é possível encontrar várias alternativas que permitam estimar corretamente os parâmetros do modelo de formação de imagens e, dessa forma, obter resultados satisfatórios na restauração de imagens subaquáticas.

- Partindo do fato de que os modelos de formação de imagens em meios participativos apresentam uma aproximação das degradações em cenas subaquáticas reais, é possível implementar, em imagens com degradações reais, a mesma estrategia de restauração utilizada para as imagens degradadas artificialmente realizando pequenas mudanças na métrica de avaliação.

\subsection{OBjetivos}

\subsubsection{Objetivo Geral}

O objetivo geral deste trabalho é desenvolver uma estratégia de restauração de imagens subaquáticas otimizada mediante a implementação de diferentes algoritmos baseados em populações e inteligência de enxames, e mediante a utilização de métricas apropriadas, que permitam medir a qualidade das imagens sem precisar de uma referência.

\subsubsection{Objetivos Específicos}

Os objetivos específicos deste trabalho são os seguintes:

1. Estudar e implementar diversos algoritmos de otimização baseados em populações e inteligência de enxames e sua aplicabilidade a sistemas de restauração de imagens subaquáticas.

2. Desenvolver um sistema de avaliação de qualidade de imagens, a fim de definir uma ou várias métricas que possam ser utilizadas como função objetivo.

3. Analisar o desempenho dos algoritmos implementados e gerar combinações dos mesmos, que permitam um melhor resultado.

4. Desenvolver uma base de dados de imagens subaquáticas que permita treinar adequadamente as métricas de avaliação de qualidade das imagens. 


\subsection{Aspectos Metodológicos do Trabalho}

A metodologia utilizada para o desenvolvimento do presente trabalho é composta de sete etapas, a saber:

1. Na primeira etapa foi realizada uma revisão bibliográfica do estado da arte das técnicas de restauração de imagens. Este estudo inicial levou à um estudo mais detalhado sobre os modelos de formação de imagens em meios participativos. Também foi necessário uma revisão sobre o estado da arte na utilização de métricas para a avaliação de qualidade de imagens e a sua implementação em ambientes subaquáticos. Além disso, também foi revisado o estado da arte dos algoritmos de otimização por inteligência de enxames, levando em conta aspectos de implementação em restauração e/ou processamento de imagens.

2. Na segunda etapa foram implementados os modelos de degradação de imagens em meios subaquáticos. Esta etapa consistiu na implementação de três modelos propostos na literatura que representam adequadamente as interações entre o ambiente e a cena. Também, desenvolveu-se uma ferramenta que permite escolher cada um dos modelos de formação e mudar os parâmetros para análise das degradações na imagem. Esta etapa foi fundamental para entender as diferenças e características de cada modelo de formação de imagens, assim como para realizar os primeiros testes de restauração, os quais foram desenvolvidos com degradações simuladas sobre uma imagem de referência. É importante ressaltar que os modelos físicos que representam as degradações não são o foco principal deste trabalho, razão pela qual o desenvolvimento de novos modelos não é um objetivo da presente pesquisa.

3. Na terceira etapa foram implementadas e analisadas várias métricas de avaliação objetiva de qualidade para imagens digitais com e sem referência. Esta etapa permitiu fazer uma escolha de duas métricas para os primeiros testes de restauração. A definição das métricas é fundamental no processo de restauração, já que esta corresponde à função que pretende-se otimizar mediante os algoritmos de otimização.

4. Na quarta etapa foram realizados os primeiros testes de restauração. Para estes teste foram utilizadas imagens degradadas artificialmente usando os modelos de formação de imagens implementados na segunda etapa. Estes testes foram realizados empregando duas técnicas de otimização bio-inspirada. A primeira abordagem consistiu em um otimizador PSO (Particle Swarm Optimization) mono-objetivo que utiliza a métrica NIQE (vide seção 4 ) como função objetivo no processo de otimização. A segunda abordagem consistiu na implementação de uma estratégia de otimização multi-objetivo baseada no algoritmo de Evolução Diferencial (DE - Differential Evolution) onde foi utilizada uma métrica de avaliação de 
contraste junto com a métrica NIQE utilizada na primeira abordagem. Esta etapa permitiu definir uma estratégia de restauração inicial que será implementada posteriormente em imagens subaquáticas reais.

5. Na quinta etapa foi criado um banco de imagens subaquáticas reais. Esta etapa consistiu na montagem de uma sistema de aquisição de cenas subaquáticas formado por uma câmera de fotografia convencional e um aquário. Para a adquisição foi utilizada água com diferentes características objetivando gerar degradações diferentes. Posteriormente, foi realizada uma análise subjetiva do banco de imagens. Esta análise consistiu na avaliação da qualidade das imagens adquiridas feita por um grupo de pessoas. Esta análise é muito importante a fim de comparar a métrica objetiva com as avaliações de qualidade feitas pelos avaliadores humanos. Este processo justifica-se levando em conta que o objetivo principal de uma métrica objetiva de qualidade de imagens é dar um valor numérico que apresente um alto valor de correlação com a avaliação subjetiva realizada por observadores humanos. A partir desta etapa, foi definida a métrica de avaliação objetiva que será utilizada para os testes de restauração das imagens subaquáticas reais. Nas imagens reais não foi possível encontrar mais de uma métrica objetiva que apresentasse um alto grau de correlação com as avaliações subjetivas. Porém, a métrica NIQE, utilizada na quarta etapa apresentou excelentes resultados na avaliação objetiva das imagens.

6. Na sexta etapa foram implementados os algoritmos de restauração das imagens com degradações reais. Nesta etapa, foram testados cinco algoritmos de otimização bio-inspirada. Tomaram-se como base dois algoritmos baseados em populações, sobre os quais foram implementadas metodologias de diversidade, gerando mais dois algoritmos de otimização. Além desses quatro algoritmos, implementou-se também o algoritmo de Evolução Diferencial dando um total de cinco algoritmos diferentes de otimização. Devido a que a métrica NIQE apresentou o melhor desempenho na avaliação objetiva das imagens, a abordagem de otimização mono-objetivo foi a indicada para esta etapa de testes.

7. Na sétima e ultima etapa foi feita uma comparação de desempenho dos algoritmos de otimização. Para esta análise foram utilizados testes de significância.

\subsection{Contribuições do Trabalho}

As principais contribuições deste trabalho são as seguintes:

- Ferramenta de degradação e restauração manual de imagens: A primeira contribuição deste trabalho foi a implementação dos modelos de degradação de imagens e inversão dos mesmos. 
Para a visualização das imagens degradadas ou restauradas foi criada uma ferramenta no MATLAB que permite modificar os parâmetros de formação de imagens para três modelos diferentes propostos na literatura. É importante ressaltar que os modelos matemáticos que descrevem as interações entre a luz e o meio de propagação representam adequadamente as degradações presentes em uma imagem submersa em um meio subaquático. Por esta razão, não é necessário desenvolver novos modelos de propagação da luz, sendo os existentes suficientes para o desenvolvimento deste trabalho.

- Banco de imagens subaquáticas: Como já mencionado, foi criado um banco de imagens subaquáticas com degradações reais. A cada imagem está atribuído um valor de qualidade subjetivo produto da análise feita pelos avaliadores humanos. Esta contribuição é muito importante devido a falta de um banco de imagens subaquáticas na internet com informação de qualidade para cada imagem do banco.

- Estratégia para restauração automática de imagens subaquáticas: Esta corresponde à contribuição mais importante deste trabalho. Foram apresentadas várias estratégias de restauração automática utilizando diferentes algoritmos de otimização bio-inspirada. Além da implementação, foi realizada uma análise de desempenho, possibilitando uma comparação entre os algoritmos.

- Produção bibliográfica: Por ultimo, no contexto deste trabalho foram realizadas duas publicações:

1. Multi-objective Differential Evolution Algorithm for Underwater Image Restoration: Este trabalho foi apresentado no CEC2015 (Congress on Evolutionary Computation 2015) na cidade de Sendai (Japão) na modalidade de apresentação oral. Neste trabalho foi apresentada a implementação de um sistema de restauração automática de imagens subaquáticas utilizando um algoritmo de otimização multi-objetivo por evolução diferencial (MODE). Neste caso, foram consideradas imagens com degradações simuladas mediante os modelos de formação de imagens. O processo de otimização obteve valores estimados muito aproximados aos valores utilizados para degradar as imagens. Além disso, fazendo uma análise subjetiva das imagens, elas apresentam, em muitos casos, melhor nitidez e contraste se comparadas com a imagem de referência.

2. A Real-time Stereo Vision System for Distance Measurement and Underwater Image Restoration: Este trabalho foi publicado no Journal of the Brazilian Society of Mechanical Sciences and Engineering, Volume 38, Issue 7 (Impresso). Este trabalho apresenta o desenvolvimento de um sistema embarcado em tempo real para medição de distâncias e restauração de imagens subaquáticas utilizando a técnica de visão estéreo. Visando alcançar um alto desempenho e uma implementação de baixo custo, 
o sistema completo foi desenvolvido utilizando um projeto hardware/software. Em outras palavras, os módulos do sistema que precisam realizar tarefas mais intensas no nível de pixeis são mapeadas diretamente em hardware paralelizando algumas tarefas e aumentando a velocidade de processamento. Além disso, tarefas menos complexas, que precisam ser feitas apenas uma vez para cada imagem, são implementadas utilizando um processador embarcado (NIOS II - Altera Corp.). A plataforma desenvolvida utiliza duas câmeras CMOS idênticas para o sistema de visão estéreo, um FPGA de baixo custo e uma tela para visualização das imagens. Utilizando esta abordagem, o sistema apresentou um consumo de potência de aproximadamente $115 \mathrm{~mW}$ e alcança uma taxa de processamento de até 26 quadros por segundo para imagens de $800 \times 480$, mostrando que o sistema é aplicável em tarefas de tempo real.

\subsection{Estrutura do TeXto}

Este documento está organizado da seguinte forma:

Inicialmente, no Capítulo 2, apresentam-se os modelos de degradação de imagens para ambientes subaquáticos assim como os algoritmos utilizados na literatura para restauração deste tipo de imagens. Posteriormente, no Capítulo 3 são apresentados os algoritmos de otimização bio-inspirados baseados em meta-heurísticas. Em seguida, no Capítulo 4 serão apresentados os fundamentos da avaliação de qualidade em imagens digitais e as métricas utilizadas neste trabalho. Posteriormente, no Capítulo 5 são apresentadas as implementações dos modelos de formação de imagens em meios participativos, assim como os detalhes da criação do banco de imagens subaquáticas e sua análise subjetiva. No Capítulo 6 são apresentados os testes finais do processo de restauração baseado em otimização bio-inspirada para imagens com degradações artificiais. Neste último são apresentadas duas abordagens de otimização, sendo a primeira mono-objetivo e a segunda multi-objetivo. Posteriormente, no Capítulo 7, são apresentados os testes de restauração aplicados a imagens com degradações reais utilizando diferentes algoritmos de otimização bio-inspirada. Por último, no Capítulo 8, será feito um discernimento sobre os resultados apresentados nos capítulos anteriores, assim como a comparação de desempenho dos algoritmos de otimização baseada em testes de significância. Assim, no final do documento serão apresentadas as conclusões e perspectivas de trabalhos futuros. 


\section{Modelos de FormaÇão e RestauraÇão de IMAGENS EM Meios PARTICIPATIVOS}

Em muitas aplicações a imagem medida é uma versão degradada da imagem real que representa a cena de maneira ideal. Esta degradação pode ser ocasionada por (a) distorções atmosféricas, (b) aberrações óticas, (c) sensor blur, (d) borramento por movimento, e (e) ruído. Os algoritmos de restauração de imagens pretendem recuperar a imagem real partindo de uma imagem degradada. Este problema, que requer a inversão de um modelo físico, é tipicamente mal-condicionado, o que significa que a solução não satisfaz pelo menos uma das seguintes características: (a) a solução deve existir; (b) deve ser única ou (c) deve ser estável com relação a pequenas perturbações na imagem [17].

Uma imagem pode apresentar diferentes tipos de degradações, sendo o borramento uma das mais comuns. O borramento de uma imagem consiste na perda de informação de alta frequência, como por exemplo das bordas dos objetos contidos na cena. O termo deblurring é frequentemente usado para a restauração de imagens degradadas por borramento. Embora o processo de degradação é não linear e variante no espaço, um grande número de problemas poderiam ser direcionados com um modelo linear invariante ao deslocamento LSI (Linear ShiftInvariant - vide Figura 2.1, que consideram que as caraterísticas das imagem não dependem da posição dos objetos na cena. A restauração de imagens em modelos LSI é chamada de deconvolução, já que a saída deste tipo de sistemas é a convolução de uma imagem com a resposta do sistema ao impulso (a função de espalhamento pontual (PSF)). No caso da PSF ser também uma função resposta ao impulso, e existe somente o ruído, o processo de restauração é chamado de filtragem. Caso a PSF não seja conhecida, o problema é abordado e denotado como restauração cega [17].

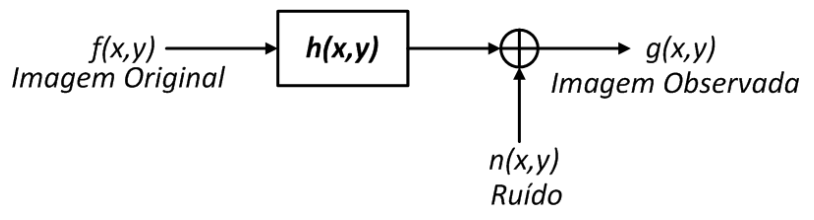

Figura 2.1. Modelo LSI, onde $h(x, y)$ representa a PSF do sistema 
Para um sistema LSI, o processo de formação da imagem pode ser formulado como mostrado na equação 2.1) (vide Figura 2.1).

$$
g(x, y)=h(x, y) * f(x, y)+n(x, y)
$$

onde $f(x, y)$ é a imagem real que se pretende recuperar a partir de uma medição degradada $g(x, y),(x, y)$ são coordenadas espaciais, "*” é a operação de convolução, $h(x, y)$ é a PSF do sistema, e $n(x, y)$ é o ruído aditivo. Na Figura 2.1 se apresenta um diagrama de blocos do processo. Essa formulação também pode ser formulada no domínio da frequência, como apresentado na equação 2.2.

$$
G(u, v)=H(u, v) F(u, v)+N(u, v)
$$

onde $G(u, v), H(u, v), F(u, v)$, e $N(u, v)$ são transformadas de $g(x, y), h(x, y), f(x, y)$, e $n(x, y)$, respectivamente.

Neste cenário, a PSF apresenta informações sobre o meio de transmissão da imagem, o sistema óptico da câmera, entre outras características do processo de adquisição da imagem. Sua transformada de Fourier $H(u, v)$ é a resposta em frequência do sistema de formação de imagem sendo também denotada como função de transferência óptica (Optical Transfer Function - OTF)[17.

A OTF descreve a transmissão da luz através do meio no domínio das frequências espaciais, sendo utilizada para medir o desempenho e/ou qualidade de um sistema óptico ou do sistema de adquisição (câmera, sistema de vídeo, microscópio, etc.). A magnitude e a fase da OTF são chamadas de função de transferência de modulação (MTF) e função de transferência de fase $(\mathrm{PTF})$, respectivamente. Embora $h(x, y)$ satisfaz certas condições de simetria, a PTF não é zero, causando distorções de fase no processo de formação de imagens. Além disso, a MTF fornece informação sobre a quantidade de luz que passa através do meio e do sistema óptico para diferentes componentes de frequência, sendo muito útil para analisar o desempenho do sistema de adquisição, incluindo a resolução de um sistema óptico [17]. Em resumo, a análise no domínio da frequência de um sistema de adquisição proporciona um conhecimento adicional em relação ao comportamento do sistema.

Em geral, as principais técnicas de restauração desenvolvidas na área de visão computacional desconsideram os efeitos do meio. Consequentemente, esses métodos não podem ser aplicados quando o meio onde a cena está inserida não pode ser desconsiderado (como é no caso de imagens subaquáticas). Este tipo de meios se conhecem como meios participativos. A partir do final da 
década de 90 apresentou-se um aumento no número de trabalhos voltados ao uso de imagens de cenas em ambientes atmosféricos e subaquáticos, em condições onde a ação do meio não pode mais ser negligenciada.

Neste capítulo serão mencionados os trabalhos mais representativos sobre os modelos de degradação de imagens subaquáticas. Os modelos discutidos e apresentados foram tomados de referências clássicas na área de processamento de imagens e de modelamento de sistemas ópticos. Estes modelos são de vital importância para o entendimento dos fatores e fenômenos físicos responsáveis pela degradação das imagens quando são adquiridas em um ambiente submarino. Além disso, e tendo em conta que o problema de restauração de imagens é resumido à inversão de um modelo de degradação, os modelos apresentados neste capítulo serão utilizados ao longo do trabalho para o desenvolvimento das tarefas de restauração.

\subsection{Modelo De JAFFe-MCGlamery}

Os modelos físicos existentes são bastante complexos e, geralmente, não podem ser aplicados em sistemas de visão computacional, devido à grande quantidade de parâmetros e variáveis a ter em conta. McGlamery [19] e Jaffe [18] apresentam uma simplificação ao modelo físico de formação de imagens. McGlamery (1979) desenvolveu uma base teórica enquanto Jaffe (1990) reportou extensões ao modelo e uma aplicação no projeto de um sistema de adquisição de imagens subaquáticas objetivando maximizar o contraste da cena e reduzir os efeitos da dispersão.

A luz interage com o meio aquático através de dois processos: absorção e dispersão. Absorção é a perda na potência lumínica enquanto a luz viaja pelo meio, sendo que depende do índice de refração do mesmo. Dispersão -Scattering- refere a qualquer deflexão da luz em relação à linha reta. Em ambientes subaquáticos, essas deflexões podem-se apresentar devido a partículas de tamanho comparável ao comprimento de onda da luz (difração), ou a regiões com índice de refração diferente da água (refração)[10]. Da mesma forma, a dispersão da luz pode ser de dois tipos: (a) quando uma fração de luz refletida pelas partículas de água é captada pela câmera antes de atingir os objetos da cena, o processo é chamado de back-scattering, sendo que esse fenômeno é o responsável pela perda de contraste na imagem; e (b) quando a luz é desviada aleatoriamente no caminho entre o objeto e a câmera, o processo é chamado de forward-scattering, causando o borramento da imagem [10].

Nesse modelo, assume-se que a irradiância $E_{T}$, em um pixel específico, ou seja, um ponto no plano de imagem, pode ser modelada como uma combinação linear de três fatores: (a) $E_{b}$ : irradiância devido ao efeito de back-scattering; (b) $E_{f}$ : irradiância devido ao efeito de forwardscattering; (c) $E_{d}$ : irradiância direta. 
Assim, a superposição linear do back-scatter, forward-scatter e da irradiância direta gera a irradiância total $E_{T}$ incidente em um ponto do plano da imagem como mostrado na equação (2.3).

$$
E_{T}=E_{b}+E_{f}+E_{d}
$$

Para modelar as interações da luz com o meio, assume-se que este é isotrópicd ${ }^{1}$ e homogêned ${ }^{2}$ e as interações modeladas são a atenuação e a dispersão.

Segundo Jaffe [18], os fenômenos de atenuação e dispersão podem ser modelados juntos utilizando a equação (2.4).

$$
E\left(p_{2}\right)=E\left(p_{1}\right) e^{-r(a+b)},
$$

onde $E\left(p_{2}\right)$ é a irradiância incidente num ponto $p_{2}$ da imagem, $E\left(p_{1}\right)$ é a radiância de um ponto $p_{1}$ da cena, $r$ é a distância em que a luz se propaga no meio participativo desde o ponto $p_{1}$ da cena até a câmera, $a$ e $b$ são os coeficientes de absorção e dispersão do meio, modelando a atenuação da intensidade luminosa por unidade de distância.

Com base nessas suposições, Jaffe e McGlamery modelam os demais fatores da Equação (2.3). Neste caso, modelos analíticos são construídos para capturar os efeitos da iluminação, da reflectância do objeto e da câmera. Cada um desses efeitos influem diretamente nos valores da irradiância total $E_{T}$ descrita na equação (2.3). Assim, cada um dos efeitos ligados à iluminação, à reflectância e à câmera serão descritos a seguir.

\subsubsection{Iluminação}

Considere um ponto $p^{\prime}$ localizado em uma área infinitesimal de superfície $d A$ iluminada por uma fonte de luz localizada a uma distância $R_{s}$, com emissão de energia caracterizada pela função $f_{b}\left(\theta_{s}, \varphi_{s}\right)$, onde $\theta_{s}$ e $\varphi_{s}$ definem a direção de iluminação, que faz um ângulo $\gamma$ com o vetor normal à superfície de $d A$ [18] (vide Figura 2.2].

A irradiância $E^{\prime}$ incidente em $d A$, localizado em $p^{\prime}$, pode ser escrita pela equação [2.5] [18].

$$
E^{\prime}\left(p^{\prime}\right)=\cos \gamma \frac{e^{-c R_{s}}}{R_{s}^{2}} f_{b}\left(\theta_{s}, \varphi_{s}\right)
$$

\footnotetext{
${ }^{1}$ Meio Isotrópico: Meio para o qual sua propriedades não dependem da direção em que são examinadas.

${ }^{2}$ Meio Homogêneo: Meio que mantem as mesmas propriedades físicas e químicas em todos e cada um dos seus pontos.
} 


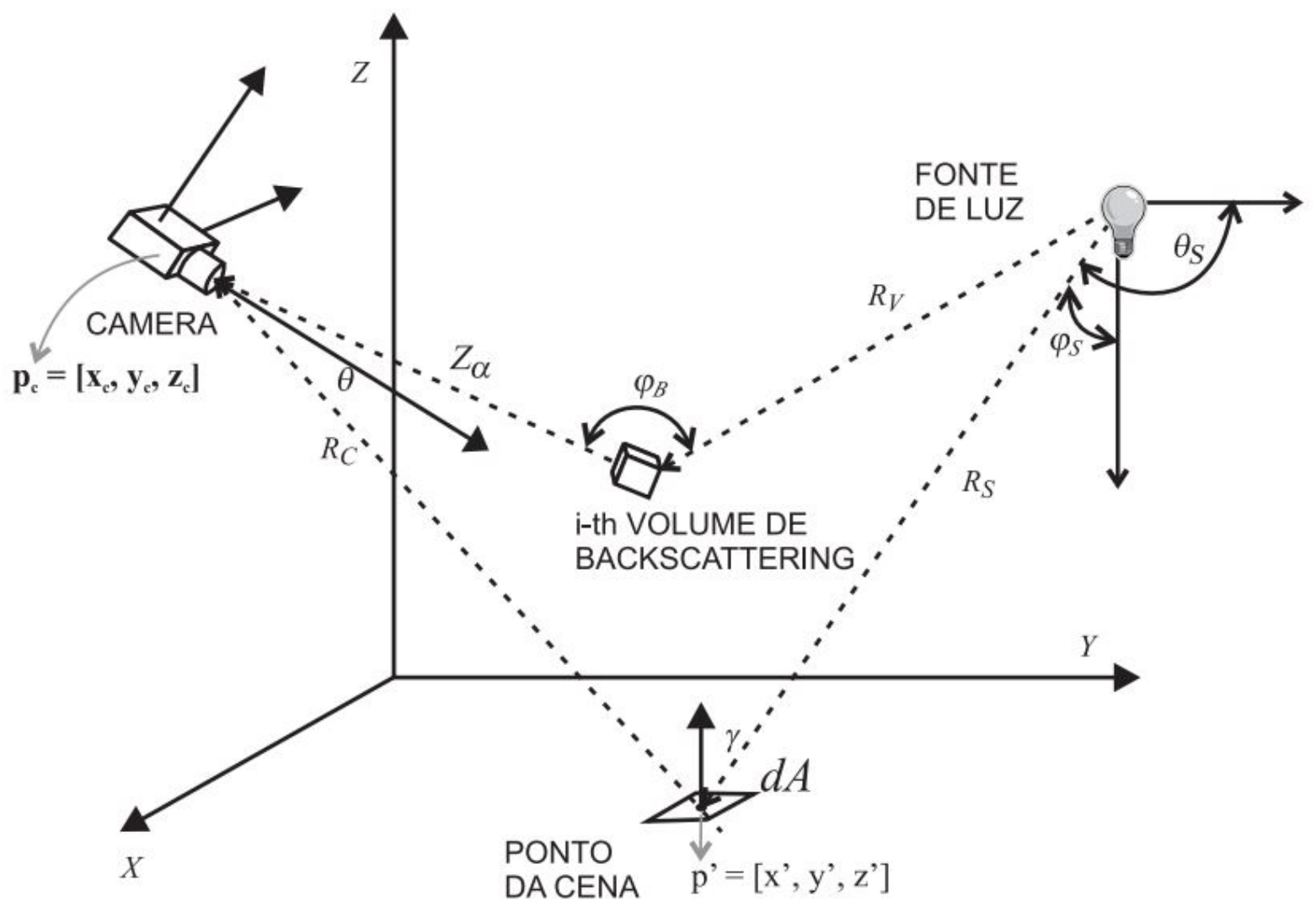

Figura 2.2. Modelo de Jaffe-McGlamery (imagem adaptada de [20]).

onde, $c$ é o coeficiente de atenuação dado por $c=a+b$. Esse coeficiente é a medida da perda de luz por unidade de longitude devido aos efeitos de absorção e dispersão. Valores típicos dos coeficientes de atenuação em águas oceânicas profundas e águas costeiras são $0,05 m^{-1}$ e $0,2 m^{-1}$, respectivamente [10].

Parte da irradiância que chega à superfície $d A$ é devida ao forward scattering. Incluindo este efeito na Equação (2.5), obtém-se a equação (2.6).

$$
E_{I}\left(p^{\prime}\right)=E_{I}^{\prime}\left(p^{\prime}\right) * g\left(x^{\prime}, y^{\prime}, R_{s}, G, c, B\right)+E_{I}^{\prime}\left(p^{\prime}\right)
$$

onde, $\left(x^{\prime}, y^{\prime}, 0\right)$ é a posição do ponto $p^{\prime}, G$ é uma constante empírica tal que $|G|<c$ e $B$ é uma função de atenuação também determinada empiricamente. O operador $<*>$ denota a operação de convolução e $g$ é a $P S F$, que pode ser descrita pela equação 2.7) e modela o espalhamento da luz em torno do ponto $p^{\prime}$ [10], [17].

$$
g\left(x^{\prime}, y^{\prime}, R_{s}, G, c, B\right)=\left[e^{-G R_{s}}-e^{-c R_{s}}\right] \Im^{-1}\left\{e^{-B R_{s} \omega}\right\}
$$


O símbolo $\Im^{-1}$ representa a transformada de Fourier inversa e $\omega$ é a frequência radial em radianos por segundo [18].

\subsubsection{Reflectância do Objeto}

Quando a luz encontra algum obstáculo ela pode ser absorvida, transmitida, refletida externamente ou ser dispersada internamente e, posteriormente, ser re-emitida (comum em objetos translúcidos). Considerando-se que o obstáculo é a superfície de algum objeto pertencente à cena, pode-se modelar esses fenômenos usando-se modelos matemáticos conhecidos como modelos de reflectância. O modelo de reflectância é implementado por funções de reflectância, onde procura-se quantificar a razão entre a quantidade de luz refletida e a quantidade de luz incidente. Geralmente, utiliza-se uma variação do modelo de reflectância Lambertiano, onde a reflectância da superfície é representada por meio de um mapa de reflectância planar $P\left(x^{\prime}, y^{\prime}\right)$ que corresponde, essencialmente, a um fator de atenuação. Dessa forma, $P$ é equivalente à constante de albedo 9 .

\subsubsection{Câmera}

A irradiância no plano de imagem é modelada a partir de 3 fatores de atenuação da radiância que chega à câmera [9].

1. Atenuação periférica: devido à óptica, ou seja, à existência de uma abertura finita na câmera. Esse fator de atenuação é modelado por $\frac{\cos ^{4} \theta}{F}$, onde $\theta$ é o ângulo formado entre o eixo-óptico da câmera e a direção da luz incidente e $F$ é o $f$-number da lente que expressa a abertura em função da distância focal.

2. Transmitância da lente: modelada por meio de um coeficiente multiplicativo $T_{l}$.

3. O terceiro fator, que depende da distância focal da lente, $F_{l}$ e da distância da câmera à cena, $R_{c}$, é modelado por $\frac{R_{c}-F_{l}}{R_{c}}$.

Assim, a atenuação total da luz entrando na câmera, antes de alcançar o plano de imagem, é mostrada na equação (2.8) 9].

$$
\frac{T_{l} \cos ^{4} \theta}{F}\left[\frac{R_{c}-F_{l}}{R_{c}}\right] .
$$


Portanto, além das características do meio, a óptica da câmera é um fator importante na irradiância total recebida pelo sensor de imagem, atenuando ou degradando a imagem captada.

\subsubsection{Descrição Final do Modelo Jaffe-McGlamery}

De posse dos resultados acima, podem-se obter as equações para descrever cada um dos três fatores que compõem a irradiância total $E_{T}$, o componente de iluminação direta, $E_{d}$, o componente de back-scattering, $E_{b}$, e o componente de forward-scattering, $E_{f}$. Assim, tem-se um modelo completo para formação de imagens subaquáticas, onde cada um dos componentes é detalhado a seguir:

1. Componente Direto: $E_{d}$ na Equação 2.3 pode ser escrito pela equação 2.9 como uma função da irradiância $E_{I}$ na superfície da cena no ponto $p^{\prime}$.

$$
E_{d}(x, y)=\left\{M\left(p^{\prime}\right) \frac{T_{l} \cos ^{4} \theta}{F}\left[\frac{R_{c}-F_{l}}{R_{c}}\right]\right\} E_{I}\left(p^{\prime}\right) e^{-c R_{c}}
$$

onde $R_{c}$ é a distância entre o ponto $p^{\prime}$ e a câmera. A função $M\left(p^{\prime}\right)$ representa o mapa de refletância da superfície. $M\left(p^{\prime}\right)<1$ e os valores típicos para objetos oceânicos são $0,02<M\left(p^{\prime}\right)<0,1[23]$.

2. Componente Forward Scattering: equação 2.10.

$$
E_{f}=E_{d} * g\left(x, y, R_{s}, G, c, B\right)
$$

3. Componente Back-Scattering: para se calcular o componente $E_{b}$, o modelo deve levar em consideração contribuições da luz de um grande volume de água entre a cena e a câmera. Considera-se que a irradiância em um volume diferencial $\Delta V^{\prime}$ (vide Figura 2.2) é dada por $E_{s}=E_{s, d}+E_{s, f}$, onde os componentes $E_{s, d}$ e $E_{s, f}$ são representados pelas equações (2.11) e 2.12, respectivamente.

$$
E_{s, d}=\frac{e^{-c R_{v}}}{R_{v}^{2}} b\left(\theta_{i}, \varphi_{i}\right),
$$




$$
E_{s, f}=E_{s, d} * g\left(\Delta V^{\prime}, R_{s}, G, c, B\right)
$$

A intensidade radiante resultante dispersada na direção da câmera por $\Delta V^{\prime}$ é dada pela equação 2.13 .

$$
H_{b}=\beta\left(\varphi_{b}\right) E_{s} \Delta V^{\prime},
$$

onde $\beta\left(\varphi_{b}\right)$ é a função de dispersão do volume e $\varphi_{b}$ é o ângulo formado entre a radiância incidente e a irradiância refletida de $\Delta V^{\prime}$ (vide Figura 2.2). A irradiância devido à intensidade radiante de $\Delta V^{\prime}$ é calculada considerando o componente direto da equação (2.14.

$$
E_{b, d}=\sum_{i=1}^{N} e^{-c Z_{c i}} \frac{\pi \Delta Z_{i}}{4 F^{2}} \cos ^{3} \theta T_{l}\left[\frac{Z_{c i}-f_{l}}{Z_{c i}}\right]^{2} \frac{H_{b}}{\Delta V^{\prime}} .
$$

Para o cálculo do termo $E_{b}$, deve-se simular um componente aditivo correspondente à luz dispersada, obtendo-se a equação 2.15.

$$
E_{b}=E_{b, d}+E_{b, d} * g\left(p, R_{s}, G, c, B\right) .
$$

Embora, o modelo físico formulado por Jaffe [18] e McGlamery [19] apresenta uma representação matemática bastante completa das interações entre a luz e o meio, este modelo continua sendo bastante complexo e com demasiados parâmetros a serem considerados. Por esta razão, outros autores apresentam trabalhos na simplificação do modelo descrito acima, permitindo uma melhor implementação em tarefas de restauração automática. A seguir serão apresentadas ditas simplificações

\subsection{Modelo Simplificado De Schechner}

Em [5], Schechner e Karpel (2004) propõem uma nova simplificação ao modelo originalmente proposto por Jaffe e McGlamery, descrito na Seção 2.1. Trata-se de uma forte simplificação do termo referente ao forward-scattering. Neste modelo considera-se que o efeito devido ao backscattering na observação de cenas amplas (com grande separação entre o fundo da cena e a 
câmera) é mais intenso que o efeito devido ao forward-scattering na mesma situação, assim, este último é desconsiderado do modelo.

Considere um fluxo de energia radiante, $L\left(x_{o}, y_{o}\right)$, percorrendo uma distância $d$ desde o ponto $p\left(x_{o}, y_{o}\right)$ no objeto, até a câmera. Segundo Schechner e Karpel [24], pode-se modelar a radiância percebida pelo sensor pela soma de dois termos como mostrado na equação 2.16 .

$$
L\left(x_{o}, y_{o}\right)=S\left(x_{o}, y_{o}\right)+E_{b}\left(x_{o}, y_{o}\right)
$$

Sendo que a radiância do ponto $\left(x_{o}, y_{o}\right)$ é representada pelo fator $L\left(x_{o}, y_{o}\right)$, o termo $S\left(x_{o}, y_{o}\right)$ corresponde à degradação de $L\left(x_{o}, y_{o}\right)$, devido aos efeitos de absorção e dispersão (vide equação (2.17)).

$$
S\left(x_{o}, y_{o}\right)=D\left(x_{o}, y_{o}\right)+F\left(x_{o}, y_{o}\right)
$$

onde $D\left(x_{o}, y_{o}\right)$ corresponde ao termo de transmissão direta enquanto que, $F\left(x_{o}, y_{o}\right)$ corresponde ao termo de dispersão da luz no meio em pequenos ângulos relativos à direção de visualização.

Enquanto um raio de luz se propaga no meio partindo do objeto em direção ao sensor, parte de sua energia é perdida devido à absorção e à dispersão. A fração de energia que chega no sensor corresponde ao termo $D\left(x_{o}, y_{o}\right)$ da equação 2.18 .

$$
D\left(x_{o}, y_{o}\right)=L_{0}\left(x_{o}, y_{o}\right) e^{-c d}
$$

onde $c=a+b$ é o coeficiente de atenuação, a é o coeficiente de absorção e $b$ é o coeficiente de dispersão total do meio. O coeficiente de dispersão $b$ expressa a característica de um volume infinitesimal de água dispersar fluxo luminoso em todas as direções.

O componente de dispersão $F\left(x_{o}, y_{o}\right)$ (vide equação (2.19) ) é similar ao componente de transmissão direta, sendo também conhecido como forward-scattering.

$$
F\left(x_{o}, y_{o}\right)=D\left(x_{o}, y_{o}\right) * g_{d},
$$

onde $g_{d}$ é uma função de espalhamento pontual - PSF, sendo esse termo o responsável pelo borramento das bordas na imagem. Já que a PSF $g_{d}$ é parametrizada pela distância $x$, quanto maior este parâmetro, mais largo será o suporte do kernel de borramento utilizado. Existem vários modelos diferentes de PSF na literatura ([18], [19] e [25]); entretanto, esses modelos são 
semelhantes a filtros passa-baixa, e nesses trabalhos são parametrizados por várias constantes empíricas.

O segundo termo da Equação (2.16), $E_{b}(d)$, refere-se ao back-scattering ou in-scattering e é similar ao que foi verificado no meio atmosférico por Narasimhan et al [26], podendo ser modelado pela equação (2.20) [27].

$$
E_{b}\left(x_{o}, y_{o}\right)=\beta\left(1-e^{-c d}\right)
$$

onde $\beta$ é uma constante de proporcionalidade que depende da natureza da iluminação no meio. Se o objeto está a uma distância muito grande da cena, a radiância devido ao efeito de backscattering é máxima, sendo encontrada assumindo-se $d=\infty$, de onde obtém-se $\beta=L_{\infty}$ [27].

Nos trabalhos realizados por Schechner e seus colegas as equações (2.16), 2.17) e 2.20) são combinadas na equação (2.21), que modela a irradiância $L\left(x_{o}, y_{0}\right)$, que posteriormente é transferida para o pixel $I\left(x_{i}, y_{i}\right)$.

$$
L\left(x_{o}, y_{o}\right)=\underbrace{L_{0}\left(x_{o}, y_{o}\right) e^{-c d}}_{\text {TransmissoDireta }}+\underbrace{L_{\infty}\left(1-e^{-c d}\right)}_{\text {Back-scattering }} .
$$

Pode ser observado que o efeito de borramento (Equação 2.19) não é modelado na Equação 2.21 do trabalho de Schechner. Segundo o autor, o termo de forward-scattering não é a causa dominante de degradação do contraste da imagem, como é o caso do back-scattering [5], 24]. Entretanto, em situações onde a distância média da cena à câmera é relativamente pequena essa afirmação não é válida. Esse fato foi observado por Trucco e Olmos-Antillon em [20], sendo discutido na Seção 2.3

\subsection{Modelo Simplificado Proposto por Trucco E Olmos-AnTILlon}

O modelo utilizado no trabalho de Trucco e Olmos-Antillon [20] também é baseado no modelo proposto por Jaffe e McGlamery, exposto na Seção 2.1. Mais especificamente, alguns termos do modelo de formação de imagem são desconsiderados, sendo dada ênfase principal ao termo responsável pelo Forward-Scattering. A principal contribuição do trabalho está no desenvolvimento de um algoritmo iterativo de restauração que faz uso de uma versão simplificada do modelo de Jaffe e McGlamery.

Neste caso, nenhuma informação a priori é levada em consideração no processo de aquisição 
de imagens. O trabalho apresentado por Trucco e Olmos-Antillon [20] considera que a iluminação da cena é uniforme, assumindo assim que as imagens são obtidas em águas rasas sob iluminação ambiente.

A irradiância proveniente de um dado ponto da cena que dista $R_{c}$ do sensor é calculada considerando-se somente o termo referente ao forward-scattering, como descrito na Seção 2.1 . obtendo-se a equação 2.22 .

$$
E_{f}=E_{d} * g\left(x, y, R_{c}, G, c, B\right) .
$$

Para este caso, o modelo está centrado no desenvolvimento da PSF, $g\left(x, y, R_{c}, G, c, B\right)$. Na Seção 2.1, essa PSF é descrita pela equação (2.7).

$$
g\left(x, y, R_{c}, G, c, B\right)=\left[e^{-G R_{s}}-e^{-c R_{s}}\right] \Im^{-1}\left\{e^{-B R_{s} \omega}\right\} .
$$

Para simplificar a equação acima, a diferença entre as exponenciais é aproximada por uma constante, como definido pela equação 2.24.

$$
K \sim\left[e^{-G R_{s}}-e^{-c R_{s}}\right]
$$

A equação 2.24 pode ser considerada uma aproximação razoável, uma vez que, $G$ e $c$ não apresentam variações consideráveis em situações práticas [20].

Os autores assumem que o termo referente ao forward-scattering é a principal fonte de degradação. De forma similar, Zhang e Negahdaripour [28 também concordam com a ideia, e acrescentam que a atenuação devida ao meio deve ser incorporada ao modelo. Porém, os mesmos autores alertam que o efeito de back-scattering, sem incluir informações da cena, também deve ser minimizado ao se projetar sistemas de visão computacional.

Com as simplificações impostas, o modelo resume-se à construção de um filtro inverso no domínio da frequência. Segundo Trucco e Olmos-Antillon, aplicando-se a transformada de Fourier à Equação 2.23 do modelo proposto, obtém-se a equação 2.25.

$$
G\left(f, R_{c}, c, K\right)=K e^{-B R_{c} \omega} .
$$

Além disso, em situações de interesse prático, a constante $B$ é aproximada satisfatoriamente pelo fator de atenuação $c$, como mostrado na equação 2.26 ).

$$
G\left(f, R_{c}, c, K\right) \approx K e^{-c R_{c} \omega} .
$$


Dessa forma, o filtro inverso obtido no domínio da frequência e usado no processo de restauração é dado pela equação (2.27).

$$
\frac{1}{G\left(f, R_{c}, c, K\right)}=\frac{1}{K} e^{c R_{c} \omega}
$$

\subsection{Modelo Simplificado Proposto Por Wagner}

As restrições impostas pelos modelos propostos por Schechner e Trucco-Olmos restringem o conjunto de cenas passíveis de restauração. O modelo proposto por Trucco-Olmos [20] pode apresentar problemas em restaurar imagens nas quais o objeto encontra-se distante do plano da câmera, onde existe uma grande influência do efeito de back-scattering. Além disso, embora o modelo proposto por Schechner [5] seja mais geral, apresenta falhas para cenas em águas turvas situadas a distâncias mais próximas da câmera, o forward-scattering, responsável pelo borramento, domina o processo de formação.

O trabalho apresentado por Wagner [9] propõe um modelo que apresenta os benefícios de ambos os métodos supracitados, porém mantendo a simplicidade dos modelos originais.

Considerando-se a simplificação do termo referente ao forward-scattering, $E_{f}\left(x_{o}, y_{o}\right)$, proposta por Trucco e Olmos-Antillon, assim como a simplificação do termo referente ao back-scattering, $E_{b}\left(x_{o}, y_{o}\right)$, proposta por Schechner, a irradiância $L\left(x_{o}, y_{o}\right)$ percebida pelo sensor proveniente de um ponto $p^{\prime}\left(x_{o}, y_{o}\right)$ localizado a uma distância $d$ (vide Figura 2.2 , pode ser calculada pela combinação linear dos termos $E_{f}\left(x_{o}, y_{o}\right)$ e $E_{b}\left(x_{o}, y_{o}\right)$, obtendo-se a equação 2.28, dada por:

$$
L\left(x_{o}, y_{o}\right)=E_{f}\left(x_{o}, y_{o}\right)+E_{b}\left(x_{o}, y_{o}\right)
$$

Tomando como base as expressões para $E_{f}\left(x_{o}, y_{o}\right), E_{d}\left(x_{o}, y_{o}\right)$ e $E_{b}\left(x_{o}, y_{o}\right)$, dadas pelas equações 2.22, 2.9 e 2.15 respetivamente, pode-se formar a expressão dada na equação 2.29

$$
L\left(x_{o}, y_{o}\right)=E_{d}\left(x_{o}, y_{o}\right) * g\left(x_{o}, y_{o}, d, G, c, B\right)+L_{\infty}\left(1-e^{-c d}\right)
$$

onde $L_{\infty} \approx \beta$ e $E_{d}$ é dado pela equação 2.9 apresentada na Seção 2.1.4. e fazendo $R_{c}=d$, obtém-se:

$$
E_{d}(x, y)=\left\{M\left(p^{\prime}\right) \frac{T_{l} \cos ^{4} \theta}{F}\left[\frac{d-F_{l}}{d}\right]\right\} E_{I}\left(p^{\prime}\right) e^{-c d}
$$

onde o termo $E_{I}\left(p^{\prime}\right)$ corresponde à irradiância na superfície da cena no ponto $p^{\prime}$ localizado na 
posição $\left(x_{o}, y_{o}\right)$ a uma distância $d$ da câmera. Devido a que a equação 2.30 contem parâmetros referentes à câmera e o meio, pode ser simplificada na equação 2.31)

$$
E_{d}(x, y)=L_{0}\left(x_{o}, y_{o}\right) e^{-c d}
$$

Portanto, o modelo de formação de imagens proposto por Wagner [9] está representado pela equação 2.32, dada por:

$$
L\left(x_{o}, y_{o}\right)=L_{0}\left(x_{o}, y_{o}\right) e^{-c d} * g(.)+L_{\infty}\left(1-e^{-c d}\right)
$$

Nesta equação, a imagem captada pelo sensor está dada pelo termo $L\left(x_{o}, y_{o}\right), L_{\infty}$ é uma constante de proporcionalidade que depende da natureza da iluminação no meio [5], $c$ e $d$ correspondem ao coeficiente de atenuação do meio e a distância entre o ponto $\left(x_{o}, y_{o}\right)$ e a câmera, respetivamente. Além disso, encontra-se na equação 2.32 a PSF $g($.$) e sua representação no$ domínio da frequência está dada pela equação 2.26 proposta por Trucco e Olmos-Antillon em [20]. Por ultimo, o termo $L_{0}\left(x_{o}, y_{o}\right)$ corresponde à imagem sem degradações. Neste contexto, o processo de restauração de imagens subaquáticas tem como objetivo principal encontrar a imagem $L_{0}\left(x_{o}, y_{o}\right)$.

Este modelo de formação de imagens é mais geral que os modelos apresentados nas seções 2.2 e 2.3. porém, por se tratar de um modelo simplificado, devem-se impor algumas restrições quanto às características da cena [9].

A seguir são listadas as restrições do modelo e algumas simplificações adicionais apresentadas no trabalho [9]:

- Considera-se que o meio em que a cena está submersa é homogêneo e isotrópico;

- assume-se que não há fontes de luzes internas ao meio;

- as características da refletância dos objetos presentes na cena devem ser simples, uma vez que, reflexos e brilhos especulares não estão incorporados no modelo;

- os efeitos que resultam na formação de padrões de brilho e de raios de luz que dispersam ao passar pela superfície da água não são abordados, assim como o efeito de reflexão da luz na superfície;

- assume-se que a cena encontra-se submersa em águas rasas. Essa é uma restrição razoável considerando-se que além da própria câmera, nenhum outro sensor auxiliar será utilizado na adquisição dos dados de entrada; 
- assume-se a existência de iluminação ambiente suficiente no processo de captura das imagens.

As últimas duas restrições são necessárias para garantir alguma visibilidade inicial na imagem adquirida. A restrição referente à homogeneidade do meio garante que somente um conjunto de parâmetros é suficiente para restaurar a imagem completa. Para simplificar o modelo não foram consideradas fontes de iluminação interna, enquanto os reflexos e brilhos especulares não são considerados neste modelo de formação de imagens [9].

\subsection{RestauraÇÃo De Imagens Subaquáticas por InVersão DO MODELO}

Objetivando apresentar a metodologia de restauração de imagens baseada na inversão de um modelo de formação de imagens em meios participativos, nesta seção será utilizado como exemplo o modelo estudado na Seção 2.4, já que trata-se de um modelo mais geral se comparado com os modelos apresentados nas seções 2.2 e 2.3. Esta mesma metodologia pode ser facilmente adaptada para os modelos de Schechner e Trucco-Olmos.

Visando eliminar o operador de convolução, pode-se representar a equação 2.32 no domínio da frequência como apresentado na equação 2.33

$$
L(u, v)=L_{0}(u, v) G(u, v)+\Im\left\{L_{\infty}\left(1-e^{-c d}\right)\right\}
$$

onde o operador $\Im$ corresponde à transformada de Fourier, $L_{\infty}$ é a constante de iluminação do meio, $c$ é o coeficiente de atenuação, $d$ é a distância entre a câmera e o objeto e $L_{0}(u, v)$ corresponde à imagem sem degradações. Além disso, a função $G(u, v)$ está dada pela equação (2.26) e corresponde à transformada de Fourier da PSF.

Lembrando que o objetivo principal do processo de restauração consiste em encontrar a imagem $L_{0}\left(x_{o}, y_{o}\right)$, pode-se encontrar uma expressão para este termo no domínio da frequência, representado pela equação 2.34 .

$$
L_{0}(u, v)=\frac{L(u, v)-\Im\left\{L_{\infty}\left(1-e^{-c d}\right)\right\}}{G(u, v)} .
$$

Assim, o processo de inversão do modelo é completado realizando a transformada de Fourier inversa sobre o resultado da equação anterior, dando como resultado a equação (2.35). 


$$
L_{0}\left(x_{o}, y_{o}\right)=\Im^{-1}\left\{\frac{L(u, v)-\Im\left\{L_{\infty}\left(1-e^{-c d}\right)\right\}}{G(u, v)}\right\} .
$$

Por último, para completar o processo de restauração automática, devem-se estimar os parâmetros desconhecidos do modelo inverso apresentado na equação 2.35). No caso do modelo apresentado por Wagner, os parâmetros que devem ser estimados são: (a) o coeficiente de atenuação $c$, (b) o ganho $K$ da $\operatorname{PSF}(G(u, v)$ - vide equação 2.26$)$ ) e (c) a constante $L_{\infty}$. Em relação à distância $d$ entre a câmera e a cena, esta pode ser medida ou estimada utilizando sensores de distância. Um exemplo disto pode ser visto nos trabalhos apresentados por Nascimento [29] e por Sanchez-Ferreira [30], onde é utilizado um sistema de visão estereoscópica objetivando medir a distância entre a câmera e um objeto para eliminar o efeito da transmissão direta, o qual gera uma perda de contraste na imagem.

A estimação dos parâmetros supracitados é talvez a etapa mais importante do processo de restauração. Para isto podem ser utilizados algoritmos de otimização os quais permitem estimar parâmetros ótimos que melhorem o valor de aptidão do processo, geralmente representada mediante uma métrica de avaliação de imagens. Os algoritmos de otimização utilizados neste trabalho correspondem a métodos meta-heurísticos que serão discutidos no Capítulo3. Da mesma forma, no Capítulo 4 serão apresentadas as funções objetivo utilizadas para o desenvolvimento deste trabalho.

\subsection{Análise Comparativa dos Modelos de FormaÇão de IMAGENS EM Meios PARTICIPATIVos}

Neste capítulo foram apresentados quatro modelos de formação de imagens em meios participativos. Pode-se afirmar que o modelo mais completo é aquele proposto por Jaffe e McGlamery [18], [19], apresentado na Seção 2.1. Porém, este modelo possui a maior quantidade de parâmetros a serem considerados. Esse fato conduz a uma maior complexidade na implementação ou na simulação deste modelo. Além disso, conta-se com duas simplificações do modelo de Jaffe e McGlamery, apresentadas originalmente por Schechner [5], e Trucco e Olmos [20], as quais permitem uma maior facilidade na implementação do modelo. A simplificação proposta por Y. Schechner (Seção 2.2) considera que o efeito de forward-scattering pode ser eliminado do modelo de formação da imagem final, sendo esta simplificação válida somente para cenas onde a distancia entre os objetos e a câmera é bastante ampla. O caso contrário é estudado por Truco e Olmos-Antillon (Seção 2.3), que considera situações onde a distância média entre a cena e a câmera é relativamente pequena, assim, o termo correspondente ao efeito de back-scattering é desconsiderado e é dada ênfase principal ao termo responsável pelo Forward-Scattering. 
Tabela 2.1. Análise comparativa dos modelos de formação de imagens em meios participativos

\begin{tabular}{|l|c|c|c|}
\hline Modelo & Complexidade & Simplificação & $\begin{array}{c}\text { distância } \\
\text { objeto-câmera }\end{array}$ \\
\hline Jaffe-McGlamery [18], [19] & alta & Nenhuma (Modelo Base) & Qualquer \\
\hline Wagner [9] & média-baixa & $\begin{array}{c}\text { Não considera os } \\
\text { parâmetros da câmera }\end{array}$ & Qualquer \\
\hline Trucco-Olmos [20] & baixa & $\begin{array}{c}\text { back-scattering } \\
\text { Não considera os } \\
\text { parâmetros da câmera }\end{array}$ & Curta \\
\hline Schechner [5] & baixa & $\begin{array}{c}\text { forward-scattering } \\
\text { Não considera os } \\
\text { parâmetros da câmera }\end{array}$ & Grande \\
\hline & & \multicolumn{2}{|}{} \\
\hline
\end{tabular}

Tabela 2.2. Parâmetros a serem estimados pelo processo de otimização

\begin{tabular}{|c|l|}
\hline \multicolumn{1}{|c|}{ Modelo } & Parâmetros \\
\hline Trucco-Olmos & $\begin{array}{l}K \text { - Ganho da PSF } \\
c \text { - Coeficiente de Atenuação }\end{array}$ \\
\hline Schechner & $\begin{array}{l}c \text { - Coeficiente de Atenuação } \\
L_{\infty} \text { - Constante de iluminação }\end{array}$ \\
\hline \multirow{2}{*}{ Wagner } & $K$ - Ganho da PSF \\
& $\begin{array}{l}c \text { - Coeficiente de Atenuação } \\
L_{\infty} \text { - Constante de iluminação }\end{array}$ \\
\hline
\end{tabular}

Em conclusão, a utilização de um modelo ou de outro dependerá fortemente da distância média entre a cena e a câmera. Devido a este problema, Wagner [9] apresentou um modelo de formação de imagens em meios participativos mais recente que surge de combinar os dois modelos anteriores, apresentando um modelo mais geral e para uma ampla faixa de valores da distância entre a câmera e o objeto. A Tabela 2.1 apresenta um resumo comparativo dos modelos expostos neste capítulo.

Além disso, a Tabela 2.2 apresenta os parâmetros que devem ser estimados em um processo de restauração automático para as três simplificações apresentadas neste capítulo.

Neste trabalho foram implementados as três simplificações do modelo de Jaffe-MacGlamery assim como o algoritmos para inversão dos mesmos. Devido às vantagens em relação à generalidade e complexidade, decidiu-se utilizar a simplificação proposta por Wagner (vide Seção 2.4 como modelo de formação de imagens no processo de restauração automática. Como 
dito anteriormente, embora este modelo apresente uma simplificação de um modelo mais geral (Jaffe-MacGlamery - Seção 2.1), está definido para uma ampla faixa de distâncias sem aumentar consideravelmente a complexidade computacional, apresentando uma melhor alternativa se comparado com os modelo propostos por Schechner e Trucco-Olmos.

\subsection{Considerações Finais do Capítulo}

O problema da restauração é tratado como uma operação inversa ao processo de formação da imagem, fato pelo qual foi introduzido um modelo geral de degradação linear LSI (vide Figura 2.1]. Em alguns algoritmos de restauração, considera-se que são conhecidos todos os parâmetros da função de degradação PSF e do ruído, porém, na maioria das aplicações reais não se tem informação sobre esses parâmetros. Nesse caso, os algoritmos de restauração cega são os encarregados de estimar a função de degradação para, com essa informação, estimar a imagem real, sendo este o caso de estudo deste trabalho.

Além disso, foram apresentados os modelos de formação de imagens em meios participativos mais referenciados na literatura. O modelo de Jaffe-McGlamery apresenta uma descrição detalhada das degradações inseridas pelo meio, porém este modelo apresenta demasiados parâmetros a serem considerados, dificultando sua implementação em algoritmos de restauração automática. Na literatura, apresentam-se três simplificações deste modelo: (a) Trucco-Olmos apresenta um modelo de formação de imagens para distâncias curtas; (b) Schechner trata o caso contrario, considerando distâncias maiores entre a câmera e o objeto; e por ultimo, (c) Wagner apresenta um modelo simplificado que permite considerar os principais efeitos para uma ampla faixa de distâncias. Estas simplificações facilitam a implementação, sendo passíveis para processos de restauração automática. Nesse contexto, o modelo apresentado por Wagner foi escolhido como base para o processo de restauração já que apresenta um modelo mais completo e de baixa complexidade computacional.

Em conclusão, os algoritmos de restauração para imagens subaquáticas precisam tanto de um modelo de degradação adequado quanto de um algoritmo que possa estimar os parâmetros ótimos desse modelo a fim de encontrar uma imagem que possa-se aproximar à cena sem as degradações inseridas pelo meio. 


\section{Algoritmos de OtimizaÇÃo Bio-Inspirados}

Como foi discutido no capítulo 2, os algoritmos de restauração de imagens subaquáticas requerem a estimação de determinados parâmetros do modelo físico. Esses parâmetros estão fortemente ligados à qualidade do resultado obtido pelo sistema de restauração. Desta forma, os algoritmos de otimização são uma ferramenta muito utilizada para encontrar os valores ótimos para esses parâmetros de restauração, conseguindo assim uma imagem restaurada com alto nível de qualidade.

Neste capítulo serão tratados os conceitos básicos de otimização, assim como a nomenclatura que vai ser utilizada ao longo deste trabalho. Por último, são apresentados os algoritmos de otimização bio-inspirados baseados em inteligência de enxames, que são o foco deste trabalho. A informação contida neste capítulo é importante para entender as implementações feitas neste trabalho, apresentadas nos Capítulos 6 e 7 .

\subsection{Conceitos BÁsicos de OtimizaÇÃo.}

Otimização é o ato de obter o melhor resultado sob determinadas circunstâncias [12]. No projeto, construção e manutenção de qualquer sistema o engenheiro deve tomar decisões em várias etapas. O objetivo principal dessas decisões é minimizar o esforço e maximizar o beneficio. Devido a que o esforço ou o beneficio, em qualquer situação prática, pode ser expresso como uma função de determinadas variáveis de decisão, a otimização pode ser definida como o processo realizado para obter as condições que dão o valor máximo (ou mínimo de uma função), chamada de função objetivo ou função custo.

Na Figura 3.1 pode ser visto que, se um ponto $x^{*}$ corresponde ao valor mínimo de uma função $f(x)$, o mesmo ponto corresponde também ao valor máximo do negativo da função, $-f(x)$ [12].

No contexto deste trabalho, todos os problemas de otimização são considerados de minimização, os quais podem ser definidos da seguinte maneira: seja $f: \Re^{n} \rightarrow \Re$, encontrar $x^{*} \in \Re^{n}$, para o qual $f\left(x^{*}\right)<f(x)$, i.e., $x=\left(x_{1}, \ldots, x_{n}\right)$.

Entretanto, a maioria dos problemas práticos apresentam não linearidades e interações com- 


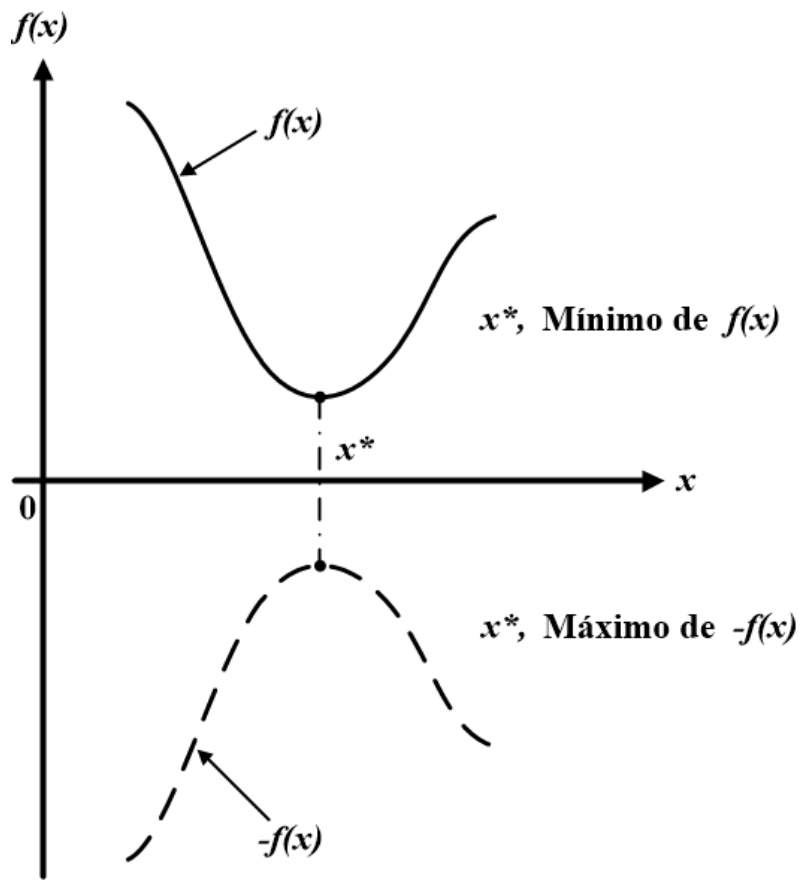

Figura 3.1. Mínimo de $f(x)$ igual ao máximo de $-f(x)$ [12].

plexas entre as variáveis do projeto $x$ e as restrições do sistema, formando um espaço de busca $S$, e contendo em alguns casos várias soluções ótimas. Dessa forma, surge uma subdivisão das técnicas para a solução de problemas de otimização: otimização local e otimização global. Um ponto $x^{*}$ é um ótimo local de $f$ se existe uma vizinhança $V=x:\left|x^{*}-x\right|<\epsilon$ em torno de $x^{*}$ tal que $f\left(x^{*}\right)<f(x), \forall x \in V \subset S \subseteq \Re^{n}$. Um ponto $x^{*}$ é um ótimo global de $f$ se $f\left(x^{*}\right)<f(x), \forall x \in V \subset S \subseteq \Re^{n}$, sendo $S$ o espaço de busca [13.

\subsubsection{Elementos de um Modelo de Otimização}

A solução de um problema de otimização requer como primeira instância uma formulação matemática de um modelo que preserve uma equivalência coerente com o problema real. A abstração de um modelo de otimização envolve múltiplas etapas de tentativa e erro, comumente dependendo de critérios subjetivos, tais como experiência, criatividade e poder de síntese, que não podem ser regulados pelo estabelecimento de regras fixas [13]. Os elementos básicos de um modelo de otimização são descritos a seguir (as definições foram tomadas de [12], [13]):

1. Variáveis de decisão: as variáveis de decisão são as incógnitas que definem a solução do modelo.

2. Espaço de busca: o espaço de busca é o conjunto de pontos que representam as soluções factíveis e infactíveis ao problema de otimização. Esse espaço é determinado pelo limite superior e inferior das variáveis de decisão. 
3. Função objetivo: a função objetivo é aquela função matemática que deve ser maximizada ou minimizada e que representa o problema de otimização e as interações entre as variáveis de decisão. Também é referenciada como função custo. O valor da função objetivo avaliada em uma possível solução é conhecido como valor de aptidão.

4. Restrições: as restrições são funções matemáticas que limitam o espaço de soluções factíveis do problema de otimização. São determinadas pelas limitações físicas de sistema.

5. Ótimo local: um ótimo local é um ponto máximo ou mínimo que ocorre em um subespaço do espaço de busca.

6. Ótimo global: o ótimo global é o ponto do espaço de busca onde a função objetivo alcança o valor máximo ou mínimo.

Problemas que envolvem muitos ótimos locais são chamados de multimodais. Entretanto, problemas com um único ótimo global são chamados de unimodais ou problemas convexos [13].

\subsubsection{Classificação dos Métodos de Otimização}

Segundo S. S. Rao [12], os algoritmos de otimização podem ser classificados de muitas maneiras: com base na existência de restrições, na natureza das variáveis de projeto, na estrutura física do problema, na natureza das equações envolvidas, no número de funções objetivo, etc. Porém, neste trabalho, estes algoritmos serão classificados em três categorias: (a) métodos exatos, (b) métodos heurísticos e (c) métodos meta-heurísticos.

\subsubsection{Métodos Exatos}

Os métodos exatos geralmente utilizam algoritmos determinísticos para realizar uma busca do espaço de soluções no intuito de encontrar o ótimo global da função objetivo. Técnicas de programação matemática tais como o algoritmo Simplex para programação linear, métodos baseados em derivadas para programação não linear, ou algoritmos de programação dinâmica fazem parte dos métodos exatos. Em muitos problemas de otimização a relação entre as soluções candidatas e o valor de aptidão é complexa, fazendo com que o problema seja difícil de resolver de forma determinística. Adicionalmente, problemas de alta dimensionalidade conduzem a tempos de execução elevados (horas ou dias) e, portanto, algoritmos não determinísticos devem ser considerados [12]. 


\subsubsection{Métodos Heurísticos}

São métodos que utilizam uma ou mais informações referentes ao problema para guiar o processo de busca de uma solução ótima [31]. Os métodos heurísticos não garantem encontrar a solução ótima de um problema, porém, podem encontrar soluções aceitáveis (sub-ótimas) em um tempo polinomial. A principal desvantagem dos métodos heurísticos é que são desenvolvidos para resolver classes específicas de problemas, carecendo de generalidade [13].

\subsubsection{Métodos Meta-heurísticos}

São métodos de generalização de heurísticas que permitem resolver diversos tipos de problemas sem precisar grandes mudanças nos algoritmos [13]. Estes métodos geralmente utilizam estatísticas obtidas de amostras do espaço de busca que permitem resolver uma ampla gama de problemas, sendo comum a utilização de modelos baseados em fenômenos naturais ou processos físicos no intuito de aplicar uma filosofia que permita o desenvolvimento de algoritmos heurísticos. Entre as técnicas de otimização meta-heurísticas mais utilizadas podem-se mencionar algoritmos bio-inspirados tais como os algoritmos genéticos [32], otimização por colônia de formigas [33], otimização por enxame de partículas [34], entre outros. Os métodos de otimização meta-heurísticos são o foco do presente trabalho.

Neste trabalho, serão considerados os algoritmos de otimização bio-inspirados baseados em populações, já que estes apresentam resultados satisfatórios para problemas de otimização complexos, onde as funções objetivo apresentem não linearidades [12], [13]. Na seção 3.1.3, será feita uma descrição mais detalhada dos algoritmos bio-inspirados.

\subsubsection{Algoritmos de Otimização Bio-inspirados}

Nas últimas décadas tem surgido uma nova ciência computacional baseada em meta-heurísticas inspiradas na natureza, na biologia e em processos físicos denominada computação natural. Esta ciência compreende áreas de atuação em processos de otimização, inteligência artificial (redes neurais artificiais, lógica nebulosa, etc.), biocomputação para análise de DNA, fractais, entre outros.

Algoritmos de otimização bio-inspirados (baseados em populações), dentre os quais se destacam os algoritmos evolutivos e os algoritmos de enxames, fazem parte dos métodos de computação natural. Estes algoritmos utilizam técnicas computacionais baseadas nos princípios biológicos evolutivos encontrados na natureza, tais como a seleção natural e herança genética, mutação e comportamentos coletivos para intercâmbio de informação [13]. 
Os algoritmos bio-inspirados baseados em populações podem ser classificados em dois grupos (vide Figura 3.2): (a) os algoritmos evolutivos e (b) os algoritmos de de enxames. Os algoritmos evolutivos incluem os algoritmos genéticos, a programação evolutiva, estratégias evolutivas e a programação genética. Estas técnicas estão baseadas no princípio de sobrevivência dos mais fortes, reproduzindo apenas as soluções que mais se aproximam à solução ótima [13. Além disso, os algoritmos de enxames consideram um conjunto de técnicas baseadas no comportamento coletivos de algumas espécies naturais, permitindo um intercâmbio eficiente de informação entre os indivíduos de uma colônia. Este conjunto de técnicas é chamado de Inteligência de Enxames. Assim, a estrutura organizacional das abelhas, o caminho ótimo percorrido por uma colônia de formigas e o agrupamento de cardumes de peixes e bandos de aves, na procura de alimento, são somente alguns exemplos do sucesso deste tipo de comportamento social.

Algoritmos Evolutivos

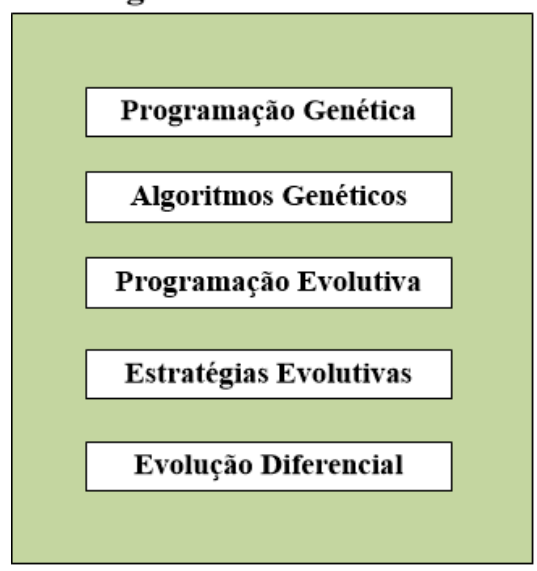

Figura 3.2. Classificação dos algoritmos bio-inspirados baseados em populações [13.

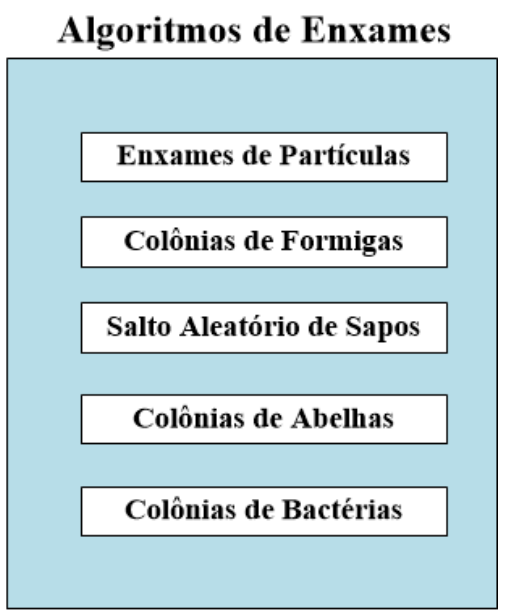

Além disso, os algoritmos de otimização bio-inspirados baseados em populações são uma excelente alternativa para a otimização de processos de restauração de imagens em meios subaquáticos, já que os modelos de degradação de imagens considerados neste trabalho são altamente não-lineares devido aos processos físicos de propagação da luz (vide capítulo 2). Assim, os algoritmos de otimização bio-inspirados serão o foco deste trabalho.

\subsection{Otimização por EnXame de Partículas (PSO)}

O algoritmo PSO foi proposto originalmente por Kennedy e Eberhart [15, [34, 35] como uma técnica de otimização estocástica inspirada no comportamento social de bandos de aves e cardumes de peixes na procura de alimento. No algoritmo PSO a população é chamada de enxame e cada individuo é chamado de partícula. Cada possível solução ao problema de otimização 
vai ser representada pela posição de uma partícula. O termo partícula é utilizado como um compromisso no qual os indivíduos de um enxame podem ser interpretados como pontos, sem massa nem volume [13].

No algoritmo PSO cada partícula tem uma velocidade aleatória associada, permitindo que as soluções potenciais (posição das partículas) se movimentem pelo espaço de busca do problema de otimização. Entretanto, cada partícula mensura a sua aptidão mediante a avaliação da função custo e conserva seu conhecimento do melhor valor de aptidão, utilizando uma memória individual e uma memória coletiva. A memória individual permite que a partícula lembre a posição em que encontrou um melhor valor de aptidão, enquanto a memória coletiva permite que as partículas lembrem a posição em que o enxame encontrou o melhor valor global de aptidão [13].

Os termos que serão utilizados neste trabalho são:

1. Partícula ou agente: individuo do enxame.

2. Enxame: coleção de indivíduos.

3. Posição $(x)$ : coordenadas de uma partícula no espaço $N$-dimensional que representa uma possível solução ao problema.

4. Aptidão: o valor que representa quão boa é uma solução. Geralmente é a avaliação da função objetivo $f(x)$

5. pbest $\left(y_{i}\right)$ : posição da melhor aptidão para uma determinada partícula.

6. gbest $\left(y_{s}\right)$ : posição da melhor aptidão para o enxame inteiro.

7. $v_{\max }$ : velocidade máxima permitida em uma direção determinada.

\subsubsection{Algoritmo PSO básico}

Considerando um espaço de busca $N$-dimensional e um enxame com $S$ partículas, a posição da $i$-ésima partícula do enxame na $j$-ésima dimensão pode ser atualizada mediante as equações (3.1) e 3.2.

$$
\begin{gathered}
v_{i j}^{(t+1)}=v_{i j}^{(t)}+c_{1} U_{1 j}\left(y_{i j}^{(t)}-x_{i j}^{(t)}\right)+c_{2} U_{2 j}\left(y_{s j}^{(t)}-x_{i j}^{(t)}\right) \\
x_{i j}^{(t+1)}=x_{i j}^{(t)}+v_{i j}^{(t+1)}
\end{gathered}
$$

onde $U_{1 j}$ e $U_{2 j}$ são números aleatórios uniformemente distribuídos entre 0 e $1, y_{i j}$ é a melhor 
posição individual da $i$-ésima partícula na $j$-ésima dimensão e $y_{s j}$ é a melhor posição global entre todas as partículas na $j$-ésima dimensão. As velocidades $v_{i j}$ estão limitadas na faixa $\left[-v_{\max }, v_{\max }\right]$ evitando assim que as partículas abandonem o espaço de busca.

Os parâmetros $c_{1}$ e $c_{2}$ representam o coeficiente cognitivo e o coeficiente social, respectivamente. O comportamento do algoritmo PSO muda radicalmente dependendo dos valores desses parâmetros. Um valor grande do coeficiente cognitivo $c_{1}$ indica partículas com alta autoconfiança na sua experiência, enquanto um valor grande do coeficiente social $c_{2}$ proporciona às partículas maior confiança no enxame [36]. Para funções objetivo unimodais é aconselhável utilizar pequenos valores do coeficiente cognitivo e valores grandes para o coeficiente social, enquanto para funções multimodais é necessário encontrar um balanço entre os dois coeficientes visando melhorar o desempenho do algoritmo [34], [36].

O Algoritmo 1 apresenta o pseudocódigo do PSO. O mesmo pode ser visto como um algoritmo iterativo, em que a cada iteração é calculada uma nova posição para cada partícula no enxame. No intuito de conferir a conveniência das posições geradas, as mesmas são avaliadas utilizando a função objetivo $f$. Para cada partícula, se o valor da função objetivo na posição atual $f\left(x_{i}\right)$ é menor que o valor da função objetivo da melhor posição individual $f \min _{k}$ (vide a linha 12 do Algoritmo 1), então a melhor posição individual é substituída pela posição atual da partícula $\left(y_{i}=x\right)$. Se o valor da função objetivo da posição atual $f\left(x_{i}\right)$ é menor que o valor da função objetivo da melhor posição global $f\left(y_{s}\right)$ então a melhor posição global é substituída pela posição atual da partícula $\left(y_{s}=x\right)$.

\subsubsection{Topologias GBEST e LBEST}

Quando o PSO é utilizado para resolver problemas de otimização multimodal é importante considerar a sociometria do enxame, diferenciando a forma como a informação deve ser compartilhada entre as partículas, no intuito de melhorar o desempenho do algoritmo [37]. Diversas tipologias de enxame têm sido propostas, porém as mais utilizadas são conhecidas como GBEST e LBEST (vide figura 3.3).

A topologia GBEST, também conhecida como topologia tipo estrela, caracteriza-se pela total interconexão do enxame [38]. Nela, cada partícula pode se comunicar com qualquer outra diretamente. Do mesmo modo, todas as partículas são atraídas para a melhor solução encontrada pelo enxame até então, a qual é denominada Melhor Global - Global Best (GBEST). Esta topologia tem como característica a rápida convergência, obtida pelo uso da partícula GBEST no termo social da equação de atualização da velocidade da partícula. Isso faz com que todas as partículas do enxame sejam direcionadas em poucas iterações para o espaço de busca próximo à partícula GBEST, o que pode nem sempre ser desejado. Por exemplo, se o ótimo global não 


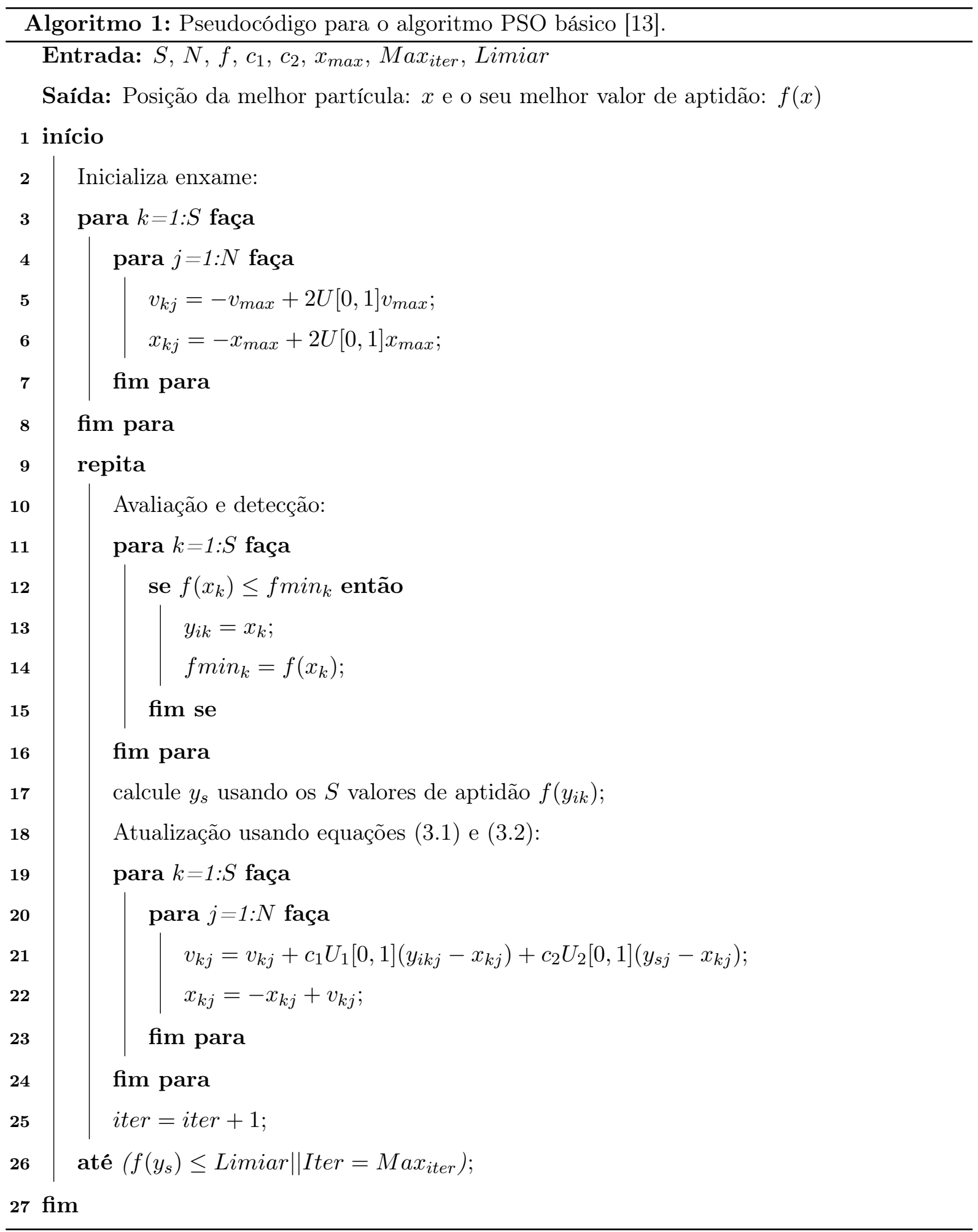




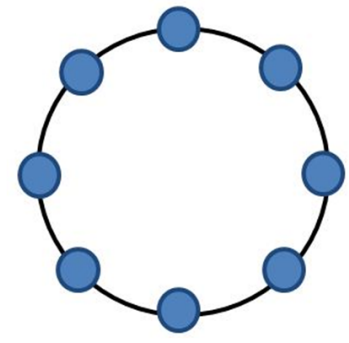

(a)

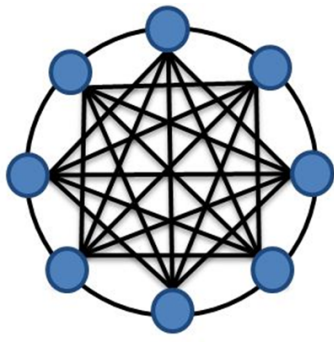

(b)

Figura 3.3. Topologias no algoritmo PSO. (a) LBEST. (b) GBEST

está próximo do GBEST atual, o enxame pode ficar preso nesta região, impossibilitando-o de explorar outras áreas que poderiam ser mais promissoras, ou seja, o enxame pode ficar preso em um mínimo local. O PSO com topologia em estrela, comumente conhecido como PSO GBEST, é mais adequado para problemas unimodais [38].

Além disso, a topologia LBEST, ou topologia em anel, se caracteriza pela comunicação direta de uma partícula apenas com partículas de sua vizinhança de tamanho $n$ [39]. Por exemplo, se $n=2$, uma partícula de índice $k$ se comunica somente com seus vizinhos imediatos $k-1$ e $k+1$. Do ponto de vista da atualização da velocidade, cada partícula busca imitar o comportamento de seu melhor vizinho, denominado Melhor Local - Local Best (LBEST). Deste modo, a influência da melhor partícula da vizinhança atinge um número limitado de outras partículas, e, assim, a propagação de informações é bem mais lenta. Isso faz com que a convergência do PSO sob essa topologia também seja mais lenta. Contudo, a varredura do espaço de busca é mais ampla que na topologia em estrela, visto que o enxame não está inteiramente concentrado em uma única região, possibilitando soluções de melhor qualidade para problemas multimodais. Deve ser levado em conta, no entanto, que há um gasto computacional extra associado ao cálculo da vizinhança de cada partícula.

\subsection{Otimização por Colônia de Abelhas Artificiais (ABC)}

Nas colônias de insetos, cada indivíduo parece ter sua própria agenda; e ainda assim, o grupo como um todo parece ser altamente organizado. Os algoritmos baseados na inteligência de enxames, e no comportamento de colônias de insetos, têm mostrado a sua eficiência na solução de problemas com alto grau de dificuldade [40, [41, [42]. Um enxame é um grupo de sistemas multiagente, como por exemplo as abelhas, em que simples agentes coordenam suas atividades para resolver o complexo problema da disponibilização da mão de obra para diversos locais em ambientes dinâmicos. Em uma colônia real de abelhas, estas estão separadas em três grupos: (a) 
abelhas exploradoras, (b) abelhas operárias e (c) abelhas seguidoras.

Inicialmente, o processo de busca de alimento começa pelas abelhas exploradoras que procuram fontes de alimento se movimentado aleatoriamente. Ao retornar para a colmeia, elas se comunicam usando uma dança, com o fim de recrutar outras abelhas para ir até a fonte de alimento. As seguidoras são abelhas que aguardam na colmeia, e sua função inicial é escolher a abelha que vão seguir. Estas parecem aprender a informação contida na dança das exploradoras em relação à fonte de alimento: A vivacidade da dança indica a distância da colmeia até a fonte de néctar e a orientação da dança indica a direção com relação ao sol [13]. Após a dança, as abelhas exploradoras transformam-se em operárias e abandonam a colmeia para coletar o néctar junto com suas companheiras, as abelhas seguidoras. O número de abelhas seguidoras destinadas para cada abelha operária dependem da qualidade e quantidade total de néctar. As abelhas operárias, junto com as seguidoras, se deslocam até a fonte de alimento para explorá-la. Desta forma, uma boa fonte de alimento é explorada, e o número de operárias neste local é reforçado [40]. Assim que uma fonte for explorada totalmente, a abelha operária responsável se transforma em uma abelha exploradora à procura de novas fontes de alimento. Em alguns casos, podem existir abelhas exploradoras que não vão ser seguidas pelas abelhas seguidoras, devido a que a fonte encontrada não é de boa qualidade ou não tem suficiente néctar. Neste caso, essas abelhas saem na procura de melhores fontes de alimento.

No algoritmo ABC (Artificial Bee Colony), uma fonte de alimento representa uma possível solução ao problema de otimização, sendo a qualidade de uma fonte de alimento indicada por uma quantidade numérica, geralmente o valor da função objetivo. O número de operárias ou de seguidoras é igual ao número de fontes de alimento em torno da colmeia [43]. O intercâmbio de informação é simulado pelo cálculo de probabilidade em função da qualidade da fonte de alimento, como mostrado na equação (3.3) [43].

$$
p_{i}=\frac{f_{i}}{\max (f)}
$$

onde $f_{i}$ é o valor de aptidão da $i$-ésima fonte de alimento, com $i=1, \ldots, S$, sendo $S$ o tamanho do enxame, $p_{i}$ é a probabilidade da $i$-ésima solução e $\max (f)$ o valor máximo da função custo entre toda a população de soluções. As abelhas seguidoras usam o vetor de probabilidades para escolher as fontes de alimento a serem exploradas, criando novas soluções por meio de uma busca local usando a equação (3.4.

$$
x_{i j}^{(t+1)}=x_{i j}^{(t)}+\phi_{i j}\left(x_{i j}^{(t)}-x_{k j}^{(t)}\right),
$$


sendo $k=1, \ldots, S, j=1, \ldots, N$, onde $N$ é a dimensionalidade do problema, $\phi_{i j}$ é um número aleatório com distribuição uniforme na faixa $[-1,1]$. Nesta equação $k$ e $j$ são gerados aleatoriamente com $k \neq i$.

O pseudocódigo do ABC é apresentado no Algoritmo 2. Cada iteração é dividida em duas partes: fase das operárias e fase das seguidoras.

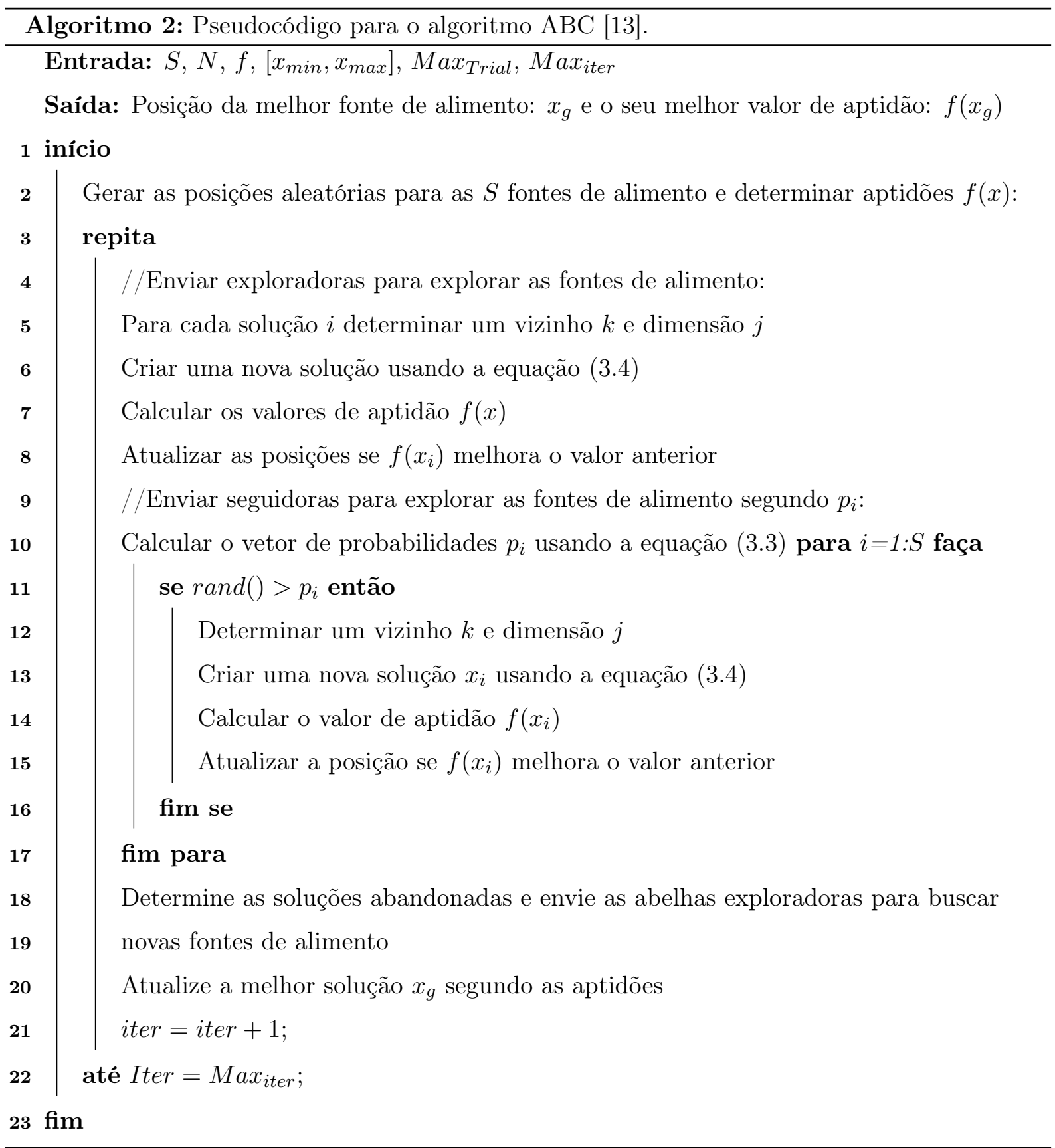

Na primeira fase (vide linhas 5 a 8), para cada solução $i$ determina-se aleatoriamente um vizinho $k(k \neq i)$ e uma dimensão $j$. Posteriormente, usando a equação (3.4), se determina uma nova posição para cada operária. Para cada nova posição calcula-se o valor de aptidão. Se o valor da função objetivo é menor que o valor anterior (caso de minimização) então a nova posição 
é atualizada, caso contrário se incrementa o contador trial $_{i}$.

Na segunda fase (vide linhas 10 a 18), são calculadas as probabilidades $p_{i}$ segundo os valores de aptidão (equação (3.3)). Passo seguinte, são enviadas as seguidoras de acordo com os valores de $p_{i}$, calculando uma nova posição para cada seguidora. Se o valor da função objetivo é menor que o valor anterior então a nova posição é atualizada, caso contrario incrementa-se o contador trial $_{\text {. }}$.

Finalmente, se para cada solução $i$ o contador trial $_{i}$ é igual ao número máximo de tentativas permitidas sem melhoramento no valor de aptidão $\left(\right.$ Max $\left._{\text {Trial }}\right)$ então a fonte é abandonada e uma exploradora é enviada para explorar aleatoriamente novas soluções, vide linha 19. Observe-se que para cada iteração a função custo é avaliada $2 S$ vezes, primeiro na fase de operárias e depois na fase de seguidoras.

\subsection{Otimização por Evolução Diferencial (DE)}

A Evolução Diferencial (DE - Diferencial Evolution) [44] foi apresentada como uma versão melhorada do Algoritmo Genético, resolvendo de forma mais rápida os problemas de otimização. É uma meta-heurística baseada em população desenvolvida para ser um método de busca paralela, direta e estocástica [45].

O DE é um algoritmo bastante simples, porém muito eficiente [46]. As etapas principais deste algoritmo são apresentadas na figura 3.4. A continuação serão explicadas cada uma das etapas apresentadas na figura 3.4

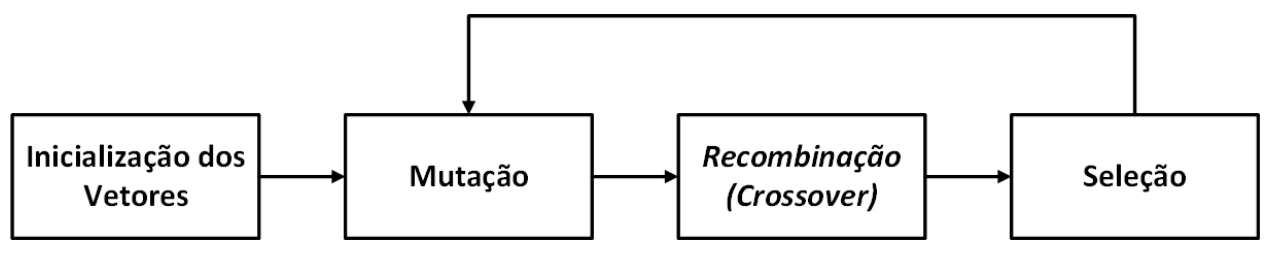

Figura 3.4. Etapas principais do DE [46].

\subsubsection{Inicialização do Vetor de Parâmetros}

O algoritmo DE busca um ponto ótimo global em um espaço $D$-dimensional de parâmetros reais $\Re^{D}$. Este começa com uma população de $N P$ vetores de parâmetros reais inicializados aleatoriamente. Cada vetor, também conhecido como genoma/cromossomo, forma uma possível solução ao problema de otimização multidimensional [46]. Denotando as futuras gerações da Evolução Diferencial como $G=0,1, \ldots, G_{\max }$. Uma vez que os vetores de parâmetros são 
susceptíveis de ser alterados ao longo de diferentes gerações, pode-se adotar a seguinte notação para representar o $i$-ésimo vetor da população na atual geração:

$$
\vec{X}_{i, G}=\left[x_{1, i, G}, x_{2, i, G}, x_{3, i, G}, \ldots, x_{D, i, G}\right] .
$$

Para cada um dos parâmetros do problema, pode haver um determinado intervalo dentro do qual o valor do parâmetro deve ser limitado, muitas vezes porque os parâmetros estão relacionados com componentes físicos ou medidas que têm limites naturais (por exemplo, se um parâmetro é um comprimento ou massa, ele não pode ser negativa) [46]. A população inicial (em $G=0$ ) deve cobrir este espaço de busca, tanto quanto possível, aleatorizando uniformemente os indivíduos dentro de dito espaço restrito pelos limites máximos e mínimos prescritos, dados por: $\vec{X}_{m i n}=$ $\left[x_{1, \min }, x_{2, \min }, \ldots, x_{D, \min }\right]$ e $\vec{X}_{\max }=\left[x_{1, \max }, x_{2, \max }, \ldots, x_{D, \max }\right]$. A partir desse momento, pode ser inicializado o $j$-ésimo componente do $i$-ésimo vetor como mostrado na equação 3.6 .

$$
x_{j, i, 0}=x_{j, \min }+\operatorname{rand}_{i, j}[0,1]\left(x_{j, \max }-x_{j, \min }\right),
$$

onde $\operatorname{rand}_{i, j}[0,1]$ é um número aleatório entre 0 e 1 com distribuição uniforme.

\subsubsection{Mutação}

Biologicamente, "mutação" significa uma súbita mudança nas características genéticas de um cromossomo. No entanto, no contexto do paradigma de computação evolutiva, a mutação é também visto como uma mudança ou perturbação com um elemento aleatório [44], [45], [46]. Na literatura [4], um vetor "pai", obtido a partir de uma solução atual, é chamado de vetor objetivo (target). Além disso, um vetor "mutante" obtido a partir da operação de mutação diferencial é chamado de vetor doador (donor) e, finalmente, uma descendência formada pela combinação dos vetores objetivo e doador é conhecida como vetor teste (trial). Em uma das formas mais simples de mutação por evolução diferencial, para criar o vetor doador para cada $i$-ésimo vetor objetivo da população atual, outros três vetores de parâmetros, $\vec{X}_{r_{1}^{i}}, \vec{X}_{r_{2}^{i}}$ e $\vec{X}_{r_{3}^{i}}$ são escolhidos aleatoriamente na população atual. Os índices $r_{1}^{i}, r_{2}^{i}$ e $r_{3}^{i}$ são inteiros aleatoriamente escolhidos com valores entre $[1, N P]$, os quais devem ser diferentes do índice do vetor base $i$. Assim, a diferença entre qualquer dois destes três vectores é dimensionada por um número escalar $F$, tipicamente no intervalo entre 0,4 e 1 [46], e diferencia dimensionada por $F$ é adicionada ao terceiro vetor, obtendo assim o vetor doador $\vec{V}_{i, G}$. Este processo pode ser representado pela equação 3.7 


$$
\vec{V}_{i, G}=\vec{X}_{r_{1}^{i}, G}+F\left(\vec{X}_{r_{2}^{i}, G}-\vec{X}_{r_{3}^{i}, G}\right)
$$

Além disso, este processo pode ser representado como mostrado na figura 3.5 para um problema de otimização bidimensional.

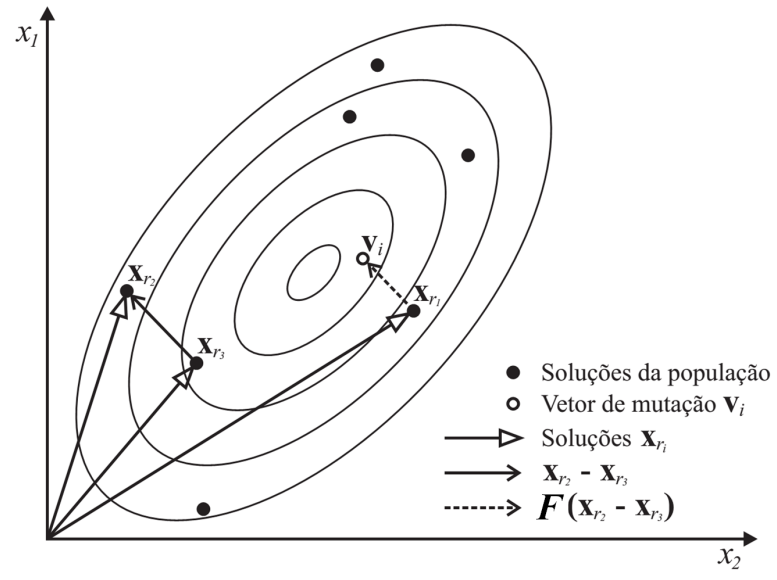

Figura 3.5. Exemplo do operador de mutação do algoritmo DE para um problema de duas variáveis (Adaptado de [45]).

\subsubsection{Recombinação / Crossover}

Após gerar o vetor de doadores através da mutação, é aplicada uma operação de recombinação para aumentar o potencial de diversidade da população. Nesta operação, o vector doador troca seus componentes com o vector objetivo $\vec{X}_{i, G}$ no âmbito desta operação para formar o vetor teste $\vec{U}_{i, G}=\left[u_{1, i, G}, u_{2, i, G}, u_{3, i, G}, \ldots, u_{D, i, G}\right]$. Os algoritmos de Evolução diferencial podem utilizar duas classes de métodos de recombinação: (a) Recombinação Exponencial e (b) Recombinação Binomial [44.

A recombinação linear é aplicada a todos as variáveis $D$ sempre que um número gerado aleatoriamente entre 0 e 1 for menor ou igual ao valor de $C r$, chamado de taxa de recombinação e aparece como um parâmetro de sintonização do algoritmo, assim como $F$. Neste caso, a quantidade de parâmetros herdados do doador tem uma distribuição binomial. O esquema pode ser resumido como

$$
u_{j, i, G}=\left\{\begin{array}{lrr}
v_{j, i, G} & \text { se } & \text { rand }[0,1] \leq C r \text { ou } j=j_{\text {rand }} \\
x_{j, i, G} & & \text { Qualquer outro caso }
\end{array}\right.
$$

onde $j_{\text {rand }} \in[1,2, \ldots, D]$ é um índice escolhido aleatoriamente, o qual garante que $\vec{U}_{i, G}$ terá pelo menos um componente de $\vec{V}_{i, G}$. 


\subsubsection{Seleção}

Visando manter o tamanho da população constante nas futuras gerações, o próximo passo do algoritmo realiza uma seleção para determinar se o vetor objetivo sobrevive à nova geração, por exemplo, em $G=G+1$. A operação de seleção está descrita pela equação 3.9

$$
\vec{U}_{i, G+1}=\left\{\begin{array}{ccc}
\vec{U}_{i, G} & \text { se } & f\left(\vec{U}_{i, G}\right) \leq f\left(\vec{X}_{i, G}\right) \\
\vec{X}_{i, G} & \text { se } & f\left(\vec{U}_{i, G}\right)>f\left(\vec{X}_{i, G}\right)
\end{array}\right.
$$

onde $f(\vec{X})$ é a função objetivo a ser minimizada. Portanto, se o novo vetor teste produz um valor igual ou inferior da função objetivo, ele substitui o vetor objetivo correspondente na próxima geração; caso contrário, este vetor é mantido na população. Desta forma, a população melhora ou mantem o valor de aptidão, mas nunca deteriora sua solução [46].

Sendo discutidas todas a etapas do processo de evolução diferencial, o algoritmo 3 apresenta o pseudocódigo do processo completo de otimização por evolução diferencial.

\subsection{OtimizaÇÃo Multi-ObJetivo}

Segundo [47], os problemas de otimização multiobjetivo, podem ser definidos como um problema em determinar um vetor de variáveis de decisão que satisfaz restrições e otimiza uma função vetorial, cujos elementos representam as funções objetivo. Tais funções formam uma descrição matemática de critérios de desempenho que geralmente estão em conflito uns com os outros. Assim, o termo "otimizar" significa encontrar uma solução desse tipo em que os valores de todas as funções objetivo sejam aceitáveis para o tomador de decisão (DM - Decision Maker).

Matematicamente, o problema de otimização (minimização) multi-objetivo pode ser descrito como a minimização de um vetor de funções objetivo dado por

$$
\vec{f}:=\left[f_{1}(\vec{x}), f_{2}(\vec{x}), \ldots, f_{n}(\vec{x})\right]
$$

sujeito a

$$
\vec{g}_{i}(\vec{x}) \leq 0 i=1,2, \ldots, m
$$

e

$$
\vec{h}_{j}(\vec{x})=0 i=1,2, \ldots, p
$$




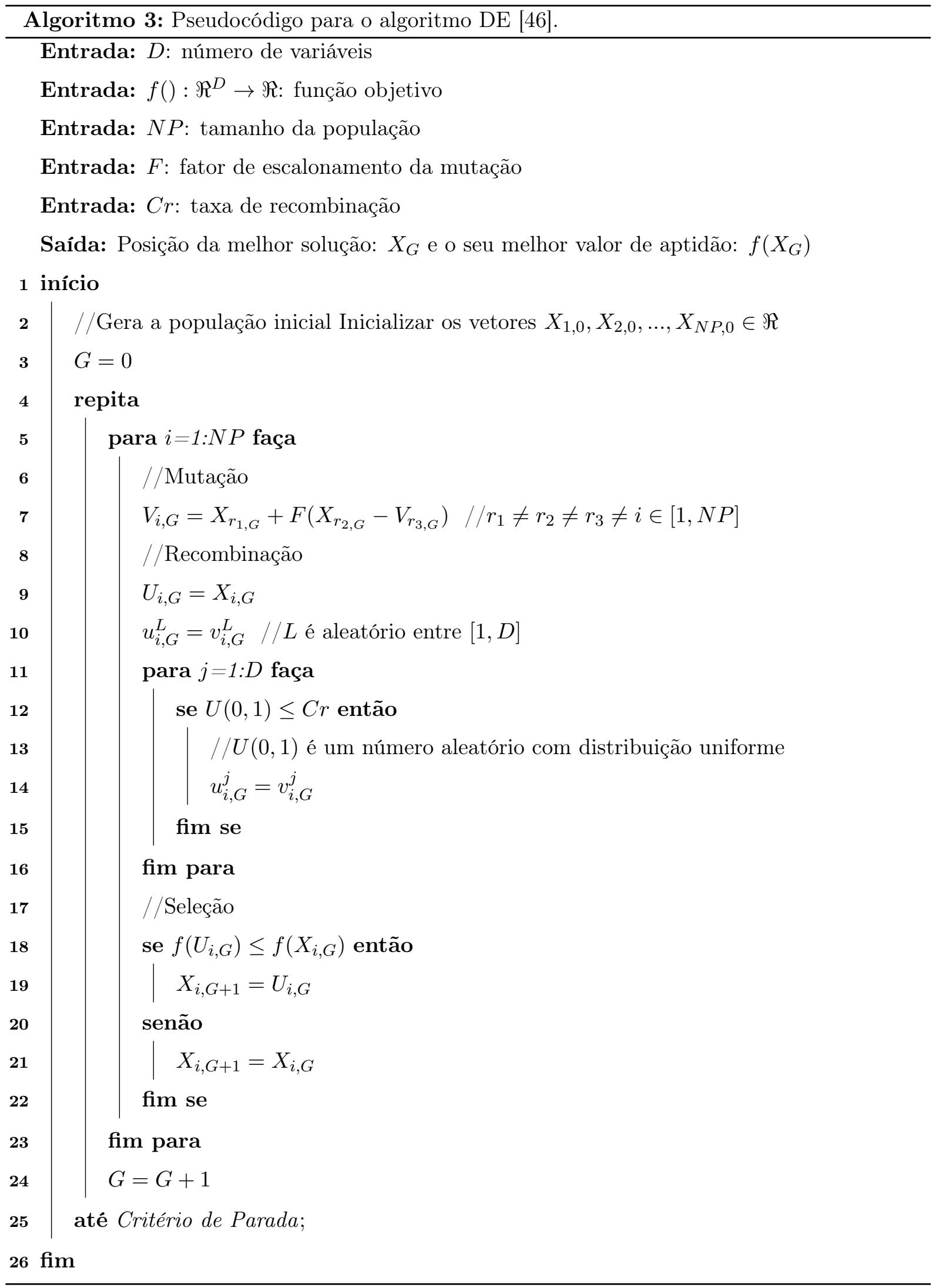


onde $\vec{x}=\left[x_{1}, x_{2}, \ldots, x_{n}\right]^{T}$ é o vetor das variáveis de decisão; $f_{i}: \Re^{n} \rightarrow \Re, i=1,2, \ldots, n$ são as funções objetivo e $g_{i}, h_{j}: \Re^{n} \rightarrow \Re i=1,2, \ldots, m i=1,2, \ldots, p$ são as funções de restrição do problema.

Para descrever o conceito de otimização multi-objetivo, algumas definições serão apresentadas [47, [48].

Definição 1. Dados dois vetores $\vec{x}, \vec{y} \in \Re^{n}$, afirma-se que $\vec{x} \leq \vec{y}$ se $x_{i} \leq y_{i}$ para todo $i=1,2, \ldots, n$ e que $\vec{x}$ domina $\vec{y}$, (denotado por $\vec{x} \prec \vec{y}$ ) se $\vec{x} \leq \vec{y}$ e $\vec{x} \neq \vec{y}$.

Definição 2. Afirma-se que um vetor de variáveis de decisão $\vec{x} \in X \subset \Re^{n}$ é não dominado em relação a $X$, se existe outro vetor $\vec{x}^{\prime} \in X$ tal que $f\left(\vec{x}^{\prime}\right) \prec f(\vec{x})$.

Definição 3. Dada uma função $F(\vec{x})$, afirma-se que um vetor de variáveis de decisão $\vec{x} \in$ $\Omega \subset \Re^{n}$, onde $\Omega$ é uma região factivel, é uma solução Pareto Ótima se ele é não dominado em relação a $F$.

Definição 4. O Conjunto Pareto Ótimo $P^{*}$ é definido por $P^{*}=\{\vec{x} \in \Omega \mid \vec{x}\}$, quando $\vec{x}$ é uma solução Pareto Ótima.

Definição 5. A Fronteira de Pareto $F P^{*}$ é definida por: $F P^{*}=\left\{f(\vec{x}) \in \Re^{n} \mid \vec{x} \in P^{*}\right\}$.

A figura 3.6 ilustra um caso de Fronteira de Pareto considerando um problema com dois objetivos. Assim, deseja-se determinar o conjunto Pareto Ótimo de um conjunto $F$ de todos os vetores de variáveis de decisão que satisfaçam as equações 3.11 e 3.12

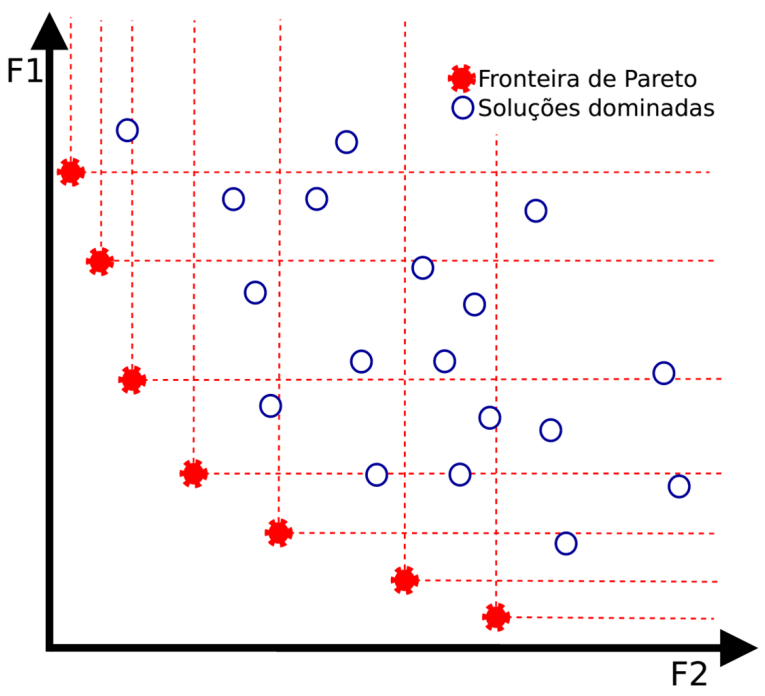

Figura 3.6. Fronteira de Pareto de um conjunto de soluções para um problema de minimização com dois objetivos.

Das [49] observou que, a partir da experiência prática, dado um conjunto de soluções que compõem a curva ou superfície de um dado problema multiobjetivo, o usuário geralmente opta 
por uma solução localizada "no meio" da curva. Esta solução compreende o ponto de maior protuberância da curva ou o "joelho" da curva. A Figura 3.7 ilustra uma fronteira de Pareto de um problema com dois objetivos de minimização onde o joelho da curva é destacado. Nesta figura, aparece o Vetor Ideal $z^{*}$ com componentes $z_{i}$. Os componentes do vetor $z^{*}$ são obtidos minimizando cada uma das funções objetivo individualmente, condicionadas à região fatível [50]. O conceito de joelho é explorado por vários algoritmos de otimização [49].

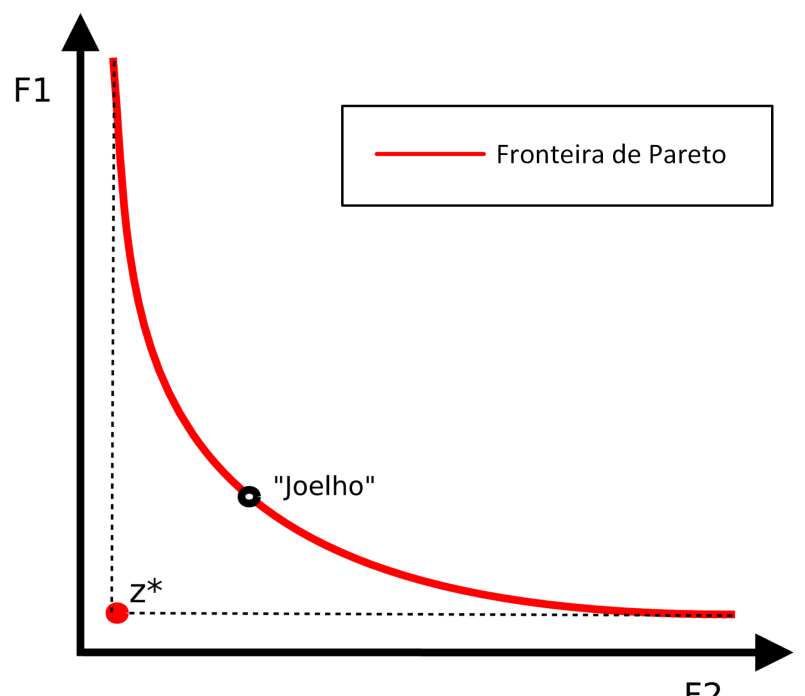

F2

Figura 3.7. Exemplo de Fronteira de Pareto para um problema de minimização com destaque para o joelho da curva [49].

Assim, a otimização multiobjetivo tem como meta encontrar um conjunto de soluções que não são dominadas por nenhuma outra no espaço dos objetivos e, na maioria das aplicações, a procura pelo conjunto Pareto ótimo é considerada um problema NP-Difícil [47].

Algoritmos evolutivos são boas opções para resolver problemas multi-objetivo, tendo em conta que os mesmos lidam simultaneamente com um conjunto de possíveis soluções. Assim, pode-se encontrar um conjunto completo de soluçôes Pareto ótimo em uma única rodada do algoritmo, ao invés de ter que executar um conjunto de rodadas independentes como é o caso das técnicas de programação matemática tradicionais [51].

De acordo com Branke [50], estes algoritmos devem gerar um conjunto de soluções devendo possuir: (a) uma boa convergência para a fronteira de Pareto ótima e (b) uma boa diversidade nas soluções obtidas.

A figura 3.8 ilustra três conjuntos de soluções distintos para um problema de otimização com dois objetivos de minimização. Em todos os casos, a curva contínua representa a Fronteira de Pareto real e os círculos representam as respectivas soluções de cada conjunto de soluções. O conjunto ilustrado pela figura 3.8 (a) mostra algumas soluções com boa convergência próximas à fronteira de Pareto. Porém tais soluções estão concentradas em uma única região, não contendo 
soluções que cubram outras regiões da fronteira. Situação oposta é ilustrada pela figura 3.8(b), em que observa-se um conjunto de soluções com boa diversidade, isto é, cobrindo todas as regiões ao longo da fronteira. Todavia, essas soluções apresentam uma convergência ruim, pois estão longe da fronteira de Pareto. Finalmente, uma situação em que o conjunto de soluções apresenta boa convergência e boa diversidade é ilustrada pela figura 3.8(c). As soluções apresentam-se próximas à fronteira de Pareto e estão equilibradamente bem distribuídas ao longo da curva.

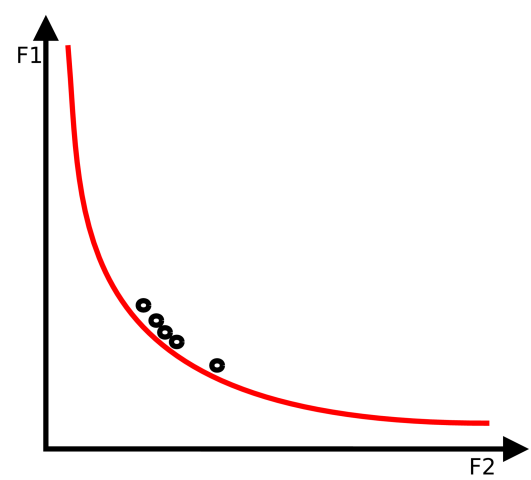

(a) Boa convergência e diversidade ruim.

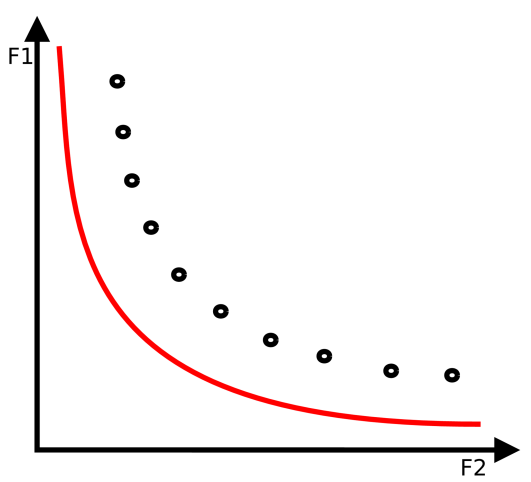

(b) Boa diversidade e convergência ruim.

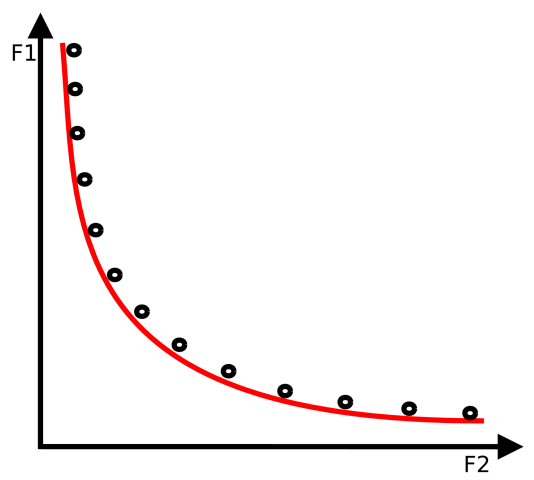

(c) Boa convergência e boa diversidade.

Figura 3.8. Exemplos com três conjuntos de soluções que ilustram relações entre convergência e diversidade.

\subsubsection{Otimização Multi-objetivo por Evolução Diferencial (MODE)}

O algoritmo de Evolução Diferencial (DE) tem sido aplicado a problemas multi-objetivo com resultados satisfatórios. Este algoritmo segue um esquema essencialmente semelhante ao descrito para o caso mono-objetivo, apresentado na seção 3.4 (vide algoritmo 3). Entretanto, são dois os objetivos aqui tratados, pelo que não é possível realizar a operação de seleção entre o indivíduo pai $\vec{x}_{i, G}$ e o indivíduo de teste $\vec{u}_{i, G}$. Como procuram-se pontos que componham a fronteira de Pareto do problema, o que é feito é uma operação de união entre o conjunto de pontos da geração presente $\vec{x}_{i, G}$ e o conjunto de pontos de teste $\vec{u}_{i, G}$, conforme descrito no algoritmo 4 . Após isso, é realizada uma operação de dominância entre todos os pontos do conjunto $\left.\left.X_{a u x} \equiv\left\{x_{i, G}\right\}\right|_{N P} ^{i=1} \cup\left\{u_{i, G}\right\}\right|_{N P} ^{i=1}$ 
e tomam-se os primeiros $N P$ pontos do ranque de dominância para a próxima geração.

\subsection{Métodos de Adição de Diversidade Artificial}

Segundo os estudos realizados por Mendes [52] existe uma forte relação entre a topologia social do enxame e a robustez à convergência prematura. A diversidade do enxame é um fator de importância na execução do algoritmo PSO e, em geral, nos algoritmos baseados em populações. Existem muitas discussões em relação à diversidade nos algoritmos evolutivos, como os algoritmos genéticos [32]. Além disso, muitos estudos tem sido realizados sobre a diversidade de população no algoritmo PSO [53], [54], [55].

O problema da convergência prematura reside no fato de que as partículas se movimentam pelo espaço de busca e, caso elas se agruparem em um curto intervalo de tempo, essas partículas perderão seu potencial de busca [56]. Assim, a convergência prematura destas partículas em torno a um ótimo local é um problema comum para algoritmos baseados em populações. Os métodos de adição de diversidade artificial consistem em técnicas adaptativas que visam evitar o problema da convergência prematura. Este problema é mais comum naqueles algoritmos que têm uma tendencia a seguir o indivíduo com um melhor valor de aptidão, como por exemplo o algoritmo PSO com topologia GBEST [13] (vide seção 3.2.2). Como foi discutido anteriormente, o algoritmo PSO com este tipo de topologia tem tendência a convergir rapidamente, porém, também tende a encontrar soluções sub-ótimas quando a melhor partícula encontra-se presa em um ótimo local [37, [38].

Visando manter a diversidade do enxame, têm surgido alguma propostas aplicadas principalmente ao algoritmo PSO. Por exemplo, Lovbjerg e Krink [57] apresentam om algoritmo PSO auto-organizado objetivando auxiliar o enxame a manter a diversidade diminuindo a vulnerabilidade à convergência em ótimos locais. Além disso, encontram-se métodos de adição de diversidade que utilizam técnicas de evasão de colisões entre as partículas do enxame [58] ou com partículas com extensão espacial (tratadas como esferas) [59], [60]. Entretanto, estes métodos demandam um alto consumo dos recursos computacionais, já que provocam um aumento na complexidade computacional dos algoritmos [13. Além disso, exstem algoritmos de adição de diversidade com menor complexidade computacional e que apresentaram resultados satisfatórios. Estes algoritmos são: (a) o método atrativo-repulsivo [61] e (b) o método de aprendizado em oposição [62] que serão apresentados a continuação. 


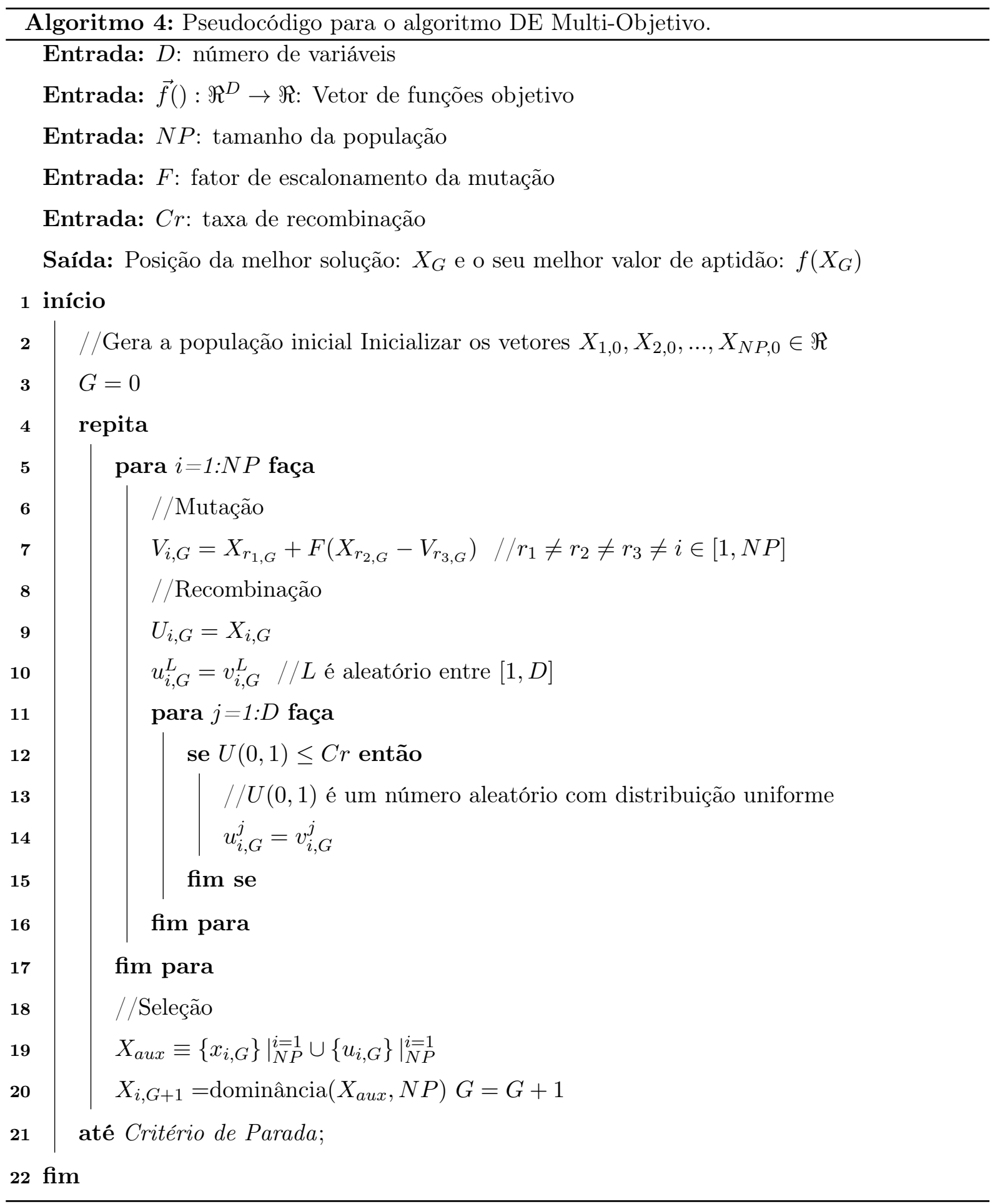




\subsubsection{O Método Atrativo-Repulsivo}

O método atrativo-repulsivo foi proposto por Rget e Vesterstrom [61]. Neste método, realizase uma medida da diversidade do enxame para guiar o seu comportamento. Esta medida de diversidade é feita utilizando a distância euclidiana entre as partículas como mostrado nas equações (3.13) e (3.14).

$$
\begin{aligned}
\operatorname{diversidade}(S) & =\frac{1}{S L} \sum_{i=1}^{S} \sqrt{\sum_{j=1}^{N}\left(x_{i j}-\bar{x}_{j}\right)^{2}} \\
\bar{x}_{j} & =\frac{1}{S} \sum_{i=1}^{S} x_{i j},
\end{aligned}
$$

em que $S$ é o tamanho do enxame, $L$ o comprimento da maior diagonal no espaço de busca e $N$ corresponde à dimensionalidade do problema de otimização.

Esta técnica, inicialmente aplicada ao algoritmo PSO, utiliza as equações anteriores para calcular uma medida da diversidade a cada iteração e assim comutar entre a fase de atração e de repulsão. Para isso, a equação modificada do calculo da velocidade das partículas, apresentada na equação 3.15, é utilizada. Quando a diversidade é inferior a um valor mínimo (dlow), o enxame muda para a fase repulsiva $(\operatorname{dir}=-1)$ e então o enxame aumenta a sua diversidade. Quando a diversidade ultrapassa o limite superior $($ dhigh $)$, o enxame entra na fase atrativa $(\operatorname{dir}=1) \mathrm{e}$ então as partículas começam a convergir novamente como no algoritmo PSO original (vide seção 3.2 .1 .

$$
v_{i j}^{(t+1)}=v_{i j}^{(t)}+\operatorname{dir}\left[c_{1} U_{1 j}\left(y_{i j}^{(t)}-x_{i j}^{(t)}\right)+c_{2} U_{2 j}\left(y_{s j}^{(t)}-x_{i j}^{(t)}\right)\right]
$$

\subsubsection{O Método de Aprendizado em Oposição - OBL}

De forma geral, os métodos de otimização evolutiva começam com soluções iniciais (população inicial). Na ausência de informação a priori sobre a solução, usualmente, começa-se com distribuindo a população de forma aleatória. O tempo de execução do algoritmo está diretamente relacionado à distância entre essas soluções iniciais e a solução ótima. Assim, pode-se melhorar a probabilidade de iniciar com uma melhor solução se for avaliada simultaneamente a solução oposta. Esta estrategia pode ser aplicada também a cada solução na população atual e não somente à população inicial. Desta forma, o método OBL permite não só melhorar a qualidade da solução senão também preservar a diversidade do enxame. 
A abordagem OBL, apresentada inicialmente por Tizhoosh [62], está baseada no conceito do número oposto, definido pela equação (3.16).

$$
\breve{x}=a+b-x
$$

sendo $x$ um número real definido na faixa $[a, b]$ e $\breve{x}$ o número oposto de $x$. Esta definição também é válida para pontos $N$-dimensionais $x_{i}$ definidos na faixa $\left[a_{i}, b_{i}\right]$, com $i=1,2,3, \ldots, N$.

A técnica OBL foi inicialmente aplicada em algoritmos genéticos no qual o conceito de anticromossoma permite que o processo de busca seja acelerado. O OBL também foi aplicado no treinamento de redes neurais artificiais em que o conceito de peso oposto e rede oposta permitiram melhorar os resultados do treinamento [62].

\subsection{Considerações Finais do Capítulo}

Neste capítulo foram abordados os conceitos básicos de otimização, considerados relevantes para o desenvolvimento deste trabalho. O estudo das técnicas de otimização mostrou que as meta-heurísticas apresentam melhores resultados para problemas complexos em que métodos exatos, baseados no cálculo do gradiente, são de difícil implementação e apresentam soluções sub-ótimas.

Meta-heurísticas baseadas em populações, dentre as quais se destacam os algoritmos evolutivos e os algoritmos baseados em inteligência de enxames, utilizam técnicas bio-inspiradas nos princípios biológicos evolutivos encontrados na natureza, tais como seleção natural, herança genética e comportamentos coletivos para intercâmbio de informação. Neste trabalho foram utilizados os algoritmos de otimização baseados em meta-heurísticas devido à sua simplicidade de implementação e os excelentes resultados apresentados no estado da arte e em experiencias anteriores [13] realizadas no LEIA-GRACO (Laboratório de Sistemas Embarcados e Aplicações em Circuitos Integrados).

Além disso, em alguns casos pode ser necessário avaliar mais de uma função objetivo, fazendo indispensável a utilização de técnicas de otimização multi-objetivo, cujo conceito foi apresentado na seção 3.5 .

Como foi discutido neste capítulo, os algoritmos baseados em populações podem apresentar problemas de convergência prematura. Visando solucionar estes problemas surgiram os métodos de adição de diversidade artificial, os quais permitem evitar a convergência do algoritmo para um ótimo local. Existem muitos tipos de algoritmos para adição de diversidade, porém, muitos também são de alta complexidade computacional e demandam um alto consumo de recursos. 
Além disso, podem-se encontrar outros algoritmos de implementação simples e que não aumentam consideravelmente a complexidade computacional do algoritmo, como por exemplo o método atrativo-repulsivo, inicialmente aplicado para o PSO e o método de aprendizado em oposição, que teve sua origem nos algoritmos genéticos. Devido à simplicidade destes últimos dois métodos, decidiu-se implementá-los neste trabalho aos algoritmos PSO e ABC. 


\section{AvaliaÇão de Qualidade em Imagens Digitais}

Uma das questões chaves em trabalhos que lidam com a melhora de imagens por meio de técnicas de restauração é a avaliação da qualidade da imagem (IQA - Image Quality Assessment) resultante do processo. A forma mais confiável de avaliar a qualidade da imagem é de forma subjetiva [63], 64], 65]. Porém, esses métodos requerem vários observadores para participar dos experimentos e proporcionar assim sua opinião pessoal em relação à qualidade da imagem, o que os torna muito custosos e, portanto, demandando muito tempo. Assim, os métodos de avaliação subjetiva não são adequados para as aplicações práticas. Por este motivo, na atualidade são pesquisados/procurados métodos automáticos de avaliação para a qualidade das imagens, que permitam sua utilização em aplicações de processamento de imagens.

Segundo a disponibilidade de uma imagem de referência, as métricas de qualidade podem ser categorizadas em duas classes [66]: (a) de referência completa (FR-IQA: Full Reference Image Quality Assessment) [67], 68]; (b) sem referência (NR-IQA: No-Reference Image Quality Assessment) [69]-73].

Objetivando avaliar a qualidade da imagem, o método FR-IQA requer uma imagem de referência completa, na qual não se tem presença de ruído e está em perfeito estado [63]. Essa métrica pode ser utilizada somente em aplicações nas quais a imagem de referência estiver disponível, tais como compressão de imagens 67], 668], marca d'água (watermarking) [68], [74], entre outras.

Outro objetivo importante destas métricas, além de fornecer um valor numérico que represente a qualidade da imagem, consiste em conseguir uma boa correlação entre a métrica objetiva e a percepção humana sobre a qualidade da imagem [75], [76], [77], [78]. Assim, deve-se realizar um estudo subjetivo sobre as imagens que serão posteriormente analisadas pela métrica objetiva. Esta análise subjetiva permite assim avaliar o desempenho das métricas objetivas mediante uma análise de correlação [78].

Neste capítulo, serão discutidos os conceitos de implementação de algumas métricas objetivas que foram importantes no desenvolvimento desta tese. Também será discutido o conceito e algumas técnicas de avaliação subjetiva. O procedimentos referentes às implementações e análises de desempenho destas métricas, assim como a escolha das mesmas para o processo de restauração 
serão discutidos no Capítulo 5 - Seções 5.2 e 5.4 .

\subsection{Métricas de Qualidade com Referência Completa (FR-IQA)}

As métricas mais simples de avaliação com imagem de referência são o Erro Quadrático Médio - MSE (Equação 4.1) ) e seu correspondente Peak Signal-to-Noise Ratio - PSNR (Equação 4.2).

$$
\begin{gathered}
M S E=\frac{\sum_{i, j}[f(i, j)-\hat{f}(i, j)]^{2}}{M N}, \\
P S N R=10 \log _{10}\left(\frac{M A X^{2}}{M S E}\right)=20 \log _{10}\left(\frac{M A X}{\sqrt{M S E}}\right),
\end{gathered}
$$

onde $f$ é uma imagem $M \times N$ tomada como referência, $\hat{f}$ é a imagem estimada, $M A X$ é o máximo valor que pode tomar um pixel na imagem (255 para imagens de 8 bits).

MSE e PSNR são amplamente utilizadas, já que têm significados físicos claros e são adequadas para otimização [63]. Porém, nos processos de restauração automática de imagens subaquáticas não se tem disponibilidade de uma imagem de referência, portanto, é necessária a implementação de uma métrica sem referência. Algumas destas métricas serão apresentadas a seguir.

\subsection{MÉtricas de Qualidade Sem Referência (NR-IQA)}

Em muitas aplicações reais, não se tem acesso a uma imagem de referência para avaliação da qualidade. Portanto, as técnicas de avaliação sem imagem de referência são necessárias para controlar a qualidade da imagem. Existem diversas técnicas para avaliação sem referência, nas quais os fatores de qualidade são descritos por quantidades físicas apropriadas [79], ou pela estatística das imagens [76].

Nesta seção serão apresentadas as métricas implementadas no contexto deste trabalho, as quais foram submetidas a um processo de avaliação de desempenho (vide Seções 5.2 e 5.4 ) objetivando escolher a melhor ou as melhores métricas para sua implementação ao processo de restauração. 


\subsubsection{Métrica Baseada em Ruído e Borramento (BN-IQA)}

Embora a qualidade de uma imagem seja afetada por muitas características como o matiz, as bordas, contraste, entre outras, a métrica apresentada nesta seção assume que o ruído e o borrado (blurring) são os fatores mais importantes na degradação da qualidade da imagem [75]. A métrica proposta em [75] estima o ruído e o borramento em um domínio espacial.

- Estimativa do Borramento: O borramento é percebido por observadores humanos independentemente da fonte de borrado, por exemplo, redução de ruído, compressão, borrado por movimento, e fora de foco. Assim, esta métrica também pretende estimar o ruído sem nenhuma informação sobre o fonte de borrado.

A estimação de borramento é dividida em duas etapas: a primeira etapa consiste na deteç̧ão de bordas, enquanto que a segunda etapa determina se as bordas detectadas estão borradas ou não.

Assim, esta métrica determina o borramento pela diferença entre a intensidade do pixel atual e o valor meio dos pixeis vizinhos. Assim, esta diferença é normalizada pela média. Se o valor de intensidade do pixel central está perto do valor médio de intensidade dos pixeis vizinhos, considera-se que o pixel central pertence a a uma borda borrada. Na Figura 4.1 . é explicado graficamente a estimação de borrado de um pixel $f(x, y)$.

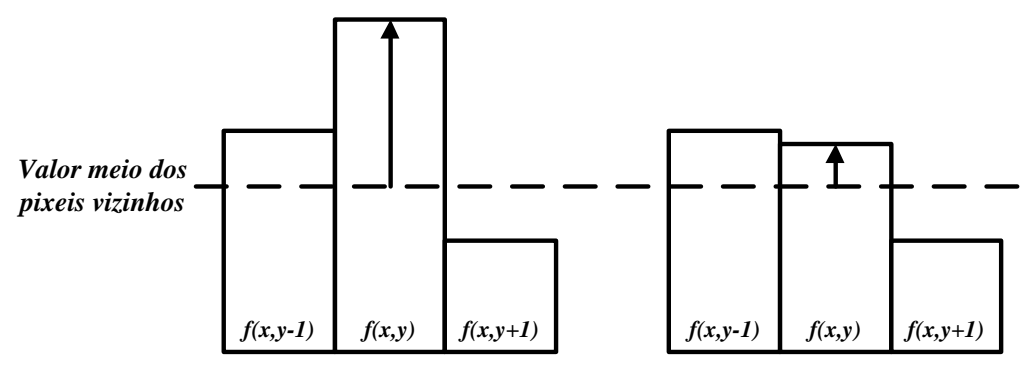

(a)

(b)

Figura 4.1. Estimação de borramento. (a) Borda com baixo nível de borrado. (b) Borda com alto nível de borrado. Adaptada de 75

Para estimar matematicamente o nível de borramento das imagens, vai-se definir $f(x, y)$ como uma imagem de tamanho $M \times N$, para $x \in[1, M]$ e $y \in[1, N]$. A diferença horizontal absoluta de um pixel é definida como mostrado na equação (4.3).

$$
D_{h}(x, y)=|f(x-1, y)-f(x+1, y)| .
$$

Adicionalmente, o valor médio dessa diferença, para a imagem completa, é calculado se- 
gundo a equação 4.4.

$$
\bar{D}_{h}=\frac{1}{M \times N} \sum_{x=1}^{M} \sum_{y=1}^{N} D_{h}(x, y) .
$$

No caso em que o valor de (4.3) é maior que o valor de (4.4), o pixel $f(x, y)$ converte-se em um possível pixel de borda $C_{h}(x, y)$ (vide equação 4.5$)$ ). Se o valor de $C_{h}(x, y)$ do pixel central é maior que o valor dos pixeis vizinhos à esquerda e direita $C_{h}(x-1, y)$ e $C_{h}(x+1, y)$, se estima que o pixel central $f(x, y)$ pertence a uma borda $E_{h}(x, y)$ (vide equação (4.6).

$$
\begin{gathered}
C_{h}(x, y)= \begin{cases}D_{h}(x, y), & \text { se } D_{h}(x, y)>\bar{D}_{h}, \\
0, & \text { caso contrário. }\end{cases} \\
E_{h}= \begin{cases}1, & \text { se } C_{h}(x, y)>C_{h}(x-1, y) \& C_{h}(x, y)>C_{h}(x+1, y), \\
0, & \text { caso contrário. }\end{cases}
\end{gathered}
$$

Por último, vai se definir se o pixel detectado está borrado ou não. Para isto, tem de ser calculado um valor que permita tomar a decisão, determinado a partir das equações (4.7) e (4.8).

$$
\begin{gathered}
A_{h}(x, y)=\frac{1}{2}(f(x-1, y)+f(x+1, y)) . \\
B R_{h}=\frac{\left|f(x, y)-A_{h}(x, y)\right|}{A_{h}(x, y)} .
\end{gathered}
$$

Da mesma forma pode ser estimado esta quantidade em sentido vertical $B R_{v}$, a partir das equações (4.3) até (4.8). Assim, o maior valor entre $B R_{h}$ e $B R_{v}$ é selecionado para a decisão final, como mostrado na equação 4.9.

$$
B(x, y)= \begin{cases}1, & \text { se } \max \left\{B R_{h}, B R_{v}\right\}<T h_{B}, \\ 0, & \text { caso contrário. }\end{cases}
$$

A equação 4.9 significa que o pixel central com um valor de $\max \left\{B R_{h}, B R_{v}\right\}$ sob $T h_{B}$ é considerado como borrado. No trabalho apresentado pelo autor da métrica [75], o valor de $T h_{B}$ é determinado experimentalmente. Finalmente, o valor médio de borramento e a razão de borramento para a imagem inteira são calculados pelas equações (4.10) e (4.11).

$$
B l u r_{\text {mean }}=\frac{\text { Sum }_{\text {blur }}}{B l u r_{\text {cnt }}}
$$




$$
B l u r_{\text {ratio }}=\frac{\text { Blur }_{\text {cnt }}}{\text { Edge }_{\text {cnt }}},
$$

onde $S u m_{b l u r}$ e $B l u r_{c n t}$ são a suma dos valores máximos entre $B R_{h}$ e $B R_{v}$ e a quantidade de pixeis borrados, respectivamente. Edge $e_{\text {cnt }}$ é quantidade de pixeis detectados como bordas.

- Estimação do Ruído: Devido a que o ruído ao longo das bordas é perceptualmente menos aparente, o ruído é estimado fora da região das bordas. O ruído pode afetar a detecção de bordas. Por isso, é necessário realizar uma filtragem de ruído antes de detectar as bordas [75]. Neste caso, a imagem filtrada vai ser chamada de $g(x, y)$. Assim, os pixeis das bordas são detectados em forma similar àquela utilizada para estimar o borramento (vide equações 4.12 e 4.13$)$.

$$
\begin{gathered}
D_{h}(x, y)=|g(x-1, y)-g(x+1, y)| . \\
\bar{D}_{h}=\frac{1}{M \times N} \sum_{x=1}^{M} \sum_{y=1}^{N} D_{h}(x, y) .
\end{gathered}
$$

Adicionalmente, as equações 4.12 e (4.13) são obtidas também no sentido vertical. Assim, continua-se encontrando os possíveis pixeis ruidosos usando a equação (4.14).

$$
N_{\text {cand }}(x, y)= \begin{cases}\max \left\{D_{h}(x, y), D_{v}(x, y)\right\}, & \text { se } D_{h}(x, y) \geq \bar{D}_{h} \& D_{v}(x, y) \geq \bar{D}_{v} \\ 0, & \text { caso contrário. }\end{cases}
$$

onde $N_{\text {cand }}(x, y)$ representa um pixel candidato a ruído, que deve ser zero na região das bordas [75]. A decisão final dos pixeis que representam o ruído na imagem é dada pela equação 4.15.

$$
N(x, y)= \begin{cases}N_{\text {cand }}(x, y), & \text { se } N_{\text {cand }}(x, y)>\bar{N}_{\text {cand }} \\ 0, & \text { caso contrário }\end{cases}
$$

com $\bar{N}_{\text {cand }}$ como sendo o valor médio de $N_{\text {cand }}$. Desta forma são estimados o valor médio do ruído $N o i s e_{\text {mean }}$ e a razão de ruído $N o i s e_{\text {ratio }}$ na imagem, como mostrado nas equações 4.16) e 4.17), respectivamente.

$$
\text { Noise }_{\text {mean }}=\frac{\text { Sum }_{\text {noise }}}{\text { Noise }_{\text {cnt }}},
$$




$$
\text { Noise }_{\text {ratio }}=\frac{\text { Noise }_{\text {cnt }}}{M \times N},
$$

onde Sum $_{\text {noise }}$ e Noise $_{\text {cnt }}$ correspondem à soma de $N(x, y)$ e a quantidade total de pixeis ruidosos, respectivamente.

- Definição da métrica: As características obtidas anteriormente são combinadas para gerar um modelo de predição de qualidade da imagem. A métrica proposta é um modelo linear, representado pela equação 4.18).

$$
B N I Q A=1-\left(w_{1} \text { Blur }_{\text {mean }}+w_{2} \text { Blur }_{\text {ratio }}+w_{3} \text { Noise }_{\text {mean }}+w_{4} \text { Noise }_{\text {ratio }}\right),
$$

onde Blur $_{\text {mean }}$, Blur $_{\text {ratio }}$, Noise $_{\text {mean }}$ e Noise ratio $_{\text {correspondem aos valores obtidos das }}$ equações 4.10, 4.11, 4.16 e 4.17. $w_{1}, w_{2}, w_{3}, w_{4}$ são pesos estimados a partir de teste subjetivos de qualidade. No trabalho apresentado em [75], os autores estimam estes pesos mediante regressão linear.

\subsubsection{Métrica de Qualidade de Imagens Naturais (NIQE)}

A métrica NIQE Natural Image Quality Evaluator [76] está baseada na construção de uma coleção de características de "qualidade conhecida" que tentam ser ajustadas a um modelo Gaussiano multivariável (MGV). Assim, as características de qualidade conhecida são derivadas a partir de um modelo estatístico de cenas naturais (NSS). Esse modelo é simples, porém altamente regular [76]. Todavia, a qualidade de uma imagem de teste é expressada como a distância entre o MGV ajustado e as características NSS extraídas da imagem de teste, assim como pelo modelo MGV das características de qualidade conhecida, extraídas a partir de imagens naturais de "boa qualidade" [76].

A seguir serão discutidos alguns aspectos necessários para o entendimento desta métrica:

- NSS no domínio espacial: O modelo completamente sem referência apresentado em 76] está baseado em características NSS no domínio espacial, perceptivamente relevantes, extraídas a partir de blocos da imagem (patches) que capturam efetivamente as estatísticas de imagens naturais. O modelo espacial NSS clássico [80] começa pre-processando a imagem com processos de remoção média local e normalização, como mostrado na equação 4.19).

$$
\hat{I}(i, j)=\frac{I(i, j)-\mu(i, j)}{\sigma(i, j)+1}
$$


onde $i \in\{1,2, \ldots, M\}$ e $j \in\{1,2, \ldots, N\}$ são índices espaciais da imagem $I(i, j)$ de tamanho $M \times N . \mu(i, j)$ e $\sigma(i, j)$ representam o valor médio e o contraste local, respectivamente (vide equações 4.20 e (4.21)).

$$
\begin{gathered}
\mu(i, j)=\sum_{k=-K}^{K} \sum_{l=-L}^{L} \omega_{k, l} I(i+k, j+l), \\
\sigma(i, j)=\sqrt{\sum_{k=-K}^{K} \sum_{l=-L}^{L} \omega_{k, l}[I(i+k, j+l)-\mu(i, j)]^{2}},
\end{gathered}
$$

onde $\omega=\left\{\omega_{k, l} \mid k=-K, \ldots, K, l=-L, \ldots, L\right\}$ é uma função $2 \mathrm{D}$ de ponderação circular Gaussiana amostrada para três valores de desvio padrão $(K=L=3)$ e normalizada a um. Tem sido observado que os coeficientes achados na equação (4.19) seguem uma distribuição Gaussiana quando computados para imagens naturais que têm sofrido pouca ou nenhuma distorção aparente [80]. No entanto, este modelo ideal é violado quando as imagens não derivam de uma fonte natural (por exemplo, gráficos de computador) ou quando as imagens naturais estão sujeitas a distorções não naturais [76], [80].

As características NSS usadas na métrica NIQE são similares às utilizadas pela técnica BRISQUE, apresentada em [81]. No entanto, NIQE só usa as características NSS de um conjunto de imagens naturais, enquanto BRISQUE é treinado com características obtidas a partir de dois conjuntos de imagens: (1) imagens naturais e (2) imagens degradadas. A técnica BRISQUE também está baseada em julgamentos humanos da qualidade das imagens. Portanto, BRISQUE está limitado ao tipo de distorções com que foi treinado [76].

- Seleção dos blocos: Uma vez são calculados os coeficientes da equação 4.19], a imagem é dividida em blocos de tamanho $P \times P$. As características NSS são calculadas a partir dos coeficientes de cada bloco. Não obstante, somente um subconjunto de blocos é usado. Isto é devido a que cada imagem é submetida a algum tipo de distorção limitante [82]. Por exemplo, existe uma perda de resolução devido ao borramento por desfocagem em partes da maioria das imagens, geralmente devido à profundidade de campo limitada (DOF) das câmeras [76]. Devido a que os humanos tendem a medir a qualidade das imagens segundo a nitidez [83], as medições de qualidade mais importantes podem ser feitas a partir de blocos com alto nível de nitidez [76]. Deixando de lado a questão estética de ter algumas partes de uma imagem mais nítidas do que as outras, qualquer tipo de borrado representa uma perda potencial de informação visual [76]. 
Os autores de [76] utilizam um dispositivo simples para selecionar, dentre um conjunto de blocos, aqueles que apresentam a maior quantidade de informação e têm a menor probabilidade de terem sido submetidos a algum tipo de degradação. Este subconjunto de blocos é utilizado para construir um modelo da estatística dos blocos de imagens naturais [76].

Em trabalhos anteriores, a variança calculada pela equação 4.21 tem sido ignorada na análise de imagens baseada em NSS, porém a mesma é uma fonte muito rica em informação que pode ser utilizada para estimar o nível de nitidez local de uma imagem[76]. Numerando os blocos com $b=1,2, \ldots, B$, como sendo $B$ o número total de blocos, uma forma direta de calcular o desvio padrão médio local de cada bloco com índice $b$ está definida pela equação 4.22 [76].

$$
\delta(b)=\sum \sum_{(i, j) \in \text { patchb }} \sigma(i, j)
$$

onde $\delta$ denota a nitidez local.

Uma vez a nitidez local de cada bloco é calculada pela equação 4.22, aqueles blocos com nível de nitidez maior que um limiar $T$ são selecionados. O limiar $T$ é selecionado como sendo uma fração $p$ do maior valor de nitidez na imagem. Nos experimentos apresentados pelos autores [76], foi utilizado um valor nominal de $p=0,75$. Os autores observaram que têm-se variações muito pequenas no desempenho do algoritmo quando $p$ varia na faixa de $[0,6-0,9]$. Exemplos da seleção dos blocos são apresentados na Figura 4.2 .

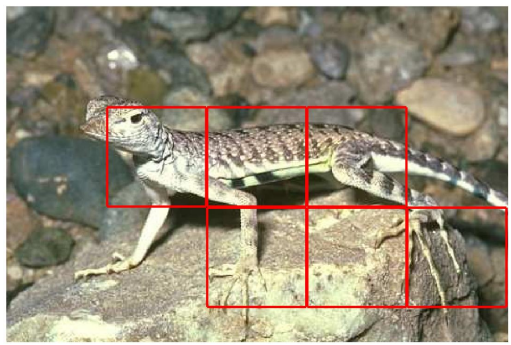

(a)

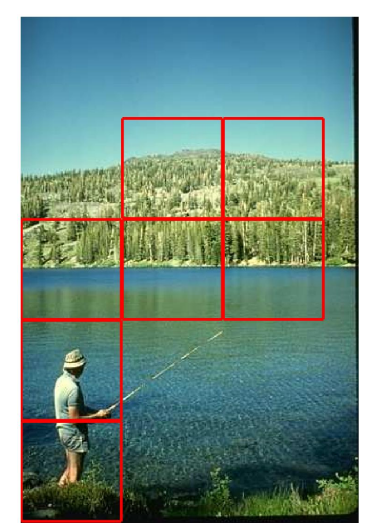

(b)

Figura 4.2. Seleção de blocos. Os quadros vermelhos marcados nas imagens (a) e (b) descrevem casos de blocos de imagem naturais selecionados através da medida de nitidez local (vide equação 4.22 ). Tomada de [76].

- Caracterização dos blocos: Dado um conjunto de blocos de imagens naturais, a sua estatística é caracterizada pelas propriedades NSS calculadas a partir de cada bloco selecionado 
[81. Estudos anteriores sobre a medição de qualidade baseada em NSS têm demostrado que a distribuição Gaussiana generalizada (GGD) captura efetivamente o comportamento dos coeficientes calculados pela equação 4.19 de imagens naturais, assim como versões degradas das mesmas [84]. A GGD com média zero está representada pela equação 4.23).

$$
f(x ; \alpha, \beta)=\frac{\alpha}{2 \beta \Gamma(1 / \alpha)} \exp \left(-\left(\frac{|x|}{\beta}\right)^{\alpha}\right)
$$

onde $\Gamma($ ) é a função gamma, representada pela equação 4.24

$$
\Gamma(\alpha)=\int_{\infty}^{0} t^{a-1} e^{-t} d t, a>0 .
$$

Os parâmetros da GGD $(\alpha, \beta)$ podem ser estimados usando a metodologia apresentada em [85]. Neste caso, tem sido observado que o comportamento dos coeficientes de (4.19) segue uma estrutura regular. No entanto, as distorções perturbam esta estrutura de correlação [81. Este desvio pode ser calculado por meio da análise da distribuição dos produtos de pares de coeficientes adjacentes em sentido horizontal, vertical e diagonal [76]: $\hat{I}(i, j) \hat{I}(i, j+$ 1), $\hat{I}(i, j) \hat{I}(i+1, j), \hat{I}(i, j) \hat{I}(i+1, j+1)$, e $\hat{I}(i, j) \hat{I}(i+1, j-1)$, para $i \in\{1,2, \ldots, M\}$ e $j \in\{1,2, \ldots, N\}[81]$.

Neste contexto, os produtos dos coeficientes vizinhos são modelados mediante uma distribuição Gaussiana assimétrica generalizada (AGGD), apresentada na equação (4.25) [86].

$$
f\left(x ; \gamma, \beta_{l}, \beta r\right)= \begin{cases}\frac{\gamma}{\left(\beta_{l}+\beta r\right) \Gamma\left(\frac{1}{\gamma}\right)} \exp \left(-\left(\frac{-x}{\beta_{l}}\right)^{\gamma}\right) & \forall x \leq 0 \\ \frac{\gamma}{\left(\beta_{l}+\beta r\right) \Gamma\left(\frac{1}{\gamma}\right)} \exp \left(-\left(\frac{-x}{\beta_{r}}\right)^{\gamma}\right) & \forall x \geq 0\end{cases}
$$

Os parâmetros da $\operatorname{AGGD}\left(\gamma, \beta_{l}, \beta r\right)$ podem ser estimados usando a metodologia apresentada em [86]. Assim, a média da distribuição é apresentada na equação (4.26).

$$
\eta=\left(\beta_{r}-\beta l\right) \frac{\Gamma(2 / \gamma)}{\Gamma(1 / \gamma)}
$$

Desta forma, ao extrair estimativas ao longo das quatro orientações, 16 parâmetros são encontrados, produzindo um total de 18 parâmetros. Todas as características são calculadas para dois tamanhos diferentes dos blocos (geralmente $P \times P$ e $P / 2 \times P / 2$ ) a fim de capturar o comportamento a múltiplas escalas, produzindo assim um conjunto de 36 características [76].

- Modelo Gaussiano Multivariável (MGV): Um modelo simples de características NSS calculadas a partir de blocos de imagens naturais pode ser obtido mediante o ajuste com uma 
distribuição MGV (vide equação 4.27)), proporcionando uma boa representação de ditas características.

$$
f_{X}\left(x_{1}, \ldots, x_{k}\right)=\frac{1}{(2 \pi)^{k / 2}|\Sigma|^{1 / 2}} \exp \left(-\frac{1}{2}(x-\nu)^{T} \Sigma^{-1}(x-\nu)\right)
$$

onde $\left(x_{1}, \ldots, x_{k}\right)$ são as características calculadas a partir das equações 4.23$)-(4.26)$, e $\nu$ e $\Sigma$ denotam o vetor de médias e a matriz de covariança do modelo MGV, sendo calculadas usando um procedimento padrão de estimação de máxima probabilidade [87]. Os autores de [76] utilizam 125 imagens naturais com tamanhos entre $480 \times 320$ até $1280 \times 720$ para obter o modelo gaussiano. Estas imagens são chamadas de imagens de treinamento.

- $O$ indice NIQE: O índice NIQE [76] é encontrado calculando as 36 características NSS dos blocos de tamanho $P \times P$ da imagem a ser analisada, ajustando essas características com o modelo MGV apresentado na equação 4.27). Depois, o modelo MGV ajustado é comparado com o modelo MGV natural. O critério de nitidez (vide equação 4.22) não é aplicado neste caso, já que a perda de nitidez é um índice importante na medição da distorção, pelo que negligenciar os blocos degradados levaria a uma avaliação incorreta da gravidade da distorção [76]. Os autores da métrica usaram blocos de $96 \times 96$, porém, observaram uma estabilidade no desempenho com blocos de tamanhos entre $32 \times 32$ até $160 \times 160$.

Finalmente, a qualidade da imagem degradada é expressada como a distância entre o modelo de características NSS conhecidas e o modelo MGV ajustado às características extraídas da imagem degradada, como mostrado na equação (4.28) [76].

$$
D\left(\nu_{1}, \nu_{2}, \Sigma_{1}, \Sigma_{2}\right)=\sqrt{\left(\left(\nu_{1}-\nu 2\right)^{T}\left(\frac{\Sigma_{1}+\Sigma_{2}}{2}\right)^{-1}\left(\nu_{1}-\nu 2\right)\right)}
$$

onde $\nu_{1}, \nu_{2}$ e $\Sigma_{1}, \Sigma_{2}$ são os vetores das médias e as matrizes de covariança do modelo MGV natural e o modelo MGV da imagem degradada, respectivamente.

\subsubsection{Métrica de Distribuição de Contraste Local}

A definição de contraste local $C L$ para um ponto da imagem na posição $(i, j)$ é a relação entre o valor absoluto do gradiente de intensidade bidimensional $\left(|\nabla I|_{i, j}\right)$ e a média de intensidade local $\left(\bar{I}_{i, j}\right)$ [88] (vide equação 4.29). A aproximação discreta para o valor absoluto do gradiente de intensidade esta dada pela equação 4.30 . 


$$
\begin{gathered}
C L=\frac{|\nabla I|_{i, j}}{\bar{I}_{i, j}} . \\
|\nabla I|_{i, j}=\sqrt{\left(\frac{I_{i+1, j}-I_{i-1, j}}{2 \Delta x}\right)^{2}+\left(\frac{I_{i, j+1}-I_{i, j-1}}{2 \Delta y}\right)^{2}},
\end{gathered}
$$

onde $\Delta x=\Delta y$ são as distâncias entre pixeis vizinhos. Além disso, a média de intensidade local está dada pela equação 4.31.

$$
\bar{I}_{i, j}=\frac{I_{i, j+1}+I_{i, j-1}+I_{i+1, j}+I_{i-1, j}}{4} .
$$

Para cada imagem, o contraste local, dado pela equação 4.29), é calculado para todos os pontos da imagem e os valores são arranjados em histogramas de frequência. Assim, é encontrado o mínimo e o máximo valor de contraste local $\left(C L_{\min }\right.$ e $C L_{\max }$, respectivamente). Portanto, o valor de qualidade, em relação a distribuição de contraste na imagem está dado pela equação 4.32 .

$$
R=C L_{\max }-C L_{\min }
$$

A figura 4.3 apresenta duas situação diferentes de contraste para a mesma cena. Nesta figura pode-se observar que quanto melhor a distribuição de contraste na imagem, o valor de $R=C L_{\max }-C L_{\min }$ será maior.

\subsubsection{Avaliação de Cor em Imagens Subaquáticas (UCIQE)}

Geralmente, na avaliação da cor de uma imagem é necessário encontrar uma métrica que: (a) esteja correlacionada com a percepção humana; (b) seja capaz de detectar as distorções clássicas presentes em água turva; (c) seja passível de sua utilização em processos de restauração; e (d) tenha baixo custo computacional, podendo ser implementada em aplicações de tempo real [77].

No trabalho apresentado por Y. Miao [77], o conjunto de imagens a serem estudadas consiste de imagens subaquáticas coloridas adquiridas para o monitoramento de tubulações em ambiente submarino. A maioria destas imagens estão borradas, apresentando baixo contraste e grave difusão de cores.

A fim de selecionar a melhor métrica para este problema, dois aspectos básicos foram considerados: o mais obvio foi a correlação com as avaliações subjetivas, e o segundo foi o custo 


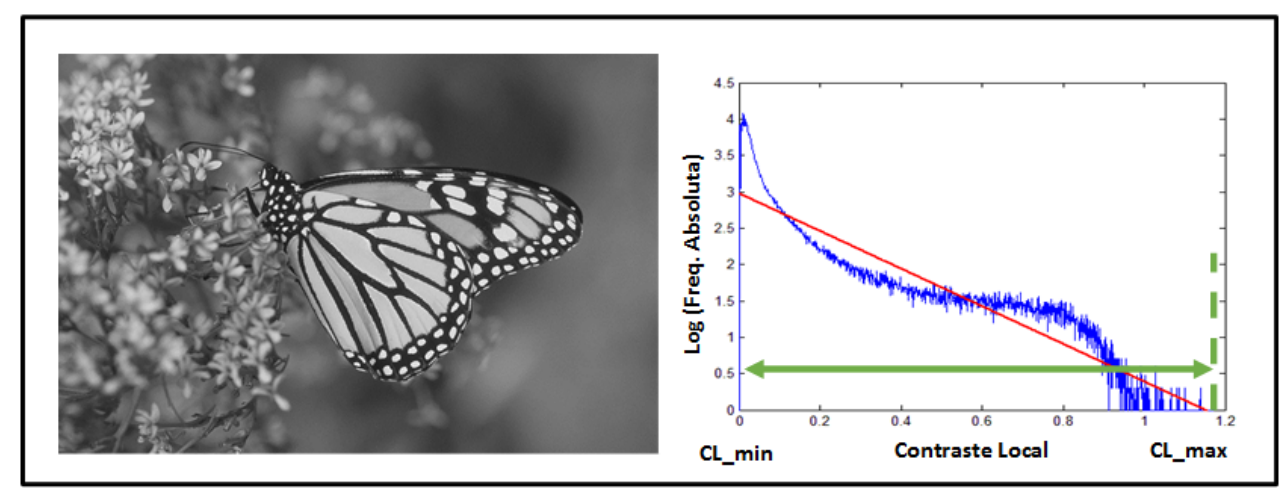

(a)

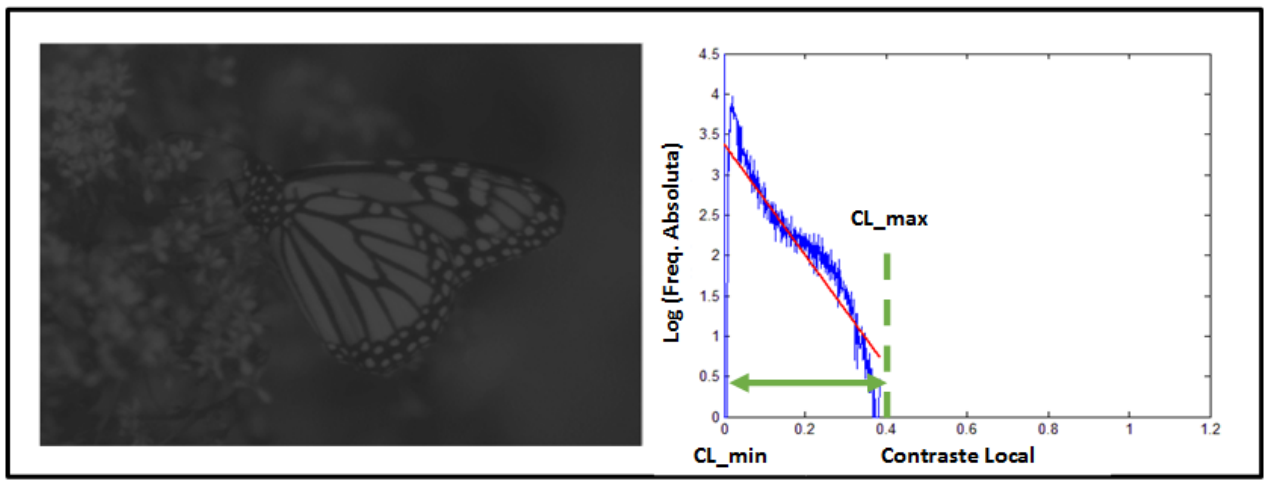

(b)

Figura 4.3. Exemplo de funcionamento da métrica de distribuição de contraste.

computacional [77]. Além disso, os autores utilizam o espaço de cor CIELab, já que é um espaço de cor uniforme e independente do dispositivo de captura [89].

CIELab é um modelo cromático normalmente utilizado para descrever todas as cores que podem ser captadas pelo olho humano. Foi desenvolvido pela Comissão Internacional da Iluminação (Commission Internationale d'Eclairage - CIE). Os três parâmetros do modelo representam a luminosidade da cor $L$ (valores entre 0 - 100\%), a é sua posição entre vermelho e verde (valores negativos indicam verde enquanto valores positivos indicam vermelho), e o canal $b$ a posição entre amarelo e azul (valores negativos indicam azul e valores positivos indicam amarelo) [89].

Assim, utilizando o espaço de cor CIELab, Hasler e Suesstrunk [89] apresentam um trabalho para extrair 9 características de imagens naturais (fora da água) diretamente relacionadas com a qualidade das cores, borramento e contraste. Algumas destas características são consideradas por Y. Miao [77] para a análise de imagens subaquáticas e são apresentadas a continuação.

Denotando $I_{p}=\left[L_{p}, a_{p}, b_{p}\right]$ como os valores de um pixel $p=1,2, \ldots, N$ no espaço CIELab, sendo $N$ o tamanho da imagem, definem-se as seguintes características [89]:

- Chroma $-C_{I}$ : Esta informação está relacionada diretamente com a distribuição de cores na imagem, sendo dada pela equação 4.33 [89]. 


$$
C_{p}=\sqrt{a_{p}^{2}+b_{p}^{2}}
$$

onde $a$ e $b$ corresponde aos dois últimos canais do modelo CIELab.

- Desvio padrão do Chroma - $\sigma_{c}$ : Dado pela equação (4.34] 89].

$$
\sigma_{c}=\sqrt{\frac{1}{N} \sum_{N}^{p=1}\left(C_{p}-\mu_{c}\right)^{2}} .
$$

onde $\mu_{c}$ corresponde ao valor médio do chroma, dado pela equação (4.35) 89].

$$
\mu_{c}=\frac{1}{N} \sum_{N}^{p=1} C_{p} .
$$

- Contraste da Luminância - con $_{L}$ : calculada como a diferença entre a soma dos valores do $1 \%$ dos pixeis da parte inferior e a soma dos valores do $1 \%$ dos pixeis da parte superior 77.

- Saturação média - $\mu_{s}$ : Dada pela equação 4.36 89].

$$
\mu_{s}=\frac{1}{N} \sum_{N}^{p=1} S_{p} .
$$

onde $S_{p}$ é chamado de saturação da imagem (vide equação 4.37) ) e corresponde à relação entre o chroma e a iluminação dada pelo canal $L$ do espaço CIELab[89].

$$
S_{p}=\frac{C_{p}}{L_{p}}
$$

Uma vez definidas estas características da imagem, os autores definem a métrica como uma combinação linear dos parâmetros supracitados, como mostrado na equação (4.38] [77].

$$
U C I Q E=c_{1} \sigma_{c}+c_{2} \operatorname{con}_{L}+c_{3} \mu_{s} .
$$

onde $c_{1}, c_{2}$ e $c_{3}$ são coeficientes ponderados, os quais são calculados aplicando uma regressão linear a partir dos dados da avaliação subjetiva.

Além disso, é importante notar que os três parâmetros $\operatorname{con}_{L}, \sigma_{c}$ e $\mu_{s}$ são calculados independentemente. Assim, estes podem ser processados em paralelo objetivando acelerar o processo 
de avaliação da imagem [77]. Para avaliação de imagens subaquáticas coloridas com distorções como borramento, difusão de cor e neve marina, os coeficientes obtidos pelos autores foram $c_{1}=0,4680, c_{2}=0,2745$ e $c_{3}=0,2576$.

\subsubsection{Qualidade Média de Imagens Subaquáticas Baseada em Regiões (PUIQ)}

Esta métrica foi proposta por Y. Miao [90] e apresenta um valor de qualidade $Q$ para medição do contraste e borramento ocasionados pelos efeitos de forward-scattering e back-scattering em imagens de vídeo. A diferença de outras métricas para avaliação de qualidade de imagens subaquáticas, a métrica proposta no trabalho em [90] não está diretamente aplicada à imagem inteira, neste caso, realiza-se uma análise por regiões (patches). Os passos estão descritos no Algoritmo 5 [90.

Para a avaliação de imagens subaquáticas, o objeto é mais importante para a análise e monitoramento; portanto, a nitidez das bordas do objeto é considerado o fator principal. Por esta razão, os autores propõem valores de $W_{1}=0,2, W_{2}=0,3$ e $W_{3}=0,5$. Assim, se não existe um objeto na cena, o valor de $Q$ será menor que 0,5 [90].

\subsubsection{Discussão Sobre as Métricas de Avaliação Objetiva Sem Referência}

Assim, havendo apresentado algumas métricas de avaliação objetiva de imagens sem referência, a Tabela 4.1 apresenta um resumo das métricas discutidas (sem referência), em relação às degradações principais para as quais foram projetadas. Como foi discutido no Capítulo 2, as principais degradações inseridas por um meio subaquático são aquelas referentes ao borramento, ruído e perda de contraste e, embora a maioria destas métricas tenham sido projetadas para imagens naturais (não subaquáticas), as degradações estudadas em cada uma delas tornam viável sua implementação em sistemas de avaliação de imagens subaquáticas. Por esta razão foram escolhidas estas métricas de avaliação objetiva para sua implementação e teste.

\subsection{AvaliaÇÃo Subjetiva de Imagens}

O desenvolvimento de um estudo subjetivo precisa representar com precisão o âmbito de aplicações e dos algoritmos de avaliação de qualidade em que as imagens seriam usadas, tanto para treinamento como para teste. Por exemplo, se a métrica de avaliação de qualidade é 


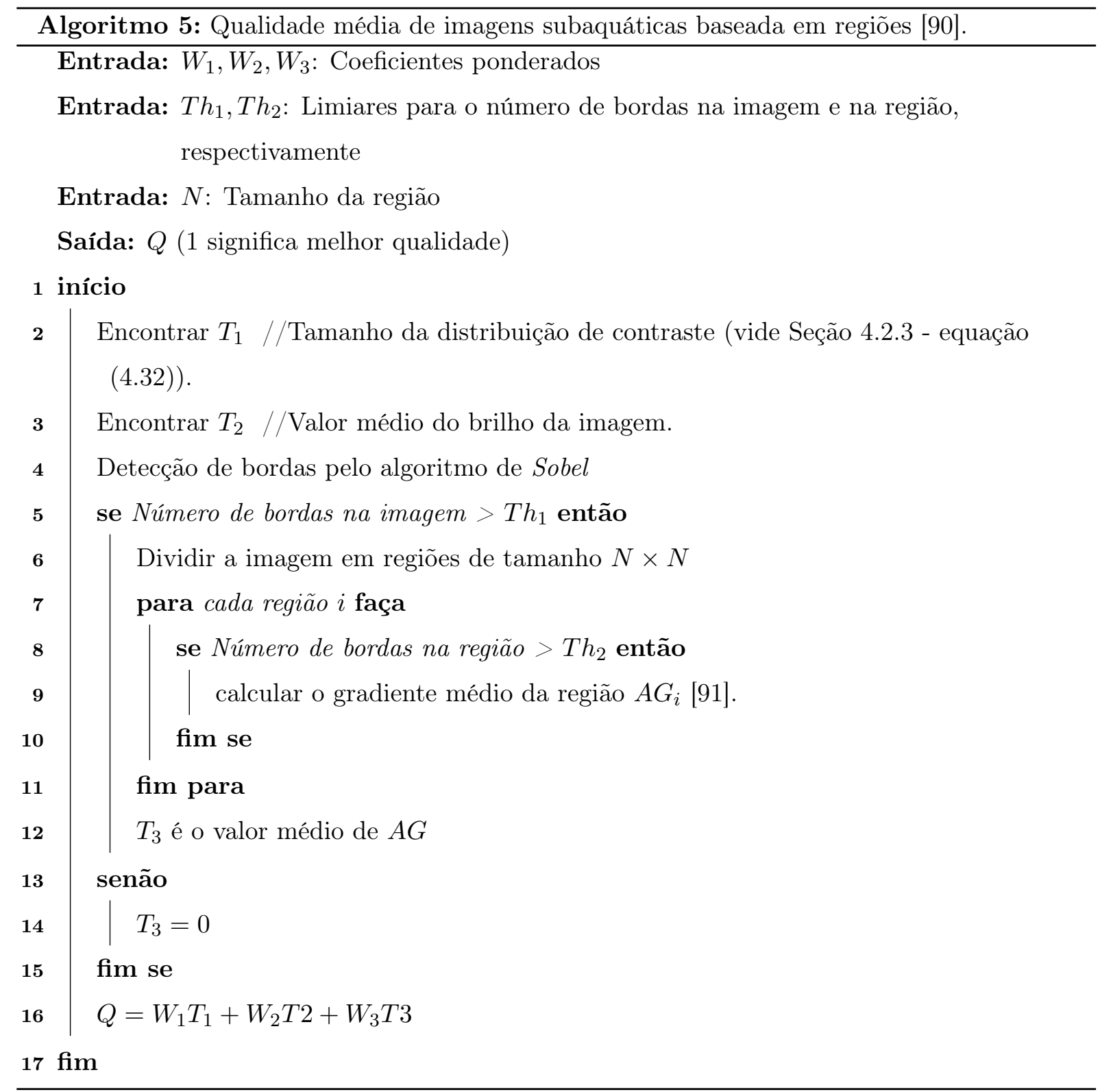

Tabela 4.1. Métricas de avaliação objetiva de imagens sem referência (NRIQA).

\begin{tabular}{|c|l|}
\hline Métrica & Degradações Medidas \\
\hline BN-IQA [75] & $\begin{array}{l}\text { - Borramento das bordas } \\
\text { - Ruído }\end{array}$ \\
\hline NIQE [76] & - Borramento \\
\hline Distribuição de Contraste Local [88] & - Contraste \\
\hline UCIQE [77] & - Difussão de Cor \\
& - Contraste \\
\hline PUIQ [90] & - Borramento das bordas \\
\hline
\end{tabular}


requerida somente para imagens comprimidas JPEG, então o estudo deve envolver somente imagens comprimidas JPEG. Infelizmente, essa dependência da aplicação final limita o objetivo da análise subjetiva.

Além disso, os estudos subjetivos são bastante trabalhosos e consomem muito tempo, sendo que um estudo do compromisso entre a aplicabilidade dos seus resultados e o custo do estudo é inevitável [78].

Uma grande quantidade de metodologias para análise subjetiva de qualidade de imagens estão disponíveis na literatura, tendo cada uma delas seu próprio domínio, vantagens e desvantagens [92], [93], 94], [95], 96].

Além disso, várias metodologias têm sido apresentadas objetivando o desenvolvimento de testes de analise subjetiva de qualidade de imagens que permita obter resultados confiáveis. A maioria dos experimentos atuais para avaliação de qualidade de imagens são realizados utilizando a norma ITUR BT.500. Esta norma propõe diferentes métodos para análise subjetiva de qualidade de imagens de televisão e contem informação sobre as condições de visualização, instruções sobre a metodologia do experimento, materiais e a apresentação de resultados.

No contexto geral, a norma supracitada apresenta três tipos de metodologias experimentais que podem ser usadas para análise subjetiva de imagens [78]:

1. métodos de estímulo duplo (double-stimulus).

2. métodos de estímulo único (single-stimulus).

3. métodos de escolha forçada (forced-choice).

Os métodos de estímulo duplo são geralmente utilizados para testar métricas de avaliação de imagens com referência completa. Nessa metodologia, são apresentadas a imagem de teste (degradada ou não) e a imagem de referência correspondente, uma após a outrâ Assim, o observador humano atribui um índice de qualidade para cada imagem. Desta forma, a qualidade relativa da imagem de teste pode ser determinada, sendo que todas a fontes de erro sistemático (que possam resultar) são minimizadas. Os métodos de estímulo duplo são mais robustos; sendo considerado que os resultados têm maior estabilidade e reproduzibilidade [78]. No entanto, esta metodologia requer de uma imagem de referência da qual não se dispõe na maioria das aplicações práticas. Além disso, as metodologias de estímulo único são mais adequadas para aplicações práticas devido a que não se tem posse de uma imagem de referência. Neste caso, somente a imagem de teste é avaliada por um observador humano, [78].

\footnotetext{
${ }^{1} \mathrm{~A}$ ordem de apresentação da imagem de teste e a imagem de referência é aleatória
} 
Além disso, a terceira metodologia é um sistema de escolha forçada entre duas imagens que podem ser diferentes perceptualmente. O objetivo é julgar se são ou não diferentes. Neste caso, duas imagens são apresentadas, uma após a outra, em ordem aleatório; onde o sujeito escolhe uma de duas alternativas para avaliá-las, como por exemplo melhor/pior, boa/ruim, sem distorção/com distorção, etc. Assim, neste caso, não é feita uma avaliação de qualidade, simplesmente é realizada uma comparação entre as imagens. Essa metodologia é muito complexa e requer muitas tentativas. Além disso, é muito difícil atribuir uma escala de qualidade as imagens [78].

Os resultados poderiam ser apresentados mediante uma classificação subjetiva, como por exemplo: excelente, bom, ruim e etc para os resultados de qualidade. No entanto, estes resultados de classificação não são fiáveis. Uma razão para isso é que os observadores são propensos a atribuir diferentes escalas de qualidade para cada cena. Assim, a seguir são apresentados brevemente os dois métodos de pontuação maiormente utilizados no IQA subjetivo:

- MOS (Mean Opinion Score): O índice MOS corresponde ao valor médio de todas as avaliações dadas pelos diferentes avaliadores para uma mesma imagem. Assim, o índice MOS para a $i$-ésima imagem está dado por:

$$
M O S_{i}=\frac{1}{N} \sum_{j=1}^{N} I_{i j}
$$

onde $N$ corresponde ao número de avaliadores e $I_{i j}$ representa a avaliação dada pelo $j$-ésimo avaliador para a $i$-ésima imagem.

- DMOS (Difference Mean Opinion score): Em vez de aplicar diretamente os resultados da classificação, as métricas IQA modernas usam diferenças de qualidade entre imagens. O DMOS é definido como a diferença entre o índice de qualidade bruto das imagens de referência e de teste. O DMOS da $i$-ésima imagem é calculado utilizando a seguinte equação:

$$
D M O S_{i}=\frac{1}{N} \sum_{j=1}^{N}\left(R e f_{i j}-I_{i j}\right),
$$

onde $N$ representa a quantidade total de avaliadores, $I_{i j}$ corresponde à avaliação dada pelo $j$-ésimo avaliador à $i$-ésima imagem, e $R e f_{i j}$ representa a avaliação dada pelo $j$-ésimo avaliador à imagem de referência correspondente à imagem $i$. 


\subsection{Bancos de Imagens e Análise de CorrelaÇão}

Como foi discutido anteriormente, o objetivo principal de uma análise de qualidade de imagens (IQA) consiste em modelar uma métrica objetiva que apresente valores de qualidade semelhantes às avaliações humanas [97]. Objetivando atingir este objetivo, um grande número de pesquisadores têm realizado experimentos subjetivos e criado bancos de imagens naturais. Nesta seção serão apresentados os seis bancos de imagens naturais mais utilizados. Estes bancos são: (a) Cornell-A57 [98], (b) ICV [99], (c) Tampere Image Dataset TID2008 [100,, (d) LIVE [101], [97], (e) Toyoma-MICT [102] e (f) CSIQ [103].

\subsubsection{Bancos de Imagens para Avaliação de Qualidade}

O banco Cornell-A57 [98] está formado por 54 imagens degradadas com 6 tipos diferentes de distorções. As distorções em este banco de imagens são: quantização, ruído branco Gaussiano (WGN), compressão JPEG e JPEG2000, borramento por filtro Gaussiano.

Além disso, o banco de imagens IVC [99] consiste de 10 imagens de referência e 185 versões degradadas das mesmas. Os tipos de distorção são: compressão JPEG2000 e JPEG e borramento.

O Banco TID2008 [100] está formado por 1700 imagens geradas a partir de 25 imagens de referência com 17 tipos de distorções em quatro níveis diferentes. 654 observadores humanos de três países diferentes participaram na análise subjetiva. Condições de iluminação, tamanho da tela, tipo de monitor, entre outros parâmetros foram variados durante o experimento. Algumas das distorções presentes neste banco de dados são: ruído aditivo Gaussiano, masked noise, ruído espacialmente correlacionado, ruído de alta frequência, ruído impulsivo, borramento Gaussiano, filtragem, Compressão JPEG, Compressão JPEG2000, erros de transmissão em compressão JPEG e JPEG2000, variações de contraste, entre outras. As avaliações de cada imagem no banco TID2008 estão reportadas como a média das opiniões (MOS - Mean Opinion Score).

Além disso, o banco LIVE (Laboratory for Image and Video database) [101, [97] é o mais utilizado e referenciadona literatura [104]. Este banco consiste em 29 imagens de referência e as suas versões degradadas, entre elas: compressão JPEG, compressão JPEG2000, ruído branco Gaussiano, borramento, desvanecimento Rayleigh (Rayleigh Fading). O total de imagens degradadas no banco de imagens é de 779. Os índices de avaliação subjetiva estão dados como DMOS (Difference Mean Opinion Score).

O Banco Toyoma-MICT [102] apresenta um total de 196 imagens (168 imagens degradadas e 28 de referência). As distorções presentes são as compressões JPEG e JPEG2000. O método utilizado para avaliação subjetivas das imagens foi o de estímulo único e os índices de qualidade 
estão dados como MOS.

Por último, o banco CSIQ (Categorical Subjective Image Quality) [103] está formado por 30 imagens de referência, cada uma degradada com seis níveis de distorção diferentes para as distorções: compressão JPEG e JPEG2000, decremento do contraste global, ruído branco e rosa aditivo Gaussiano e borramento Gaussiano.

Na Tabela 4.2 apresenta-se um resumo dos bancos de imagens citados acima. Em uma etapa inicial deste trabalho foi utilizado o banco de imagens LIVE [101, [97] a fim de comparar o desempenho de algumas métricas de avaliação objetiva. Esta análise justifica-se levando em conta que deve-se escolher uma métrica adequada para guiar o processo de restauração das imagens. Como será discutido no Capítulo 6, esta etapa inicial consistiu na restauração de imagens que foram degradadas artificialmente, utilizando as implementações dos modelos de formação de imagens discutidos no Capítulo 2. Porém, a restauração de imagens degradadas artificialmente não é o objetivo principal deste trabalho e, portanto, devia-se realizar uma análise de correlação entre as métricas objetivas e um banco de imagens subaquáticas reais, que permitisse identificar qual seria a melhor métrica para este tipo de imagens.

Assim, na literatura foi possível encontrar somente um trabalho que apresenta a avaliação subjetiva de um banco de vídeos subaquáticos. No trabalho apresentado por Moreno-Roldan et. al. 105] aborda-se o tema da avaliação da qualidade em potenciais serviços de transmissão de vídeo subaquático, a partir de um ponto de vista subjetivo. Os autores apresentam a metodologia e os resultados de um teste planejado de acordo com métodos psicométricos. Os indivíduos utilizados no processo de avaliação foram cientistas especialistas em oceanografia. As sequências de vídeo foram capturadas em expedições recentes, sendo processadas a fim de simular condições que pudessem ser encontradas em processos de transmissão de vídeos subaquáticos, tais como largura de banda limitada e grandes retardos na transmissão. Embora o artigo [105] apresenta uma boa descrição sobre a análise subjetiva realizada pelos autores, o mesmo não disponibiliza nenhum banco de vídeos nem os valores MOS encontrados.

Adicionalmente, no capítulo publicado por C. J. Prabhakar e P. U. Praveen Kumar [106] em 2014 os autores afirmam que, atualmente, não há nenhum banco de imagens subaquáticas disponível para comparar e avaliar os resultados de uma métrica objetiva voltada para este tipo de imagens. Por esta razão, no contexto desta tese, decidiu-se criar um banco de imagens subaquáticas, assim como realizar uma análise subjetiva que permita avaliar o desempenho das métricas de qualidade de imagens objetivas que foram apresentadas neste capítulo (vide Seção 4.2). Os detalhes sobre a metodologia para adquisição e avaliação subjetiva das imagens subaquáticas serão apresentados na Seção 5.3 . 
Tabela 4.2. Bancos de Imagens para Análise Subjetiva.

\begin{tabular}{|c|c|c|c|}
\hline Banco & $\begin{array}{l}\text { Quantidade } \\
\text { de Imagens }\end{array}$ & Degradações & $\begin{array}{l}\text { Índice de } \\
\text { Avaliação }\end{array}$ \\
\hline Cornell-A57 98 & 54 degradadas & $\begin{array}{l}\text {-Quantização } \\
\text {-Ruído branco } \\
\text { Gaussiano (WGN) } \\
\text {-Compressão JPEG } \\
\text { e JPEG2000 } \\
\text {-Borramento por } \\
\text { filtro Gaussiano }\end{array}$ & MOS \\
\hline IVC 99 & $\begin{array}{l}10 \text { de Referência } \\
185 \text { degradadas }\end{array}$ & $\begin{array}{l}\text {-Compressão JPEG } \\
\text { e JPEG2000 } \\
\text {-Borramento }\end{array}$ & MOS \\
\hline TID2008 [100 & $\begin{array}{c}1700 \text { degradadas } \\
\text { a partir de } 25 \\
\text { imagens de Referência }\end{array}$ & $\begin{array}{l}\text {-Ruído Gaussiano } \\
\text {-Ruído espacialmente } \\
\text { correlacionado } \\
\text {-Ruído de alta } \\
\text { frequência } \\
\text {-Ruído impulsivo } \\
\text {-Borramento Gaussiano } \\
\text {-Compressão JPEG } \\
\text { e JPEG2000 } \\
\text {-Variações de Contraste }\end{array}$ & MOS \\
\hline LIVE 101] & $\begin{array}{l}29 \text { de Referência } \\
779 \text { degradadas }\end{array}$ & $\begin{array}{l}\text {-Compressão JPEG } \\
\text { e JPEG2000 } \\
\text {-Ruído branco } \\
\text { Gaussiano (WGN) } \\
\text {-Borramento } \\
\text {-Desvanecimento Rayleigh }\end{array}$ & DMOS \\
\hline Toyoma-MICT [102] & $\begin{array}{c}28 \text { de Referência } \\
168 \text { degradadas }\end{array}$ & $\begin{array}{l}\text {-Compressão JPEG } \\
\text { e JPEG2000 }\end{array}$ & MOS \\
\hline CSIQ [103 & $\begin{array}{l}30 \text { de referência } \\
866 \text { degradadas }\end{array}$ & $\begin{array}{l}\text {-Compressão JPEG } \\
\text { e JPEG2000 } \\
\text {-Perda de Contraste } \\
\text {-Ruído branco e rosa } \\
\text {-Borramento Gaussiano }\end{array}$ & DMOS \\
\hline
\end{tabular}




\subsubsection{Análise de Correlação}

Uma vez se tem disponibilidade de um banco de imagens com informação de avaliações subjetivas para cada imagem, pode-se proceder a realizar uma análise de correlação, a qual visa comparar o desempenho de uma nova métrica objetiva em relação a uma já existente. Nesta seção serão discutidos os dois métodos baseados em correlação mais referenciados na literatura [107.

- Coeficiente de Correlação Linear de Pearson - PLCC: é um coeficiente de correlação linear entre o índice de qualidade objetivo e o subjetivo. O PLCC reflete o grau de relacionamento linear entre duas variáveis. O PLCC pode ser calculado utilizando a equação 4.41).

$$
P L C C=\frac{\sum_{i=1}^{M_{d}}\left(q_{i}-\bar{q}\right)\left(s_{i}-\bar{s}\right)}{\left(\sum_{i=1}^{M_{d}}\left(q_{i}-\bar{q}\right)^{2}\right)^{1 / 2}\left(\sum_{i=1}^{M_{d}}\left(s_{i}-\bar{s}\right)^{2}\right)^{1 / 2}} .
$$

onde $s_{i}$ e $q_{i}$ são os índices de avaliação subjetiva e objetiva, respectivamente, para a $i$-ésima imagem em um banco de com $M_{d}$ imagens, e $\bar{q}$ e $\bar{s}$ correspondem aos valores médios dos índices de avaliação objetivos e subjetivos, respectivamente.

- Coeficiente de Correlação Linear de Spearman - SRCC: é um coeficiente de correlação não-linear entre o índice de qualidade objetivo e o subjetivo. O SRCC avalia quão bem uma função monótona arbitrária pode descrever a relação entre duas variáveis, sem fazer quaisquer suposições sobre a distribuição das variáveis frequência [108]. O SRCC pode ser descrito mediante a equação 4.42.

$$
S R C C=1-\frac{6 \sum_{i=1}^{M_{d}} d_{i}^{2}}{M_{d}\left(M_{d}^{2}-1\right)} .
$$

onde $d_{i}$ corresponde à diferença entre as avaliações objetiva e subjetiva da $i$-ésima imagem.

\subsection{Considerações Finais do Capítulo}

Objetivando saber se a solução encontrada no processo de restauração é ótima, deve ser utilizado algum método para validar a qualidade da imagem resultante do processo de restauração. Neste capítulo foram apresentados os métodos mais comuns de avaliação da qualidade de uma imagem. Esses métodos podem ser classificados em: (a) métodos de avaliação com referência completa, os quais necessitam uma imagem de referência para realizar a avaliação; e (b) métodos 
de avaliação sem referência, que são mais adequados para aplicações reais, nas que nem sempre conta-se com uma imagem de referência.

As métricas sem referência discutidas neste capítulo apresentam uma boa opção para este trabalho, já que são métricas que representam quantidades de forma adequada às distorções que pode sofrer uma imagem em ambientes subaquáticos, e portanto foram implementadas e analisadas. Para esta análise de desempenho, é necessário contar com um banco de imagens subaquáticas que tenha sido submetido a uma análise subjetiva de qualidade. Por esta razão decidiu-se construir dito banco de imagens utilizando uma montagem simples que será descrita na Seção 5.3, onde também serão descritos os procedimentos referentes à sua análise subjetiva.

Além disso, como foi discutido nos Capítulos 2 e3, é necessário dispor de uma função objetivo adequada para guiar o processo de restauração baseado em otimização. Por esta razão, tornase indispensável a implementação de um sistema para análise da correlação entre as métricas e a análise subjetiva realizada anteriormente (vide Seção 4.4.2). O resultado de este processo de análise de correlação consiste na escolha das métricas que foram definitivas para o processo de restauração. Os detalhes desta análise, assim como a justificativa da escolha da métrica definitiva, serão apresentados na Seções 5.2 e 5.4. 


\section{Desenvolvimento das Ferramentas para Análise das Métricas e Testes de RestauraÇÃo}

No contexto da Restauração de imagens, é necessário contar com ferramentas que permitam realizar uma análise das métricas de avaliação de imagens, as quais seriam utilizadas como elementos de medição da qualidade das imagens restauradas e, além disso, que possam ser utilizadas como funções objetivo capazes de guiar corretamente o processo de otimização.

No contexto deste trabalho, foram implementadas duas abordagens para a restauração de imagens subaquáticas. A primeira abordagem consiste na implementação de uma estratégia de restauração baseada em imagens degradadas artificialmente. Esta abordagem, que será apresentada no Capítulo 6, visa testar o desempenho dos algoritmos de otimização bio-inspirada ao problema de restauração de imagens subaquáticas. É por esta razão que é necessário o desenvolvimento de uma ferramenta que permita inserir degradação artificiais a uma imagem, seguindo os modelos de formação de imagens em meios participativos apresentados no Capítulo 2. Os detalhes sobre a implementação dos modelos de degradação, assim como, o desenvolvimento da Ferramenta de Degradação de Imagens em Meios Participativos (FDIMP) são apresentados neste capítulo (vide Seção 5.1).

Além disso, a estratégia de restauração de degradações artificiais tem um segundo objetivo, que consiste em encontrar uma métrica de avaliação de imagens que permita guiar o processo de otimização. Por esta razão, na Seção 5.2 , são apresentadas as implementações de duas métricas de qualidade de imagens sem referência, BN-IQA (vide Seção 4.2.1) e NIQE (vide Seção 4.2.2), assim como uma análise de correlação que permitiu identificar a métrica mais adequada para guiar os primeiros testes de restauração.

Finalmente, a segunda abordagem está baseada na restauração de imagens com degradações reais. Neste caso, é indispensável realizar testes de desempenho das métricas de avaliação para este tipo de imagens. Assim, objetivando realizar uma análise de correlação (vide Seção 4.4.2), é necessário contar com um banco de imagens degradadas que tenham sido submetidas a uma avaliação subjetiva. Devido à carência de bancos de imagens subaquáticas com avaliações subjetivas, no contexto deste trabalho, criou-se o Banco de Imagens Subaquáticas LEIA (LEIA Underwater 
Image Database - UID-LEIA). A metodologia seguida para a obtenção e análise subjetiva das imagens do UID-LEIA é apresentada neste capítulo (vide Seção 5.3). Posteriormente, utilizando as imagens do banco UID-LEIA, foi realizado um estudo sobre o desempenho das métricas de avaliação objetiva com relação às degradações próprias de ambientes subaquáticos, e que será apresentado na Seção 5.4 .

\subsection{ImplementaÇÃo dos Modelos de FormaÇÃo de Imagens em Meios Participativos}

No Capítulo 2 foram expostos e analisados os modelos de formação de imagens em meios participativos ou, mais especificamente, em meios subaquáticos. Estes modelos visam simular os efeitos físicos que geram as principais degradações na imagem final captada pela câmera. Como mencionado anteriormente, estes efeitos geram degradações tais como borramento, ruído, perda de contraste, neve marina, entre outras. Portanto, a implementação destes modelos torna-se fundamental para as etapas de restauração, que consistem na inversão do modelo de formação da imagem, como explicado na Seção 2.5 .

Atualmente, existem quatro modelos de formação de imagens: (a) modelo de Jaffe-McGlamery [19], [18]; (b) modelo de Schechner [5]; (c) modelo de Trucco-Olmos [20]; e (d) modelo de Wagner [9]. Embora o modelo mais geral e completo é aquele apresentado por Jaffe-McGlamery (vide Seção 2.1), também é considerado o mais complexo, possuindo a maior quantidade de parâmetros a serem considerados; fazendo inviável a sua implementação para processos de restauração automática [20]. Por esta razão, neste trabalho foram consideradas as três simplificações apresentadas para o modelo de Jaffe-McGlamery: (a) simplificação de Trucco-Olmos, (b) simplificação de Schechner e (c) simplificação de Wagner. Os detalhes sobre a implementação dos modelos supracitados, assim como da Ferramenta de Degradação de Imagens em Meios Participativos (FDIMP) serão apresentados nesta seção.

\subsubsection{Implementação do Modelo de Trucco e Olmos-Antillon}

Como foi discutido na Seção 2.3. este modelo considera uma simplificação do modelo de Jaffe-McGlamery [19], [18] (vide Seção 2.1). Dita simplificação consiste em eliminar o termo referente ao back-scattering, responsável principalmente pela perda de contraste na imagem. Esta simplificação é justificada pelos autores, afirmando que, para pequenas distâncias, são mais fortes as degradações devidas ao efeito de forward-scattering.

Objetivando uma implementação mais simples deste modelo, todo o processo se dá no domínio 
da frequência, evitando assim realizar a operação de convolução espacial. Para isto, é utilizada a Transformada Discreta de Fourier (TDF), disponível no pacote de processamento de imagens de MATLAB. O problema principal está na construção da PSF, ou filtro de convolução, que é a responsável pelo borramento da imagem.

O processo de degradação inicia-se realizando uma atenuação da imagem de entrada $I$ devida ao efeito de transmissão direta segundo a equação 2.31. A imagem resultante deve ser levada para o domínio da frequência e, posteriormente, deslocando os componentes de baixa frequência para o centro da imagem. Assim, em posse da imagem no domínio da frequência, procede-se ao desenvolvimento do filtro a partir dos parâmetros de entrada $c, K$ e $d m$, que correspondem ao coeficiente de atenuação, ganho do filtro e distância média entre a câmera e a cena, respectivamente. O filtro deve ser modelado para realizar uma filtragem passa-baixa seguindo a equação 2.25). O parâmetro referente à frequência radial $\omega$ é assim obtido a partir da distância (em pixeis) de todos os pontos da imagem com relação a o centro da mesma [20]. Uma representação visual do filtro no domínio da frequência obtido neste processo pode ser observado na Figura 5.1 .

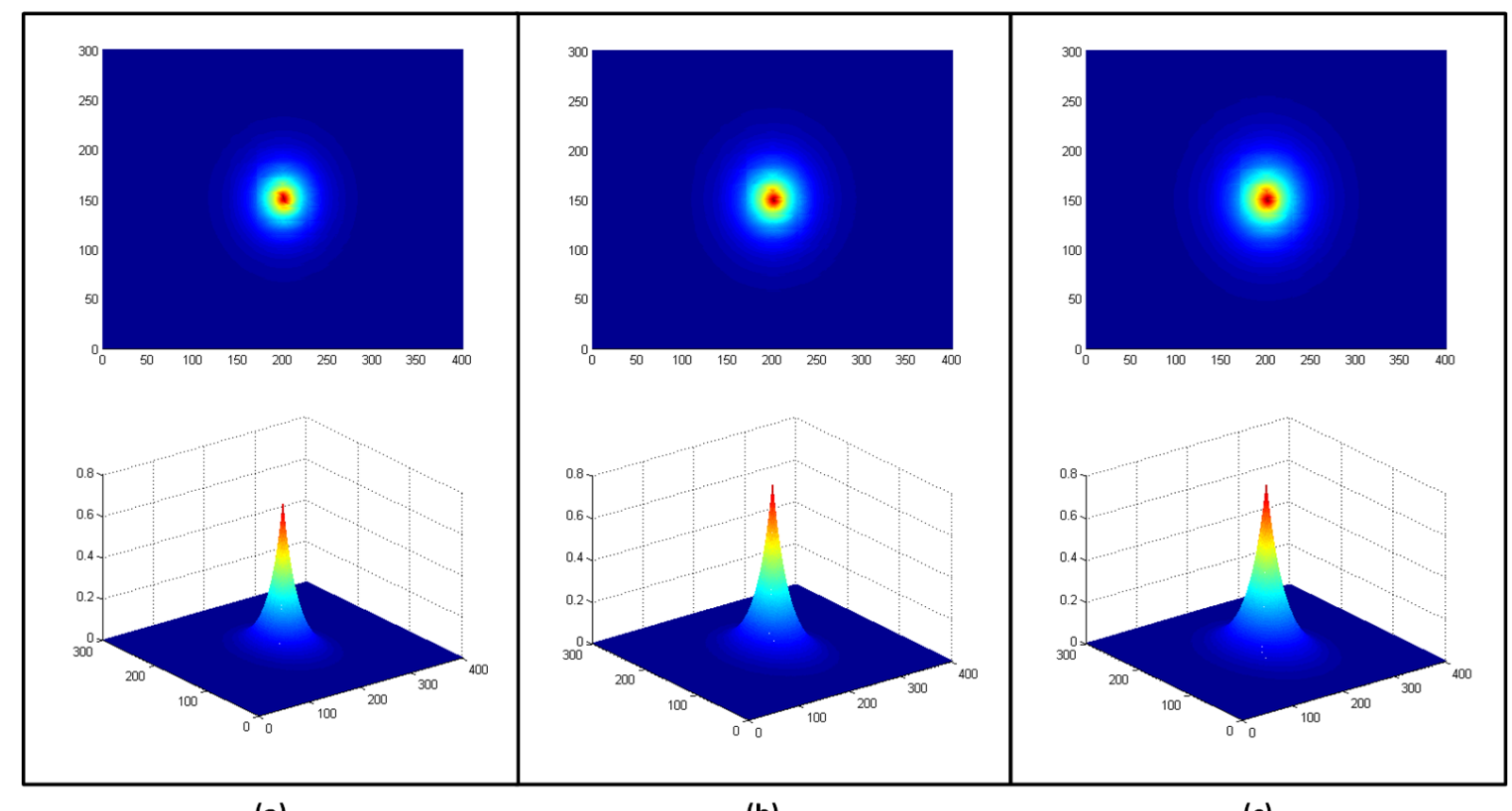

(a)

(b)

(c)

Figura 5.1. Exemplo de filtro no domínio da frequência para o modelo de Trucco-Olmos $d m=0,8 m$. (a) Canal R com $c_{r}=0,5 m^{-1}$ e $K_{r}=0,7$. (b) Canal G com $c_{g}=0,45 m^{-1}$ e $K_{g}=0,8$. (c) Canal B com $c_{b}=0,4 m^{-1}$ e $K_{b}=0,8$.

O próximo passo consiste em realizar a filtragem utilizando o filtro obtido no passo anterior. Esta filtragem corresponde a uma operação de convolução, porém, devido a que tanto a imagem como o filtro encontram-se no domínio da frequência, esta operação corresponde à multiplicação ponto a ponto entre o filtro e a imagem. Por fim, a imagem degradada final $I_{d e g}$ é obtida 
aplicando a Transformada Inversa de Fourier (TIF) à imagem resultante do passo anterior. Um exemplo do resultado obtido aplicando este modelo de formação de imagens pode ser observado na Figura 5.2 .

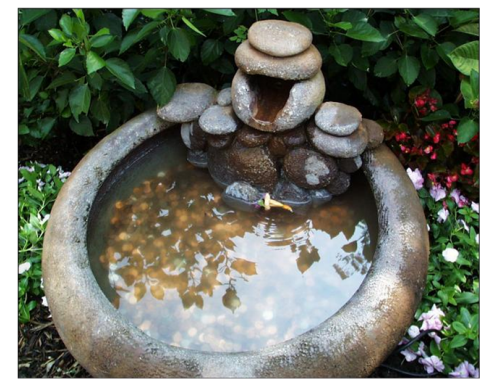

(a)

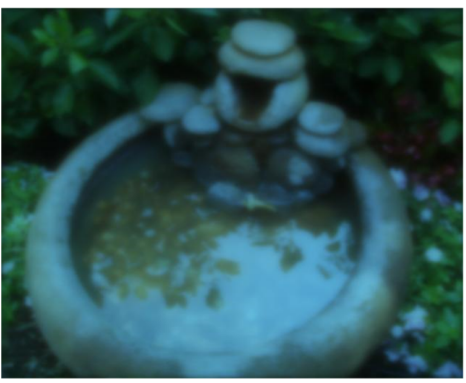

(b)

Figura 5.2. Exemplo de degradação de uma imagem utilizando o modelo de Trucco-Olmos. (a) Imagem original. (b) Imagem degradada (parâmetros de degradação: $c_{r}=0,5 m^{-1}, K_{r}=0,7, c_{g}=0,45 m^{-1}, K_{g}=0,8, c_{b}=0,4 m^{-1}$, $\left.K_{b}=0,8, d m=0,8 m\right)$.

Observa-se na Figura 5.2 (b) que a principal degradação presente na imagem é o borramento causado pelo efeito de forward-scattering, neste caso, modelado como um filtro passa-baixa. Embora possa ser observada uma pequena perda de contraste, esta é gerada pela etapa de atenuação devido ao efeito de transmissão direta.

O pseudo-código para o processo de restauração está descrito no Algoritmo 6. Neste caso, a complexidade computacional do algoritmo é de $O(3 M N \cdot \log (M N))$, devido à operação de convolução no domínio da frequência para uma imagem colorida de tamanho $M \times N$.

\subsubsection{Implementação do Modelo de Schechner}

Como foi discutido na Seção 2.2, este modelo considera uma simplificação muito forte do modelo de Jaffe-McGlamery [19], [18] (vide Seção 2.1). Dita simplificação consiste em eliminar o termo referente ao forward-scattering, responsável principalmente pelo borramento da imagem. Esta simplificação é justificada pelos autores, afirmando que, para grandes distâncias, são mais fortes as degradações devidas ao efeito de back-scattering.

A implementação do modelo simplificado de Schechner é muito mais simples e direta, se comparada com a implementação do modelo de Trucco e Olmos-Antillon. Neste modelo, o processo de degradação é levado integralmente no domínio espacial, já que não conta com a operação de convolução referente ao efeito de forward-scattering. Assim, o processo de degradação pelo modelo de Schechner se traduz na aplicação direta da equação (2.21). Neste caso, os parâmetros de entrada correspondem ao coeficiente de atenuação $c$, a contante referente à iluminação da 


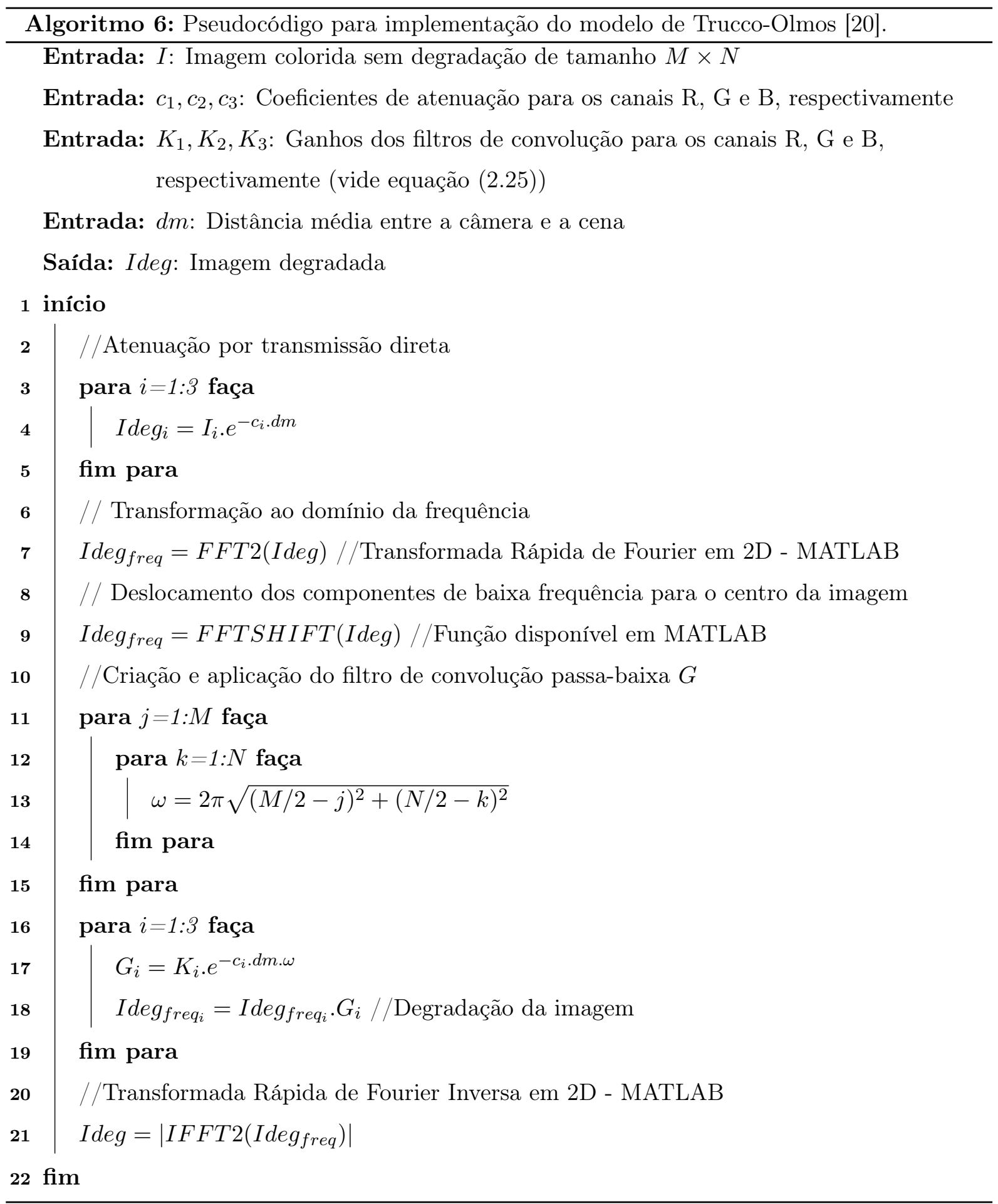


cena $L_{\infty}$, e a distância média entre câmera e objeto $d m$.

Inicialmente, deve-se atenuar a imagem simulando o efeito de transmissão direta dado pela equação 2.31. Posteriormente, ao resultado anterior, deve ser somado o valor da constante dada pelo termo $L_{\infty}(1-\exp (-c . d m))$. Esta última operação possui o maior custo computacional deste modelo de degradação, que apresenta uma complexidade computacional $O(3 M N)$, para uma imagem colorida de tamanho $M \times N$. O processo de degradação pelo modelo de Schechner está descrito no Algoritmo 7 .

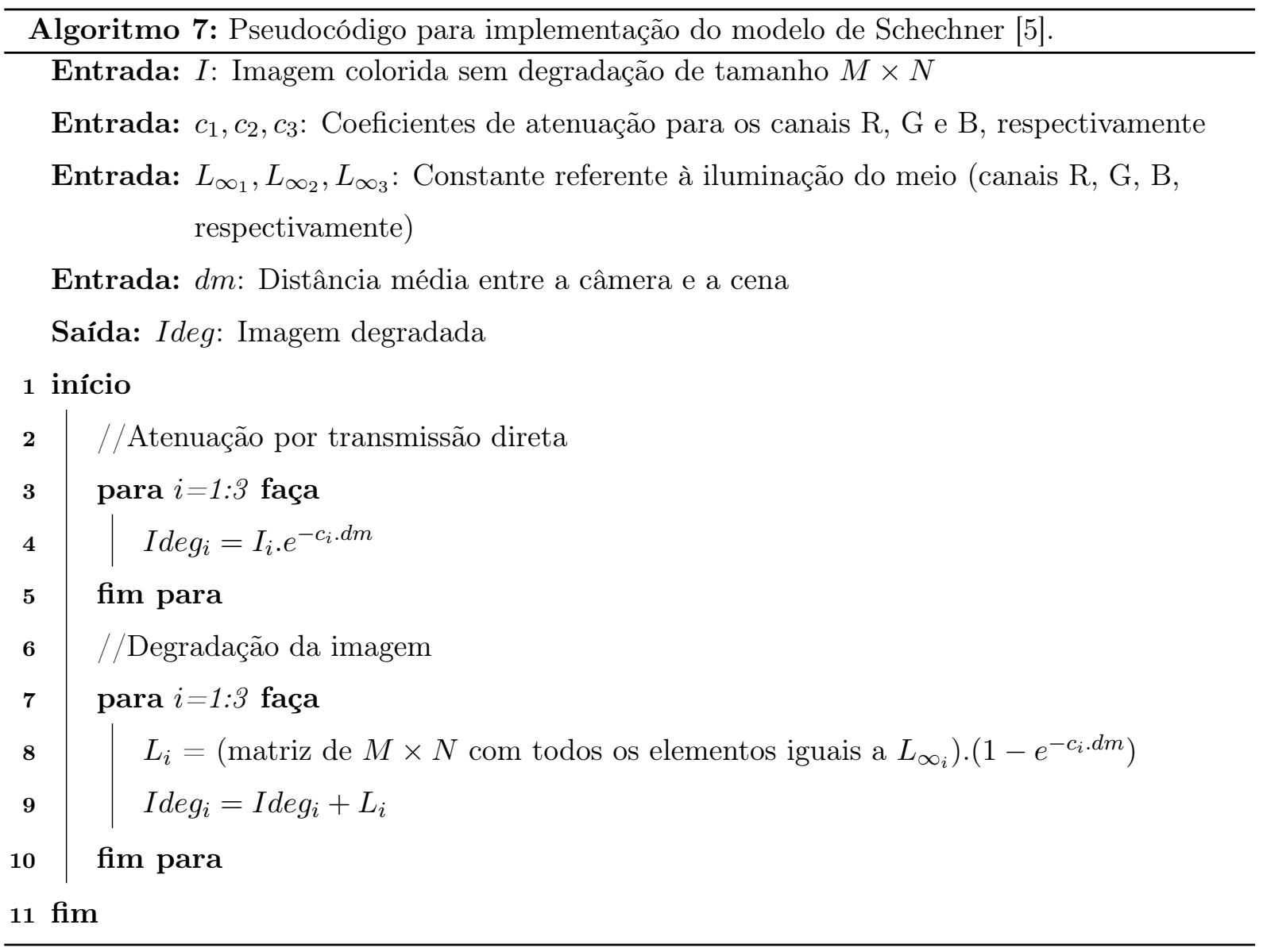

A Figura 5.3 apresenta um exemplo de degradação gerado pela implementação do Algoritmo 7. Nesta figura pode ser observado que a principal degradação apresentada pela imagem (Figura 5.3(b)) é uma perda de contraste considerável em relação à imagem original (Figura 5.3(a)). Isto deve-se a que não foi aplicado nenhum filtro de convolução sobre a imagem [10].

Além disso, na Figura 5.4 é aplicado o mesmo processo de degradação, porém mudando o valor da distância para $d m=0,8 m$. Na Figura pode-se observar que a degradação entre a imagem original e a imagem degradada é mínima, apresentando uma leve perda de contraste, mas sem comprometer significativamente a qualidade da imagem resultante. Este caso $(d m=0,8 m)$ é mais apropriado para o modelo de Trucco-Olmos (vide Algoritmo 6), já que o mesmo está projetado para distâncias na faixa entre 0,2 e 1,0 metros, aproximadamente [20]. 


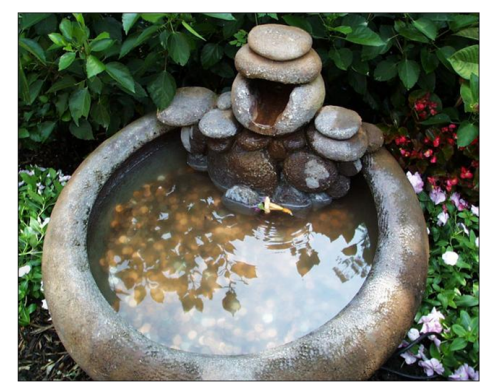

(a)

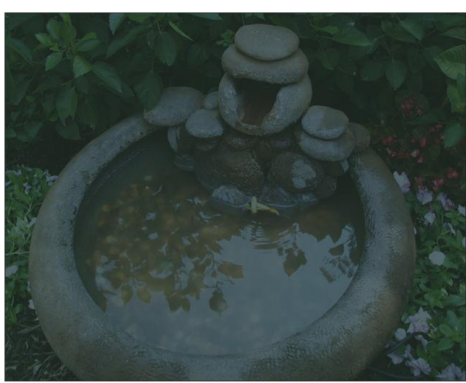

(b)

Figura 5.3. Exemplo de degradação de uma imagem utilizando o modelo de Schechner. (a) Imagem original. (b) Imagem degradada (parâmetros de degradação: $c_{r}=0,5 m^{-1}, L_{\infty_{r}}=35, c_{g}=0,45 m^{-1}, L_{\infty_{g}}=50, c_{b}=$ $\left.0,4 m^{-1}, L_{\infty_{b}}=45, d m=3 m\right)$.

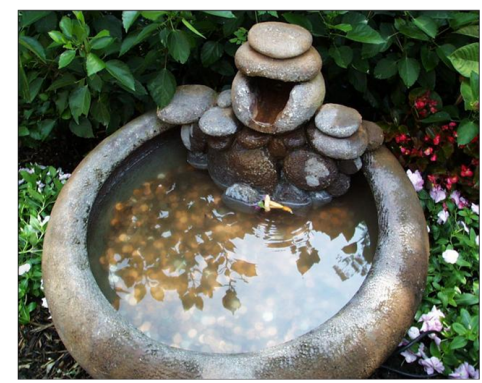

(a)

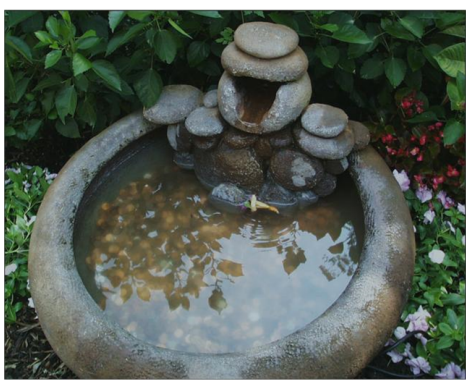

(b)

Figura 5.4. Exemplo de degradação de uma imagem utilizando o modelo de Schechner. (a) Imagem original. (b) Imagem degradada (parâmetros de degradação: $c_{r}=0,5 m^{-1}, L_{\infty_{r}}=35, c_{g}=0,45 m^{-1}, L_{\infty_{g}}=50, c_{b}=$ $\left.0,4 m^{-1}, L_{\infty_{b}}=45, d m=0,8 m\right)$.

\subsubsection{Implementação do Modelo de Wagner}

A simplificação proposta por Wagner [9] apresenta um modelo com as características dos dois modelos anteriores. Este modelo considera tanto o efeito relacionado ao back-scattering quanto o efeito de borramento devido ao forward-scattering (vide Seção 2.4). A complexidade da implementação deste modelo encontra-se na criação e aplicação do filtro de convolução, o qual é desenvolvido como explicado na implementação do modelo de Trucco e Olmos-Antillon e que, como foi discutido na Seção 5.1.1, apresenta um custo computacional $O(3 M N \cdot \log (M N))$ para uma imagem colorida de tamanho $M \times N$.

Para este modelo, os parâmetros de entrada correspondem ao coeficiente de atenuação $c$, o ganho do filtro de convolução $K$, a contante referente à iluminação de meio $L_{\infty}$ e a distância média entre a câmera e o objeto $d m$. O processo, igual que nos outros modelos, inicia com a atenuação devido ao efeito de transmissão direta. Após realizar a atenuação, deve-se levar a imagem 
resultante ao domínio da frequência utilizando a TDF disponível na toolbox de processamento de imagens do MATLAB, deslocando os componentes de baixa frequência para a parte central da imagem. Posteriormente, realiza-se a operação de filtragem multiplicando, ponto a ponto, a imagem atenuada no domínio da frequência com o filtro passa baixa criado utilizando a equação 2.25). Em posse da imagem filtrada no domínio da frequência, esta deve ser levada de novo para o domínio espacial para, assim, realizar a operação referente ao efeito do back-scattering. Dita operação consiste na adição do termo $L_{\infty}\left(1-e^{-c . d m}\right)$ e, desta forma, obter a imagem degradada final. Este procedimento está descrito no Algoritmo 8.

Além disso, a Figura 5.5 apresenta um exemplo de degradação devida à implementação do modelo de Wagner. Neste caso, pode-se observar que a imagem degradada apresenta tanto o borramento devido ao efeito de forward-scattering como também a perda de contraste referente ao back-scattering.

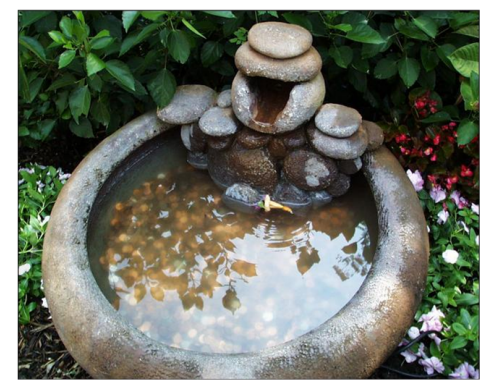

(a)

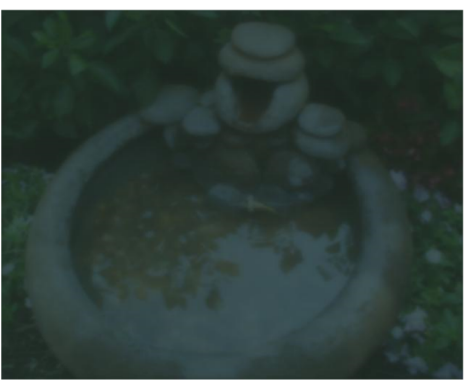

(b)

Figura 5.5. Exemplo de degradação de uma imagem utilizando o modelo de Wagner. (a) Imagem original. (b) Imagem degradada (parâmetros de degradação: $c_{r}=0,5 m^{-1}, K_{r}=0,7, L_{\infty_{r}}=35, c_{g}=0,45 m^{-1}, K_{g}=0,8$, $\left.L_{\infty_{g}}=50, c_{b}=0,4 m^{-1}, K_{b}=0,8, L_{\infty_{b}}=45, d m=3 m\right)$.

\subsubsection{Ferramenta de Degradação de Imagens em Meios Participativos (FDIMP)}

Nas seções anteriores foram expostas as implementações realizadas para os modelos de formação de imagens em meios participativos. Para estas implementações foi desenvolvida a Ferramenta de Degradação de Imagens em Meios Participativos (FDIMP) que permite variar os parâmetros de degradação. Esta ferramenta foi implementada utilizando o MATLAB. A Figura 5.6 apresenta a interface gráfica da FDIMP.

Além das opções básicas para carregar e apresentar as imagens, a ferramenta pode ser dividida em três partes principais. A primeira, marcada pelo quadro verde na Figura 5.6, permite escolher o modelo de formação desejado para a degradação das imagens. As opções disponíveis 


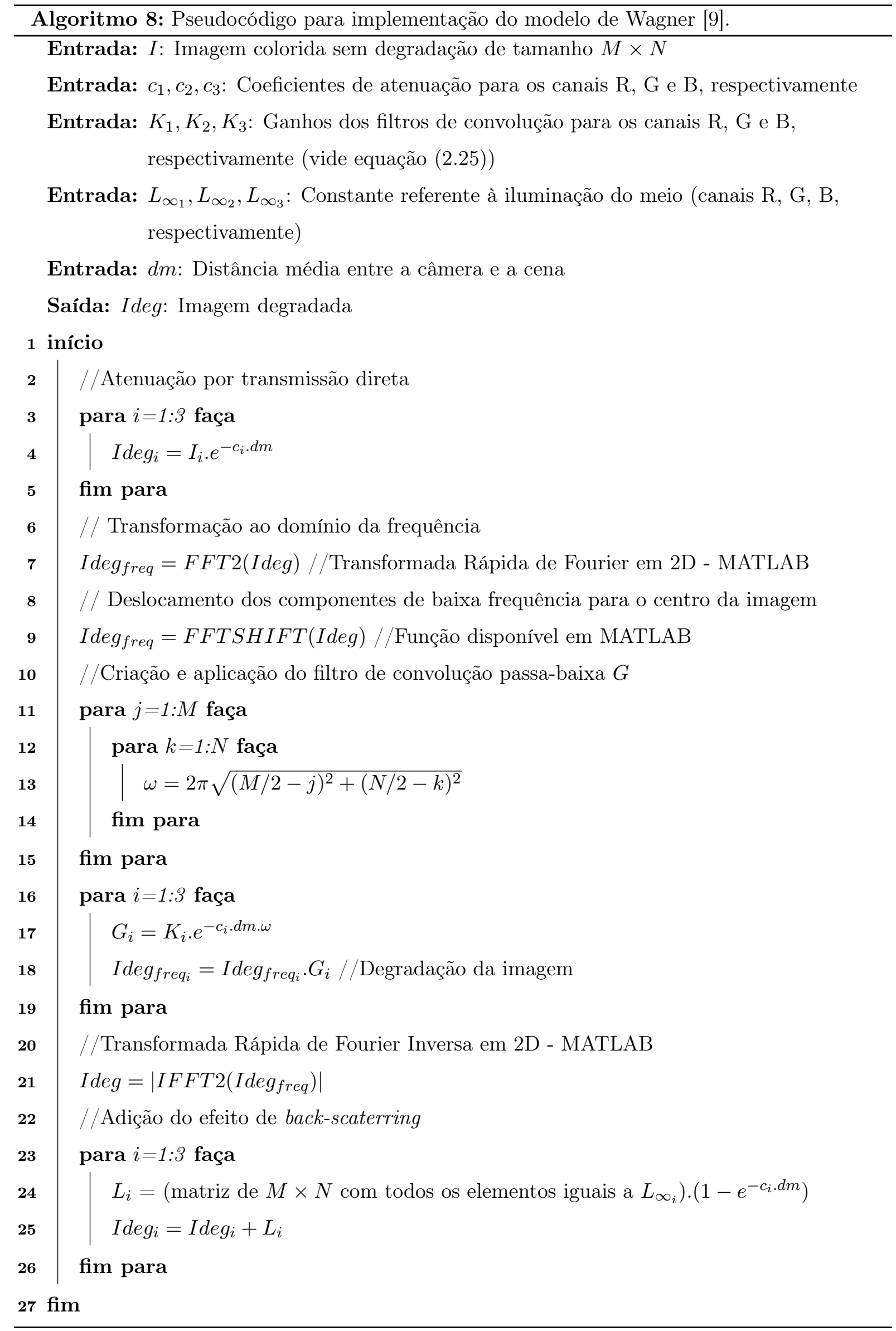




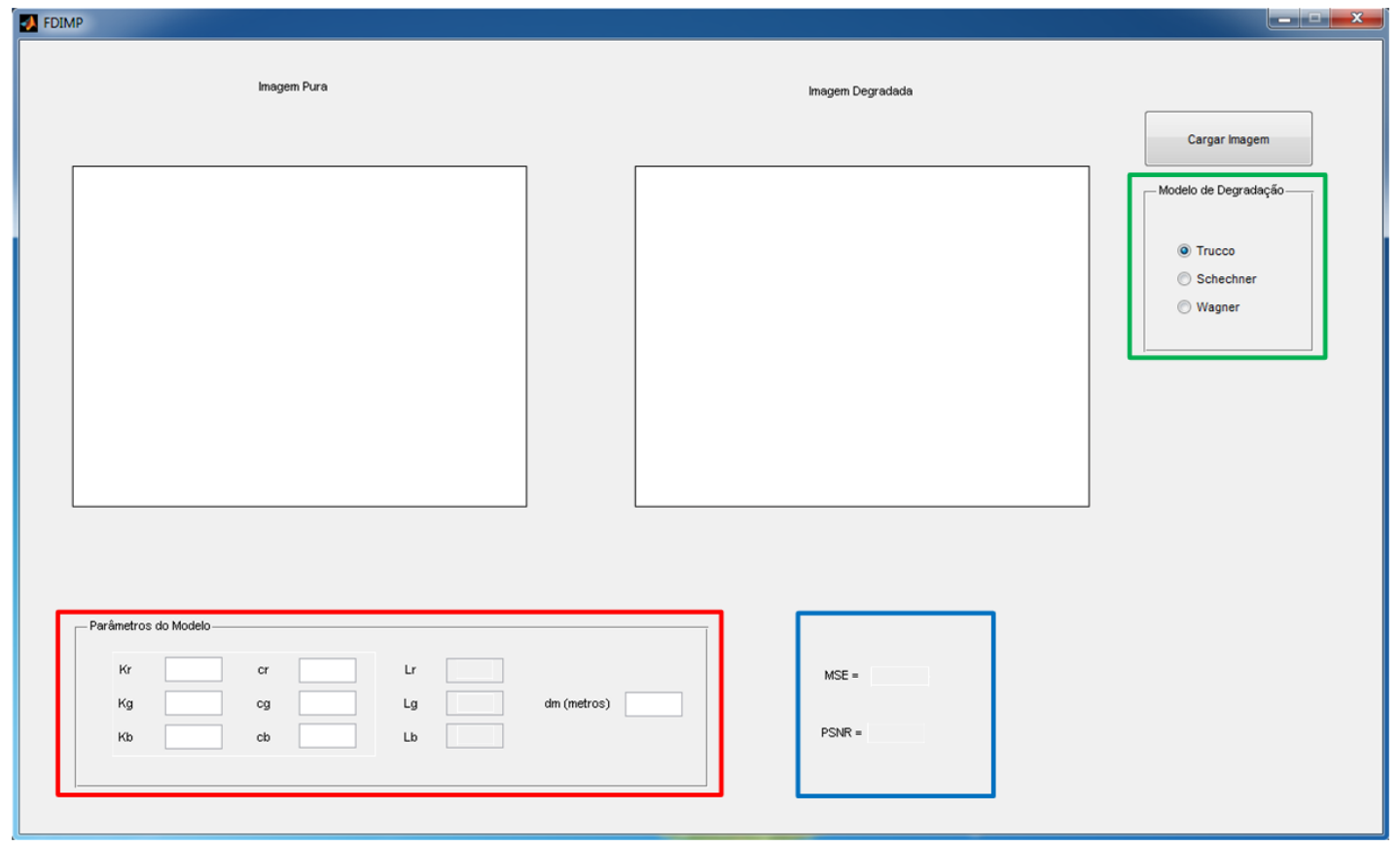

Figura 5.6. Ferramenta de Degradação de Imagens em Meios Participativos - FDIMP (Interface).

correspondem aos três modelos implementados nas Seções 5.1.1, 5.1.2 e 5.1.3. A segunda parte, dentro do quadro vermelho na Figura 5.6. corresponde à definição dos parâmetros de entrada de cada modelo. Assim, se o modelo escolhido para degradação da imagem é marcado na opção Trucco (vide Figura 5.7), somente poderão ser inseridos os valores referentes aos coeficientes de atenuação $c_{r}, c_{g}, c_{b}$ e os ganhos da PSF $K_{r}, K_{g}, K_{b}$. Da mesma forma, se for escolhido o modelo de Schechner (vide Figura 5.8), serão habilitados os parâmetros referentes à constante de iluminação $L_{\infty_{r}}, L_{\infty_{g}}, L_{\infty_{b}}$ e os ganhos da PSF, $K_{r}, K_{g}, K_{b}$, serão desabilitados. Por último, se for marcada a opção para o modelo de Wagner (vide Figura 5.9p, serão habilitadas todas as opções correspondentes aos parâmetros de entrada do algoritmo de degradação. Finalmente, a distância média entre a câmera e o objeto permanece habilitada em todos os modelos, já que a atenuação devida à transmissão direta está considerada em todos eles.

Em uma terceira característica da FDIMP, que corresponde ao quadro azul na Figura 5.6. são apresentados valores da qualidade da imagem degradada. Neste caso fora implementadas as métricas MSE e PSNR discutidas na Seção 4.1. Estas métricas foram escolhidas devido a que conta-se com a imagem original e, portanto, pode ser utilizada uma métrica de avaliação de imagens com referência completa (FR-IQA). 


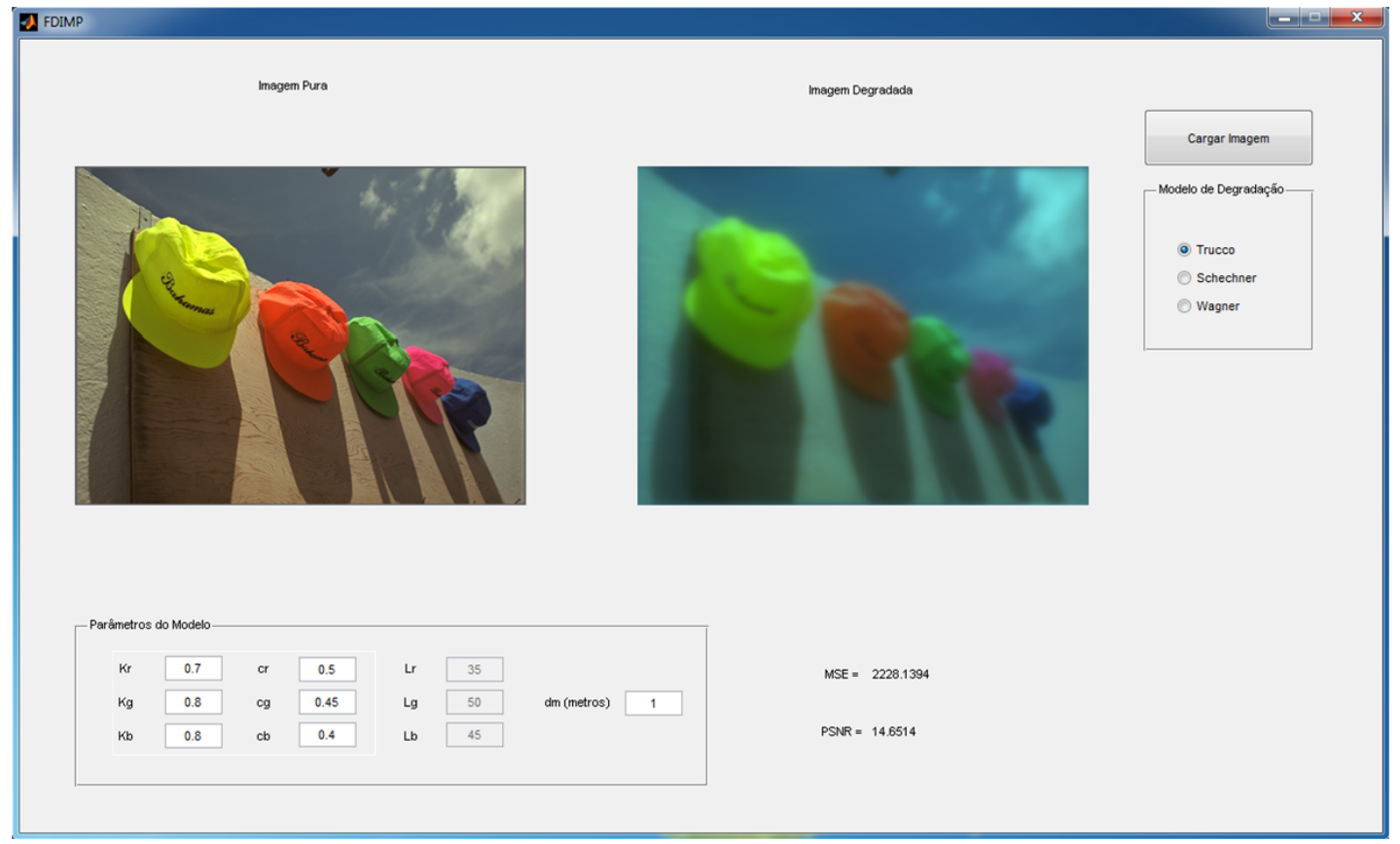

Figura 5.7. Ferramenta de Degradação de Imagens em Meios Participativos - FDIMP (Opção Trucco).

\subsection{Análise de Desempenho das Métricas de AvaliaÇão para Imagens COM DegradaÇões ARTificiais}

Como foi discutido no Capítulo 4, existem dois tipos de métricas para avaliação de qualidade de imagens: (a) com referência completa (FR-IQA) e (b) sem referência (NR-IQA). A diferença entre as duas reside na necessidade (ou não) de uma imagem de referência, de preferência não degradada. As métricas com referência realizam uma comparação entre duas imagens, enquanto as métricas sem referência não precisam uma imagem de referência. Este fato faz com que as métricas de análise de qualidade sem referência sejam mais complexas, do ponto de vista computacional.

Além disso, nos processos de restauração automática de imagens subaquáticas não é possível ter disponibilidade de uma imagem de referência para fins de comparação. Em outras palavras, as métricas de avaliação de imagens com referência não são indicadas para este tipo de processos e, por isto, devem ser testadas métricas sem referência para guiar o processo de otimização.

Assim, esta seção trata sobre as implementações das métricas de avaliação de imagens que foram utilizadas na primeira parte deste trabalho, onde se considera somente imagens degradadas artificialmente, utilizando a FDIMP apresentada na Seção 5.1.4. Inicialmente foram implementadas duas métricas sem referência: (a) Métrica BN-IQA (vide Seção 4.2.1) e (b) métrica NIQE (vide Seção 4.2.2). 


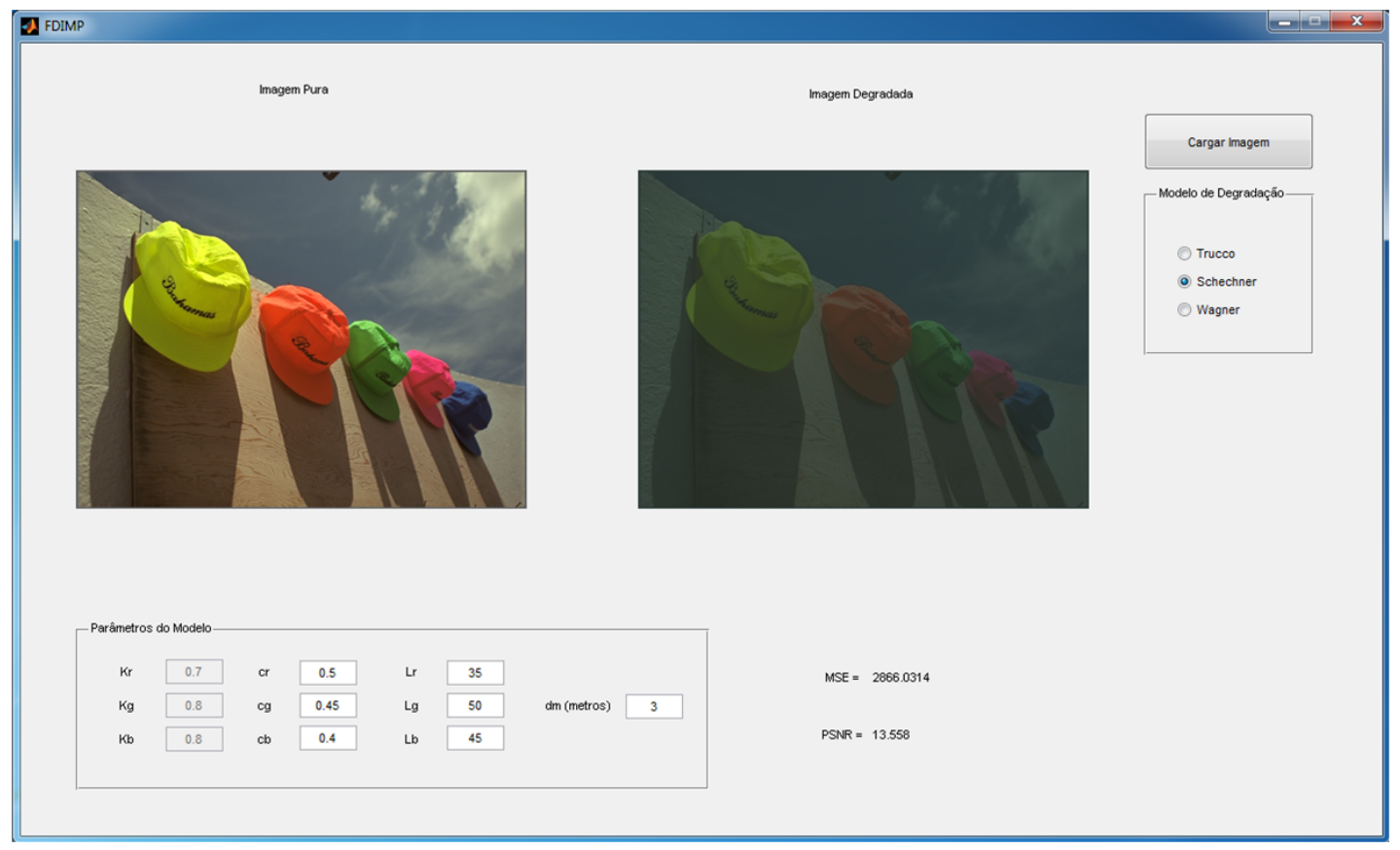

Figura 5.8. Ferramenta de Degradação de Imagens em Meios Participativos - FDIMP (Opção Schechner).

Como foi discutido na Seção 4.4.2, o desempenho das métricas pode ser medido utilizando coeficientes de correlação. Neste trabalho foi utilizado o Coeficiente de Correlação de Spearman $(S R C C)$ para medir a correlação entre os valores gerados pela métrica analisada e o índice de avaliação subjetiva (vide Seção 4.3). Assim, todas as imagens utilizadas nesta etapa do trabalho pertencem ao banco de imagens LIVE [101. Este banco de imagens consta de 29 imagens de referência, sem distorção aparente. Além disso, o banco também conta com 779 versões degradadas a partir das imagens de referência com diferentes tipos de distorções (vide Seção 4.4.1) e suas respectivas avaliações subjetivas especificadas utilizando o índice DMOS Difference Mean Opinion Scores, permitindo assim, realizar a análise de desempenho baseada em correlação.

A primeira métrica implementada foi a BN-IQA apresentada na Seção 4.2.1. Esta métrica está focada no cálculo de quantidades que representa o nível do ruído e borramento que possui uma imagem. Para o treinamento da métrica foram utilizadas 15 imagens com ruído branco e 15 com borramento Gaussiano, para um total de 30 imagens degradadas de treinamento (todas elas disponíveis no banco LIVE [101]). Estes tipos de degradação foram escolhidos para treinar o sistema, já que são as principais degradações que sofre uma imagem em ambientes subaquáticos [10].

Neste contexto, o treinamento consistiu em obter os valores Blur mean, Blur $_{\text {ratio }}$, Noise $_{\text {mean }}$, Noise ratio, apresentados na equação 4.18) (vide Seção 4.2.1).

Objetivando definir os valores dos pesos $\omega_{1}, \omega_{2}, \omega_{3}, \omega_{4}$ da equação 4.18), foi implementado 


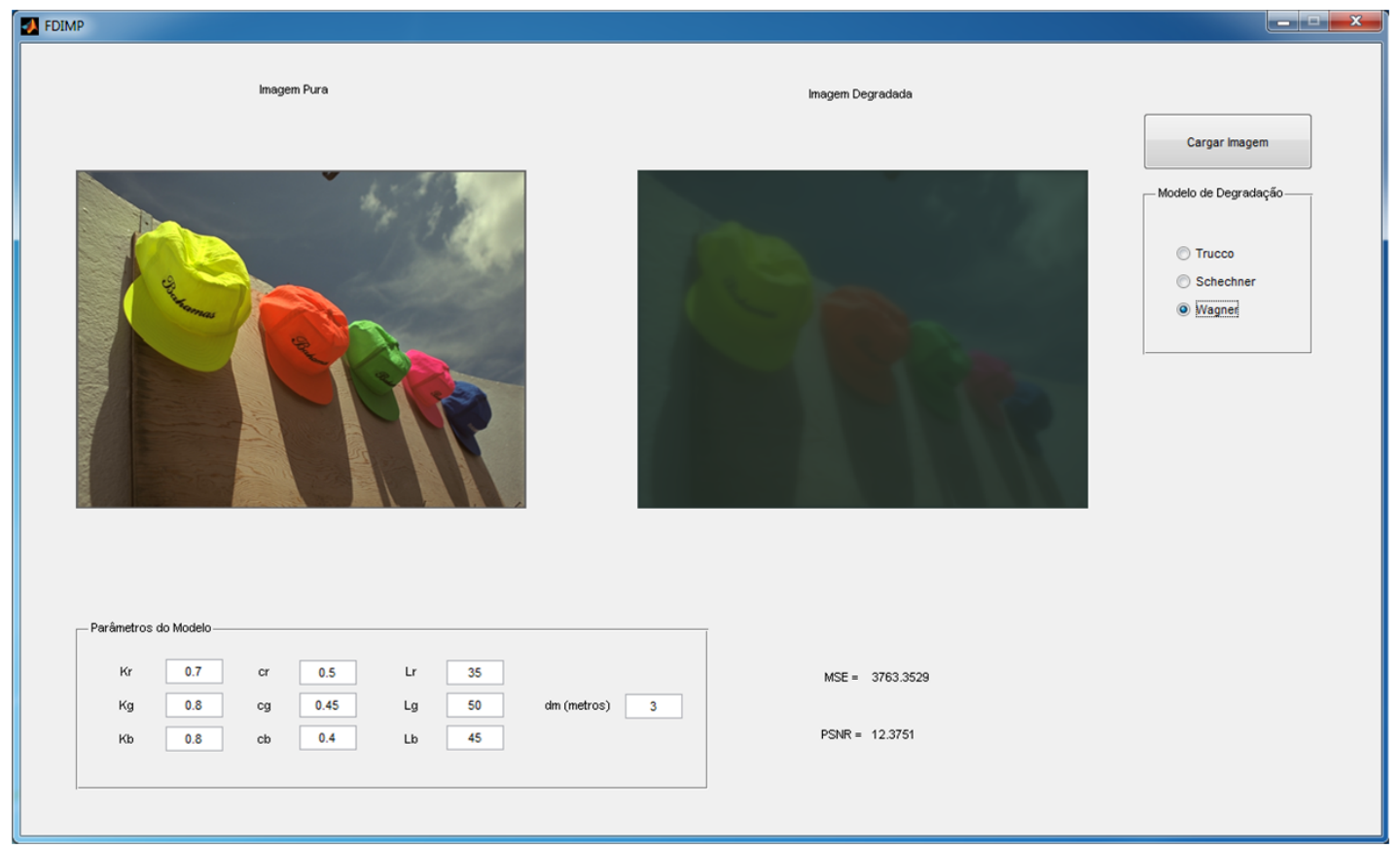

Figura 5.9. Ferramenta de Degradação de Imagens em Meios Participativos - FDIMP (Opção Wagner).

o algoritmo de otimização bio-inspirado PSO (vide Seção 3.2), utilizando o coeficiente SRCC como função objetivo. Neste caso, busca-se maximizar a correlação SRCC entre o índice DMOS fornecido no banco LIVE e o valor de qualidade encontrado pela métrica para as imagens com borramento e ruído branco do banco LIVE. Assim, o algoritmo PSO foi rodado 32 vezes, calculando assim a média dos 32 valores encontrados para cada peso. Os valores estimados foram $\omega_{1}=1,3187, \omega_{2}=2,4223, \omega_{3}=-1,0295$, e $\omega_{4}=-0,7162$. A correlação média obtida no processo de otimização foi de 0,8750 .

Com os pesos $\omega_{1}, \omega_{2}, \omega_{3}, \omega_{4}$ calculados pelo PSO, o sistema foi testado com 159 imagens degradadas com ruído branco e 159 imagens degradadas com borramento Gaussiano do banco LIVE. Estas imagens correspondem a um conjunto diferente àquele utilizado para o treinamento da métrica. O coeficiente de correlação SRCC entre os valores obtidos para a métrica BN-IQA e os índices de avaliação subjetiva DMOS fornecidos pelo banco de imagens foi de 0,8193 .

Adicionalmente, foi implementada a métrica NIQE, discutida na Seção 4.2.2. Esta técnica está baseada no cálculo estatístico de características NSS de imagens naturais. Para o treinamento da métrica NIQE foram utilizadas as 29 imagens de referência do banco de imagens LIVE [101], já que, como foi discutido na Seção 4.2.2, o treinamento desta métrica consiste em criar um modelo baseado em imagens com pouca ou nenhuma distorção [78]. Após realizado o treinamento, a métrica foi testada para 87 imagens degradadas com ruído branco e 87 imagens degradadas por borramento Gaussiano, para um total de 174 imagens degradadas. Assim como na métrica BN-IQA, estes tipos de degradação foram escolhidos por serem os principais efeitos 
Tabela 5.1. Coeficientes de correlação SRCC obtidos para cada uma das métricas.

\begin{tabular}{|l|c|}
\hline Métrica & SRCC \\
\hline NIQE & $\mathbf{0 , 9 4 9 7}$ \\
\hline BN-IQA (Treinamento) & 0,8750 \\
\hline BN-IQA (Teste) & 0,8193 \\
\hline PSNR (com referência) & 0,9198 \\
\hline
\end{tabular}

gerados na degradação das imagens subaquáticas [10]. Finalmente, o índice de correlação SRCC entre os valores encontrados pela métrica NIQE e os índices DMOS fornecido pelo banco de imagens foi de 0,9497 .

Finalmente, objetivando realizar uma comparação entre as métricas NIQE e BN-IQA e uma métrica de avaliação com referência (FR-IQA), foi realizada a análise de correlação para o PSNR (vide Seção 4.1). Esta análise foi realizada com um total de 348 imagens do banco LIVE, divididas em 174 imagens degradadas com ruído branco e 174 com ruído Gaussiano. O SRCC encontrado para esta métrica foi de 0,9198. Como foi mencionado anteriormente, esta métrica foi implementada somente para fins de comparação com as métricas NIQE e BN-IQA, já que na área de estudo deste trabalho não se conta com imagens de referência.

A Tabela 5.1 apresenta um resumo dos resultados obtidos a partir da análise de correlação das métricas supracitadas.

Como pode ser observado na Tabela 5.1, a métrica com maior coeficiente de correlação é a NIQE com um SRCC de 0,9497. É importante ressaltar que este valor é maior que o obtido para o PSNR (0,9198), sendo esta uma métrica com referência completa. Além disso, os valores obtidos para a métrica baseada em ruído e borramento BN-IQA são menores que as outras duas métricas. Porém, isto não significa que as métricas apresentem baixo desempenho. Métricas sem referência com estes valores de correlação são consideradas aceitáveis e podem ser usadas para ter uma boa estimativa da qualidade de uma imagem. Devido a estes resultados, foi possível definir a métrica NIQE como função objetivo para guiar o processo de restauração de degradações artificiais apresentado no Capítulo 6 .

\subsection{CRIAÇÃo DE UM BANCo de IMAgens SubaquÁticas}

Objetivando aplicar as estratégias de restauração baseadas em otimização bio-inspirada em imagens reais, é necessário contar com um banco de imagens subaquáticas que permita realizar uma análise subjetiva de qualidade. Esta análise permitirá realizar um estudo de correlação 
para as métricas de avaliação. Isto justifica-se levando em conta que, a partir deste momento, todas as imagens terão degradações reais e a análise objetiva deve ser validada para este tipo de degradações. Por esta razão, no contexto deste trabalho, foi realizado um experimento para adquisição e avaliação de um banco de imagens subaquáticas. Este banco está formado por 85 imagens de referência (sem água) e 255 imagens com diferentes níveis de degradação. A análise subjetiva foi realizada para 135 imagens degradas. O banco de imagens subaquáticas foi chamado de UID-LEIA (Underwater Image Database - LEIA). Os detalhes sobre a adquisição e avaliação subjetiva das imagens serão apresentados nesta seção.

\subsubsection{Aquisição das Imagens}

A primeira parte desta etapa consistiu na aquisição das imagens referentes ao banco. Os experimentos foram realizados com o auxílio de um aquário contendo água com diferentes níveis de turbidez por experimento. A montagem experimental pode ser vista a Figura 5.10. Para a adquisição das imagens foi utilizada uma câmera comercial Canon SX50HS e foi considerada iluminação natural (sem fontes de luz artificial).
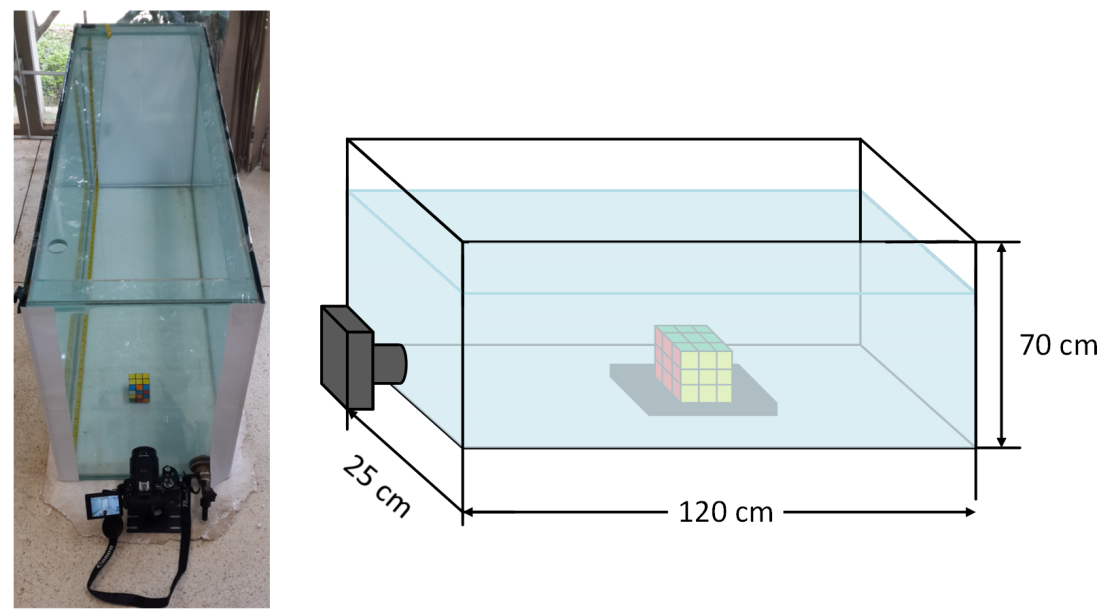

Figura 5.10. Montagem experimental para adquisição do banco de imagens.

Inicialmente, o experimento consistiu em adquirir imagens de referência. As imagens de referência, neste contexto, não devem apresentar nenhuma degradação significativa. Por esta razão, estas imagens foram adquiridas no aquário sem água. O procedimento consistiu em colocar vários objetos a diferentes distâncias em relação à câmera. Estas distâncias vão desde os 20 até os 100 centímetros com variações de 5 centímetros em cada captura. Com este procedimento foram aquiridas 85 imagens de referência em total. A Figura 5.11 apresenta alguns exemplos das imagens aquiridas neste experimento.

A segunda parte do experimento consistiu em aquirir imagens degradadas. Para isto, os objetos foram submersos em água com diferentes níveis de turbidez. Inicialmente, as imagens 

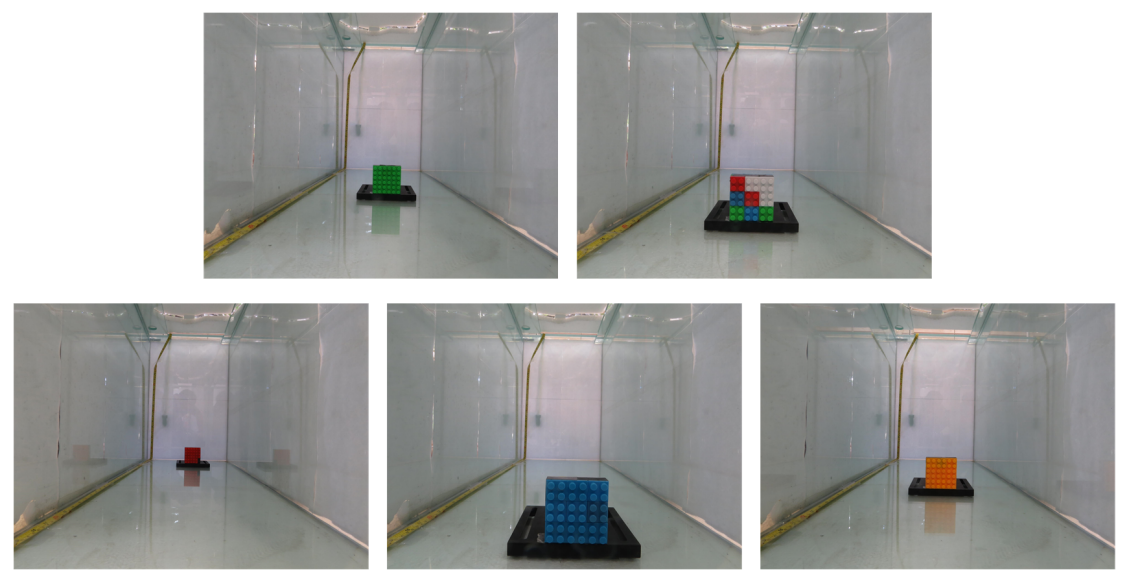

Figura 5.11. Imagens de referência adquiridas para o banco de imagens.

foram tomadas com água limpa seguindo o mesmo procedimento que foi realizado para as imagens de referência. Posteriormente, outras imagens foram adquiridas com água com diferentes níveis de visibilidade. Um total de 255 imagens foram adquiridas neste processo. Alguns exemplos destas imagens são apresentados na Figura 5.12 .
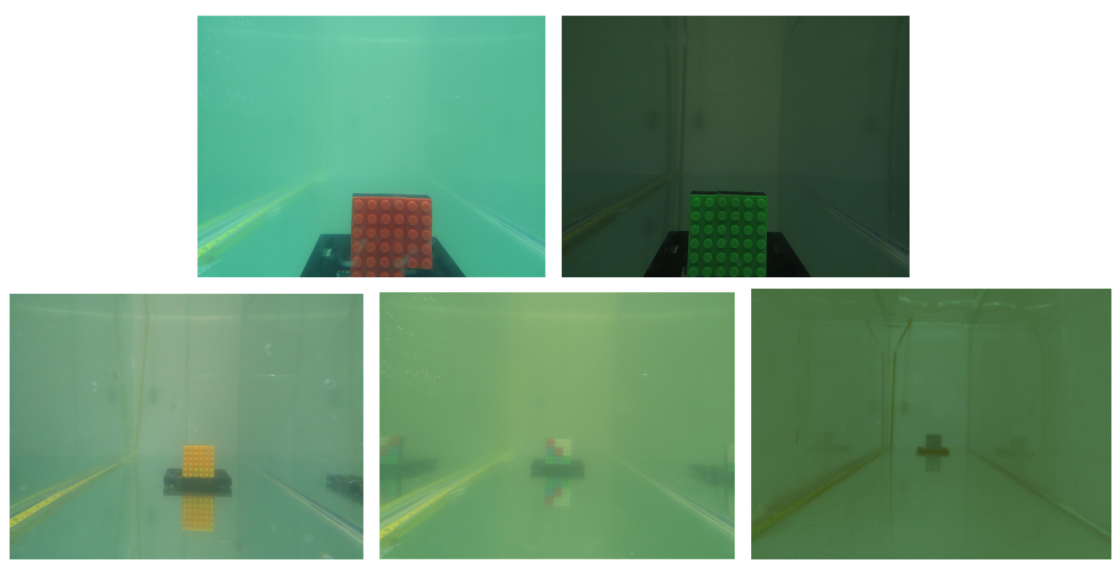

Figura 5.12. Imagens degradadas adquiridas para o banco de imagens.

Entre estas imagens foram escolhidas um total de 135 imagens para o experimento de avaliação subjetiva. Esta redução do conjunto de imagens justifica-se levando em conta o tempo necessário para avaliar o conjunto de imagens, já que um tempo elevado na etapa de avaliação pode conduzir a avaliações erradas devido à fadiga dos avaliadores, como está descrito na norma ITUR BT.500 [78]. Os detalhes sobre o experimento de avaliação subjetiva serão apresentados na próxima seção.

\subsubsection{Avaliação Subjetiva do Banco UID-LEIA}

Para a avaliação subjetiva foi utilizado o software Presentation da Neuro Behavioral Systems - neurobs [109]. Presentation é um programa de estimulação e controle de experimentos para 
Tabela 5.2. Informações sobre o experimento de avaliação subjetiva.

\begin{tabular}{|c|c|}
\hline Metodologia & Estímulo Simples (SS) \\
\hline Referência & 6 imagens (vide Tabela B.1 \\
\hline Treinamento & 6 imagens (vide Tabela B.2 \\
\hline Avaliação & 135 imagens (vide Tabela B.3 \\
\hline Índice & MOS \\
\hline Escala de avaliação & Escala contínua de degradação \\
& 24 bits 10 (vixel coloridas \\
\hline Profundidade de cor & JPEG \\
\hline Compressão & 32 avaliadores sem experiencia em PDI \\
\hline Avaliadores & 1024×768 \\
\hline Resolução da imagem & Aprox. 3 vezes a altura da imagem \\
\hline Distância entre avaliador e Monitor & LG LED de 21 polegadas \\
\hline Monitor & resolução máxima de 1920×1080 \\
\hline Iluminação da sala & Escura \\
\hline
\end{tabular}

neurociência. Ele é executado em qualquer PC com Windows, oferecendo estímulos auditivos, visuais e multimodais com precisão temporal inferior a milissegundos [109]. Nesta plataforma foi programado um teste subjetivo de estímulo único (vide Seção 4.3), sendo os índices gerados do tipo MOS (Mean Opinion Score) (vide equação (4.39)). O experimento foi dividido em três partes: (a) apresentação das imagens de referência, (b) treinamento e (c) avaliação, seguindo a norma ITUR BT.500, a qual propõe diferentes métodos para análise subjetiva de qualidade de imagens de televisão e contem informação sobre as condições de visualização, instruções sobre a metodologia do experimento, materiais e a apresentação de resultados. Um resumo sobre os materiais e metodologias utilizados neste experimento são apresentados na Tabela 5.2 .

A primeira parte do experimento, referente à apresentação das referências, consiste na apresentação aleatória de 6 imagens de referência (sem água). O objetivo principal desta etapa é mostrar para o avaliador quais são as imagens que, no contexto deste trabalho, apresentariam uma qualidade ótima. Neste ponto são ressaltadas as características nas quais o observador deve prestar maior atenção. As informações sobre as imagens utilizadas para esta etapa podem ser encontradas na Tabela B.1 do Apêndice B.

Posteriormente, a etapa de treinamento visa familiarizar ao observador com a interface gráfica da plataforma, assim como também com o processo de avaliação. Nesta etapa são apresentadas 6 imagens degradadas que não fazem parte do conjunto de avaliação na etapa posterior. Nesta 
parte do experimento, são indicados para o observador quais são os tipos de distorção que são interessantes na avaliação deste tipo de imagens, assim como também é apresentada a escala de avaliação (vide Figura 5.13). As informações sobre as imagens utilizadas para esta etapa podem ser encontradas na Tabela B.2 do ApêndiceB.

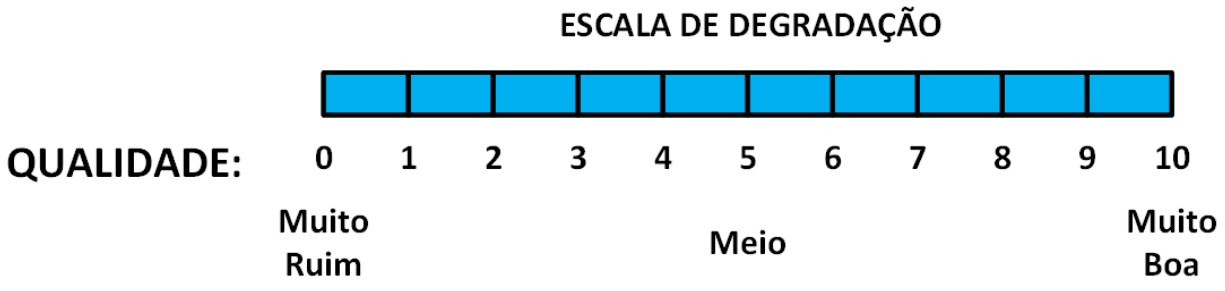

Figura 5.13. Escala de degradação utilizada nas etapas de treinamento e avaliação do experimento.

Finalmente, a etapa de avaliação é a parte central do experimento. Nesta etapa são apresentadas 135 imagens com diferentes níveis de degradação e com os objetos a diferentes distâncias. A apresentação destas imagens é aleatória, o que certifica que para cada observador se apresentarão em uma ordem diferente. Cada imagem é apresentada por 6 segundos e, após este tempo, a imagem desaparece e estará disponível uma barra de avaliação. Esta barra representa o nível de degradação da imagem com valores entre 0 e 10, sendo 0 a melhor qualidade e 10 a pior. Por último, estes valores são salvos pelo programa de avaliação junto com o nome do arquivo que representa a imagem.

Este experimento foi realizado para um total de 32 pessoas sem problemas visuais em um quarto fechado e escuro. O tempo médio de duração do experimento foi de 40 minutos por avaliador. Foi utilizado um monitor de 21 polegadas com tecnologia LED e com uma resolução máxima de $1920 \times 1080$. O resultado final consistiu calcular o valor médio das 32 avaliações para cada imagem, obtendo assim 135 valores MOS (vide equação 4.39) (um para cada imagem). As informações sobre as imagens utilizadas na etapa de avaliação, assim como os índices MOS finais obtidos para cada imagem, podem ser encontrados na Tabela B.3 do Apêndice B.

\subsection{Análise de Desempenho das Métricas de AvaliaÇão para IMAGENS DO BANCO UID-LEIA}

Como foi discutido anteriormente, a métrica de avaliação de qualidade de imagens é uma parte fundamental do processo de restauração baseado em otimização, já que esta atua como função objetivo. Além disso, a análise de desempenho apresentada na Seção 5.2 para as métricas BN-IQA e NIQE deve ser realizada de novo. Embora os resultados da análise de correlação obtidos para estas métricas tenha apresentado bom desempenho, as imagens do banco UID- 
Tabela 5.3. Valores estimados no treinamento da métrica UCIQE.

\begin{tabular}{|c|c|c|c|c|c|}
\hline & $c_{1}$ & $c_{2}$ & $c_{3}$ & SRCC (treinamento) & SRCC (teste) \\
\hline PSO & 1,2840 & 1,8746 & 1,7205 & $\mathbf{0 , 9 2 6 4}$ & $\mathbf{0 , 8 9 9 2}$ \\
\hline ABC & 1,9115 & 1,5327 & 1,2474 & 0,8541 & 0,7430 \\
\hline DE & 1,3002 & 1,9107 & 1,7309 & 0,9025 & 0,8622 \\
\hline
\end{tabular}

LEIA são imagens reais subaquáticas, o que não é o caso do banco LIVE, cujas imagens foram degradadas artificialmente. Por esta razão, é necessário analisar o desempenho das métricas para este tipo de degradações reais.

Para esta análise também foram implementadas as métricas UCIQE e PUIQ, apresentadas nas Seções 4.2.4 e 4.2.5, respectivamente. Estas métricas foram projetadas especificamente para ambientes subaquáticos [77], [90].

A métrica UCIQE está baseada no espaço de cores CIELab e consiste em um modelo cromático normalmente utilizado para descrever todas as cores que podem ser captadas pelo olho humano [77] (vide Seção 4.2.4. Após a transformação da imagem degradada para o espaço CIELab, são calculados os valores de $\sigma_{c}, c_{L}$ e $\mu_{s}$, que correspondem ao desvio padrão do chroma (equação (4.34)), o contraste da Luminância (calculada como a diferença entre os valores do $1 \%$ dos pixeis da parte inferior e o $1 \%$ dos pixeis da parte superior [77]) e a saturação média (equação (4.36)), respectivamente. De posse dos valores descritos anteriormente, se procede a calcular o conjunto de pesos $\left\{c_{1}, c_{2}, c_{3}\right\}$ apresentados na equação 4.38. Além disso, o banco UID-LEIA conta com um total de 135 imagens degradadas (vide Seção 5.3), cada uma com um índice de qualidade MOS. Para o treinamento da métrica foram utilizadas 60 imagens do banco UID-LEIA. Nesse contexto, foram testados 3 algoritmos de otimização visando encontrar os melhores valores do conjunto $\left\{c_{1}, c_{2}, c_{3}\right\}$ que apresentem um valor máximo para o coeficiente de correlação SRCC (vide Seção 4.4.2). Os algoritmos de otimização testados neste processo foram o PSO, o ABC e o DE, apresentados nas Seções 3.2, 3.3 e 3.4, respectivamente. Cada algoritmo foi executado 10 vezes e os valores de $\left\{c_{1}, c_{2}, c_{3}\right\}$ correspondem à média dos valores obtidos nas 10 execuções. A Tabela 5.3 apresenta os valores de $\left\{c_{1}, c_{2}, c_{3}\right\}$ estimados nesta etapa, assim como os valores médios de correlação encontrados pelo pelos algoritmos de otimização. Após o treinamento, foi realizada a análise de correlação para as 75 imagens restantes do banco UID-LEIA. Os valores de correlação obtidos foram 0,8992, 0,7430 e 0,8622 para os valores obtidos com o PSO, o ABC e o DE, respectivamente. Na Tabela 5.3 pode-se observar que o melhor resultado, tanto na etapa de treinamento como na etapa de teste, foi alcançado pelo PSO, o qual apresentou maiores valores de correlação.

Adicionalmente, foi implementada a métrica PUIQ, apresentada na Seção 4.2 .5 (vide Algo- 
Tabela 5.4. Valores estimados no treinamento da métrica PUIQ.

\begin{tabular}{|c|c|c|c|c|c|}
\hline & $W_{1}$ & $W_{2}$ & $W_{3}$ & SRCC (treinamento) & SRCC (teste) \\
\hline PSO & 0,1548 & 0,1645 & 0,6807 & $\mathbf{0 , 6 1 5 7}$ & 0,5905 \\
\hline ABC & 0,1276 & 0,2051 & 0,6673 & 0,6010 & 0,5661 \\
\hline DE & 0,1651 & 0,2104 & 0,6245 & 0,5984 & $\mathbf{0 , 6 0 0 2}$ \\
\hline
\end{tabular}

ritmo 5). Esta métrica também deve ser treinada para encontrar o conjunto de pesos $\left\{W_{1}, W_{2}, W_{3}\right\}$. Dito treinamento foi realizado da mesma forma que para a métrica UCIQE. Foram utilizados os algoritmos de otimização bio-inspirada PSO, ABC e DE para maximizar a correlação SRCC com um conjunto de variáveis de decisão dado por $\left\{W_{1}, W_{2}, W_{3}\right\}$ com um conjunto de 60 imagens degradadas do banco UID-LIVE. Na Tabela 5.4 são apresentados os valores obtido para $\left\{W_{1}, W_{2}, W_{3}\right\}$ no processo de otimização, assim como os valores de correlação alcançados nesta etapa. Também são apresentados os resultados referentes ao teste da métrica após o treinamento, utilizando as 75 imagens restantes. Esta métrica apresentou valores de correlação muito baixos em comparação com a métrica UCIQE. Neste caso, a máxima correlação na etapa de teste também foi alcançada pelo algoritmo PSO com um valor de 0,6157. No entanto, na etapa de teste, o melhor valor foi alcançado utilizando os valores de $\left\{W_{1}, W_{2}, W_{3}\right\}$ estimados com o algoritmo DE.

Visando testar outras possibilidades, decidiu-se implementar e testar as métricas BN-IQA, NIQE e a Distribuição de Contraste apresentadas nas Seções 4.2.1, 4.2.2 e 4.2 .3 , respectivamente, e que foram implementadas em etapas anteriores deste trabalho (vide Seção 5.2), próprias para avaliação sem referência.

Nesta etapa do trabalho, a métrica de medição de ruído e borramento BN-IQA foi treinada utilizando os algoritmos PSO, ABC e DE. Para isto, foram utilizadas 60 imagens degradadas do banco UID-LEIA objetivando estimar os valores de $\left\{w_{1}, w_{2}, w_{3}, w_{4}\right\}$ que permitam obter um valor máximo para o coeficiente de correlação SRCC. Os valores de $\left\{w_{1}, w_{2}, w_{3}, w_{4}\right\}$ estimados e os valores de correlação, tanto na etapa de treinamento como na etapa de teste são apresentados na Tabela 5.5. Para esta métrica os melhores resultados, tanto no treinamento como na etapa de teste, foram alcançados pelo algoritmo DE, já que apresenta os maiores coeficientes de correlação.

Além disso, a métrica de avaliação NIQE foi treinada utilizando as 85 imagens de referência do banco UID-LIVE, que correspondem às imagens sem água. Este treinamento foi realizado para diferentes tamanhos dos blocos. Após o treinamento, a análise de desempenho foi realizada utilizando as 135 imagens degradadas do banco UID-LEIA. O melhor valor de correlação foi alcançado para um tamanho de bloco de $36 \times 36$ e a correlação obtida foi de 0,9357 .

A métrica de Distribuição de Contraste Local não necessita uma etapa de treinamento, por- 
Tabela 5.5. Valores estimados no treinamento da métrica BN-IQA.

\begin{tabular}{|c|c|c|c|c|c|c|}
\hline & $w_{1}$ & $w_{2}$ & $w_{3}$ & $w_{4}$ & $\begin{array}{c}\text { SRCC } \\
\text { (treinamento) }\end{array}$ & $\begin{array}{c}\text { SRCC } \\
\text { (teste) }\end{array}$ \\
\hline PSO & 1,8570 & 1,9954 & $-1,0147$ & $-1,0029$ & 0,6807 & 0,6559 \\
\hline $\mathbf{A B C}$ & 1,8291 & 1,9801 & $-0,8916$ & $-1,1850$ & 0,6749 & 0,6726 \\
\hline $\mathbf{D E}$ & 1,7245 & 1,9743 & $-0,9951$ & $-0,9842$ & $\mathbf{0 , 6 9 0 1}$ & $\mathbf{0 , 6 8 6 7}$ \\
\hline
\end{tabular}

Tabela 5.6. Desempenho das métricas de avaliação objetivas implementadas no contexto deste trabalho.

\begin{tabular}{|c|c|c|}
\hline Métrica & $\begin{array}{c}\text { SRCC máximo } \\
\text { (etapa de Teste) }\end{array}$ & $\begin{array}{c}\text { Algoritmo de } \\
\text { Treinamento }\end{array}$ \\
\hline UCIQE & 0,8992 & PSO \\
\hline PUIQ & 0,6002 & DE \\
\hline BN-IQA & 0,6867 & DE \\
\hline NIQE & $\mathbf{0 , 9 3 5 7}$ & Não Aplica \\
\hline $\begin{array}{c}\text { Distribuição } \\
\text { de Contraste Local }\end{array}$ & 0,4138 & Não Aplica \\
\hline
\end{tabular}

tanto, a análise de correlação foi realizada diretamente sobre o conjunto de 135 imagens degradadas do banco UID-LEIA. Neste caso, a métrica apresentou o valor de correlação mais baixo em comparação às outras métricas. O valor do coeficiente SRCC foi de 0,4138. A Tabela 5.6 apresenta um resumo dos valores máximos de desempenho, em etapa de teste, encontrados para todas as métricas implementadas. Pode ser observado que os melhores desempenhos foram apresentados pelas métrica NIQE e UCIQE com correlações de 0,9357 e 0,8992, respectivamente. Além disso, o desempenho das outras métricas não foi aceitável. Por esta razão, as métricas NIQE e UCIQE foram escolhidas para realizar os testes de restauração das imagens do banco UID-LEIA, que serão apresentados no Capítulo 7.

\subsection{Considerações Finais do Capítulo}

Neste capítulo foram apresentadas as ferramentas que serão utilizadas para os processos de simulação e restauração de imagens subaquáticas. Inicialmente foram apresentadas as implementações dos modelos de degradação de imagens para meios participativos. No contexto deste trabalho, foram implementadas as simplificações de Trucco-Olmos, Schechner e Wagner, apresentadas nos Algoritmos 6, 7, 8, respectivamente. Estas implementações levaram ao desenvolvimento da Ferramenta de Degradação de Imagens em Meios participativos (FDIMP), apresentada 
na Seção 5.1 .4 .

Em relação aos modelos implementados, os modelos de Trucco-Olmos e Wagner mostram-se mais relevantes devido ao tipo de degradações simuladas. Já o modelo simplificado de Schechner não simula borramento nas imagens degradas, sendo que esta é uma característica muito importante das imagens em meios subaquáticos.

Neste capítulo foi apresentada também uma análise de correlação que objetiva medir o desempenho das métricas de avaliação de imagens apresentadas na Seção 4.2 . Esta análise foi realizada tanto para imagens do banco LIVE, que apresentam degradações artificiais, como também para o banco UID-LEIA, que está constituído por imagens com degradações reais. Tanto para os testes com degradações artificiais (vide Seção 5.2), como para os testes com imagens do banco UID-LEIA (vide Seção 5.4), a métrica NIQE apresentou o melhor desempenho.

Por outra parte, o banco de imagens UID-LEIA é uma contribuição importante deste trabalho, já que, atualmente, não se tem disponibilidade de bancos de imagens subaquáticas com análise subjetiva de qualidade. Este banco permitiu realizar uma análise de desempenho das métricas de avaliação sem referência implementadas para degradações reais. 


\section{Testes de RestauraÇão Para DegradaÇões ARTIFICIAIS}

Objetivando testar o desempenho dos algoritmos de otimização bio-inspirados ao problema de restauração de imagens subaquáticas, foi implementado um algoritmo de restauração de imagens em níveis de cinza degradadas mediante o modelo de Trucco descrito na Seção 2.3. Para a degradação das imagens foi utilizada a Ferramenta de Degradação de Imagens em Meios Participativos (FDIMP), descrita na seção 5.1.4. Esta estratégia apresentou resultados satisfatórios, porém com alguns problemas de contraste que serão discutidos na Seção 6.2. Adicionalmente, foi implementada uma estrategia de otimização multi-objetivo baseada no algoritmo de Evolução Diferencial (DE) (vide Seção 3.4). Todos os detalhes e resultados da implementação destas duas estrategias serão discutidos nesta seção.

\subsection{InVERsão do Modelo de Trucco-Olmos}

O processo de restauração consiste na inversão de um modelo de formação de imagens. Neste contexto, os primeiros testes de restauração foram baseados no modelo de Trucco e OlmosAntillon (vide Seção 2.3). Embora o modelo de Schechner apresenta uma menor complexidade computacional $(O(M N))$, este não simula os efeitos de borramento, os quais são muito relevantes nas imagens subaquáticas. Portanto, o modelo de degradação de Trucco-Olmos foi escolhido para esta primeira etapa por ser aquele que, com uma quantidade menor de parâmetros, conseguiu-se simular adequadamente as degradações inseridas por um meio subaquático; assim, o modelo de Trucco-Olmos está dado pela equação 6.1.

$$
L(x, y)=E_{d}(x, y) * g(x, y, c, K, d m)
$$

onde $L(x, y)$ representa a imagem captada pela câmera, $E_{d}(x, y)=L_{0}(x, y) \exp (-c . d m)$ corresponde ao efeito de atenuação por transmissão direta e $g(x, y, c, K, d m)$ representa a PSF. Este modelo, no domínio da frequência está representado pela equação 6.2. 


$$
L(u, v)=E_{d}(u, v) * G(u, v, c, K, d m)
$$

Como foi discutido na Seção 2.3. a PSF pode ser modelada como um filtro passa-baixas que, no domínio da frequência, pode ser representado pela equação (2.25). Além disso, o termo de transmissão direta contem a informação sobre a imagem sem degradação, dada por $L_{0}$.

O objetivo deste processo de restauração consiste em encontrar o valor para o termo $L_{0}(x, y)$. Assim, o processo de inversão do modelo, da como resultado a equação 6.3.

$$
L_{0}(x, y)=\Im^{-1}\left\{\frac{\Im\{L(x, y)\}}{K . e^{-c . d m}}\right\} e^{c . d m}
$$

onde $\Im$ e $\Im^{-1}$ representam a transformada de Fourier e transformada inversa de Fourier, respectivamente. Como pode ser observado, no algoritmo de restauração utilizando o modelo de Trucco-Olmos, os parâmetros de entrada são: a imagem degradada $L(x, y)$, o coeficiente de atenuação $c$, o ganho da PSF $K$ e a distância média entre a câmera e a cena $d m$. E, Além disso, a saída será dada pela imagem restaurada $L_{0}(x, y)$. O Algoritmo 9 apresenta com detalhe os passos seguidos para a inversão do modelo de Trucco-Olmos.

Este algoritmo começa levando a imagem para o domínio da frequência e deslocando as componentes de baixa frequência para a parte central da imagem nas linhas 3 e 5 , respectivamente. Posteriormente, desde a linha 7 até a linha 12, apresenta-se a parte fundamental deste algoritmo, que consiste na construção do filtro de convolução $G$ (vide equação 2.25$)$ ). Neste contexto, a linha 9 apresenta a definição da frequência radial $\omega$, sendo esta obtida a partir da distância (em pixeis) de todos os pontos da imagem com relação a o centro da mesma [20]. Esta frequência radial, é utilizada na linha 12 para a criação do filtro $G$ no domínio da frequência. Assim, na linha 13, o filtro inverso é aplicado á imagem degradada no domínio da frequência para, posteriormente, levar a imagem filtrada para o domínio espacial (linha 15). Finalmente, na linha 17, é realizada a remoção do efeito de atenuação por transmissão direta para, assim, obter a imagem restaurada $I$. Neste caso, o processo de restauração apresenta o maior custo computacional na aplicação do filtro inverso (deconvolução) que, no domínio da frequência, tem uma complexidade $O(M N . \log (M) \cdot \log (N))$ para uma imagem em níveis de cinza de tamanho $M \times N$.

Neste caso, os parâmetros de entrada $c$ e $K$ devem ser estimados corretamente mediante algoritmos de otimização, visando obter uma imagem restaurada adequadamente. Além disso, a distância média entre a câmera e a cena $d m$ pode ser estimada utilizando métodos de medição de distâncias como apresentado em [29] e [30] 


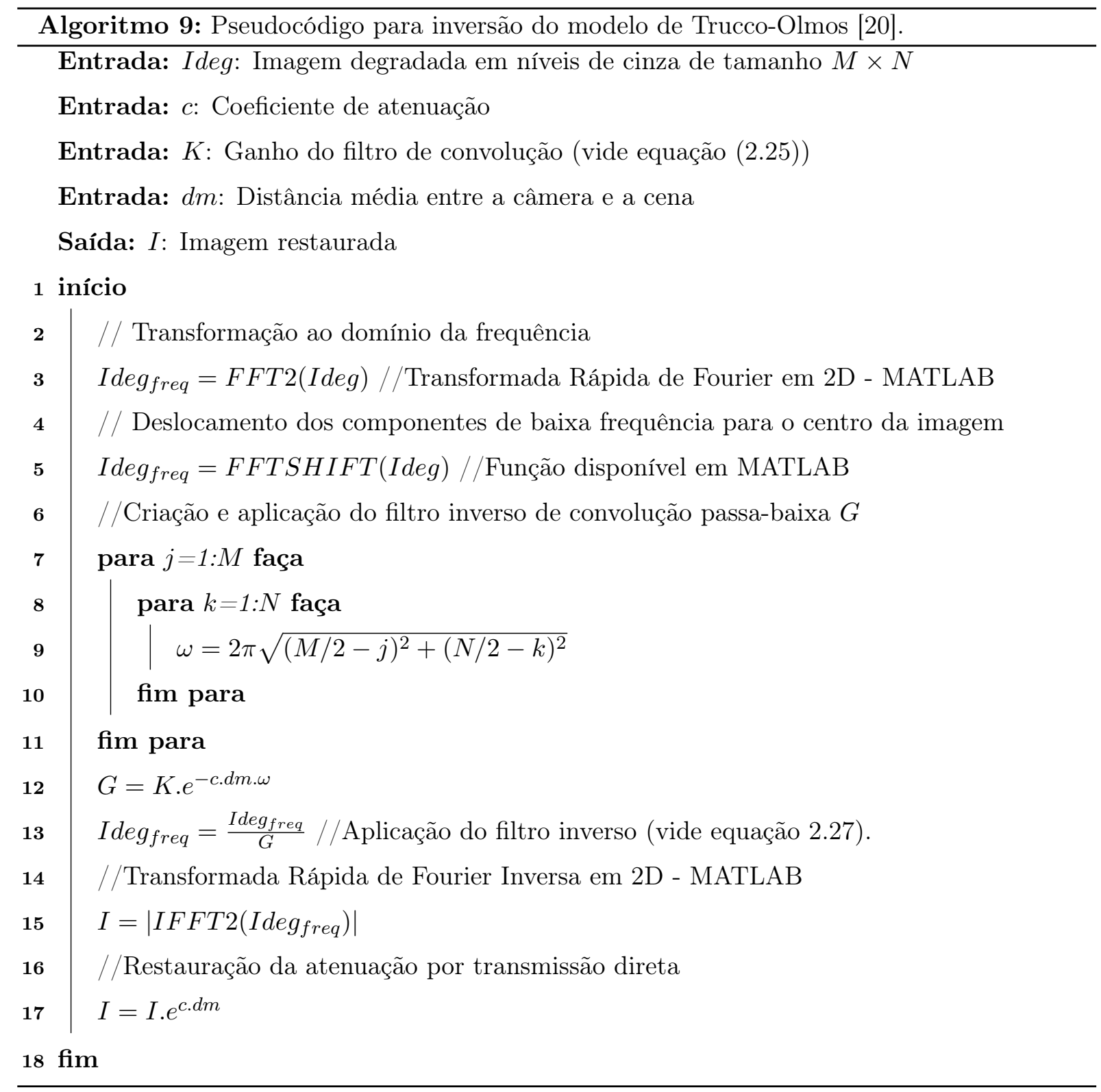




\subsection{Testes Mono-objetivo}

Objetivando encontrar os parâmetros do modelo a fim de restaurar a imagem, foram testados três algoritmos de otimização: (a) PSO, (b) fminsearch, e (c) fmincon, sendo estes dois últimos métodos exatos de otimização que fazem parte da Toolbox de otimização disponível no MATLAB. O algoritmo implementado na função fminsearch, é o método Simplex. Este método é de busca direta pelo que não utiliza gradientes nem numéricos nem analíticos. Além disso, a função fmincon faz parte dos algoritmos de programação não-linear.

A Figura 6.1 apresenta a imagem degradada, assim com também a versão original da mesma. Neste caso, a imagem foi degradada com valores de $c=0,5 m^{-1}, K=0,3$ e $d=1 m$ (vide equação (2.25)).

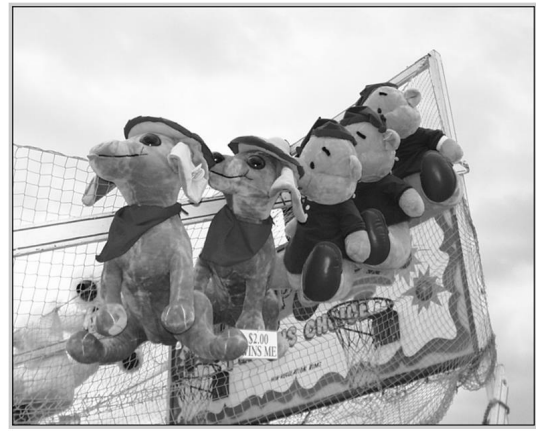

(a)

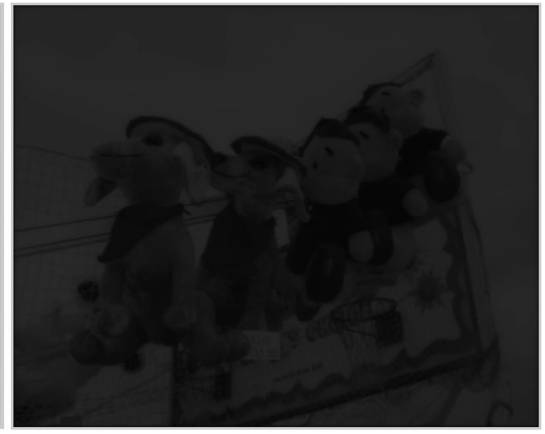

(b)

Figura 6.1. (a) Imagem original. (b) Imagem degradada com $c=0,5 m^{-1}$, $K=0,3$ e $d=1 m$.

Neste caso, foi considerada a métrica NIQE como função objetivo para o sistema de otimização, já que foi a que apresentou maior valor de correlação entre as duas métricas de avaliação de qualidade sem referência. Cada algoritmo de otimização foi executado 10 vezes. Em seguida, a imagem degradada é restaurada usando como parâmetros do modelo inverso a média dos valores estimados pelo algoritmo de otimização. As imagens resultantes são apresentadas na Figura 6.2. A Figura 6.2(a) corresponde à imagem original, a Figura 6.2(b) corresponde à imagem degradada e as Figuras 6.2(c), 6.2(d), e 6.2(e) correspondem aos resultados da restauração para os algoritmos PSO, fminsearch e fmincon, respectivamente. Além disso, a Tabela 6.1 apresenta os valores dos parâmetros encontrados, assim como os valores alcançados para a função custo, que neste caso corresponde à métrica NIQE.

Nas imagens da Figura 6.2 pode-se observar que a imagem melhor restaurada foi a que utilizou o algoritmo PSO para estimar os parâmetros. A informação contida na tabela mostra que os valores de $c$ são sempre melhor estimados do que os valores de $K$. Isto pode ser causado devido a que o índice NIQE varia muito pouco para uma grande variação de $K$ (vide Figura 6.3), o que 


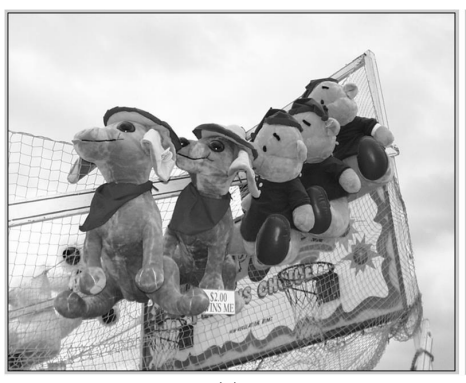

(a)

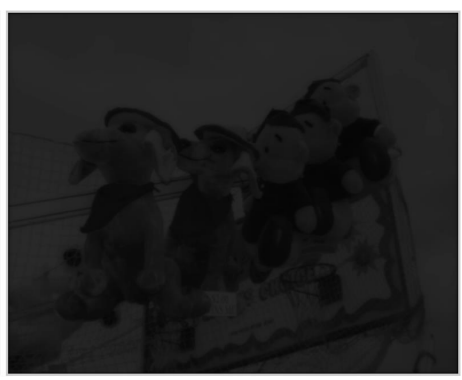

(b)

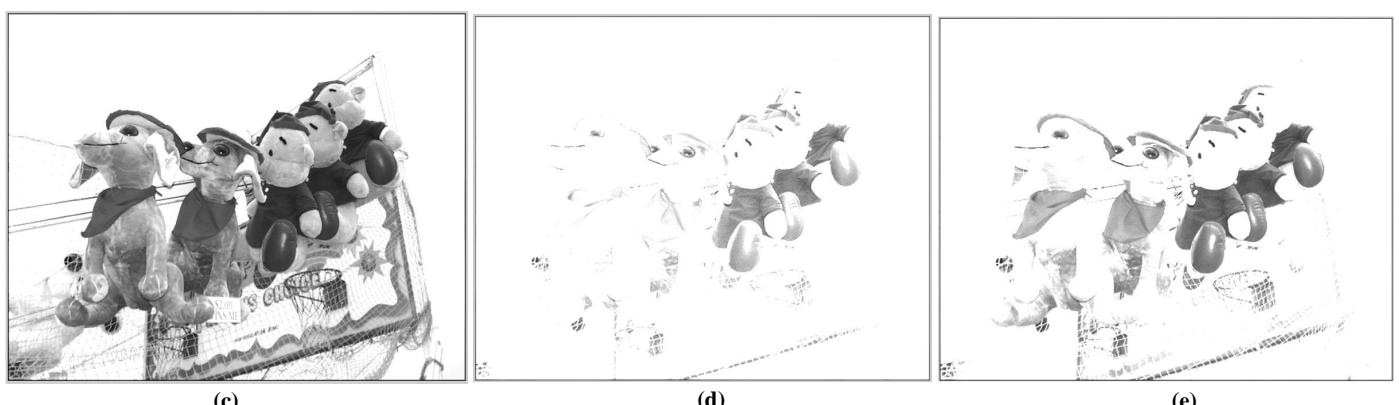

(e)

Figura 6.2. Resultado dos algoritmos de restauração. (a) Imagem original. (b) Imagem degradada com $c=0,5 m^{-1}, K=0,3$ e $d=1 m$. (c) Imagem restaurada usando PSO. (d) Imagem restaurada usando a função fminseach do MATLAB. (e) Imagem restaurada usando a função fmincon do MATLAB.

Tabela 6.1. Parâmetros encontrados pelos algoritmos de restauração para restauração da imagem da Figura 6.1(b), considerando $d=1 \mathrm{~m}$.

\begin{tabular}{|l|c|c|c|}
\hline $\begin{array}{l}\text { Algoritmo de } \\
\text { Otimização }\end{array}$ & $\begin{array}{c}\mathbf{c} \\
\left(m^{-1}\right)\end{array}$ & $K$ & $\begin{array}{c}\text { Índice } \\
\text { NIQE }\end{array}$ \\
\hline PSO & 0,4867 & 0,2180 & 2,3822 \\
\hline fminseach & 0,4706 & 0,0667 & 2,1111 \\
\hline fmincon & 0,4710 & 0,1008 & 2,4100 \\
\hline
\end{tabular}

dificulta o processo de otimização.

Para solucionar este problema, podem ser implementados algoritmos de otimização bioinspirados multiobjetivo, utilizando duas ou mais métricas como função custo. Desta forma pode-se garantir que as vantagens de determinada métrica podem ser úteis para cobrir as desvantagens das outras.

\subsection{Testes Multi-objetivo}

Visando resolver os problemas na restauração do contraste apresentados nos testes de restauração com abordagem mono-objetivo, implementou-se a métrica de Distribuição de Contraste 


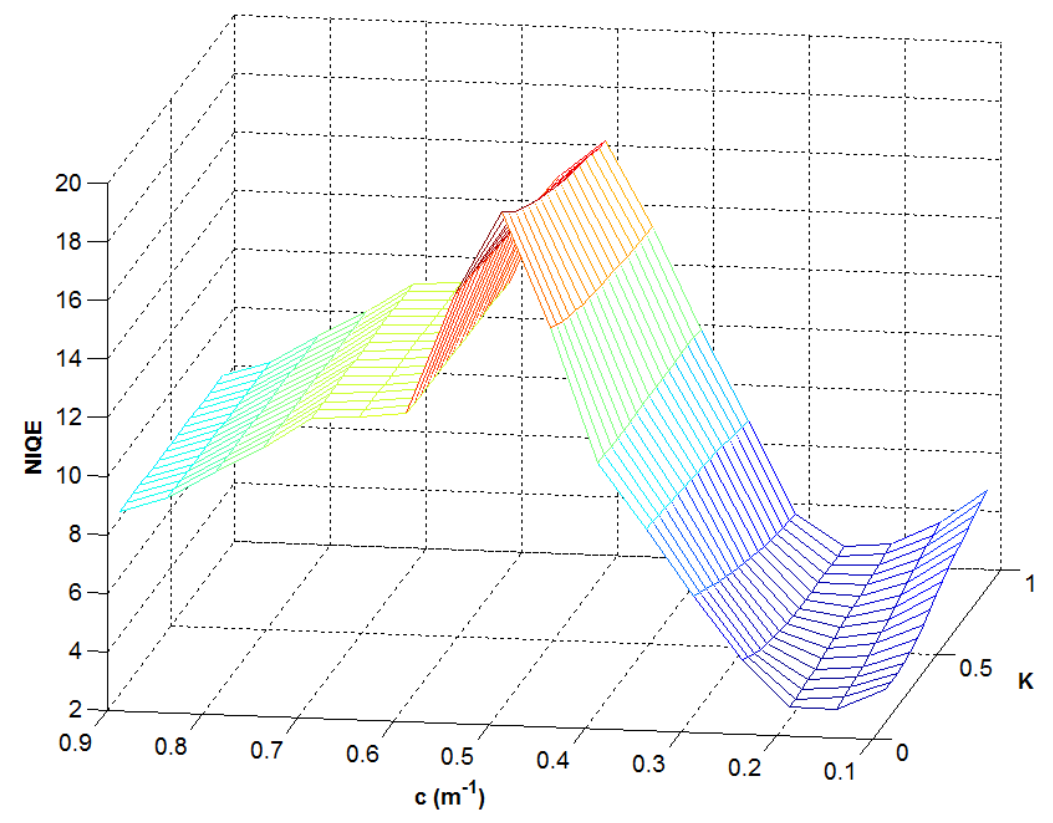

Figura 6.3. Variação do índice NIQE em relação aos parâmetros $c$ e $K$.

apresentada na Seção 4.2.3. Da mesma forma que para as métricas BN-IQA e NIQE, a análise de correlação para esta métrica foi realizada utilizando as imagens do banco LIVE [101]. Devido a que este banco não apresenta imagens com degradação de contraste, a análise foi realizada com um conjunto de 87 imagens degradadas com borramento Gaussiano. Esta escolha justifica-se levando em conta que um dos principais efeitos do borramento consiste na redução do contraste de pequenos objetos [110]. Para esta análise, o coeficiente de correlação SRCC obtido foi 0,8502. Este valor de correlação considera-se aceitável para uma métrica sem referência [104] e, por esta razão, esta métrica foi implementada nos testes multi-objetivo.

Objetivando estimar os parâmetros do modelo inverso apresentado na equação (6.3), foi implementado o algoritmo MODE, discutido na Seção 3.5.1. Neste contexto, os parâmetros $c$ e $K$ foram considerados como variáveis de decisão do processo de otimização. É importante notar que, fisicamente estes parâmetros não dependem da distância média entre a câmera e o objeto $d m$ [111], sendo que esta pode ser estimada de outras formas [29], 30].

Adicionalmente, a métrica de Distribuição de Contraste e a métrica NIQE foram utilizadas como funções objetivo do processo de otimização. Assim, baixos valores na métrica NIQE significam uma melhor qualidade da imagem. No entanto, no caso da Distribuição de Contraste, um maior valor significa melhor qualidade como mostrado na figura 4.3 [111]. Objetivando adaptar as duas métricas para um processo de minimização, o valor obtido pela métrica de Distribuição de Contraste é multiplicado por -1 .

Para apresentar um exemplo dos resultados obtidos com este processo de otimização, vai- 
se considerar a imagem apresentada na Figura 6.4. Esta imagem foi degradada utilizando o Algoritmo 6 com valores de entrada $c=0,3 m^{-1}, K=0,7$ e $d m=3 m$ [111].

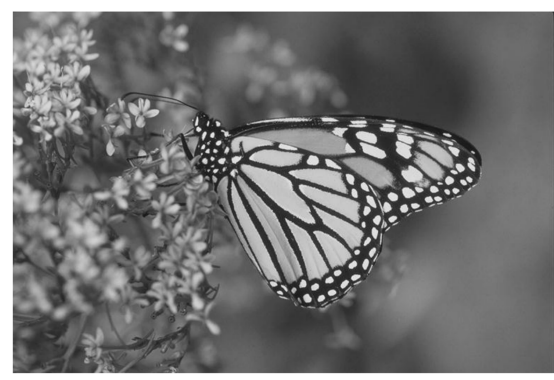

(a)

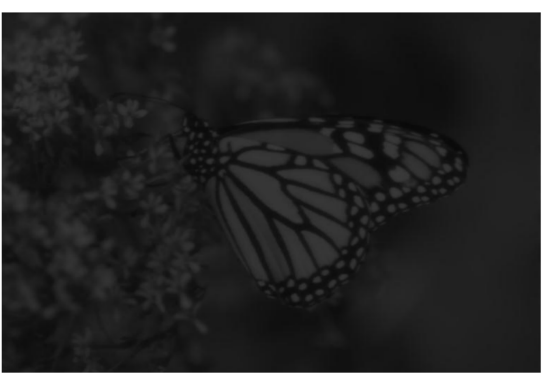

(b)

Figura 6.4. Imagem em níveis de cinza degradada utilizando o modelo de Trucco e Olmos-Antillon [11]. (a) Imagem Original. (b) Imagem degradada $\operatorname{com} c=0,3 m^{-1}, K=0,7, d m=3 m$.

O melhores resultados foram obtidos com uma população de 30 indivíduos e 250 iterações do MODE. Também, foi definido um fator de escala de 0,5 e 0,9 para a probabilidade de recombinação (vide Algoritmo 4) [111]. Duas abordagens diferentes foram implementadas para o MODE, o algoritmo PDEA [112] e o MODE/Parent [113].

O algoritmo DEMO/Parent adapta o algoritmo DE objetivando lidar com problemas multiobjetivo. Neste caso, a seleção no final de cada iteração do algoritmo é substituída por uma estratégia que considera para a solução filha o domínio sobre sua solução pai, assim: se a solução pai domina à sua solução filha, esta última é descartada. No entanto, se a solução filha domina a solução pai, a solução pai deve ser substituída pela solução filha. Caso nenhuma solução tiver domínio sobre a outra, as duas devem ser mantidas na população. Após esta seleção, a população final é truncada utilizando critérios de dominância e distância de aglomeração [113]. Além disso, o algoritmo PDEA é levemente diferente ao DEMO/Parent. Este concatena ambas populações (filha e pai) e realiza o processo de truncamento utilizando os mesmos critérios de DEMO/Parent [112.

Cada algoritmo foi executado 10 vezes. A Figura 6.5 111] apresenta as soluções não dominadas para os dois algoritmos após as 10 execuções. Nesta figura também são apresentados os valores finais das métricas para o joelho da fronteira de Pareto. Além disso, os resultados do processo de restauração podem ser observados na Figura 6.6. Também, foram implementadas duas métricas visando medir a qualidade da fronteira de Pareto obtida, chamadas de espaçamento e hiper-volume [111]. A Tabela 6.2 apresenta o resultado da métrica de espaçamento para os dois algoritmos, mostrando que os dois algoritmos apresentam desempenho similar em relação à diversidade das soluções. A Tabela 6.3, por outro lado, mostra que o algoritmo PDEA se mostrou superior com maiores valores para a média, o máximo e o mínimo na métrica de hiper-volume. Isto significa que a abordagem PDEA é capaz de cobrir uma maior área no espaço dos objetivos 
Tabela 6.2. Resultados para a métrica de espaceamento dos algoritmos DEMO/Parent e PDEA (10 execuções) [11].

\begin{tabular}{|c|c|c|}
\hline & PDEA & DEMO/Parent \\
\hline Média & 0,0638 & 0,0653 \\
\hline Desvio Padrão & 0,0220 & 0,0314 \\
\hline Mínimo & 0,0378 & 0,0312 \\
\hline Máximo & 0,0940 & 0,1152 \\
\hline
\end{tabular}

se comparada como a abordagem DEMO/Parent [111].

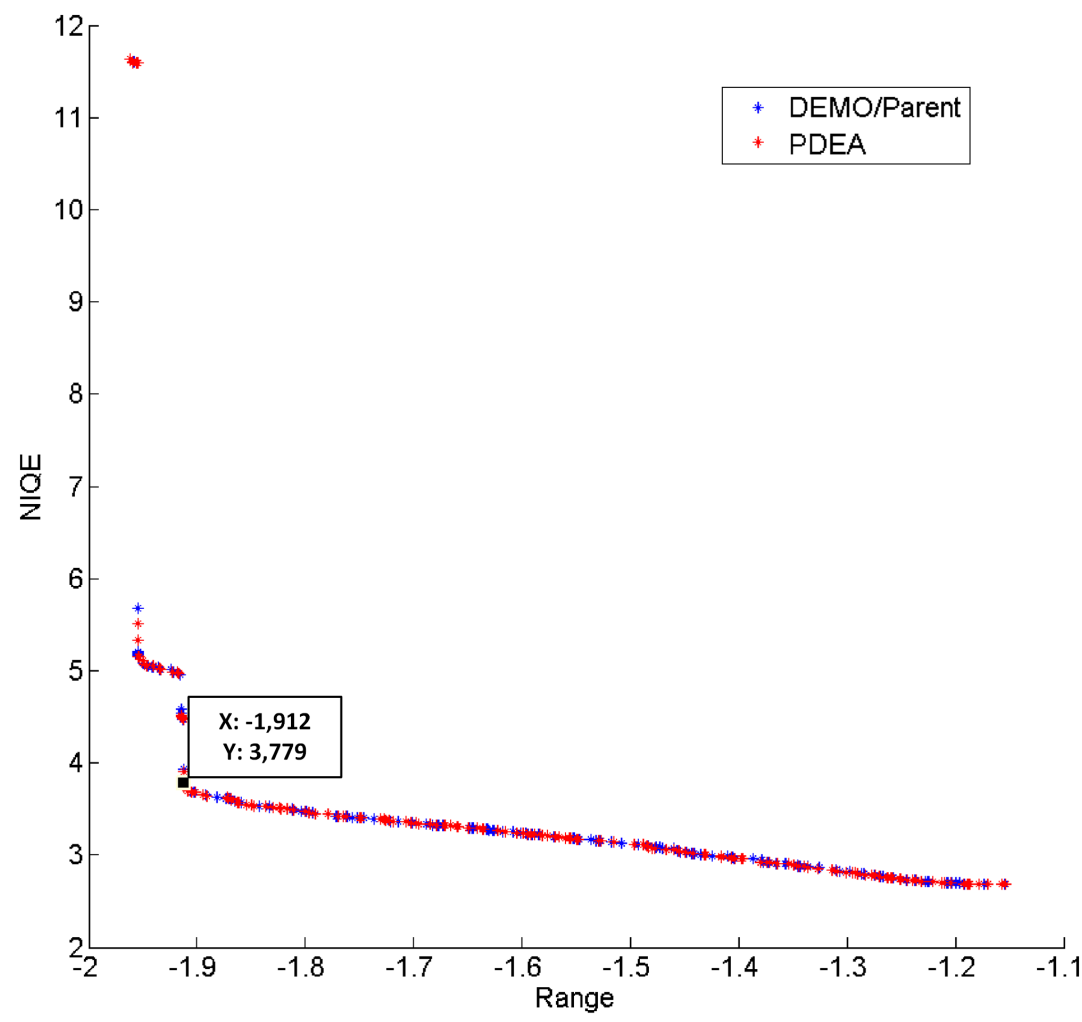

Figura 6.5. Fronteira de Pareto obtida pelo algoritmos DEMO/Parent e PDEA após 10 execuções [111].

Neste exemplo, os parâmetros utilizados para degradação foram $c=0,3 m^{-1}$ e $K=0,7$ para uma distância fixa $d m=3 m$. Após o processo de otimização, os parâmetros estimados foram $c=0,3899 m^{-1}$ e $K=0,7521$ [111]. Os valores obtidos para as funções objetivo foram NIQE $=3,779$ e Range $=1,912$. Adicionalmente, os valores de qualidade para as imagens originais são $N I Q E=3,3998$ e Range $=1,1723$, e para a imagem degradada $N I Q E=9,0044$ e Range $=0,3842$. Os resultados obtidos mostram que os valores estimados para $c$ e $K$ são muito similares àqueles utilizados no processo de degradação (vide Figura 6.4).

Além disso, os valores de qualidade da imagem restaurada, dados pelo valor final da funções 


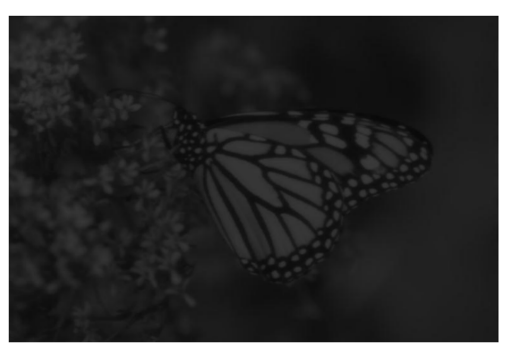

(a)

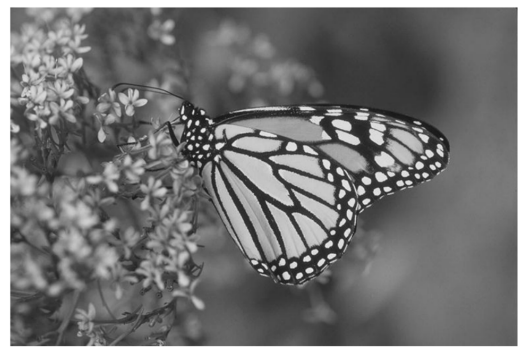

(b)

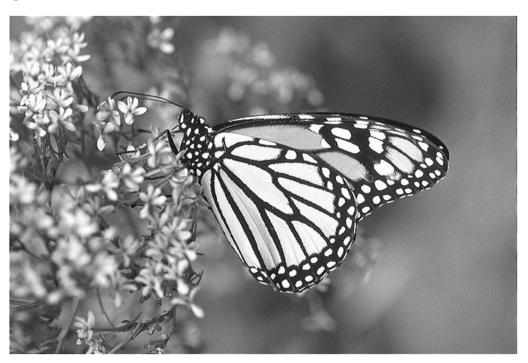

(c)

Figura 6.6. Resultados do processo de restauração da imagem [111]. (a) Imagem degradada $\left(c=0,3 m^{-1}, K=0,7, d m=3 m\right)$. (b) Imagem Original. (c) Imagem restaurada com $c=0,3899 m^{-1}, K=0,7521, d m=3 m$

Tabela 6.3. Resultados para a métrica de hiper-volume dos algoritmos DEMO/Parent e PDEA (10 execuções) [11].

\begin{tabular}{|c|c|c|}
\hline & PDEA & DEMO/Parent \\
\hline Média & 0,8820 & 0,8289 \\
\hline Desvio Padrão & 0,0700 & 0,0683 \\
\hline Mínimo & 0,7749 & 0,7668 \\
\hline Máximo & 0,9269 & 0,9259 \\
\hline
\end{tabular}

objetivo, também são similares aos medidos para a imagem original. No entanto, fazendo uma análise subjetiva da Figura 6.6, é possível afirmar que a imagem restaurada (Figura 6.6.(c)) tem, levemente, melhor qualidade se comparada com a imagem original (Figura 6.6(b)). Isto pode ser devido a que as imagens de referência do banco LIVE, que foram utilizadas nos testes de restauração, foram adquiridas em ambientes naturais e algumas podem apresentar distorções [111]. Os resultados podem sugerir que, em alguns casos, o processo de restauração está restaurando estas pequenas degradações [111].

A Figura 6.7 apresenta outros resultados utilizando diferentes imagens com diferentes valores de $c$ e $K$. Na coluna (a) estão as imagens originais (sem degradação), na coluna (b) estão as imagens degradadas e a coluna (c) pertence às imagens restauradas pelo algoritmo MODE. 


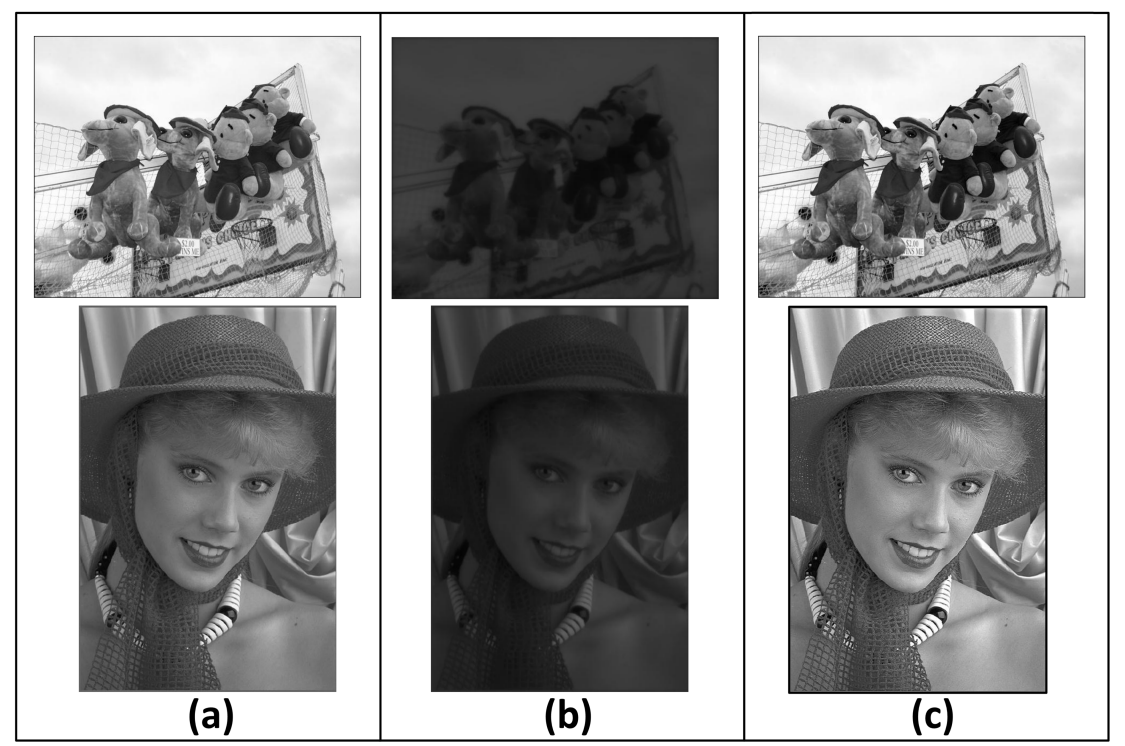

Figura 6.7. Resultados da restauração de imagens com o algoritmo MODE.

(a) Imagem original. (b) Imagem degradada. (c) Imagem restaurada usando o algoritmo MODE [111.

\subsection{Considerações Finais do Capítulo}

Neste capítulo foram apresentados os resultados obtidos nos testes de restauração para imagens com degradações artificiais. Nesta etapa do trabalho foi utilizado o modelo inverso de Trucco-Olmos, apresentado no Algoritmo 9, Este algoritmo foi escolhido devido a sua simplicidade de implementação e capacidade para simular os efeitos da água na imagem.

Duas abordagens foram testadas nesta etapa: a primeira consiste em uma estratégia de otimização PSO mono-objetivo, utilizando como função objetivo a métrica NIQE; já a segunda abordagem consistiu em uma estratégia de otimização multi-objetivo baseada no algoritmo de evolução diferencial (MODE). Para esta segunda abordagem, foi necessária a implementação da métrica de Distribuição de Contraste Local, discutida na Seção 4.2.3.

Os testes de restauração aplicados a imagens com degradações artificiais apresentaram resultados satisfatórios, porém, a imagem resultante do processo de restauração apresenta alguns problemas de contraste. Estes problemas são causados pela deficiência da métrica NIQE para medir variações de contraste neste tipo de imagens. Assim, foi necessária a implementação de uma estratégia multi-objetivo que possa, mediante a utilização de uma segunda métrica, cobrir a desvantagem da métrica NIQE.

Assim, finalmente foi apresentada a implementação de um sistema de restauração de imagens baseado no algoritmo de otimização MODE. Este algoritmo estimou parâmetros de restauração bastante similares aos utilizados no algoritmo de degradação. Realizando uma análise subjetiva 
das imagens resultantes do processo, as imagens restauradas apresentam, em alguns casos, melhor nitidez e contraste que a imagem original. No entanto, nesta parte do trabalho, foram utilizadas imagens degradadas artificialmente mediante o algoritmo de Trucco e Olmos-Antillon e torna-se necessária a implementação de uma abordagem com imagens reais. 


\section{Testes de Restauração Para DegradaÇões Reais}

Na Seção 5.4 foram definidas as melhores métricas para avaliar imagens com degradações subaquáticas reais. Para isto foi utilizado o banco de dados desenvolvido neste projeto: o UIDLEIA (vide Seção 5.3). Estas métricas serão utilizadas como funções objetivo para os processos de otimização, que objetivam estimar os parâmetros do modelo de formação de imagens inverso que levem aos melhores valores de qualidade da imagem restaurada. Nos primeiros testes de restauração com imagens degradadas artificialmente (vide Capítulo 6), foi escolhido o modelo de Trucco e Olmos-Antillon pela simplicidade de implementação. Porém, o objetivo principal de dita etapa consistia em testar os algoritmos de otimização bio-inspirados para problemas de restauração baseada em modelos de formação de imagens.

O modelo de Trucco-Olmos, discutido na Seção 2.3, apresenta uma simplificação do termo referente ao back-scattering, responsável principalmente pela perda de contraste na imagem resultante. Devido a esta simplificação, este modelo está definido para distâncias curtas entre a câmera e o objeto [20]. Apesar de que o modelo de Trucco e Olmos-Antillon apresentou resultados satisfatórios na etapa de restauração de imagens degradadas artificialmente, a etapa de restauração com imagens reais requer um modelo mais completo e, além disso, de implementação simples. Por estas razões, o modelo de Wagner [9] (vide Seção 2.4 foi escolhido para guiar os testes de restauração em imagens reais.

Além disso, diferente dos testes em imagens com degradações artificiais, nesta etapa foram consideradas imagens coloridas, já que a informação cromática é muito importante na percepção de qualidade visual de uma imagem e, portanto, na maioria das aplicações não pode ser desconsiderada. Esta consideração é muito importante levando em conta que, em meios subaquáticos, a propagação da luz é dependente do comprimento de onda e, como consequência, os canais de cor não se apresentam corretamente balanceados [9]. Portanto, o processo de restauração não deve ser realizado somente observando os valores de luminância da imagem, sendo necessário implementar uma função que permita fazer um ajuste ao valor estimado para cada parâmetro no processo de restauração. Este ajuste pode ser feito realizando um procedimento de compensação cromática.

No trabalho apresentado por Wagner [9], apresenta-se também uma estratégia de restaura- 
ção de imagens coloridas, utilizando o modelo proposto pelo autor. A diferença do trabalho apresentado no contexto desta tese, a otimização em [9] é realizada com metodologias exatas de otimização, fornecidas pelo Toolbox de otimização do MATLAB. Embora os resultados apresentados pelo Wagner apresentam uma boa qualidade, ainda possuem alguns problemas de contraste nas imagens restauradas, que se apresentam geralmente escuras.

\subsection{CompensaÇão Cromática}

O procedimento de compensação cromática, proposto por Wagner [9], possibilita corrigir o desequilíbrio do comprimento de onda em imagens subaquáticas mediante a obtenção de um conjunto de pesos referentes a cada canal de cor do espaço RGB. Posteriormente, o vetor de pesos estimado é utilizado para compensar os parâmetros do modelo segundo o valor de peso de acordo com seu canal correspondente.

A estimativa dos pesos para compensação cromática utiliza a representação da imagem, tanto no espaço RGB quanto no HSV. O espaço HSV separa de uma imagem colorida a informação referente à intensidade da sua informação cromática (matiz e saturação). A informação de saturação é utilizada para diferenciar valores de matiz considerados puros de valores impuros.

Dessa forma, analisando os valores de saturação, a imagem de entrada pode ser segmentada em regiões compostas por pixeis com a informação cromática mais relevante, sendo estas regiões formadas por cores mais puras [9]. Estas regiões são ajustadas utilizando um algoritmo de expansão cromática. Assim, as variações cromáticas médias de cada canal RGB da imagem ajustada com relação à imagem sem ajuste correspondem a cada componente do vetor de pesos $\gamma=\left(\gamma_{R}, \gamma_{G}, \gamma_{B}\right)$. O Algoritmo 10 resume o procedimento descrito.

Primeiramente, na linha 3 do algoritmo de compensação cromática, a imagem é levada para o espaço de cor HSV. Posteriormente, entre a linha 4 e 13, os pixeis do plano de saturação (plano S) são comparados com o limiar $l_{\text {sat }}$, criando uma imagem $S$ com valor de 1 nos pixeis com valores acima desse limiar e 0 no caso contrario. Assim, nas linhas 14, 15 e 16, a imagem degradada, no espaço RGB, é multiplicada ponto a ponto pela imagem $S$ gerada no passo anterior. Isto gera uma imagem filtrada I filt, onde são conservados somente os pixeis com a informação cromática mais relevante. Posteriormente, na linha 17, é realizada uma operação de expansão cromática para ressaltar ainda mais estas regiões. Finalmente, nas linhas 18 até 21 são calculados os pesos de compensação cromática que serão aplicados ao processo de restauração. Este algoritmo apresenta uma complexidade computacional $O\left(M N K_{1}\right)$ para uma imagem de tamanho $M \times N$, onde $K_{1}$ está relacionado com o tamanho dos filtros utilizados para expansão cromática e conversão do espaço de cor [9]. 


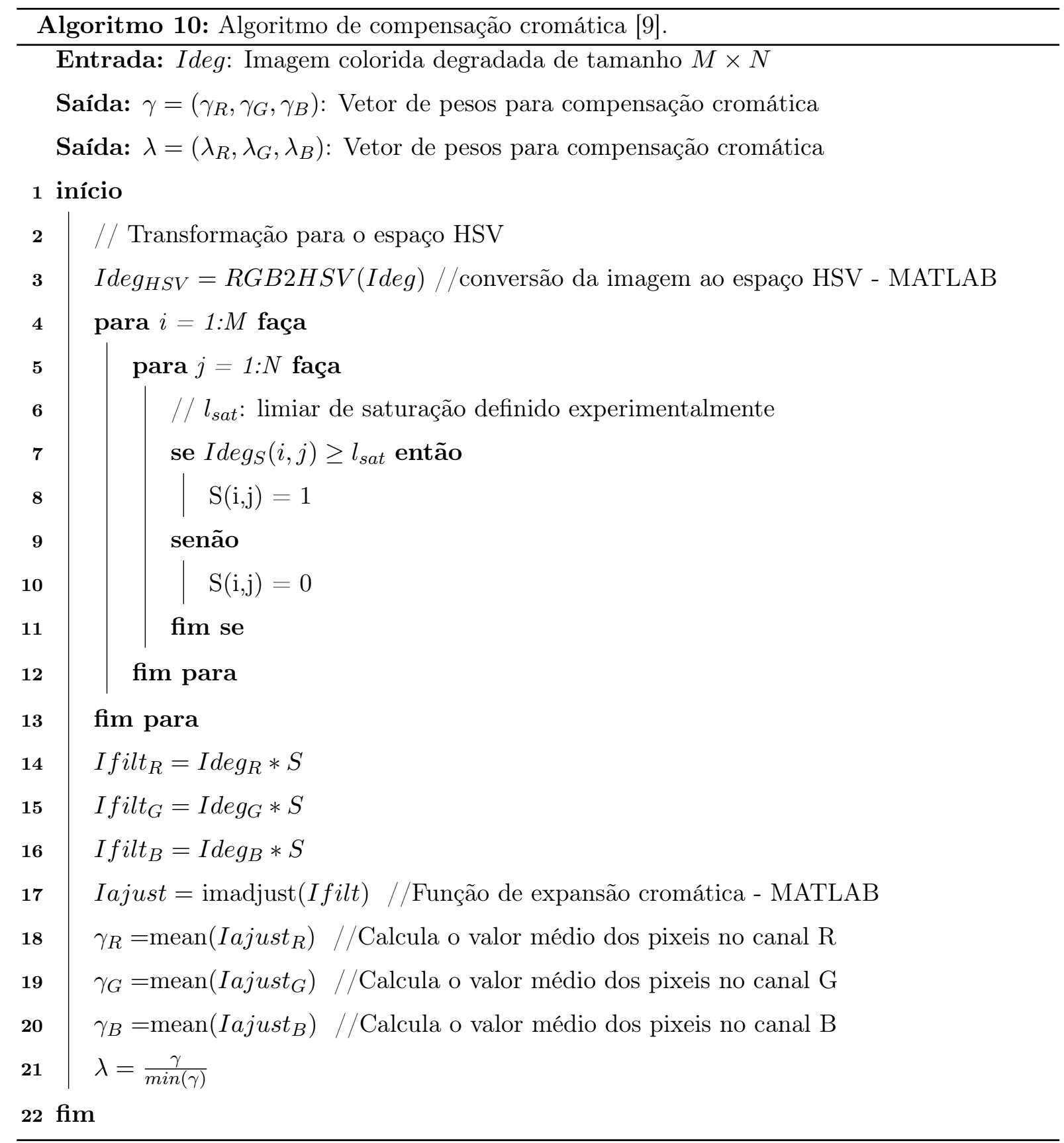




\subsection{Estratégia de RestauraÇÃo}

O procedimento de compensação cromática, descrito acima, é realizado só uma vez, sendo os pesos encontrados utilizados ao longo de todo o processo de restauração. Nesse contexto, o processo de restauração, de forma geral, está descrito no Algoritmo 11. Este algoritmo recebe como entrada uma imagem colorida degradada Ideg, a qual é submetida ao processo de compensação cromática, descrito acima, a fim de obter os pesos de compensação que serão utilizados no processo de restauração. Esta estratégia de restauração consiste em utilizar o modelo inverso de Wagner (vide Algoritmo 12) para cada canal de cor independentemente. No entanto, as variáveis de decisão correspondem somente aos três parâmetros $c, K$ e $L_{\infty}$.

O Algoritmo 11 inicia, na linha 2, realizando o processo de compensação cromática descrito na Seção 7.1 e, assim, obter os pesos $\gamma$ e $\lambda$. Posteriormente, na linha 3, é realizada uma distribuição aleatória das partículas característica dos algoritmos de otimização bio-inspirada, levando em conta que cada uma dessas partículas corresponde a uma possível solução ao problema de otimização. Assim, as primeiras soluções são testadas no modelo inverso de Wagner para cada um dos canais de cor (linhas 5, 6 e 7), multiplicando as variáveis de decisão $c, K$ e $L_{\infty}$ pelos pesos correspondentes obtidos da compensação cromática. Após obter uma primeira tentativa de restauração, na linha 8 , é avaliada a qualidade da imagem restaurada. Assim, novas soluções devem ser geradas na linha 9 objetivando obter um melhor valor da métrica na próxima iteração. Desta forma, o processo é repetido até alcançar uma condição de parada do algoritmo de otimização.

Como discutido na Seção 7.1, estes valores não podem ser os mesmos para cada plano de cor e, devido a isso, os valores estimados no processo de otimização são multiplicados pelos pesos de compensação cromática correspondentes a cada canal RGB. Após a inversão do modelo de formação de imagens, deve ser avaliada a qualidade da imagem restaurada utilizando as métricas sem referência para avaliação de imagens. Este valor de qualidade corresponde ao valor de aptidão do algoritmo de otimização, o qual deve gerar novas soluções até convergir ou até alcançar um número máximo de iterações. A Figura 7.1 apresenta um fluxograma do processo descrito acima.

Além disso, a inversão do modelo de Wagner, descrita no Algoritmo 12, consiste em isolar o termo referente à imagem sem degradações, dado pelo termo $L_{0}\left(x_{o}, y_{0}\right)$ na equação 2.32. Nesse contexto, a inversão do modelo simplificado de Wagner está dada pela equação (7.1).

$$
L_{0}\left(x_{o}, y_{o}\right)=\Im^{-1}\left\{\frac{\Im\left\{L\left(x_{o}, y_{o}\right)-L_{\infty}\left(1-e^{-c . d m}\right)\right\}}{K . e^{-c . d m . \omega}}\right\} e^{c . d m}
$$

onde $\Im$ e $\Im^{-1}$ correspondem à transformada de Fourier e à transformada inversa de Fourier, 


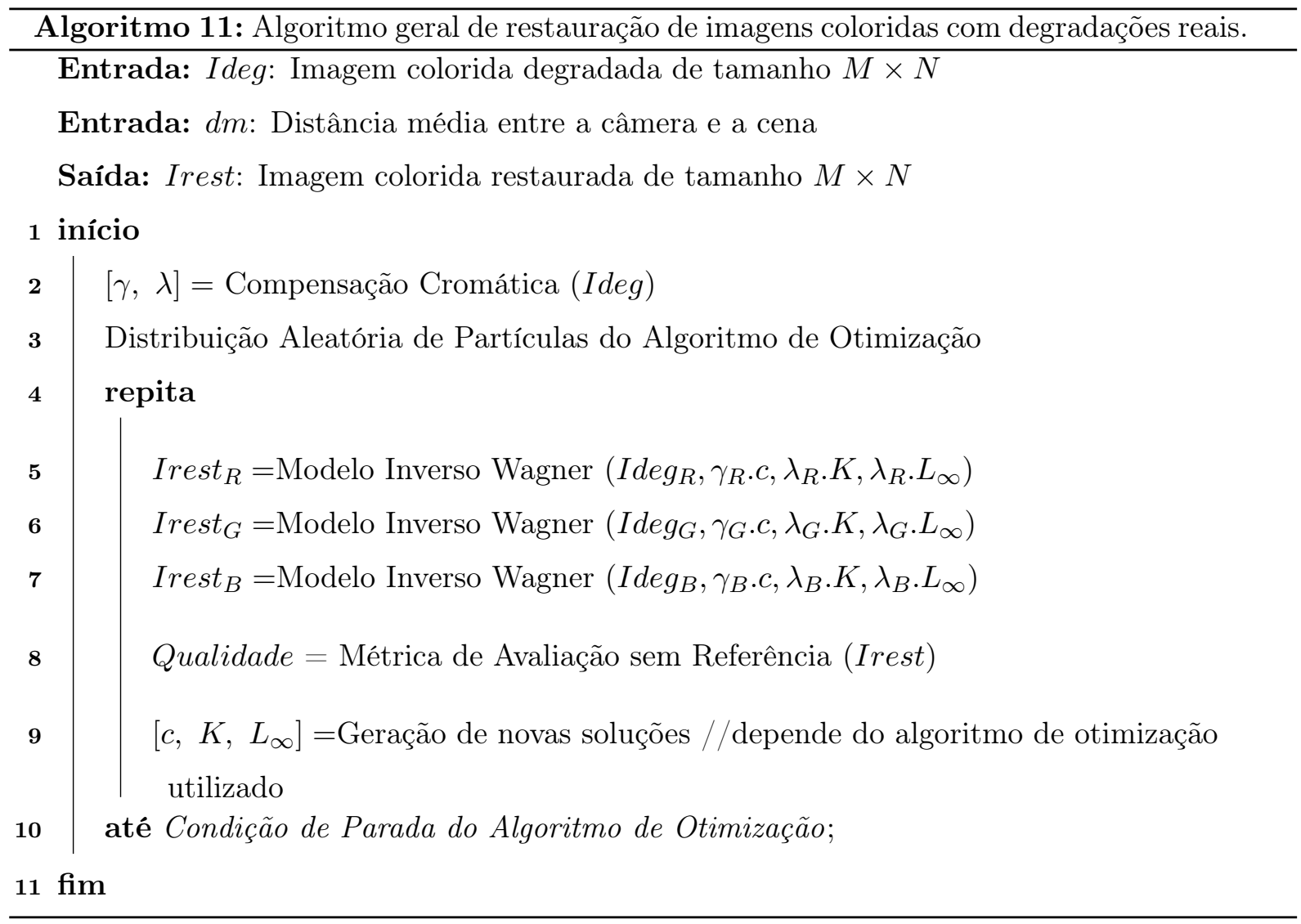

respectivamente. Neste caso, as entradas do algoritmo correspondem aos parâmetros de restauração, dados pelo coeficiente de atenuação $(c)$, o ganho da PFS $(K)$, a constante de iluminação $\left(L_{\infty}\right)$ e a distância média entre a câmera e o objeto $(d m)$.

O algoritmo de inversão do modelo de Wagner é aplicado, por separado, a cada canal de cor RGB e, portanto, o algoritmo foi implementado para imagens em níveis de cinza (vide Algoritmo 12. Este algoritmo começa, nas linhas 3 e 4, realizando a remoção do efeito de back-scattering. Assim, nas linhas 6 e 8, a imagem resultante é levada ao domínio da frequência e os componentes de baixa frequência são levados para o centro da imagem. Posteriormente, as linhas 10 até 15 apresentam o processo de criação do filtro de convolução no domínio da frequência $G$ (vide equação (2.25)). Desta forma, na linha 16, é realizada a filtragem da imagem no domínio da frequência. Assim, a imagem restaurada Irest é obtida na linha 20, após ter sido levada de volta para o domínio espacial na linha 18. Neste caso, o processo de restauração apresenta o maior custo computacional na aplicação do filtro inverso (deconvolução) que, no domínio da frequência, tem uma complexidade $O(3 M N \cdot \log (M) \cdot \log (N))$ para uma imagem colorida de tamanho $M \times N$.

O algoritmo de restauração de imagens foi implementado tomando como base três algoritmos de otimização bio-inspirada: (a) PSO, (b) ABC e (c) DE. Devido aos problemas de convergência prematura que apresenta o PSO, referenciados na literatura [13], este algoritmo foi implementado junto com os métodos de adição de diversidade discutidos na Seção 3.6. Desta forma, foram 


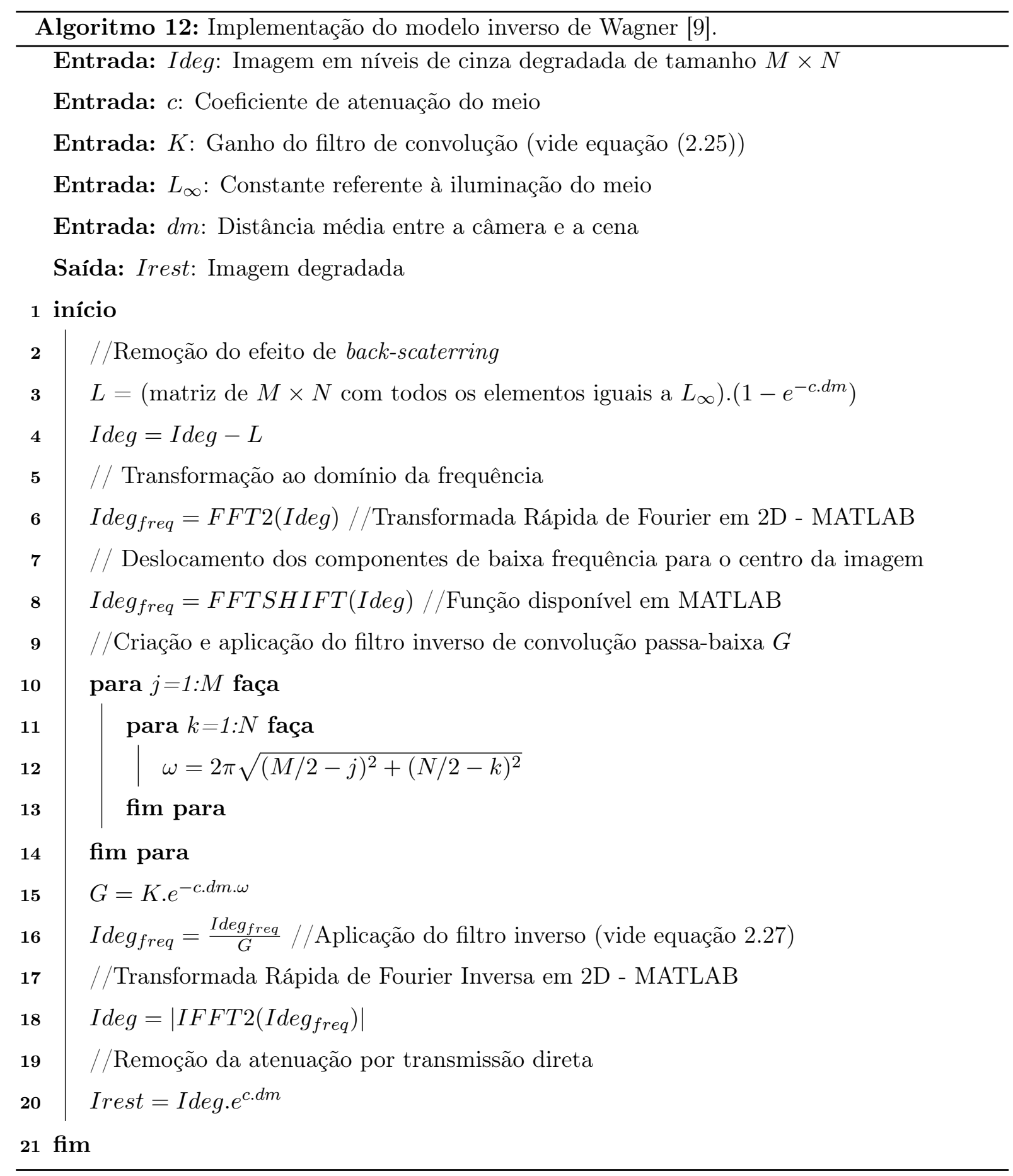




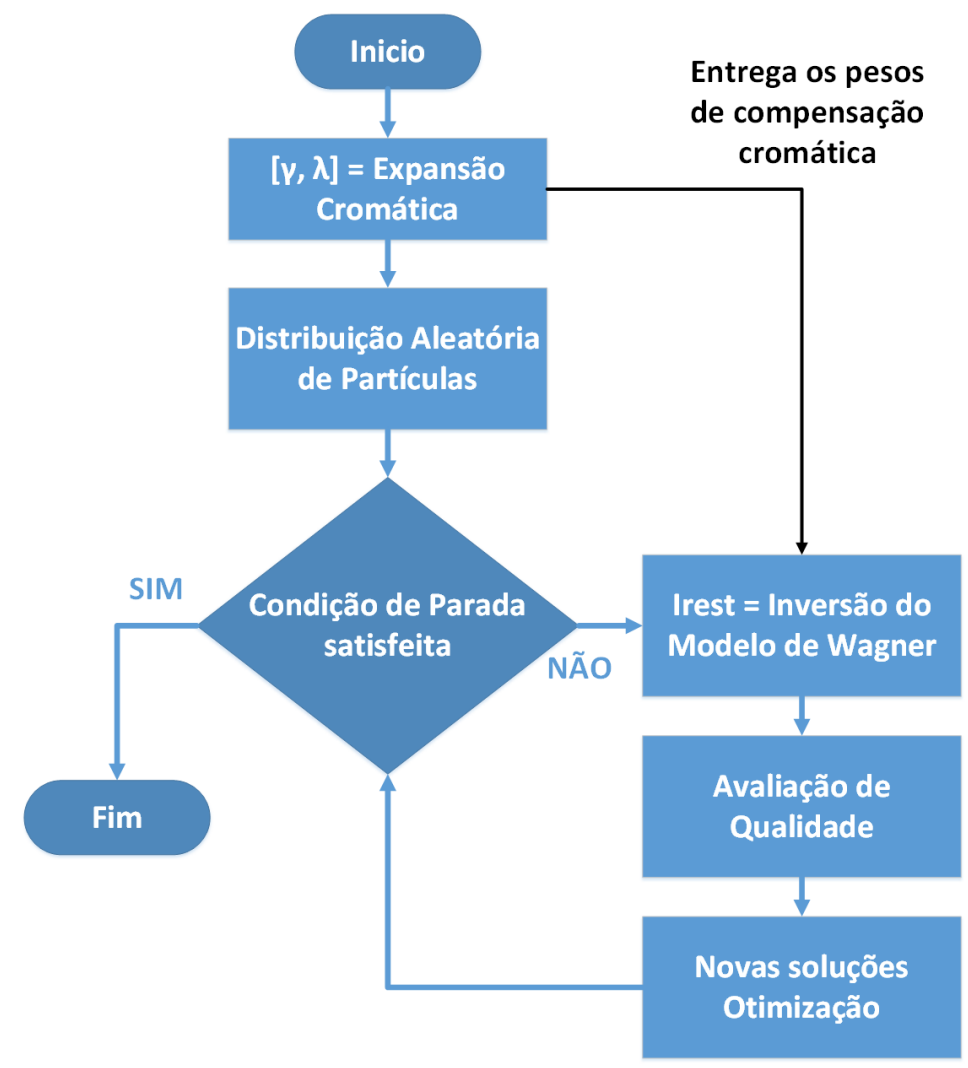

Figura 7.1. Fluxograma do algoritmo de restauração de imagens reais.

implementados o algoritmo OPSO (Opposition Based Particle Swarm Optimization) e o RAPSO (Repulsive-Attractive Particle Swarm Optimization). Além disso, o algoritmo ABC foi testado na versão clássica, e também com aprendizado por oposição OABC. Em total foram 5 algoritmos de otimização testados nesta etapa do trabalho: PSO, OPSO, ABC, OABC e DE. Estes algoritmos foram testados com duas funções objetivo diferentes: UCIQE e NIQE. Estas métricas de qualidade foram escolhidas para guiar o processo de restauração devido ao bom desempenho que apresentaram na análise de correlação (vide Seção 5.4).

As Figuras 7.2 e 7.3 apresentam os resultados do processo de restauração de imagens com degradações reais guiado pelos algoritmos de otimização bio-inspirada supracitados. Na Figura 7.2 pode-se observar que, subjetivamente, os resultados de restauração são satisfatórios para todas as imagens, porém as imagens obtidas mediante os algoritmos OPSO e ABC apresentaram imagens mais claras e com melhor restauração da informação cromática da imagem. Objetivando testar os algoritmos de otimização supracitados, cada algoritmo foi executado 50 vezes para a mesma imagem. Assim, apos encontrar a mediana, o processo de restauração mediante inversão do modelo de Wagner é realizado utilizando os valores das variáveis de decisão correspondentes ao valor da mediana. As Tabelas 7.1, 7.2 e 7.3 apresentam os valores das variáveis de decisão utilizados no algoritmo de inversão do modelo de Wagner para obter os resultados apresentados nas Figuras 7.2, 7.3 e 7.4 , respectivamente. É importante ressaltar que os valores das variáveis 
Tabela 7.1. Valores das variáveis de decisão encontrados pelos algoritmos de otimização bio-inspirada aplicados à restauração da imagem mostrada na Figura 7.2

\begin{tabular}{|c|c|c|c|c|}
\hline Algoritmo & Mediana & $c$ & $K$ & $L_{\infty}$ \\
\hline OPSO & 84,124 & $-0,102$ & $-0,335$ & $-0,560$ \\
ABC & 84,795 & $-1,516$ & $-6,181$ & $-6,658$ \\
RAPSO & 85,122 & $-0,054$ & $-0,052$ & $-1,082$ \\
DE & 85,023 & 1,717 & 1,984 & 1,905 \\
OABC & 84,804 & $-2,004$ & 1,779 & $-4,877$ \\
\hline
\end{tabular}

de decisão não representam os valores reais das propriedades físicas da água, representando simplesmente uma combinação de valores que é capaz de restaurar a imagem corretamente.

Além disso, nas Figuras 7.3 e 7.4 , apresentam-se casos nos quais o resultado da restauração não foi bem sucedido para todas as estratégias de otimização. Nestes casos, o algoritmo DE apresenta uma imagem com degradações nas cores do fundo da imagem, mostrando uma dominância de cor roxa. Da mesma forma, o algoritmo RAPSO na Figura 7.3 apresenta uma imagem onde as cores não estão bem restauradas, dando ao objeto (originalmente de cor azul) uma cor preta. Assim, neste caso, os algoritmos OPSO, ABC e OABC apresentam as melhores restaurações. Além disso, pode ser observado na Figura 7.3 que, quanto mais longe estiver o objeto da câmera, mais difícil resulta restaurar o efeito de borramento.
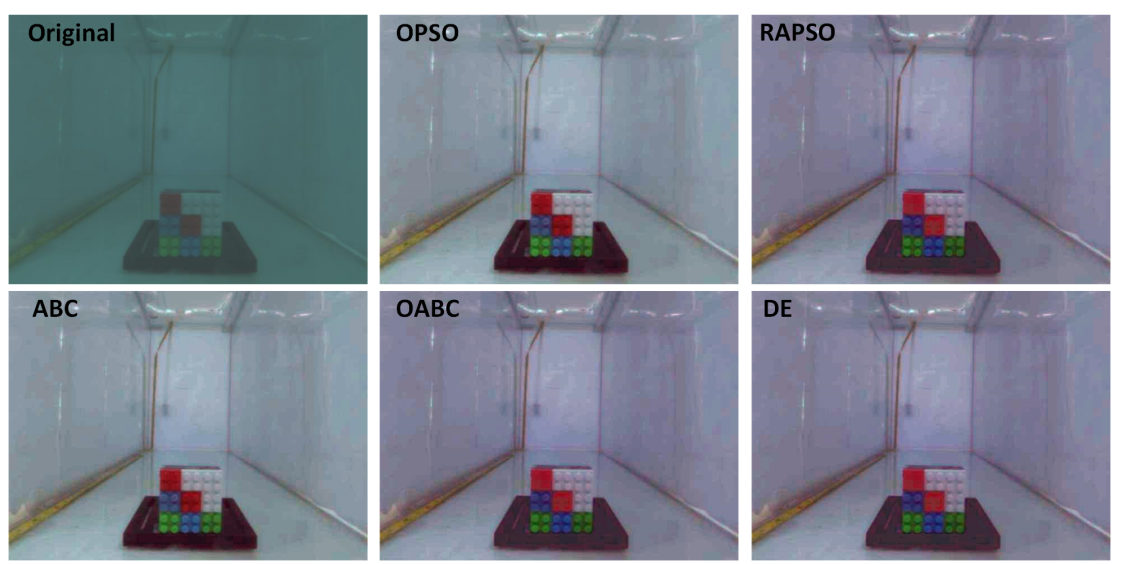

Figura 7.2. Teste de restauração em imagens reais utilizando a métrica NIQE.

É importante ressaltar que estimar os valores reais da informação referente ao meio de degradação, dada pelos parâmetros $c, K$ e $L_{\infty}$, não é o foco deste trabalho e, portanto, o interesse principal reside na qualidade da imagem restaurada. As estatísticas dos valores da métrica NIQE para as 50 execuções de cada algoritmo de otimização são apresentados nas Tabelas 7.4 , 7.5 e 7.6. para as imagens mostradas nas Figuras 7.2, 7.3 e 7.4, respectivamente. Levando em conta 
Tabela 7.2. Valores das variáveis de decisão encontrados pelos algoritmos de otimização bio-inspirada aplicados à restauração da imagem mostrada na Figura 7.3 .

\begin{tabular}{|c|c|c|c|c|}
\hline Algoritmo & Mediana & $c$ & $K$ & $L_{\infty}$ \\
\hline OPSO & 84,903 & $-0,388$ & $-0,154$ & 0,462 \\
ABC & 84,494 & $-0,318$ & 0,229 & $-0,084$ \\
RAPSO & 85,884 & 3,837 & 0,388 & 6,812 \\
DE & 85,857 & 4,080 & 4,829 & 6,309 \\
OABC & 84,528 & $-0,280$ & $-0,845$ & 2,000 \\
\hline
\end{tabular}

Tabela 7.3. Valores das variáveis de decisão encontrados pelos algoritmos de otimização bio-inspirada aplicados à restauração da imagem mostrada na Figura 7.4 .

\begin{tabular}{|c|c|c|c|c|}
\hline Algoritmo & Mediana & $c$ & $K$ & $L_{\infty}$ \\
\hline OPSO & 85,711 & 0,824 & $-0,189$ & 0,026 \\
ABC & 85,722 & 6,492 & $-4,565$ & 1,945 \\
RAPSO & 88,712 & 0,824 & $-0,130$ & 0,027 \\
DE & 88,025 & $-2,000$ & $-1,476$ & $-2,000$ \\
OABC & 85,730 & 6,641 & 4,156 & 1,923 \\
\hline
\end{tabular}



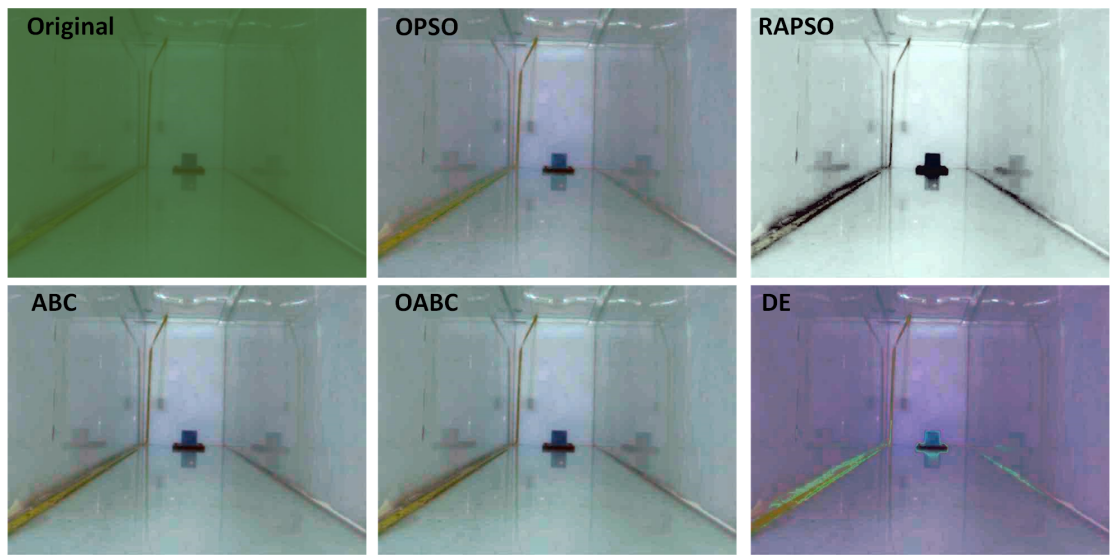

Figura 7.3. Teste de restauração em imagens reais utilizando a métrica NIQE.
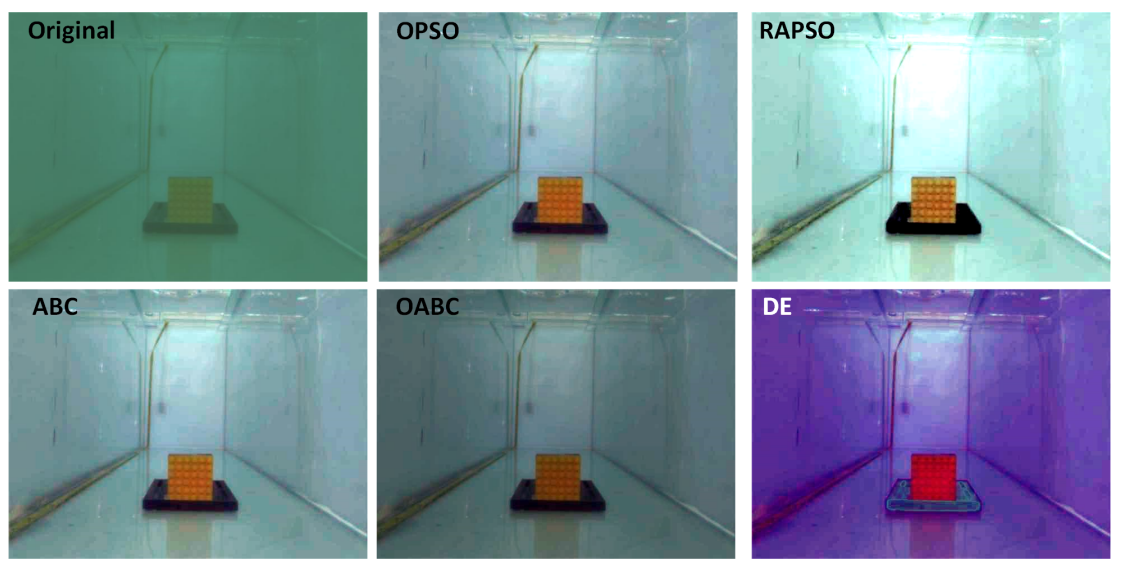

Figura 7.4. Teste de restauração em imagens reais utilizando a métrica NIQE.

que, na métrica NIQE, um valor menor significa melhor qualidade da imagem, os valores contidos na tabela indicam que os melhores resultados foram alcançados pelos algoritmos OPSO e ABC. Além disso, os valores referentes às Figuras 7.3 e 7.4 mostram que os valores mais altos são apresentados pelos algoritmos RAPSO e DE.

Um total de 20 imagens (que pertencem ao banco UID-LEIA) foram testadas utilizando os algoritmos OPSO, RAPSO, ABC, OABC e DE. Cada algoritmo foi executado 50 vezes para cada imagem. Posteriormente, para cada algoritmo de otimização (e para cada imagem) é encontrada a mediana dos valores finais da função objetivo (métrica NIQE). Os valores das variáveis de decisão correspondentes ao valor da mediana são utilizados para restaurar a imagem mediante o modelo inverso de Wagner. Neste capítulo foram apresentados três experimentos e, no Apêndice A, são apresentados 17 resultados de restauração para os algoritmos OPSO e ABC (que apresentaram melhor desempenho), assim como também para o algoritmo DE (o qual apresentou o desempenho mais baixo). 
Tabela 7.4. Estatísticas dos algoritmos de otimização bio-inspirada aplicados à restauração da imagem mostrada na Figura 7.2

\begin{tabular}{|c|c|c|c|c|c|}
\hline Algoritmo & Mediana & Média & Desvio Padrão & Mínimo & Máximo \\
\hline OPSO & 84,124 & 84,120 & 0,0142 & 84,029 & 84,125 \\
ABC & 84,795 & 84,794 & 0,0155 & 84,753 & 84,819 \\
RAPSO & 85,122 & 85,085 & 0,0671 & 84,810 & 85,124 \\
DE & 85,023 & 85,023 & 0,0095 & 85,006 & 85,044 \\
OABC & 84,804 & 84,804 & 0,0147 & 84,775 & 84,830 \\
\hline
\end{tabular}

Tabela 7.5. Estatísticas dos algoritmos de otimização bio-inspirada aplicados à restauração da imagem mostrada na Figura 7.3

\begin{tabular}{|c|c|c|c|c|c|}
\hline Algoritmo & Mediana & Média & Desvio Padrão & Mínimo & Máximo \\
\hline OPSO & 84,903 & 84,898 & 0,0108 & 84,883 & 84,909 \\
ABC & 84,494 & 84,494 & 0,0403 & 84,439 & 84,620 \\
RAPSO & 85,884 & 85,881 & 0,0074 & 85,856 & 85,901 \\
DE & 85,857 & 85,865 & 0,0134 & 85,854 & 85,909 \\
OABC & 84,528 & 84,530 & 0,0443 & 84,438 & 84,698 \\
\hline
\end{tabular}

Tabela 7.6. Estatísticas dos algoritmos de otimização bio-inspirada aplicados à restauração da imagem mostrada na Figura 7.4

\begin{tabular}{|c|c|c|c|c|c|}
\hline Algoritmo & Mediana & Média & Desvio Padrão & Mínimo & Máximo \\
\hline OPSO & 85,711 & 84,668 & 0,3945 & 85,542 & 85,820 \\
ABC & 85,722 & 85,724 & 0,0116 & 85,704 & 85,757 \\
RAPSO & 88,712 & 88,536 & 0,7126 & 85,729 & 88,739 \\
DE & 88,025 & 88,066 & 0,1473 & 87,946 & 88,733 \\
OABC & 85,730 & 85,732 & 0,0171 & 85,704 & 85,782 \\
\hline
\end{tabular}


Além disso, um ponto importante (e considerado como contribuição deste trabalho) foi a avaliação da aplicabilidade dos algoritmos de otimização baseada em meta-heurísticas escolhidos para guiar este problema específico de restauração, tendo em conta que não existe um algoritmo melhor que outro para todos os problemas; sendo que para cada problema específico deve ser feita uma análise experimental das diferentes opções (como mostrado nas discussões do teorema no-free lunch apresentadas por Wolpert e Macready [114]).

\subsection{Testes De SignifiCÂNCIA}

Os testes de significância servem para decidir se as amostras obtidas de um determinado experimento podem ser consideradas oriundas da mesma população ou de várias populações idênticas. Adicionalmente, estes testes podem ser utilizados para comparar o desempenho de dois ou mais meta-heurísticas [115].

Para comparar os resultados, foram geradas amostras para cada meta-heurística, a fim verificar a significância estatística. Cada amostra foi coletada aplicando 50 experimentos de restauração para cada uma das 5 meta-heurísticas utilizadas nos testes de restauração para imagens com degradações reais (vide Capítulo 7).

De posse das amostras de cada meta-heurística, o procedimento seguido para a realização dos testes de significância foi o seguinte [115]:

- Aplicar o teste Kolmogorov-Smirnov para testar se cada amostra segue uma distribuição normal.

- Se as amostras não seguem distribuições normais, aplicar o teste não paramétrico Wilconxon para determinar se os dados pertencem à mesma população.

- Se as amostras seguem distribuições normais, aplicar o teste de análise de variança (ANOVA) para determinar se os dados pertencem à mesma população.

- Se os testes supracitados mostram que as amostras pertencem a populações diferentes, o algoritmo de otimização que apresenta menoı ${ }^{1}$ mediana é considerado com melhor desempenho.

Para realização dos testes foram considerados os algoritmos de otimização bio-inspirados utilizados nos testes de restauração de imagens subaquáticas com degradações reais. Estes algoritmos foram: OPSO, RAPSO, ABC, OABC e DE. Cada algoritmo foi executado 50 vezes para a imagem degradada mostrada na Figura 7.2. No problema de restauração mostrado na Figura 7.2 ,

\footnotetext{
${ }^{1}$ Isto considerando um problema de minimização.
} 
Tabela 7.7. Testes de significância para os algoritmos de otimização bioinspirados aplicados ao problema de restauração apresentado na Figura 7.2

\begin{tabular}{|c|c|c|c|c|}
\hline & ABC & OABC & RAPSO & DE \\
\hline OPSO & ANOVA & ANOVA & ANOVA & Wilconxon \\
& $p=0,0004$ & $p=0,015$ & $p=0,0012$ & $p=6,5113 \times 10^{-12}$ \\
\hline ABC & & ANOVA & ANOVA & Wilconxon \\
& & $p=0,0686$ & $p=0,0002$ & $p=1,6416 \times 10^{-13}$ \\
\hline OABC & & & ANOVA & Wilconxon \\
& & & $p=0,0091$ & $p=1,5988 \times 10^{-13}$ \\
\hline RAPSO & & & & Wilconxon \\
& & & & $p=1,0072 \times 10^{-12}$ \\
\hline
\end{tabular}

todos os algoritmos apresentaram resultados satisfatórios, se for realizada uma análise subjetiva das imagens. Assim, os testes de significância podem comparar objetivamente o desempenho de cada algoritmo de otimização, utilizado para este problema.

Na Tabela 7.7 são apresentados os resultados referentes aos testes de significância para os algoritmos de otimização bio-inspirados aplicados ao problema de restauração apresentado na Figura 7.2. Neste caso, são consideradas duas hipóteses para um nível de confiança de 95\%:

- $H 0$ - as amostras pertencem à mesma população: probabilidade $p \geq 0,052$

- $H 1$ - as amostras não pertencem à mesma população: probabilidade $p<0,05$.

Assim, a Tabela 7.7 mostra que a maioria dos algoritmos apresentam distribuições normais e, portanto, o teste realizado correspondeu ao análise de variança (ANOVA). Da mesma forma, o algoritmo DE não apresentou uma distribuição normal e, por esta razão, a análise foi baseada no teste não-paramétrico. Por outra parte, quando foram comparados os algoritmos $\mathrm{ABC}$ e OABC, o valor da probabilidade $p$ foi maior que 0,05 (valor de significância). Isto significa que as distribuições geradas por estes algoritmos pertencem à mesma população e as variações nas medianas são causa somente da aleatoriedade do processo de otimização.

Além disso, com exceção da comparação entre os algoritmos ABC e OABC, a hipótese nula $H 0$ foi rejeitada na comparação de todos os demais algoritmos, o qual mostra uma diferencia estatística no comportamento dos mesmos. Neste caso, uma comparação das duas medianas pode inferir num melhor desempenho de um com respeito ao outro.

Adicionalmente, na Tabela 7.8 apresenta as medianas obtidas neste processo de otimização para cada um dos algoritmos. Nesta tabela pode ser observado que os algoritmos OPSO e

\footnotetext{
${ }^{2}$ Para um nível de confiança de $95 \%$, o nível de significância é do $5 \%$.
} 
Tabela 7.8. Valores das medianas para os testes de significância dos algoritmos de otimização aplicados ao problema de restauração mostrado na Figura 7.2 .

\begin{tabular}{|c|c|}
\hline & Mediana \\
\hline OPSO & $\mathbf{8 4 , 1 2 4}$ \\
\hline RAPSO & 85,122 \\
\hline ABC & $\mathbf{8 4 , 7 9 5}$ \\
\hline OABC & 84,804 \\
\hline DE & 85,023 \\
\hline
\end{tabular}

ABC apresentam as medianas mais baixas e, portanto, pode-se afirmar que são os algoritmos de otimização que apresentam melhor desempenho.

Neste caso, este estudo estatístico mostrou que os algoritmos OPSO e ABC foram mais eficientes para o cálculo dos parâmetros do modelo de formação de imagens subaquáticas. Este estudo mostrou estatisticamente o que foi comprovado experimentalmente pelas observações subjetivas realizadas sobre as imagens resultantes do processo de restauração apresentadas no Capítulo77. No contexto deste trabalho, considera-se que esta análise apresenta uma contribuição ao estado da arte no estudo da aplicação de algoritmos de otimização bio-inspirados para a restauração de imagens subaquáticas, devido a que um estudo deste tipo não está disponível na literatura atual. É importante ressaltar que as meta-heurísticas supracitadas comprovaram ser adequadas para processos de restauração de imagens subaquáticas devido à sua capacidade para resolver problemas multidimensionais (que é o caso do modelo de Wagner) e multimodais (que é o caso das métricas implementadas neste trabalho).

\subsection{Considerações Finais do Capítulo}

Neste capítulo foram apresentados os resultados referentes aos testes de restauração em imagens com degradações reais. Esta etapa consistiu na implementação do modelo inverso de Wagner para restauração de imagens subaquáticas coloridas. No Capítulo 6 foram consideradas imagens em níveis cinza com o objetivo de testar os algoritmos de otimização bio-inspirados aplicados ao problema de restauração de imagens subaquáticas. No entanto, a informação cromática é muito importante na percepção de qualidade visual de uma imagem e, portanto, na maioria das aplicações não pode ser desconsiderada. Porém, a presença deste tipo de informação faz com que o processo de restauração não possa ser aplicado diretamente a cada canal de cor, devido a que a propagação da luz depende do comprimento de onda da mesma. Por esta razão foi implementado o processo de compensação cromática apresentado na Seção 7.1. Este processo gera coeficientes 
que são utilizados posteriormente como pesos aplicados ao parâmetros do modelo.

Posteriormente, o processo de restauração, descrito no Algoritmo 11, foi implementado para imagens coloridas aplicando os pesos correspondentes a cada canal de cor. Adicionalmente, foram testados 5 algoritmos de otimização: OPSO, RAPSO, ABC, OABC e DE. Nestes testes, os algoritmos OPSO e ABC apesentaram os melhores resultados de restauração, mostrando imagens com melhor distribuição cromática e com menor grau de degradação. Além disso, o algoritmo DE apresentou os piores resultados. Este último não foi capaz de realizar uma restauração adequada na maioria dos casos, apresentando imagens, subjetivamente, de baixa qualidade. 


\section{Discussão de Resultados}

Nos Capítulos 5, 6 e 7 foram discutidas as metodologias e ferramentas implementadas no contexto deste trabalho. Primeiramente, foram apresentadas ferramentas importantes para a análise e desenvolvimento de processos de restauração de imagens em meios participativos. Estas ferramentas correspondem à Ferramenta de Degradação de Imagens em Meios Participativos (FDIMP) e o UID-LEIA (LEIA Underwater Image Database). Além disso, foram realizados os testes de restauração de imagens subaquáticas com degradações artificiais e reais. Neste capítulo serão discutidos os resultados obtidos nas etapas que constituem o desenvolvimento deste trabalho.

\subsection{ImplementaÇÃo dos Modelos de FormaÇão de Imagens em Meios Participativos}

Esta etapa apresenta a implementação de três modelos de formação de imagens: (a) modelo de Trucco e Olmos-Antillon, (b) modelo de Schechner e (c) modelo de Wagner. Ditos modelos correspondem simplificações do modelo de Jaffe-McGlamery. Este último consiste em um modelo de formação de imagens que considera um grande número de características e efeitos da propagação da luz em meios participativos. Embora este modelo possa simular a maioria das degradações que pode sofrer uma imagem adquirida em um meio onde a luz interage com o ambiente, dito modelo é de difícil implementação em sistemas de restauração automática. Isto é devido a que, como foi discutido no Capítulo 2, o processo de restauração de imagens consiste na inversão de um modelo de formação de imagens, cujos parâmetros devem ser estimados corretamente, com o objetivo de se obter como resultado uma imagem com o menor grau de degradação possível. Assim, quanto mais complexo for o modelo de formação de imagens utilizado, mais complexa será a implementação do modelo inverso. Portanto, os modelos simplificados apresentados por TruccoOlmos, Schechner e Wagner apresentam uma melhor alternativa para processos de restauração automática.

Desta maneira, no contexto deste trabalho foi criada a Ferramenta de Degradação de Imagens em Meios Participativos (FDIMP), cujo objetivo principal consiste em testar os três modelos 
simplificados supracitados. Na Seção 5.1 foi apresentada a metodologia seguida para a implementação destes três modelos simplificados de degradação. Um exemplo dos resultados obtidos nesta etapa podem ser observados nas Figuras 5.2, 5.3 e 5.5, que apresentam imagens degradadas utilizando os modelos de Trucco-Olmos, Schechner e Wagner, respectivamente. Nestas figuras, pode ser observado que o modelo mais completo corresponde à simplificação apresentada por Wagner.

Embora os modelos de Trucco-Olmos e Schechner apresentem alternativas de baixo custo computacional, estas simplificações estão limitadas pela distância entre o objeto e a câmera. Por exemplo, na Figura 5.2 a imagem apresenta borramento devido ao efeito de forward-scattering, porém este modelo não simula o efeito da perda de contraste devido ao back-scattering. Além disso, na Figura 5.3, que apresenta a degradação de uma imagem pelo modelo de Schechner, pode ser observado um efeito de perda de contraste muito forte, porém a imagem degradada não apresenta borramento, sendo esta uma das principais degradações das imagens subaquáticas [10]. A prova desta afirmação está representada na Figura 5.4, onde a imagem foi degradada simulando uma distância de 0,8 metros entre a câmera e o objeto, sendo esta distância mais adequada para o modelo de Trucco-Olmos [20]. Assim, a Figura 5.4(b) mostra uma imagem sem borramento e com uma leve perda de contraste, que não compromete significativamente a qualidade da imagem.

Por último, na Figura 5.5, apresenta-se um exemplo de degradação utilizando o modelo simplificado de Wagner. Neste caso, pode ser observado que a imagem degradada apresenta tanto os efeitos de borramento devidos ao forward-scattering, assim como também a perda de contraste característica do efeito de back-scattering. Portanto, este último modelo apresenta uma alternativa mais completa, em termos de degradação, se comparada com as outras duas simplificações.

Os Algoritmos 6, 7 e 8 apresentam os detalhes das implementações destes modelos de degradação. O modelo de Schechner (vide Algoritmo7) apresenta uma abordagem de baixa complexidade computacional $(O(M N)$ para uma imagem de tamanho $M \times N)$, sendo que a degradação é realizada diretamente no domínio espacial, evitando a utilização de transformadas. No entanto, como foi mencionado acima, este modelo não é aplicável para distâncias curtas. Além disso, a complexidade dos modelos de Trucco-Olmos (Algoritmo 6) e Wagner (Algoritmo 8) reside na criação e aplicação do filtro de convolução. Nestes casos, a aplicação do filtro é realizada no domínio da frequência utilizando a, apresentando uma complexidade computacional $O(M N \cdot \log (M N))$ para uma imagem de tamanho $M \times N$. A transformação para o domínio da frequência justifica-se levando em conta que o filtro de convolução, que representa o efeito de forward-scattering, pode ser construído de forma simples seguindo a equação 2.25). Neste caso, a aplicação do filtro corresponde à multiplicação ponto a ponto entre a imagem degradada pelo efeito de atenuação 
por transmissão direta e o filtro, evitando a operação de convolução no domínio espacial. Assim, neste sentido pode ser salientado que a escolha do modelo de Wagner foi sustentada tanto em termos teóricos como experimentais, no transcurso deste trabalho.

\subsection{ImplementaÇão e AnÁlise das Métricas de AvaliaÇão PARA Imagens com DegradaÇões ARTificiais}

Esta etapa consiste na implementação de duas métricas objetivas sem referência para a análise de qualidade de imagens, assim como um estudo de correlação que objetiva medir do desempenho de cada métrica, em relação a um banco de imagens predefinido. As métricas implementadas nesta etapa do trabalho foram: (a) a métrica BN-IQA e (b) a métrica NIQE.

A métrica BN-IQA (vide Seção 4.2.1) foi treinada utilizando o algoritmo de otimização PSO. Este treinamento consiste em estimas os melhores valores de $\omega_{1}, \omega_{2}, \omega_{3}$ e $\omega_{4}$, da equação (4.18), que apresentem um máximo valor de correlação em relação aos índices DMOS fornecidos pelo banco de imagens LIVE. Para dito treinamento, foram utilizadas 15 imagens com ruído branco e 15 com borramento Gaussiano, para um total de 30 imagens degradadas de treinamento (todas elas disponíveis no banco LIVE [101]). Estes tipos de degradação foram escolhidos para treinar o sistema, já que são as principais degradações que sofre uma imagem em ambientes subaquáticos [10].

Assim, o algoritmo PSO foi rodado 32 vezes, calculando assim a média dos 32 valores encontrados para cada peso. Os valores estimados foram $\omega_{1}=1,3187, \omega_{2}=2,4223, \omega_{3}=-1,0295$, e $\omega_{4}=-0,7162$. A correlação SRCC média obtida no processo de otimização foi de 0,8750 .

Com os pesos $\omega_{1}, \omega_{2}, \omega_{3}, \omega_{4}$ calculados pelo PSO, o sistema foi testado com 159 imagens degradadas com ruído branco e 159 imagens degradadas com borramento Gaussiano do banco LIVE. Estas imagens correspondem a um conjunto diferente àquele utilizado para o treinamento da métrica. O coeficiente de correlação SRCC entre os valores obtidos para a métrica BN-IQA e os índices de avaliação subjetiva DMOS fornecidos pelo banco de imagens foi de 0,8193.

Além disso, também foi implementada a métrica NIQE (vide Seção 4.2.2). O treinamento realizado para esta métrica consiste em gerar um modelo NSS das imagens de treinamento (sem degradação) e, assim, comparar com o modelo NSS da imagem degradada. O treinamento foi realizado utilizando as imagens sem degradação fornecidas no banco LIVE. Assim, para a análise de correlação foram utilizadas 87 imagens degradadas com ruído branco e 87 imagens degradadas por borramento Gaussiano, para um total de 174 imagens degradadas. Assim, o índice de correlação SRCC entre os valores encontrados pela métrica NIQE e os índices DMOS fornecido pelo banco de imagens foi de 0,9497. 
Finalmente, o desempenho das métricas NIQE e BN-IQA foi comparado com o desempenho da métrica com referência PSNR (vide Seção 4.1). A métrica PSNR foi analisada com um total de 348 imagens do banco LIVE, divididas em 174 imagens degradadas com ruído branco e 174 com ruído Gaussiano. O SRCC encontrado para esta métrica foi de 0,9198. Devido a que esta métrica necessita de uma imagem de referência disponível, esta implementação foi feita exclusivamente para fins de comparação com as métricas sem referência. Dita comparação de desempenho pode ser observada na Tabela 5.1, que apresentou um resumo dos resultados obtidos a partir da análise de correlação das métricas acima.

Como pode ser observado na Tabela 5.1, a métrica com maior coeficiente de correlação é a NIQE com um SRCC de 0,9497. É importante ressaltar que este valor é maior que o obtido para o PSNR (0,9198), sendo esta uma métrica com referência completa. Além disso, os valores obtidos para a métrica baseada em ruído e borramento BN-IQA são menores que as outras duas métricas. Porém, isto não significa que as métricas apresentem baixo desempenho. Métricas sem referência com estes valores de correlação são consideradas aceitáveis e podem ser usadas para ter uma boa estimativa da qualidade de uma imagem. Devido a estes resultados, foi possível definir a métrica NIQE como função objetivo para guiar o processo de restauração de degradações artificiais apresentado no Capítulo6.

\subsection{Testes de Restauração para Imagens Com DegradaÇões Artificiais}

Esta etapa teve como objetivo principal analisar o desempenho dos algoritmos de otimização bio-inspirados aplicados ao problema de restauração de imagens subaquáticas. Para estes testes foi implementado o modelo inverso de Trucco e Olmos-Antillon, apresentado no Algoritmo 9. Este modelo foi escolhido para os testes iniciais devido à simplicidade e custo computacional, além de simular o efeito de borramento em ambientes subaquáticos.

\subsubsection{Testes Mono-Objetivo}

Para os testes de restauração foi implementado o algoritmo PSO, sendo utilizado a métrica NIQE como função objetivo, sendo que as variáveis de decisão foram fornecidas pelo coeficiente de atenuação do meio $(c)$ e o ganho da PSF $(K)$. No contexto deste trabalho, a distância $d m$ não foi considerada como uma variável de decisão, devido que o produto $c . d m$ pode gerar infinitas combinações possíveis. Além disso, o valor de $d m$ pode ser estimado utilizando métodos com visão estéreo [30], [29]. 
O algoritmo PSO foi executado 10 vezes para cada imagem. Assim, os valores das variáveis de decisão utilizados para realizar a restauração correspondem ao valor médio dos valores encontrados nas 10 iterações do processo. Da mesma forma, o algoritmo de restauração foi testado utilizando os métodos exatos de otimização mono-objetivo fminseach e fmincon, disponíveis na Toolbox de otimização do MATLAB. Na Tabela 6.1 apresentaram-se os valores estimados para o processo de restauração apresentado na Figura 6.2, que mostra os resultados visuais da restauração de uma imagem degradada artificialmente utilizando $c=0,5 \mathrm{~m}^{-1}, K=0,3$ e $d=1 \mathrm{~m}$.

Na Tabela 6.1 pode ser observado que os parâmetros foram melhor estimados utilizando o algoritmo PSO. Da mesma forma, a Figura 6.2 também apresenta melhores resultados visuais para a imagem restaurada utilizando o algoritmo PSO. Porém, embora o resultado da restauração com PSO é satisfatório, apresentam-se alguns problemas de contraste na imagem restaurada (vide Figura 6.2(c)). Estes problemas apresentem-se devido a que a métrica NIQE não está projetada diretamente para degradações de contraste e, como pode ser observado na Figura 6.3, o valor desta métrica não é susceptível a mudanças no valor de $K$. Para solucionar este problema, se decidiu implementar algoritmos de otimização bio-inspirados multiobjetivo, utilizando duas ou mais métricas como função custo. Desta forma pode-se garantir que as vantagens de determinada métrica podem ser uteis para cobrir as desvantagens das outras.

\subsubsection{Testes Multi-Objetivo}

Para os testes multi-objetivo foi necessário definir uma métrica que pudesse resolver os problemas de contraste das imagens restauradas e que permitisse fazer uma melhor estimativa do valor de $K$. A métrica implementada nesta etapa do trabalho foi a Distribuição de Contraste Local, apresentada na Seção 4.2.3. Objetivando medir o desempenho desta métrica com relação às imagens do banco LIVE, foi realizada uma análise de correlação com um conjunto de 87 imagens degradadas com borramento Gaussiano. Esta escolha justifica-se levando em conta que um dos principais efeitos do borramento consiste em reduzir o contraste de pequenos objetos [110]. Para esta análise, o coeficiente de correlação SRCC obtido foi 0,8502. Este valor de correlação considera-se aceitável para uma métrica sem referência e, por esta razão, esta métrica foi implementada nos testes multi-objetivo.

A estratégia de restauração implementada foi baseada no algoritmo de otimização multiobjetivo por evolução diferencial (MODE), apresentado na Seção 3.5.1. Neste contexto, foram testadas duas variações deste algoritmo: DEMO/Parent e PDEA. A diferença entre as duas reside no processo de seleção. Enquanto o algoritmo DEMO/Parent realiza uma seleção baseada na dominância das soluções pai sobre as soluções filhas, o algoritmo PDEA concatena todas as soluções pai e filha. Finalmente, tanto o PDEA como o DEMO/Parent utilizam um algoritmo 
de truncamento baseado em dominância e diversidade com o objetivo reduzir a população até seu tamanho original.

A Figura 6.6 apresenta um exemplo de restauração utilizando a estratégia MODE, onde os parâmetros utilizados para degradação foram $c=0,3 m^{-1}$ e $K=0,7$ para uma distância fixa $d m=3 m$. Após o processo de otimização, os parâmetros estimados para uma correta restauração da imagem foram $c=0,3899 \mathrm{~m}^{-1}$ e $K=0,7521$. Os valores obtidos para as funções objetivo foram $N I Q E=3,779$ e Range $=1,912$. Adicionalmente, os valores de qualidade para as imagens originais são $N I Q E=3,3998$ e Range $=1,1723$, e para a imagem degradada $N I Q E=9,0044$ e Range $=0,3842$. Os resultados obtidos mostram que os valores estimados para $c$ e $K$ são muito similares àqueles utilizados no processo de degradação artificial. Por outra parte, os valores de qualidade da imagem restaurada, dados pelo valor final da funções objetivo, também são similares aos medidos para a imagem original. No entanto, fazendo uma análise subjetiva da Figura 6.6, é possível afirmar que a imagem restaurada (Figura 6.6.(c)) tem, levemente, melhor qualidade se comparada com a imagem original (Figura 6.6(b)). Isto pode ser devido a que as imagens de referência do banco LIVE, que foram utilizadas nos testes de restauração, foram adquiridas em ambientes naturais e algumas podem apresentar distorções.

Os resultados podem sugerir que, em alguns casos, o processo de restauração está restaurando estas pequenas degradações. No entanto, nesta parte do trabalho, foram utilizadas imagens degradadas artificialmente mediante o algoritmo de Trucco e Olmos-Antillon e torna-se necessária a implementação de uma abordagem mais real.

Além disso, os resultados desta etapa do trabalho foram apresentados no IEEE CEC2015 (IEEE Congress on Evolutionary Computation 2015) na cidade de Sendai (Japão), gerando a publicação apresentada em [111].

\subsection{CriaÇÃo E AnÁlise Subjetiva do UID-LEIA}

Devido à necessidade de uma abordagem com imagens subaquáticas reais, foi indispensável contar com um banco que possua um conjunto de imagens com degradações reais passíveis de análise subjetiva. A criação do banco UID-LEIA é uma das contribuições deste trabalho, devido à carência de bancos de imagens subaquáticas disponibilizados na internet. Atualmente, não existem bancos de imagens subaquáticas com informação de análise subjetiva das imagens. A análise subjetiva torna-se fundamental para a análise de desempenho das métricas de avaliação objetiva.

Nesta etapa do trabalho foi implementada uma metodologia para adquisição e análise de imagens subaquáticas. Neste contexto, foi criado o UID-LEIA (LEIA Underwater Image Da- 
tabase), cujos detalhes são discutidos na Seção 5.3. Para a aquisição das imagens foi utilizado um aquário de vidro e uma câmera digital convencional. A configuração deste experimento é mostrada na Figura 5.10. Inicialmente, foram obtidas 85 imagens sem água, que, posteriormente, são utilizadas como imagens de referência para a etapa de avaliação subjetiva. Além disso, foram adquiridas um total de 255 imagens com diferentes níveis de turbidez da água, com objetos de diferentes cores e a diferentes distâncias em relação à câmera.

Após a formação do UID-LEIA, procedeu-se a realizar a análise subjetiva das imagens do banco. Esta análise foi realizada por 32 pessoas, que indicaram o nível de degradação geral das imagens utilizando uma escala de avaliação desde 0 até 10, onde 0 representa a melhor qualidade e o valor de 10 representa uma imagem muito degradada. Assim, são analisadas 135 imagens do banco UID-LEIA, levando um tempo de experimento de aproximadamente 40 minutos por avaliador. O resultado desta avaliação foram os valores médios das avaliações, gerando um índice MOS para cada uma das 135 imagens.

\subsection{Análise das Métricas de AvaliaÇão para Imagens Com DegradaÇões Reais}

De posse das imagens com degradações reais, assim como de seus índices subjetivos de qualidade, foi realizado um estudo de desempenho baseado em correlação, visando assim determinar a melhor métrica para guiar os processos de otimização. Para tanto, foram implementadas as métricas UCIQE e PUIQ, apresentadas nas Seções 4.38 e 4.2.5. respectivamente. Além destas últimas, também foram analisadas as métricas NIQE, BN-IQA e Distribuição de Contraste que já haviam sido implementadas para análise de correlação com o banco LIVE. Assim, foi testado um conjunto de 5 métricas de avaliação de qualidade de imagens sem referência.

Para o treinamento das métricas UCIQE, PUIQ e BN-IQA foram utilizadas 60 imagens degradadas do banco UID-LEIA. Para este treinamento foram utilizados três algoritmos de otimização bio-inspirados: PSO, ABC e DE. Estes algoritmos têm como objetivo encontrar valores dos pesos de cada métrica que permitam maximizar a correlação entre as avaliações subjetivas das imagens e o valor calculado pela métrica. Assim, na etapa de treinamento, o PSO apresentou melhor valor de correlação para as métricas UCIQE e PUIQ, enquanto o algoritmo DE apresentou melhores resultados para a métrica BN-IQA.

Além disso, após o treinamento, foi realizada uma análise de correlação das métricas em relação as 75 imagens restantes do UID-LEIA (estas imagens não fizeram parte do treinamento). Estes testes geraram valores de correlação máximos de 0,8992 para a métrica UCIQE, obtido utilizando os pesos estimados com o algoritmo PSO. Da mesma forma, a métrica PUIQ apresentou 
uma correlação máxima de 0,6002 utilizando so pesos gerados pelo algoritmo DE. E, por último, a métrica BN-IQA mostrou um valor máximo de correlação de 0,6867, também utilizando os dados gerados pelo treinamento com o algoritmo DE.

Adicionalmente, a métrica NIQE foi treinada utilizando as 85 imagens de referência do banco UID-LEIA. A partir destas imagens a métrica cria um modelo NSS de referência que será comparado posteriormente como o modelo NSS da imagem degradada. Após o treinamento, a análise de correlação com base nas 135 imagens degradadas do UID-LEIA revelou um valor do SRCC de 0,9357 para a métrica NIQE.

Por último, foi realizado um estudo de correlação para a métrica de Distribuição de Contraste Local, a qual não precisa de treinamento. Esta análise foi realizada utilizando as 135 imagens degradadas do banco UID-LEIA, gerando o índice de correlação mais baixo se for comparado com as métricas supracitadas. O valor de correlação apresentado por esta métrica foi de 0,4138 . A Tabela 5.6 apresenta um resumo do desempenho apresentado pelas métricas mencionadas acima.

Em conclusão, devido ao índice de correlação SRCC, a métrica NIQE mostrou o melhor desempenho para a análise de qualidade objetiva das imagens do UID-LEIA, as quais apresentam degradações subaquáticas reais. Por esta razão, a métrica NIQE foi escolhida como função objetivo para guiar os processos de otimização que serão aplicados ao problema de restauração de imagens subaquáticas com degradações reais.

É importante ressaltar que a escolha de uma métrica adequada é uma parte fundamental na criação de uma estratégia de restauração de imagens (com degradações artificiais ou reais) baseada em otimização. Nesse contexto, foi imprescindível realizar o estudo de desempenho apresentado acima. Este estudo representa uma contribuição importante deste trabalho, já que foi realizada uma análise de cada métrica, assim como um estudo da combinação de várias delas, a fim de orientar a obtenção de uma estratégia de restauração baseado em uma possível otimização multi-objetivo (vide Seção 6.3). No contexto desta tese, esta tarefa foi exaustiva, pois, atualmente, não existe um estudo comparativo das métricas de avaliação de qualidade de imagens para imagens em meios participativos como o apresentado neste trabalho.

\subsection{Testes de RestauraÇÃo Para Imagens Com DegradaÇões Reais}

Após ter definido a melhor métrica para guiar os processos de restauração para imagens reais, o próximo passo consistiu na implementação de uma estratégia de restauração baseada no modelo inverso do Wagner. O problema principal da implementação deste modelo, descrita no Algoritmo 12 , está na criação e aplicação do filtro inverso, dado pela equação (2.27). Para isto, a imagem 
é levada para o domínio da frequência, onde é aplicado o filtro. Após o processo de filtragem, a imagem é levada de novo para o domínio espacial. A diferença do modelo inverso de Trucco e Olmos-Antillon (implementado para os testes em imagens com degradações artificiais), este modelo também considera o efeito de back-scattering, que é o principal responsável pela pela de contraste na imagem. A escolhia do modelo simplificado de Wagner para guiar este processo de restauração justifica-se levando em conta que dito modelo apresenta um bom compromisso entre a complexidade computacional e sua aplicabilidade na restauração de imagens subaquáticas, sendo capaz de simular fielmente as degradações mais representativas deste tipo de ambientes sem apresentar um alto custo computacional. Além disso, levando em conta que a informação cromática é muito importante na percepção da qualidade, este modelo foi implementado para a restauração de imagens coloridas. Assim, devido às mudanças nas propriedades da luz em relação a seu comprimento de onda, não foi possível utilizar os mesmos parâmetros para todos os canais de cor, pelo que foi necessária uma etapa de compensação cromática, descrita no Algoritmo 10 . Este algoritmo conseguiu encontrar os pesos adequados para restauração das imagens no espaço RGB.

Além disso, na estratégia de restauração foram testados 5 algoritmos de otimização bioinspirada mono-objetivo: OPSO, RAPSO, ABC, OABC e DE. Neste caso, como foi discutido na Seção 8.5, a métrica NIQE apresentou melhores resultados de desempenho e, portanto foi escolhida como função objetivo para os primeiros testes de restauração. Os resultados (vide Figuras 7.2, 7.3 e 7.4 mostraram que, visualmente, as melhores restaurações foram alcançadas utilizando os algoritmos OPSO, ABC e OABC. Da mesma forma, pode ser observado que o desempenho do algoritmo de evolução diferencial (DE) foi muito baixo, obtendo imagens com distribuições de cor muito diferentes aos esperados.

Em conclusão, embora os algoritmos DE e RAPSO não tenham apresentado soluções razoáveis, de forma geral, estes resultados mostram que os algoritmos de otimização bio-inspirada apresentam uma alternativa eficiente para resolver o problema de restauração de imagens em ambientes subaquáticos, levando em conta que estes problemas são de carácter multidimensional e multimodal. Além disso, os meios participativos, como a água, são ambientes dinâmicos onde se faz necessária a implementação de algoritmos de otimização que possa-se adaptar facilmente a ditas variações.

\subsection{COMENTÁRIOS FinAIS}

Este trabalho apresentou uma estratégia de restauração de imagens subaquáticas com uma abordagem de otimização bio-inspirada. Esta estratégia está baseada na inversão de um modelo de formação de imagens em meios participativos, cujos parâmetros devem ser estimados. Como 
foi discutido no Capítulo 1, existem duas abordagens utilizadas para a obtenção de imagens subaquáticas de melhor qualidade: melhoramento e restauração.

Embora existem vários trabalhos na área de melhoramento de imagens subaquáticas [116][120], onde estas técnicas são baseadas, principalmente, na equalização de histogramas, carecendo de generalidade; pudendo ser aplicada para situações onde foi projetada (ad-hoc)[116] e que, em alguns casos, não pode ser aplicada a processos de melhoramento automático [117].

Além disso, os algoritmos de restauração de imagens apresentados na literatura mostram uma tendência a utilizar métodos de deconvolução cega, tais como o filtro de Wiener [121], [122], [123. Este tipo de filtros, geralmente não podem ser aplicados a diferentes situações de ruído ou borramento na imagem [121]. Adicionalmente, são apresentados, com melhores resultados, os algoritmos de restauração de imagens subaquáticas baseados em modelos de formação de imagens [124], [125], 9]. Neste sentido, o trabalho de Lu et al. [125] apresenta uma estratégia para restauração do contraste em imagens subaquáticas; porém não considera o efeito de borramento, apresentando pontos de ruído nas imagens resultantes. Além disso, o trabalho de Hou et al. 124] é aplicável somente para imagens obtidas mediante um laser polarizado, precisando assim de equipamentos externos de captura diferentes a uma câmera convencional.

Já o trabalho apresentado por Wagner [9] apresenta melhores resultados e considera um modelo de formação de imagens mais geral e de baixa complexidade computacional. Wagner propõe um modelo de formação de imagens que considera tanto o efeito de forward-scattering como também o efeito devido ao back-scattering. Desta forma, o autor utiliza um conjunto de 4 métricas de avaliação de qualidade objetivando guiar um processo de otimização multi-objetivo baseado na função fgoalattain disponível no Toolbox de Otimização do MATLAB. Esta função faz parte dos métodos de programação quadrática sequencial que têm complexidade $O\left(q p^{2}\right)$ por iteração, onde $q$ corresponde ao número de restrições e $p$ ao número de variáveis.

Além disso, o trabalho apresentado no contexto desta tese, apresenta uma estratégia de otimização baseada em algoritmos bio-inspirados que, diferente do trabalho supracitado, necessita somente uma métrica de avaliação de qualidade para guiar o processo de otimização, reduzindo assim a complexidade referente à etapa de avaliação de qualidade. Da mesma forma que os resultados obtidos no contexto do presente trabalho, as imagens restauradas apresentadas no trabalho de Wagner mostram (subjetivamente) boa qualidade, porém, não pode ser realizada uma comparação objetiva dos resultados entre os dois trabalhos pelo fato de que as métricas de qualidade utilizadas são diferentes. Por esta razão também não é possível realizar comparações objetivas com outros trabalhos apresentados na literatura na área de restauração ou melhoramento de imagens, fazendo possível só uma análise subjetiva das imagens resultantes.

Também é importante ressaltar que não existe um estudo prévio sobre a implementação de 
algoritmos bio-inspirados aplicados ao problema de restauração de imagens subaquáticas com degradações reais ou artificiais. Assim, no presente trabalho, foi apresentada a implementação de 5 algoritmos de otimização bio-inspirados, dos quais os algoritmos OPSO, ABC e OABC apresentaram resultados satisfatórios, tanto objetiva como subjetivamente.

A partir das considerações acima, pode-se concluir que o trabalho apresentado no contexto desta tese alcançou os objetivos propostos e, além disso, apresentou uma nova estratégia para restauração de imagens subaquáticas baseada em otimização bio-inspirada; cujos resultados foram obtidos (para imagens degradadas de maneira real) a partir de um banco de dados de imagem geradas pelo autor desta tese.

Assim, como parte das contribuições deste trabalho está o ter-se obtido também resultados concretos sobre imagens subaquáticas, onde as degradações foram inseridas de maneira natural; dando assim um maior rigor experimental para a avaliação das restaurações. Da mesma forma, a criação do banco UID-LEIA, assim como sua avaliação subjetiva, apresentam-se como uma contribuição às ferramentas disponíveis para análise de desempenho de métricas objetivas aplicadas a imagens com degradações subaquáticas reais. Portanto, a comparação de desempenho das métricas de avaliação objetiva realizada neste trabalho também supõe um aporte importante desta tese, pois, atualmente, não está disponível outro estudo deste tipo na literatura. Por último, a aplicação de meta-heurísticas como estratégia de otimização para processos de restauração de imagens subaquáticas, assim como a análise estatística de desempenho de ditas meta-heurísticas, apresentam também uma contribuição importante ao estado da arte, tanto no campo das aplicações de algoritmos bio-inspirados como também na área de restauração e processamento de imagens subaquáticas. 


\section{Conclusões e Perspectivas de Trabalhos Futuros}

Neste trabalho foi apresentada uma estratégia de restauração de imagens subaquáticas baseada na implementação de algoritmos de otimização bio-inspirados. Neste sentido, este capítulo apresentada as conclusões deste trabalho. Finalmente, serão apresentadas as perspectivas de trabalhos futuros.

\subsection{Conclusões}

As conclusões apresentadas nesta seção estão divididas seguindo as hipóteses e objetivos propostos na Seção 1.3

- Como foi discutido nos Capítulos 6 e 7, o processo de restauração consistiu em encontrar os valores ótimos dos parâmetros que descrevem um modelo de degradação de imagens. A estimação destes parâmetros objetiva melhorar a qualidade da imagem, sendo esta qualidade medida mediante a implementação de uma métrica de avaliação de imagens sem referência. Isto leva a afirmar que o processo de restauração de imagens pode ser tratado como um problema de otimização, dando importância à pesquisa e caracterização de estratégias de otimização.

- Os algoritmos de restauração de imagens baseados em modelos de degradação apresentam um problema de otimização no qual devem ser estimados diferentes parâmetros do modelo. Por exemplo, no Capítulo 6 foi utilizado o modelo de Trucco-Olmos, o qual requer a estimação de dois parâmetros para o processo de restauração de imagens com degradações artificiais. Além disso, no Capítulo 7 foi apresentado um processo de restauração baseado no modelo de Wagner, onde 3 parâmetros devem ser estimados corretamente para obter um bom resultados de restauração de imagens com degradações reais. Nesse contexto, os algoritmos de otimização bio-inspirados mostraram um melhor desempenho que os algoritmos de otimização exatos apresentados no Capítulo 6, já que as estratégias de otimização bio-inspiradas são mais apropriadas para problemas multidimensionais. 
- As métricas utilizadas no contexto deste trabalho apresentaram um grande desafio em termos de otimização, devido a que o comportamento das métricas pode mudar para cada imagem. Além disso, estas métricas, geralmente, são multimodais. Assim, os algoritmos de otimização bio-inspirados mostraram ser mais apropriados para problemas de restauração de imagens subaquáticas.

- Os resultados apresentados no na Seção 6.2 mostraram que, em alguns casos, não é suficiente só uma métrica para avaliar completamente a qualidade das imagens restauradas. Assim, foi implementada uma estratégia multi-objetivo, a qual permitiu cobrir as desvantagens da primeira métrica mediante a adição de uma segunda métrica (Distribuição de Contraste Local).

- Uma parte importante do processo de restauração consiste em encontrar uma métrica adequada que permita guiar o processo de otimização. Neste trabalho foram implementadas e analisadas diferentes métricas de avaliação de qualidade de imagens, das quais foi escolhida aquela com melhor desempenho para guiar o processo de otimização. Nesse contexto, a métrica NIQE mostrou-se ser uma boa alternativa, tanto para a restauração de imagens com degradações artificias como para imagens com degradações reais.

- Devido a versatilidade dos algoritmos de otimização bio-inspirada, foi possível encontrar várias alternativas que permitiram restaurar corretamente as imagens degradadas. Como foi discutido no Capítulo 7, as melhores estratégias no contexto deste trabalho foram os algoritmos OPSO e ABC, as quais apresentaram as melhores restaurações e melhores valores finais da função objetivo. Neste sentido, os testes de significância corroboraram estes resultados.

- Devido a que os modelos de degradação de imagens em meios participativos apresentam um modelo bastante aproximado das degradações geradas pela interação entre a luz e a água, foi demostrado que é possível aplicar estratégias similares de restauração, tanto para imagens com degradações artificiais como também para imagens degradadas naturalmente.

\subsection{Perspectivas de trabalhos Futuros}

A restauração de imagens subaquáticas ou, de forma geral, em meios participativos é uma área muito atraente no processamento de imagens digitais e visão computacional, para aplicações em ambientes onde a luz tem interações muito fortes com o meio de propagação, como por exemplo ambientes com neblina, baixa visibilidade, polução, etc. Embora o desenvolvimento deste trabalho apresente resultados satisfatórios para uma estratégia de restauração de imagens em meios subaquáticos, existe ainda uma grande lacuna por ferramenta e estratégias de baixo 
custo e alto desempenho, que permitam lidar com este tipo de problemas. Assim, abaixo são apresentadas as perspectivas de estudos e trabalhos futuros, que podem ser realizados visando complementar os resultados apresentados no contexto deste trabalho.

- Neste trabalho foi apresentada a implementação de uma estratégia para restauração de imagens subaquáticas. O estudo de outro tipo de ambientes participativos, como por exemplo, neblina, poluição, entre outras, pode gerar como resultado uma estratégia mais geral e independente do meio de propagação da luz.

- No contexto deste trabalho foram apresentadas em total 5 estratégias de otimização bioinspiradas. O estudo e a implementação de outros métodos de otimização bio-inspirados, assim como um estudo de adição de diversidade dos algoritmos já implementados, pode apresentar alternativas com melhores resultados.

- A estratégia de restauração de imagens apresentada neste trabalho possui um tempo de execução bastante elevado, não sendo adequada para aplicações em tempo de vídeo (de 15 a 30 fps). Por esta razão, é importante realizar implementações que permitam acelerar o processo de restauração mediante a implementação de arquiteturas paralelas. Por exemplo, em [13] é apresentada a implementação em hardware de diferentes algoritmos de otimização bio-inspirada, reduzindo significativamente o tempo de processamento, porém não existem atualmente implementações em hardware que realizem um processo completo de restauração de imagens subaquáticas.

- O banco de imagens apresentado neste trabalho é uma contribuição importante para a área de processamento de imagens subaquáticas, já que existe uma carência deste tipo de ferramentas. No entanto, as imagens do banco UID-LEIA foram adquiridas em laboratório sob condições de iluminação controlada objetivando cumprir com as restrições impostas para a utilização dos modelos de formação de imagens. Desta forma, este banco pode ser melhorado, mediante a adquisição de imagens em ambientes menos controlados (como por exemplo o ambiente submarino). Também pode ser melhorada a análise subjetiva, mediante a realização de mais experimentos com um maior número de pessoas.

- Neste trabalho considera-se que a distância entre o objeto e a câmera é conhecida, porém, em algumas aplicações específicas, esta informação pode não estar disponível. Assim, a implementação de um sistema de restauração de imagens que permita também realizar uma estimativa de distância entre a câmera e o objeto é muito importante para, por exemplo, aplicações em robótica submarina. 


\section{REFERÊNCIAS BIBLIOGRÁFICAS}

[1]H. Pedrini, W. R. Schwarz, "Análise de Imagens Digitais - Princípios, Algoritmos e Aplicações", Editora Thomson, 2008.

[2]R. González, R. Woods, "Tratamiento Digital de Imágenes". Wilmington, USA: AddisonWesley, 1996. ISBN 0-201-62576-8.

[3]E. Trucco, A. Verri, "Introductory Techniques for 3-D Computer Vision", Prentice-Hall, New Jersey, USA, 1998.

[4]M. Narimani, S. Nazem, M. Loueipour, "Robotics Vision-based System for an Underwater Pipeline and Cable Tracker", OCEANS 2009 - EUROPE, pp. 1-6, Bremen, Alemanha, 2009.

[5]Y. Schechner, N. Karpel, "Clear Underwater Vision", Proc. Computer Vision and Pattern Recognition, Vol. I, pp. 536-543, 2004, Washington, DC, USA.

[6]A. K. Jain, "Fundamental of Digital Image Processing", Prentice-Hall, 1989.

[7]N. Li, Y. Li, "Image Restoration Using Improved Particle Swarm Optimization", International Conference on Network Computing and Information Security, pp. 394-397, 2011.

[8]R. Dash, B. Majhi, "Particle Swarm Optimization Based Regularization for Image Restoration", World Congress on Nature and Biologically Inspired Computing, pp. 1253-1257, 2009.

[9]W. Ferreira de Barros, "Uma Abordagem Automática para Restauração de Imagens de Cenas Subaquáticas", Tese de Doutorado, Programa de Pós-Graduação em Ciência da Computação do Instituto de Ciências Exatas da Universidade Federal de Minas Gerais (UFMG), 2010.

[10]R. Schettini, S. Corchs, "Underwater Image Processing: State of Art of Restoration and Image Enhancement Methods", EURASIP Journal on Advances in Signal Processing, Volume 2010.

[11]Y. Zhang, Z. Jia, H. Jiang, Z. Liu, "Image Restoration Based on Robust Error Function and Particle Swarm Optimization-BP Neural Network", IV International Conference on Natural Computation, pp 640-644, 2008 
[12]S. Rao, "Engineering Optimization, Theory and Practice", John Wiley and Sons, USA, 1996

[13]D. M. Muñoz, "Otimização por Inteligência de Enxames Usando Arquiteturas Paralelas para Aplicações Embarcadas", Tese de Doutorado em Mecatrônica, publicação ENM.TD-02/12, Dep. de Engenharia Mecânica, Universidade de Brasília, DF, 2012.

[14]S. Luke, "Essentials of Metaheuristics", Lulu, 2009, Available for free at http://cs.gmu.edu/ sean/book/metaheuristics/.

[15]J. Kennedy, R. Eberhart, "Swarm Inteligence", Morgan Kaufman, 2001.

[16]R. D. Christ, R. L. Wernli, "The ROV Manual: A User Guide for Observation-Class Remotely Operated Vehicles", Elsevier, 2007

[17]B. K. Gunturk, X. Li, "Image Restoration: Fundamentals and Advances", CRC Press, ISBN 978-1-4398-6955-0, 2013

[18]J. S. Jaffe, "Computer Modeling and the Design of Optimal Underwater Imaging System", IEEE Journal in Ocean Engineering, pp. 101-111, 1990.

[19]B. L. McGlamery, "A Computer Model for Underwater Camera Systems", SPIE Ocean Optics, Volume 208, pp. 221-231, 1979.

[20]E. Trucco, A. Olmos-Antillon, "Self-tuning Underwater Image Restoration", IEEE Journal of Oceanic Engineering, pp. 511-519, 2006.

[21]Z. Sun, E. Li, J. Zhang, X. Gao, "A Regularized Image Restoration Algorithm Based on Improved Hybrid Particle Swarm Optimization", The 6th International Forum on Strategic Technology, pp. 725-728, 2011.

[22]J. P. Papa, L. M. G. Fonseca, L. A. S. de Carvalho, " Projections Onto Convex Sets through Particle Swarm Optimization and its application for remote sensing image restoration", Pattern Recognition Letters 31, pp. 1876-1886, 2010

[23]T. H. Dixon, T. J. Pivirotto, R. F. Chapman, and R. C. Tyce, "A Range-Gated Laser System for Oceanic Floor Imaging", Marine Technology Society Journal, vol. 17, 1983.

[24]Y. Schechner, N. Karpel, "Recovery of Underwater Visibility and Structure by Polarization Analysis", IEEE Journal of Oceanic Engineering, pp. 570-587, 2005

[25]K. J. Voss, "Simple Empirical Model of the Oceanic Point Spread Function", Aplied Optics, pp. 2647-2651, 1991.

[26]S. G. Narasimhan, C. Wang, S. K. Nayar, "All the Images of an Outdoor Scene", European Conference on Computer Vision, Lecture Notes in Computer Science, pp. 148-162, 2002 
[27]J. P. Queiroz-Neto, "Modelagem Automática de Cenas com Iluminação não Local a Partir de Imagens", PhD Thesis, Universidade Federal de Minas Gerais, 2005

[28]S. Zhang, S. Negahdaripour, "3-d Shape Recovery of Planar and Curved Surfaces from Shading Cues in Underwater Images", IEEE Journal of Oceanics Engineering, pp. 100-116, 2002

[29]E. Nascimento, M. Campos, W. Barros, "Stereo Based Structure Recovery of Underwater Scenes from Automatically Restored Images", XXII Brazilian Symposium on Computer Graphics and Image Processing, pp. 330-337, 2009.

[30]C. Sánchez-Ferreira, J. Y. Mori, M. C. Q. Farias, C. H. Llanos, "A Real-time Stereo Vision System for Distance Measurement and Underwater Image Restoration", Journal of the Brazilian Society of Mechanical Sciences and Engineering, vol 38 pp. 2039-2049. DOI 10.1007/s40430016-0596-5, 2016.

[31]Z. Michalewicz, "Heuristic Methods for Evolutionary Computation Techniques", Journal of Heuristics, Vol. 2, No. 1, pp. 177-206, 1995.

[32]J. H. Holland. "Building blocks, cohort genetic algorithms, and hyperplanedefined functions". Evolutionary Computation, 8(4):373-391, December 2000.

[33]E. Bonabeau, M. Dorigo, G. Therculaz, "Swarm Intelligence from Natural to Artificial Systems", New York: Oxford University Press, 1999.

[34]J. Kennedy, R. Eberhart, "Particle Swarm Optimization", Proc. International Conference on Neural Networks, pp. 1942-1948, 1995.

[35]R. Eberhart, J. Kennedy, "A New Optimizer Using Particle Swarm Theory", Proc. International Symposium Micromachine and Human Science, pp. 39-43, 1995.

[36]F. Bergh, "An Analysis of Particle Swarm Optimizers", Tese de Doutorado, Department of Computer Science, University of Pretoria, South Africa, 2001.

[37]J. Kennedy. "Small Worlds and Megaminds: Effects of Neighborhood Topology on Particle Swarm Performance". In Proceedings International Congress on Evolutionary Computation, Washington DC, USA: IEEE, 1999. p. 1931-1938.

[38]ENGELBRECHT, A. P. "Fundamentals of Computational Swarm Optimization." [S.l.]: John Wiley and Sons LTD., 2005.

[39]ENGELBRECHT, A. P. "Computational Intelligence: An Introduction". 2. ed. [S.1.]: John Wiley and Sons, 2007. 
[40]S.N. Omkar, J. Senthilnath, R. Khandelwal, G. N. Naik, S. Gopalakrishnan, "Artificial Bee Colony (ABC) for Multi-objective Design Optimization of Composite Structures", Applied Soft Computing, pp. 489-499, 2011.

[41]S.N. Omkar, D. Mudigere, G. N. Naik, S. Gopalakrishna, "Vector Evaluated Particle Swarm Optimization (VEPSO) for Multi-objective Design Optimization of Composite Structures", Computers and Structures, pp. 1-14, 2008.

[42]S.N. Omkar, R. Khandelwal, S. Yathindra, G. N. Naik, S. Gopalakrishnan, "Artificial Immune System for Multi-objective Design Optimization of Composite Structures", Engineering Applications of Artificial Intelligence, pp. 1416-1429, 2008.

[43]D. Karaboga, B. Basturk, "A Powerful and Eficient Algorithm for Numerical Function Optimization ABC", Journal of Global Optimization, v. 39, pp. 459-471, 2007.

[44]K. Price, R. Storn, J. Lampinen, "Differential evolution: a practical approach to global optimization". 1a edição. Berlin, Germany: Springer-Verlag, 2005.

[45]R. Storn, K.Price, "Differential evolution - a simple and efficient heuristic for global optimization over continuous spaces". Journal of Global Optimization, 11(1):341-359, 1997.

[46]S. Das and P. N. Suganthan, "Differential Evolution: A Survey of the State-of-the-Art". In IEEE Transactions on Evolutionary Computation 15(1), pp. 4-31, 2011.

[47]C. C. Coello, G. Lamont, D. van Veldhuizen. "Evolutionary Algorithms for Solving MultiObjective Problems". 2nd ed., Genetic and Evolutionary Computation. Londres, Inglaterra, 2007.

[48]M. Reyes-sierra, C. A. C. Coello. "Multiobjective particle swarm optimizers: A survey of the state-of-the-art". International Journal of Computational Intelligence Research, 2, n. 3, p. 287-308, 2006.

[49]I. Das. "On characterizing the "knee" of the Pareto curve based on normal-boundary intersection". Structural optimization, v.18, n. 2-3, pp. 107-115, 1999.

[50]J. Branke, K. Deb, K. Miettinen, R. Slowinski. "Multiobjective Optimization, Interactive and Evolutionary Approaches [outcome of Dagstuhl seminars]"., v. 5252 da Lecture Notes in Computer Science. Springer, 2008.

[51]S. Luke. "Essentials of Metaheuristics". Lulu, 2009. Available for free at http://cs.gmu.edu/ sean/book/metaheuristics/.

[52]R. Mendes, "Population Topologies and Their Influence in PSO". Tese (Doutorado) - Universidade do Minho, 2004, Portugal. 
[53]T. Blackwell. "Particle swarms and population diversity". Soft Computing - A Fusion of Foundations, Methodologies and Applications, 9:793-802, 2005.

[54]O. Olorunda, A. P. Engelbrecht. "Measuring Exploration / Exploitation in Particle Swarms using Swarm Diversity". In Proceedings of the 2008 Congress on Evolutionary Computation (CEC 2008), p. 1128-1134, 2008.

[55]Y. Shi, R. Eberhart. "Population diversity of particle swarms". In Proceedings of the 2008 Congress on Evolutionary Computation (CEC2008), p. 1063-1067, 2008.

[56]S. Cheng. "Population Diversity in Particle Swarm Optimization: Definition, Observation, Control, and Application". Tese (Doutorado) - Universidade de Liverpool, 2013, Inglaterra

[57]M. Lovbjerg, T. Krink. "Extending Particle Swarms with Self-Organized Criticaly". In. Proc. Congress on Evolutionary Computation. Honolulu, Hawaii: IEEE, pp. 1588-1593, 2002

[58]T. Blackwell, P. Bentley. "Don't Push me! Collision-Avoiding Swarms". In. Proc. Congress on Evolutionary Computation. Honolulu, Hawaii: IEEE, pp. 1691-1696, 2002

[59]T. Krink, J. Vesterstrom, J. Riget. "Particle Swarm Optimization with Spatial Particle Extension". In. Proc. Congress on Evolutionary Computation. Honolulu, Hawaii: IEEE, pp. 14741479,2002

[60]C. Monson, K. Seppi. "Adaptive Diversity in PSO". In. Proc. Conference on Genetic and Evolutionary Computation GECCO. Seatle, USA: ACM, pp. 59-66, 2006

[61]J. Riget, J. Vesterstrom. "A diversity-guided Particle Swarm Optimizer - ARPSO". [S.l.], 2002, Reporte Técnico.

[62]H. Tizhoosh. "Opposition-based Learning a New Scheme for Machine Intelligence". In. Proc. Int. Conference on Computational Intelligence for Modelling, Control and Automation. Vienna, Austria, pp. 695-701, 2005

[63]L. Ma, S. Li, K. N. Ngan, "Reduced-reference Image Quality Assessment in Reorganized DCT Domain", Signal Processing:Image Communication, Article in Press, 2012.

[64]G. Zhai, J. Cai, W. Lin, X. Yang, W. Zhang, M. Etoh, "Cross-dimensional Perceptual Quality Assessment for Low Bit-Rate Videos", IEEE Transactions on Multimedia, pp. 1316-1324, 2008. [65]P. Le Callet, F. Autrusseau, "Subjective Quality Assessment IRCCyN/IVC database", Online Available: http://www.irccyn.ec-nantes.fr/ivcdb/.

[66]Z. Wang, A.C. Bovik, "Modern Image Quality Assessment (Synthesis Lectures on Image, Video, and Multimedia Processing)", Morgan and Claypool, New York, 2006. 
[67]L. Ma, S. Li, K.N. Ngan, "Visual Horizontal Effect for Image Quality Assessment", IEEE Signal Processing Letters, pp. 627-630, 2010

[68]F. Zhang, W. Liu, W. Lin, K.N. Ngan, "Spread Spectrum Image Watermarking Based on Perceptual Quality Metric", IEEE Transactions on Image Processing, pp. 3207-3218, 2011.

[69]S.S. Hemami, A.R. Reibman, "No-Reference Image and Video Quality Estimation: Applications and Human-Motivated Design", Signal Processing: Image Communication, pp. 469-481, 2010.

[70]L. Liang, S. Wang, J. Chen, S. Ma, D. Zhao, W. Gao, "No-reference Perceptual Image Quality Metric Using Gradient Profiles for JPEG 2000", Signal Processing: Image Communication, pp. 502-516, 2010.

[71]T. Brandao, M.P. Queluz, "No-reference Image Quality Assessment Based on DCT Domain Statistics", Signal Processing, pp. 822-833, 2008.

[72]R. Ferzli, L.J. Karam, "A No-Reference Objective Image Sharpness Metric Based on the Notion of Just Noticeable Blur (JNB)", IEEE Transactions on Image Processing, 2009.

[73]Z. Wang, A.C. Bovik, "Reduced- and No-Reference Image Quality Assessment: the Natural Scene Statistic Model Approach", IEEE Signal Processing Magazine, pp. 29-40, 2011.

[74]Y. Niu, M. Kyan, L. Ma, A. Beghdadi, S. Krishnan, "A Visual Saliency Modulated Just Noticeable Distortion Profile for Image Watermarking", European Signal Processing Conference, 2011.

[75]M. G. Choi, J. H. Jung, J. W. Jeon, "No-Reference Image Quality Assessment using Blur and Noise", International Journal of Electrical and Electronics Engineering, pp. 318-322, 2009.

[76]A. Mittal, R. Soundararajan, A. C. Bovik, "Making a Completely Blind Image Quality Analyzer", IEEE Signal Processing Letters, pp. 1-4, 2012.

[77]Y. Miao, A. Sowmya. "An Underwater Colour Image Quality Evaluation Metric". IEEE Transactions on Image Processing, Volume: 24, Issue: 12, pp. 6062-6071. DOI: 10.1109/TIP.2015.2491020, 2015

[78]R. Sheikh, "Image Quality Assessment Using Natural Scene Statistics" Ph.D. Dissertation, University of Texas at Austin, May 2004.

[79]Q. Hu, Z. X. Xie, Z. F. Wang, Y. H. Liu, "Constructing NR-IQA Function Based on Product of Information Entropy and Contrast", International Symposium on Information Science and Engieering, pp. 548-550, 2008 
[80]D. L. Ruderman, "The statistics of natural images" Network Computation in Neural Syst., vol. 5, no. 4, pp. 517-548, 1994.

[81]A. Mittal, A. K. Moorthy, and A. C. Bovik, "No-reference Image Quality Assessment in the Spatial Domain" IEEE Trans. Image Process, Vol. 21, pp. 4695-4708, 2012.

[82]A. C. Bovik, "Perceptual Image Processing: Seeing the Future" Proc. IEEE, vol. 98, no. 11, pp. 1799-1803, 2010.

[83]R. Hassen, Z. Wang, and M. Salama, "No-reference Image Sharpness Assessment Based on Local Phase Coherence Measurement" in IEEE Int. Conf. Acoust. Speech Sig. Process., pp. 2434-2437, 2010.

[84]A. K. Moorthy, A. C. Bovik, "Statistics of Natural Image Distortions" in IEEE Int. Conf. Acoust. Speech Sig. Process., pp. 962-965, 2010.

[85]K. Sharifi, A. Leon-Garcia, "Estimation of Shape Parameter for Generalized Gaussian Distributions in Sub-band Decompositions of Video" IEEE Trans. Circ. Syst. Video Technol., vol. 5, no. 1, pp. 52-56, 1995.

[86]N. E. Lasmar, Y. Stitou, Y. Berthoumieu, "Multiscale Skewed Heavy Tailed Model for Texture Analysis" in IEEE Int. Conf. Image Process., pp. 2281-2284, 2009.

[87]C. Bishop, "Pattern Recognition and Machine Learning". Springer New York, vol. 4, 2006.

[88]R. M. Balboa, N. M. Grzywacz. "Occlusions and Their Relationship with the Distribution of Contrasts in Natural Images". Vision Research, 40, pp. 2661-2669, 2000.

[89]D. Hasler, S. E. Suesstrunk, "Measuring colorfulness in natural images". in Electronic Imaging 2003, International Society for Optics and Photonics, pp. 87-95, 2003.

[90]M. Yang, A. Sowmya, "New Image Quality Evaluation Metric for Underwater Video". in IEEE Signal Processing Letters, Volume: 21, Issue: 10, pp. 1215-1219, DOI: 10.1109/LSP.2014.2330848, 2014.

[91]Q. Li, H. Feng, Z. Xu, "Digital image sharpness evaluation function". Acta Photon. Sinica, vol. 31, no. 6 , pp. 736-738, 2002.

[92]P. Corriveau, C. Gojmerac, B. Hughes, L. Stelmach, "All subjective scales are not created equal: The effects of context on different scales". Signal Processing, 1999.

[93]J.B. Martens, L. Meesters, "Image dissimilarity", Signal Processing, November 1998.

[94]A. M. van Dijk, J. B. Martens, and A. B. Watson. "Quality assessment of coded images using numerical category scaling". Proc. SPIE, March 1995. 
[95]A. M. van Dijk, J. B. Martens. "Subjective quality assessment of compressed images", Signal Processing, 1997.

[96]A. B. Watson, L. Kreslake. "Measurement of visual impairment scales for digital video" In Human Vision, Visual Processing, and Digital Display, Proc. SPIE, 2001.

[97]H. R. Sheikh, M. F. Sabir, A. C. Bovik. "A Statistical Evaluation of Recent Full Reference Image Quality Assessment Algorithms", IEEE Transactions on Image Processing, Volume: 15, Issue: 11, pp. 3440-3451, 2006

[98]D.M. Chandler, S. S. Hemami. "VSNR: A Wavelet-Based Visual Signal-to-Noise Ratio for Natural Images". IEEE Transactions on Image Processing, Volume: 16, Issue: 9, DOI: 10.1109/TIP.2007.901820, pp. 2284-2298, 2007

[99]F. A. Patrick Le Callet. "Subjective Quality Assessment IRCCyN/IVC database". DisponÃyvel em: http://www.irccyn.ec-nantes.fr/ivcdb/, 2005

[100]N. Ponomarenko, V. Lukin, K. Egiazarian, J. Astola, M. Carli, F. Battisti. "Color image database for evaluation of image quality metrics". In IEEE 10th Workshop on Multimedia Signal Processing, DOI: 10.1109/MMSP.2008.4665112, 2008.

[101]H. R. Sheikh, Z. Wang, L. Cormack and A. C. Bovik, "LIVE Image Quality Assessment Database Release 2", http://live.ece.utexas.edu/research/quality.

[102]Y. Horita, K. Shibata, and Y. Kawayoke, "MICT image quality evaluation database", [Online]. Available: http://mict.eng.u-toyama.ac.jp/mictdb.html.

[103]E. C. Larson , D. M. Chandler. "Most Apparent Distortion: Full-reference Image Quality Assessment and the Role of Strategy". Proc. SPIE 7242, Image Quality and System Performance VI, doi:10.1117/12.810071, 2009

[104]C. L. Sze, R. Heshalini, P. Raveendran, "Correlation between subjective and objective assessment of magnetic resonance (MR) images", Magnetic Resonance Imaging (2016), doi: 10.1016/j.mri.2016.03.006

[105]J. M. Moreno-Roldán, M. A. Luque-Nieto, J. Poncela, V. Díaz-del-Río, P. Otero. "Subjective Quality Assessment of Underwater Video for Scientific Applications". Sensors, 15(12), 3172331737; doi:10.3390/s151229882, 2015

[106]C. J. Prabhakar, P. U. Praveen Kumar. "Image Enhancement and Restoration Methods for Underwater Images". Chapter 6 on Research Developments in Computer Vision and Image Processing: Methodologies and Applications, DOI: 10.4018/978-1-4666-4558-5.ch006, 2014. 
[107]P. Mohammadi, A. Ebrahimi-Moghadam, S. Shirani. "Subjective and Objective Quality Assessment of Image: A Survey", submitted to Elsevier Journal of Visual Communication and Image Representation, 2014.

[108]A. Zaric, M. Loncaric, D. Tralic, M. Brzica, E. Dumic, S. Grgic . "Image Quality Assessment - Comparison of Objective Measures with Results of Subjective Test ". In Proc. ELMAR, 2010. [109]Neuro Behavioral Systems - neurobs, http://www.neurobs.com/

[110]P. Sprawls. "Optimizing Medical Image Contrast, Detail and Noise in the Digital Era". Medical Physics International Journal, vol.2, No.1, 2014.

[111]C. Sánchez-Ferreira, H. V. H. Ayala, L. S. Coelho, D. Muñoz, M. C. Q. Farias, C. H. Llanos, "Multi-objective Differential Evolution Algorithm for Underwater Image Restoration", In Proc. IEEE Congress on Evolutionary Computation (CEC2015), doi: 10.1109/CEC.2015.7256898, 2015

[112]N. K. Madavan, "Multiobjective optimization using a Pareto differential evolution approach". Proceedings of the IEEE Congress on Evolutionary Computation, vol.2, pp.1145-1150, 2002.

[113]T. Robic, B. Filipic, "DEMO: Differential evolution for multiobjective optimization". In Proceedings of Evolutionary Multi-Criterion Optimization (EMO 2005), C. Coello, A. Aguirre, and E. Zitzler, Eds., Guanajuato, Mexico, pp. 520-533, 2005.

[114]D.H. Wolpert, W.G. Macready. "No Free Lunch Theorems for Optimization". IEEE Transactions on Evolutionary Computation, Volume: 1, Issue: 1, pp. 67-82, 1997.

[115]J. Derrac, S. García, D. Molina, F. Herrera. "A practical tutorial on the use of nonparametric statistical tests as a methodology for comparing evolutionary and swarm intelligence algorithms". Swarm and Evolutionary Computation 1, pp. 3-18, 2011.

[116]G. S. Karam, Z. M. Abood, R. N. Saleh. "Enhancement of Underwater Image using Fuzzy Histogram Equalization". International Journal of Applied Information Systems, pp. 1-6, 2013.

[117]H. Zheng, B. Zheng, G. Ji, Z. Guo, Y. Sun. "Image enhancement of underwater target detection by inhomogeneous illumination". IEEE OCEANS - Yeosu, pp. 1-4, 2012.

[118]M. S. Hitam, E. A. Awalludin, W. N. J. H. W. Yussof, Z. Bachok. "Mixture contrast limited adaptive histogram equalization for underwater image enhancement". International Conference on Computer Applications Technology (ICCAT), 2013.

[119]W. N. Yussof, M. S. Hitam, E. A. Awalludin, Z. Bachok. "Performing Contrast Limited Adaptive Histogram Equalization Technique on Combined Color Models for Underwater Image Enhancement”. International Journal of Interactive Digital Media, Vol. 1, 2013. 
[120]J. Singhai, P. Rawat. "Image enhancement method for underwater, ground and satellite images using brightness preserving histogram equalization with maximum entropy". In Conference on Computational Intelligence and Multimedia Applications, pp. 507-512, 2007.

[121]Y. Ye, Z. Ye, P. Bhattacharya, J. Luo, H. Majlesein, R. Smith, K. Kang. "On linear and nonlinear processing of underwater, ground, aerial and satellite images". IEEE International Conference on Systems, Man and Cybernetics, pp. 3364-3368, 2005.

[122]Y. Miao. " Underwater image adaptive restoration and analysis by turbulence model". IEEE World Congress on In Information and Communication Technologies (WICT), pp. 1182-1187, 2012.

[123]Y. Miao, G. Cheng-long. "Underwater image restoration by turbulence model based on image gradient distribution". In IEEE International Conference on Uncertainty Reasoning and Knowledge Engineering (URKE), pp. 296-299, 2012.

[124]W. Hou, D. J. Gray, A. D. Weidemann, G. R. Fournier, J. L. Forand, "Automated Underwater Image Restoration and Retrieval of Related Optical Properties", in Proceedings of the IEEE International Geoscience and Remote Sensing Symposium (IGARSS07), pp. 1889-1892, 2007.

[125]H. Lu, Y. Li, S. Serikawa. "Underwater image enhancement using guided trigonometric bilateral filter and fast automatic color correction". In Proc of 20th IEEE international conference on image processing, 2013. 
APÊNDICES 


\section{A. OUTROS EXPERIMENTOS DE RESTAURAÇÃO}

Neste apêndice são apresentados outros resultados de restauração para diferentes imagens em diferentes condições de degradação.

O algoritmo de restauração de imagens foi implementado tomando como base três algoritmos de otimização bio-inspirada: (a) PSO, (b) ABC e (c) DE. Devido aos problemas de convergência prematura que apresenta o PSO, referenciados na literatura, este algoritmo foi implementado junto com os métodos de adição de diversidade discutidos na Seção 3.6. Desta forma, foram implementados o algoritmo OPSO (Opposition Based Particle Swarm Optimization) e o RAPSO (Repulsive-Attractive Particle Swarm Optimization). Além disso, o algoritmo ABC foi testado na versão clássica, e também com aprendizado por oposição OABC. Em total foram 5 algoritmos de otimização testados: PSO, OPSO, ABC, OABC e DE. Esses algoritmos foram guiados com a métrica NIQE como função objetivo, onde cada algoritmo foi rodado 50 vezes, para cada uma das 20 imagens escolhidas. Os resultados para cada algoritmo foram analisados como uma amostra estatística a fim de extrair sua média, mediana e desvio padrão, valor máximo e mínimo da ditribuição (tal como mostrado nas Tabelas 7.4, 7.5 e 7.6 apresentadas no Capítulo 7). A métrica NIQUE foi utilizada devido ao bom desempenho apresentado na análise de correlação (vide Seção 5.4).

As figuras neste apêndice apresentam os resultados do processo de restauração de imagens com degradações reais guiado pelos algoritmos de otimização bio-inspirada que apresentaram os melhores (OPSO e ABC) e piores resultados (DE). Objetivando testar os algoritmos de otimização supracitados, cada algoritmo foi executado 50 vezes para a mesma imagem. Assim, apos encontrar a mediana dos valores finais da métrica NIQE, o processo de restauração mediante inversão do modelo de Wagner é realizado utilizando os valores das variáveis de decisão correspondentes ao valor dessa mediana. As tabelas abaixo apresentam os valores das variáveis de decisão utilizados no algoritmo de inversão do modelo de Wagner para obter os resultados apresentados nas figuras apresentadas neste apêndice, respectivamente. É importante ressaltar que os valores das variáveis de decisão não representam os valores reais das propriedades físicas da água, representando simplesmente uma combinação de valores que é capaz de restaurar a imagem corretamente. Devido ao alto custo computacional dos algoritmos de restauração e a grande quantidade de experimentos realizados para cada um deles, os testes foram realizados sobre um total de 20 imagens escolhidas aleatoriamente dentro das 255 imagens do banco UIDLEIA. Como um exemplo do tempo de execução dos algoritmos, o OPSO apresentou um tempo 
Tabela A.1. Valores das variáveis de decisão encontrados pelos algoritmos de otimização bio-inspirada aplicados à restauração da imagem mostrada na Figura A.1.

\begin{tabular}{|c|c|c|c|c|}
\hline Algoritmo & Mediana & $c$ & $K$ & $L_{\infty}$ \\
\hline OPSO & 84,304 & $-2,292$ & 0,391 & $-2,552$ \\
ABC & 84,106 & $-2,913$ & $-1,406$ & $-2,235$ \\
RAPSO & 85,302 & $-2,929$ & $-7,000$ & $-5,141$ \\
DE & 85,649 & $-4,112$ & 6,660 & $-3,652$ \\
OABC & 84,110 & $-2,000$ & 0,290 & $-2,000$ \\
\hline
\end{tabular}

médio de execução de 5 horas (sendo este o menor tempo alcançado entre todos os algoritmos), rodando em MATLAB sobre uma máquina com Windows 10, processador core i7 e 16 GB de memória RAM.
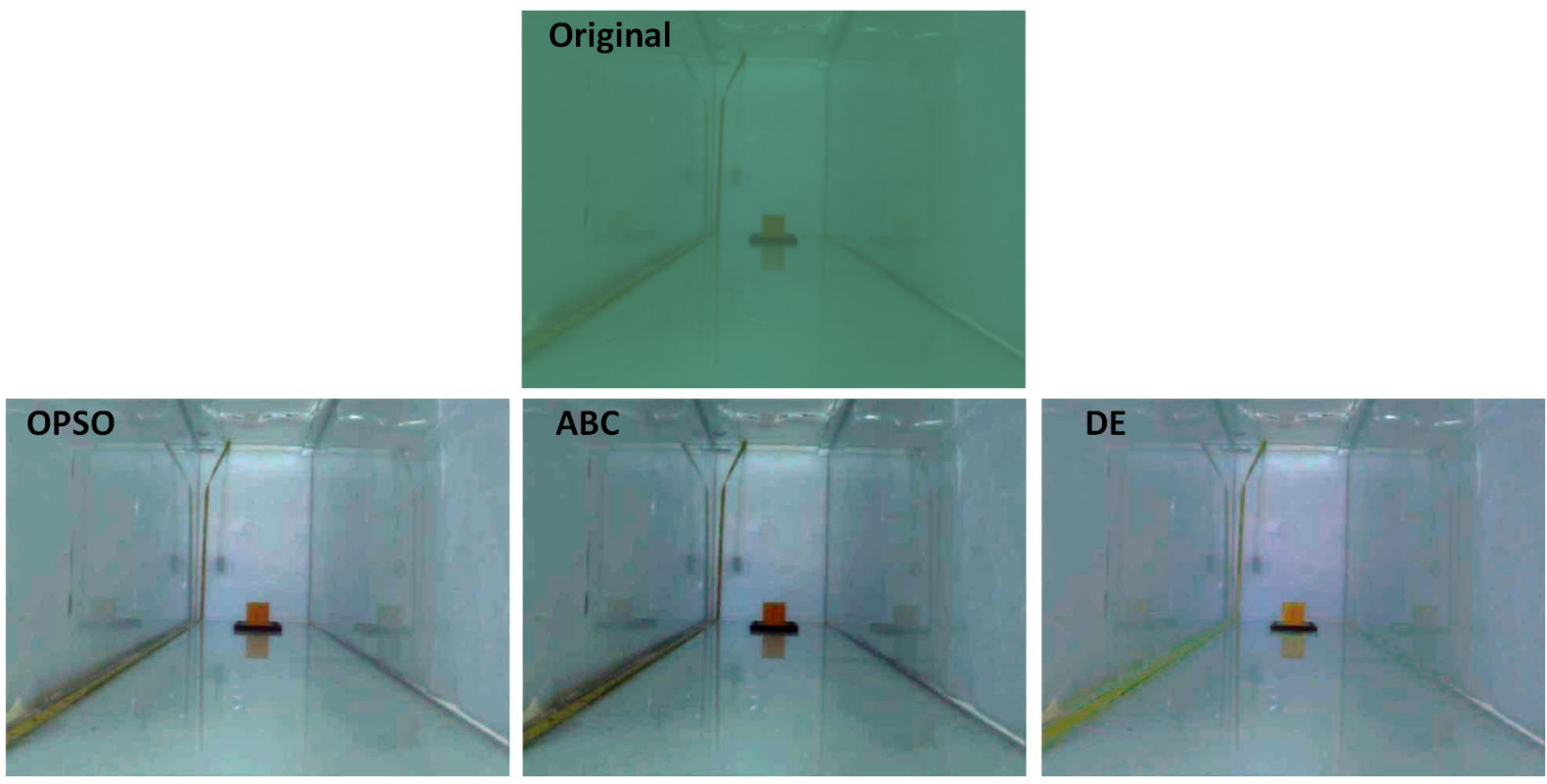

Figura A.1. Teste de restauração para imagem do UID-LEIA. 
Tabela A.2. Estatísticas dos algoritmos de otimização bio-inspirada aplicados à restauração da imagem mostrada na Figura A.1.

\begin{tabular}{|c|c|c|c|c|c|}
\hline Algoritmo & Mediana & Média & Desvio Padrão & Mínimo & Máximo \\
\hline OPSO & 84,304 & 84,719 & 0,7860 & 84,270 & 85,053 \\
ABC & 84,106 & 85,108 & 0,0144 & 85,085 & 85,155 \\
RAPSO & 85,302 & 85,341 & 0,2468 & 85,285 & 87,040 \\
DE & 85,649 & 85,752 & 0,1647 & 85,649 & 86,215 \\
OABC & 84,110 & 85,117 & 0,0341 & 85,073 & 85,315 \\
\hline
\end{tabular}
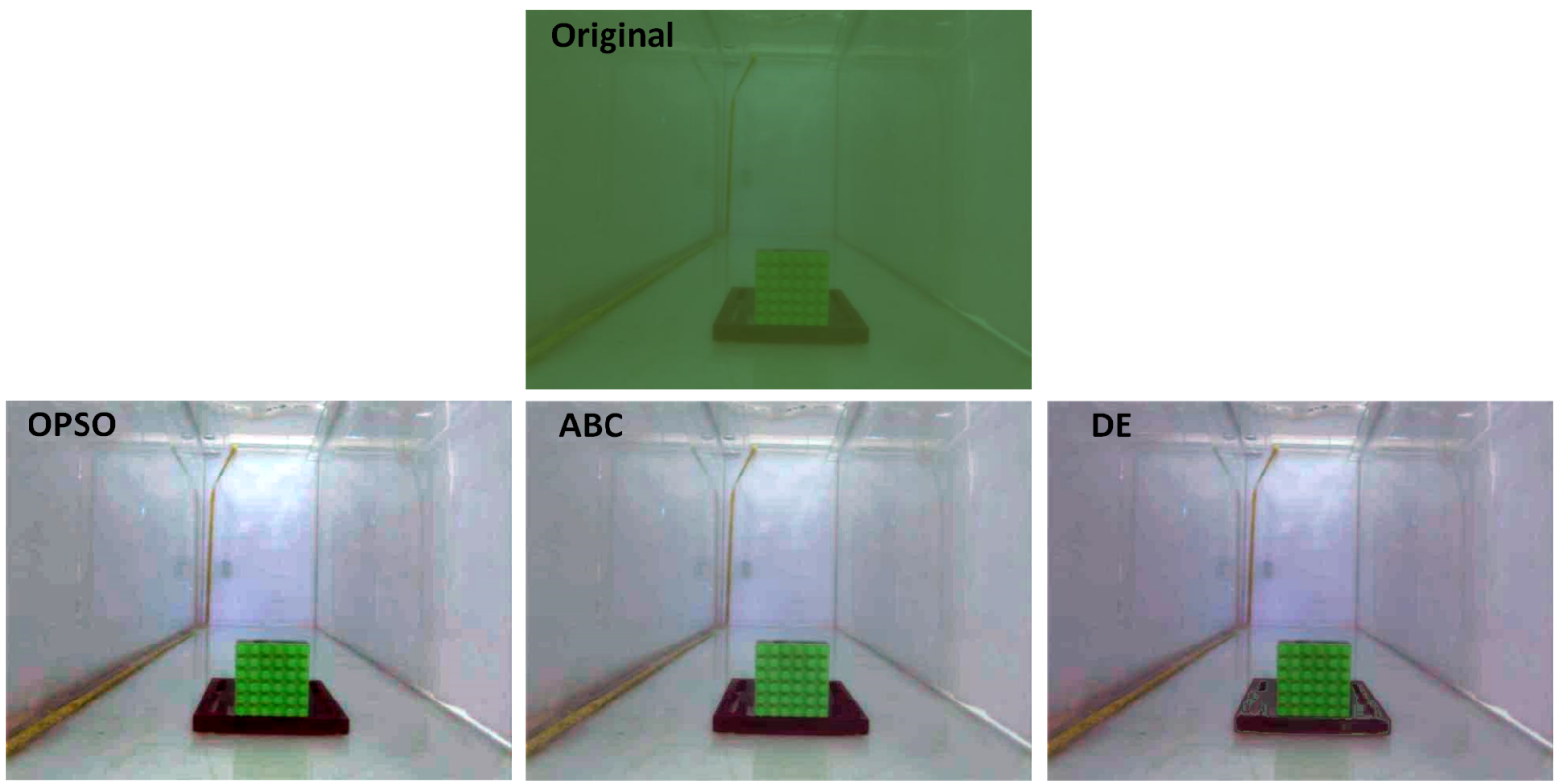

Figura A.2. Teste de restauração para imagem do UID-LEIA. 
Tabela A.3. Valores das variáveis de decisão encontrados pelos algoritmos de otimização bio-inspirada aplicados à restauração da imagem mostrada na Figura A.2.

\begin{tabular}{|c|c|c|c|c|}
\hline Algoritmo & Mediana & $c$ & $K$ & $L_{\infty}$ \\
\hline OPSO & 84,082 & $-0,256$ & 0,260 & 1,012 \\
ABC & 84,097 & 6,288 & $-3,025$ & 2,075 \\
RAPSO & 84,462 & $-1,716$ & $-0,271$ & 2,706 \\
DE & 84,470 & 2,000 & $-1,746$ & $-2,000$ \\
OABC & 84,106 & 7,000 & 6,069 & 1,975 \\
\hline
\end{tabular}

Tabela A.4. Estatísticas dos algoritmos de otimização bio-inspirada aplicados à restauração da imagem mostrada na Figura A.2

\begin{tabular}{|c|c|c|c|c|c|}
\hline Algoritmo & Mediana & Média & Desvio Padrão & Mínimo & Máximo \\
\hline OPSO & 84,082 & 84,568 & 0,0335 & 84,465 & 84,592 \\
ABC & 84,097 & 84,096 & 0,0286 & 84,059 & 84,211 \\
RAPSO & 84,462 & 84,471 & 0,0433 & 84,395 & 84,550 \\
DE & 84,470 & 84,474 & 0,0155 & 84,461 & 84,550 \\
OABC & 84,106 & 84,111 & 0,0403 & 84,061 & 84,263 \\
\hline
\end{tabular}
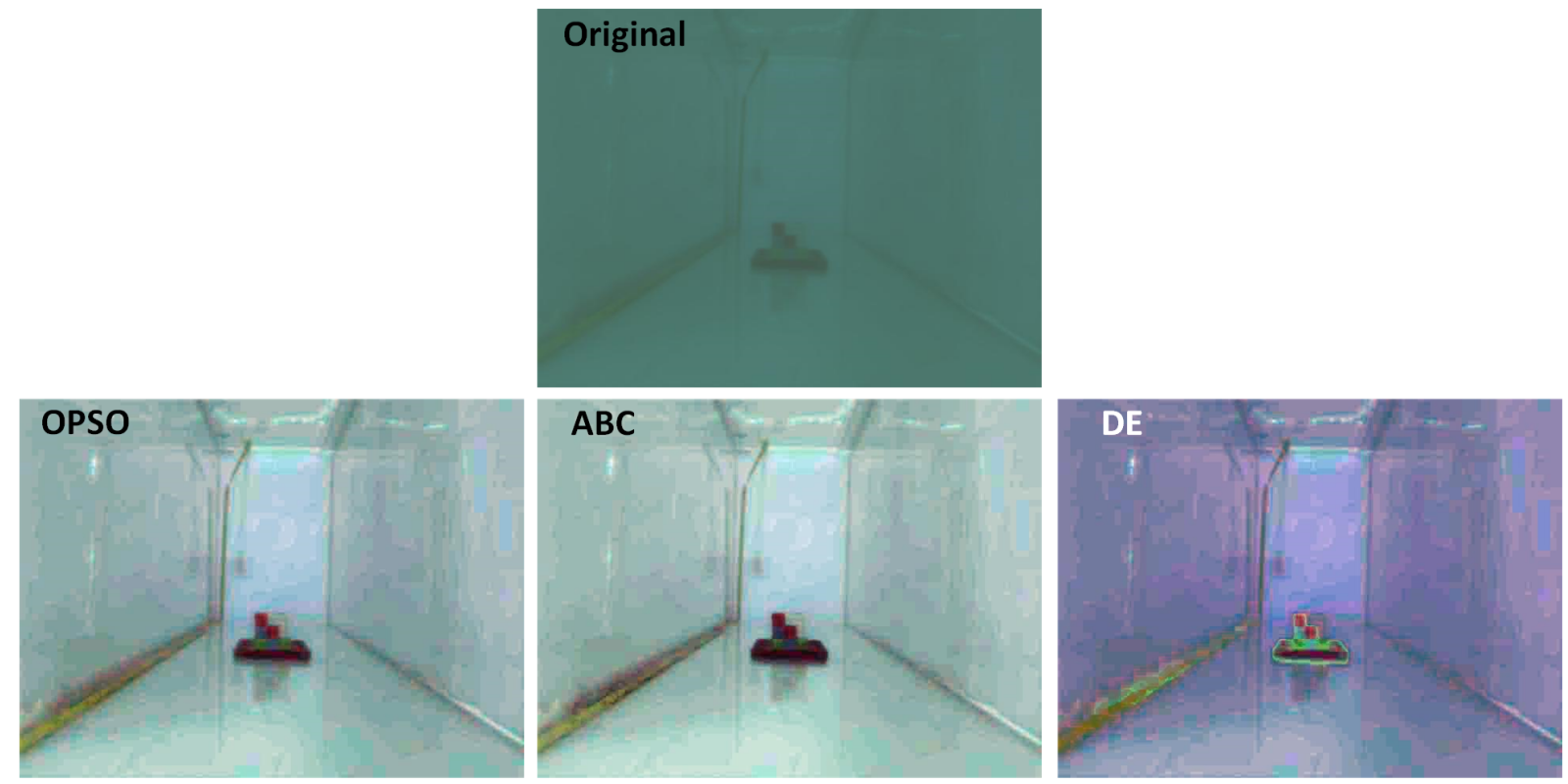

Figura A.3. Teste de restauração para imagem do UID-LEIA. 
Tabela A.5. Valores das variáveis de decisão encontrados pelos algoritmos de otimização bio-inspirada aplicados à restauração da imagem mostrada na Figura A.3.

\begin{tabular}{|c|c|c|c|c|}
\hline Algoritmo & Mediana & $c$ & $K$ & $L_{\infty}$ \\
\hline OPSO & 83,560 & $-0,059$ & 0,663 & 0,974 \\
ABC & 83,653 & $-0,110$ & $-0,723$ & 0,668 \\
RAPSO & 84,556 & 4,533 & 2,220 & 2,677 \\
DE & 84,497 & 3,837 & 3,993 & 3,137 \\
OABC & 83,687 & $-0,784$ & 0,546 & 2,000 \\
\hline
\end{tabular}

Tabela A.6. Estatísticas dos algoritmos de otimização bio-inspirada aplicados à restauração da imagem mostrada na Figura A.3

\begin{tabular}{|c|c|c|c|c|c|}
\hline Algoritmo & Mediana & Média & Desvio Padrão & Mínimo & Máximo \\
\hline OPSO & 83,560 & 83,562 & 0,0112 & 83,547 & 83,577 \\
ABC & 83,653 & 83,659 & 0,0393 & 83,601 & 83,732 \\
RAPSO & 84,556 & 84,556 & 0,0090 & 84,523 & 84,571 \\
DE & 84,497 & 84,501 & 0,0248 & 84,469 & 84,572 \\
OABC & 83,687 & 83,681 & 0,0463 & 83,594 & 83,831 \\
\hline
\end{tabular}
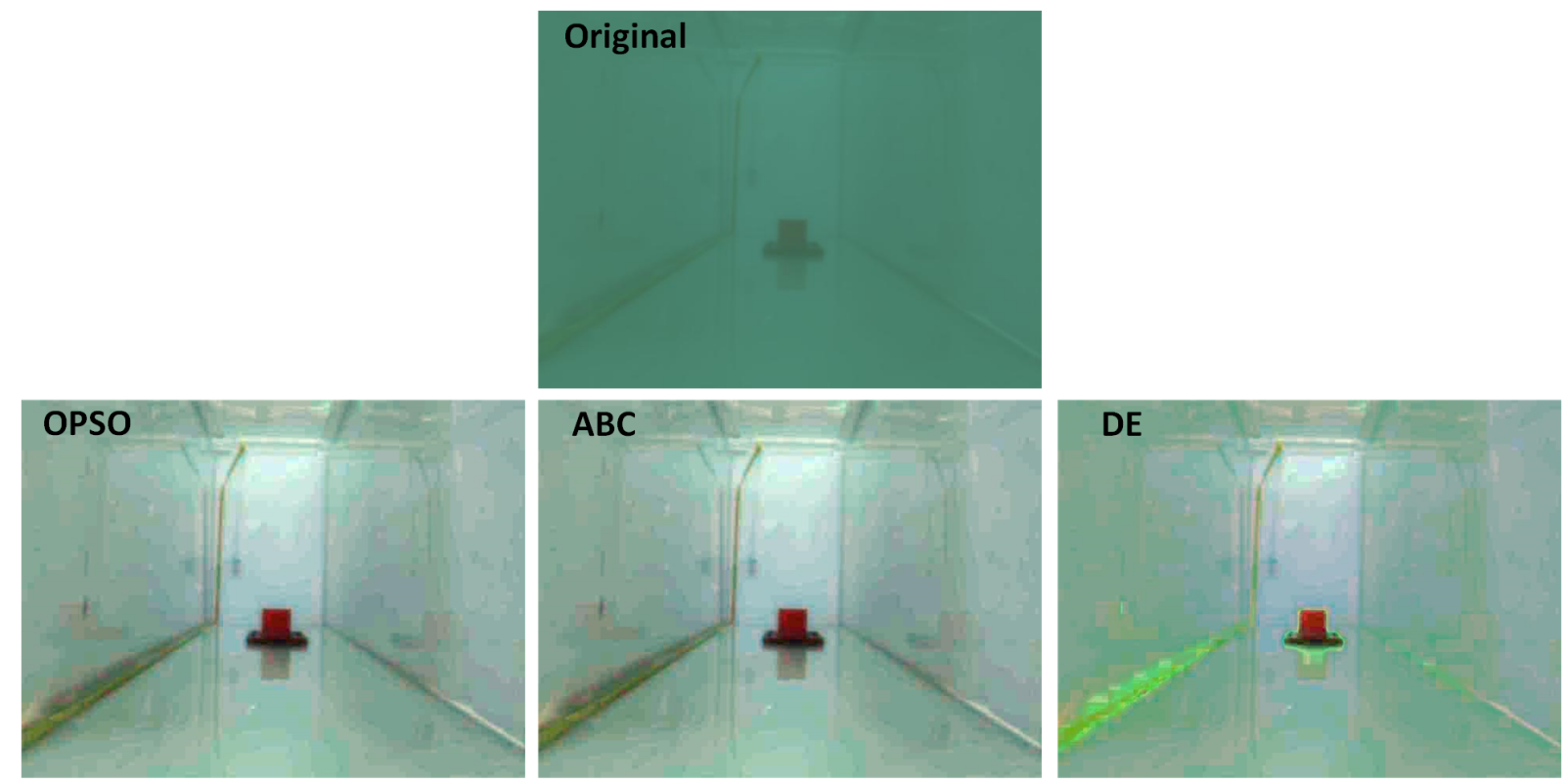

Figura A.4. Teste de restauração para imagem do UID-LEIA. 
Tabela A.7. Valores das variáveis de decisão encontrados pelos algoritmos de otimização bio-inspirada aplicados à restauração da imagem mostrada na Figura A.4.

\begin{tabular}{|c|c|c|c|c|}
\hline Algoritmo & Mediana & $c$ & $K$ & $L_{\infty}$ \\
\hline OPSO & 84,759 & $-0,252$ & $-0,211$ & 0,109 \\
ABC & 84,282 & $-0,509$ & $-0,018$ & $-0,440$ \\
RAPSO & 86,717 & $-1,706$ & 7,000 & $-7,000$ \\
DE & 86,564 & $-1,680$ & 7,000 & $-7,000$ \\
OABC & 84,291 & $-1,250$ & 0,257 & 2,000 \\
\hline
\end{tabular}

Tabela A.8. Estatísticas dos algoritmos de otimização bio-inspirada aplicados à restauração da imagem mostrada na Figura A.4

\begin{tabular}{|c|c|c|c|c|c|}
\hline Algoritmo & Mediana & Média & Desvio Padrão & Mínimo & Máximo \\
\hline OPSO & 84,759 & 84,750 & 0,0179 & 84,714 & 84,768 \\
ABC & 84,282 & 84,288 & 0,0238 & 84,249 & 84,361 \\
RAPSO & 86,717 & 86,690 & 0,0626 & 86,551 & 86,760 \\
DE & 86,564 & 86,578 & 0,0301 & 86,558 & 86,714 \\
OABC & 84,291 & 84,301 & 0,0392 & 84,244 & 84,425 \\
\hline
\end{tabular}
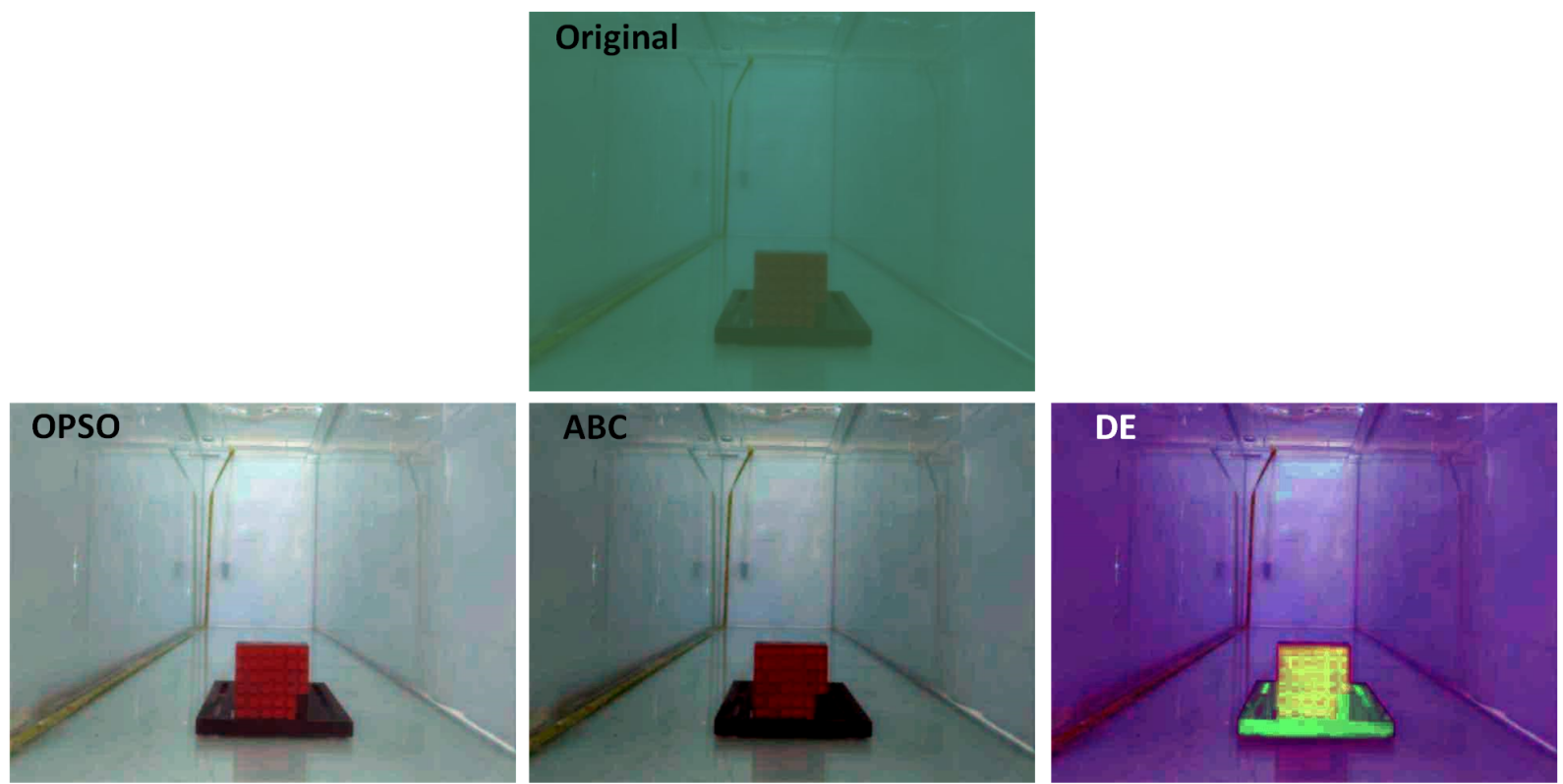

Figura A.5. Teste de restauração para imagem do UID-LEIA. 
Tabela A.9. Valores das variáveis de decisão encontrados pelos algoritmos de otimização bio-inspirada aplicados à restauração da imagem mostrada na Figura A.5.

\begin{tabular}{|c|c|c|c|c|}
\hline Algoritmo & Mediana & $c$ & $K$ & $L_{\infty}$ \\
\hline OPSO & 79,160 & $-0,509$ & $-0,002$ & 0,067 \\
ABC & 79,610 & $-0,926$ & $-0,091$ & 0,109 \\
RAPSO & 86,134 & 5,674 & 5,898 & 6,448 \\
DE & 85,989 & 5,679 & $-3,691$ & 6,456 \\
OABC & 79,626 & $-1,974$ & 2,000 & 2,000 \\
\hline
\end{tabular}

Tabela A.10. Estatísticas dos algoritmos de otimização bio-inspirada aplicados à restauração da imagem mostrada na Figura A.5.

\begin{tabular}{|c|c|c|c|c|c|}
\hline Algoritmo & Mediana & Média & Desvio Padrão & Mínimo & Máximo \\
\hline OPSO & 79,160 & 79,151 & 0,0118 & 79,131 & 79,166 \\
ABC & 79,610 & 79,620 & 0,0349 & 79,582 & 79,714 \\
RAPSO & 86,134 & 86,130 & 0,0153 & 86,095 & 86,155 \\
DE & 85,989 & 86,000 & 0,0412 & 85,982 & 86,154 \\
OABC & 79,626 & 79,644 & 0,0593 & 79,581 & 79,805 \\
\hline
\end{tabular}
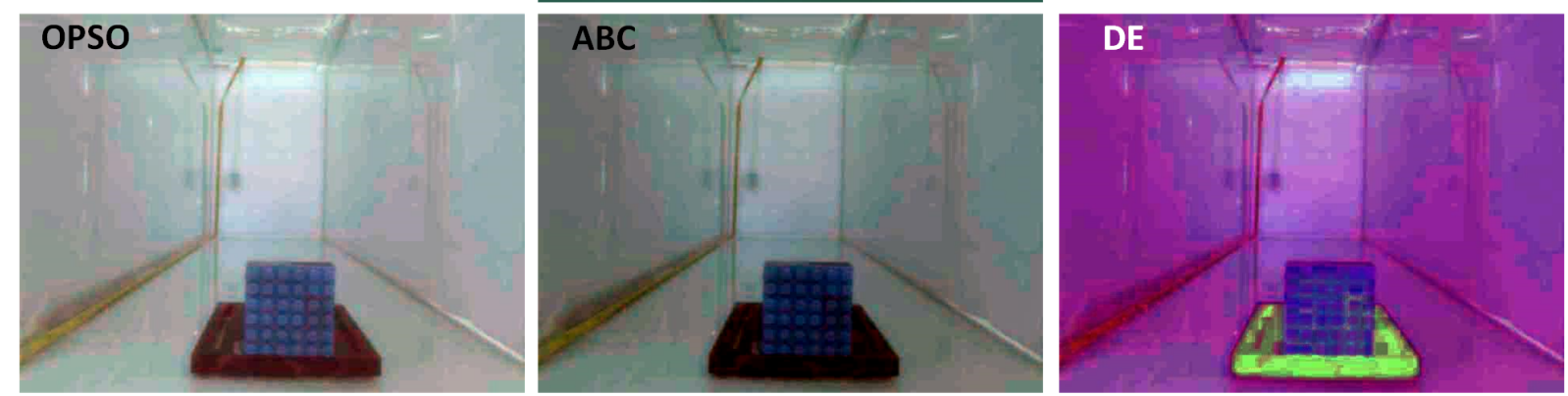

Figura A.6. Teste de restauração para imagem do UID-LEIA. 
Tabela A.11. Valores das variáveis de decisão encontrados pelos algoritmos de otimização bio-inspirada aplicados à restauração da imagem mostrada na Figura A.6.

\begin{tabular}{|c|c|c|c|c|}
\hline Algoritmo & Mediana & $c$ & $K$ & $L_{\infty}$ \\
\hline OPSO & 84,563 & $-0,229$ & 0,195 & 0,344 \\
ABC & 84,122 & 1,858 & 0,050 & $-0,916$ \\
RAPSO & 86,406 & 5,671 & $-6,507$ & 4,330 \\
DE & 86,143 & 6,081 & 4,773 & 4,073 \\
OABC & 84,147 & 2,000 & 1,943 & $-1,877$ \\
\hline
\end{tabular}

Tabela A.12. Estatísticas dos algoritmos de otimização bio-inspirada aplicados à restauração da imagem mostrada na Figura A.6.

\begin{tabular}{|c|c|c|c|c|c|}
\hline Algoritmo & Mediana & Média & Desvio Padrão & Mínimo & Máximo \\
\hline OPSO & 84,563 & 84,510 & 0,1021 & 84,917 & 85,586 \\
ABC & 84,122 & 84,129 & 0,0389 & 84,073 & 84,255 \\
RAPSO & 86,406 & 86,156 & 0,4785 & 85,270 & 86,567 \\
DE & 86,143 & 86,172 & 0,0708 & 86,139 & 86,488 \\
OABC & 84,147 & 84,195 & 0,1221 & 84,074 & 84,562 \\
\hline
\end{tabular}
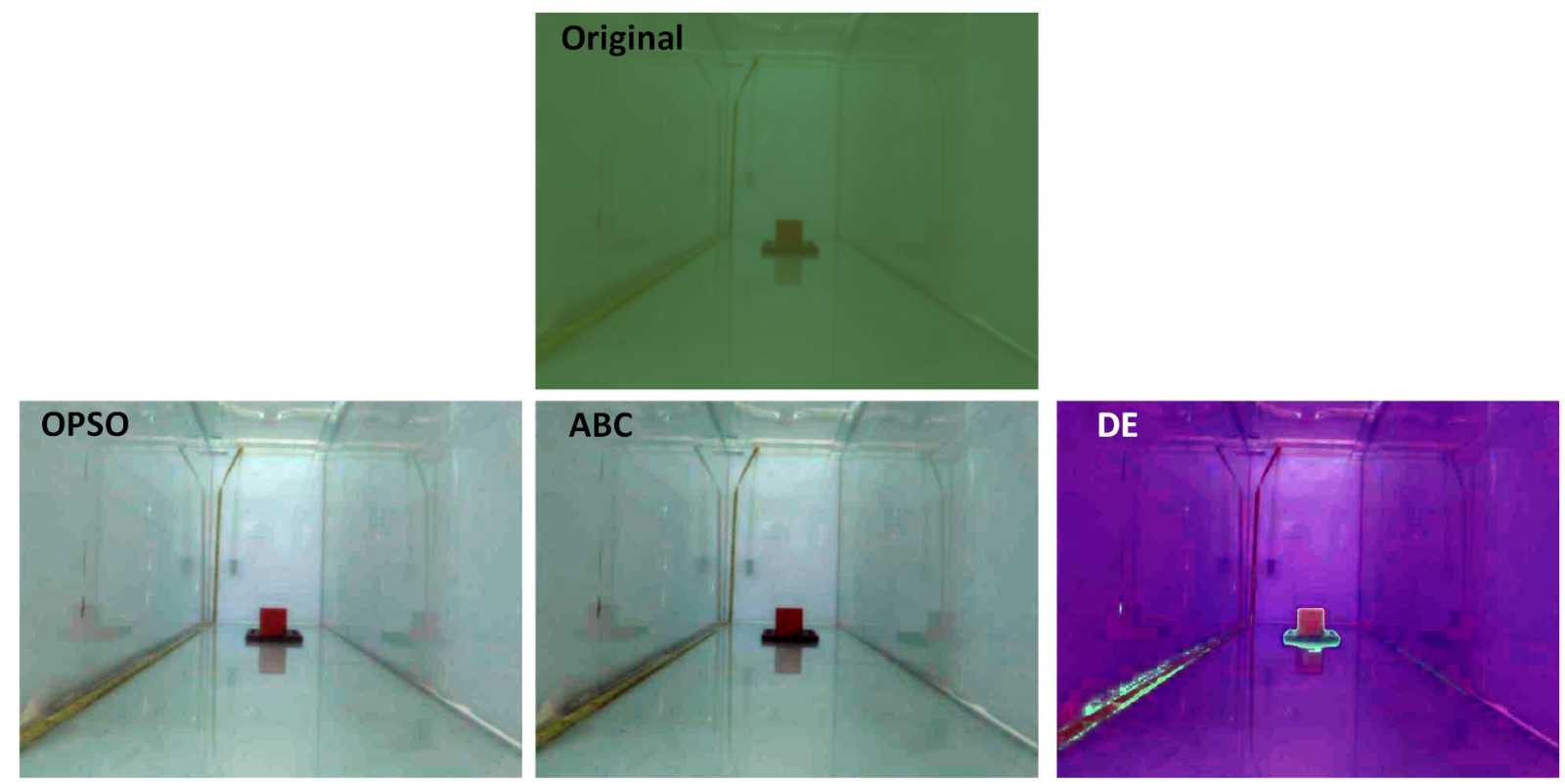

Figura A.7. Teste de restauração para imagem do UID-LEIA. 
Tabela A.13. Valores das variáveis de decisão encontrados pelos algoritmos de otimização bio-inspirada aplicados à restauração da imagem mostrada na Figura A.7.

\begin{tabular}{|c|c|c|c|c|}
\hline Algoritmo & Mediana & $c$ & $K$ & $L_{\infty}$ \\
\hline OPSO & 85,949 & $-0,419$ & $-0,160$ & $-0,071$ \\
ABC & 84,265 & $-1,998$ & $-1,350$ & 1,938 \\
RAPSO & 84,122 & $-4,489$ & 1,120 & $-5,992$ \\
DE & 85,958 & $-4,377$ & $-7,000$ & $-6,170$ \\
OABC & 84,132 & $-1,823$ & 1,042 & 2,000 \\
\hline
\end{tabular}

Tabela A.14. Estatísticas dos algoritmos de otimização bio-inspirada aplicados à restauração da imagem mostrada na Figura A.7.

\begin{tabular}{|c|c|c|c|c|c|}
\hline Algoritmo & Mediana & Média & Desvio Padrão & Mínimo & Máximo \\
\hline OPSO & 84,265 & 84,241 & 0,0818 & 84,942 & 85,269 \\
ABC & 84,122 & 84,126 & 0,0198 & 84,095 & 84,182 \\
RAPSO & 85,949 & 86,063 & 0,1551 & 85,914 & 86,266 \\
DE & 85,958 & 85,990 & 0,0856 & 85,946 & 86,236 \\
OABC & 84,132 & 84,138 & 0,0290 & 84,092 & 84,216 \\
\hline
\end{tabular}
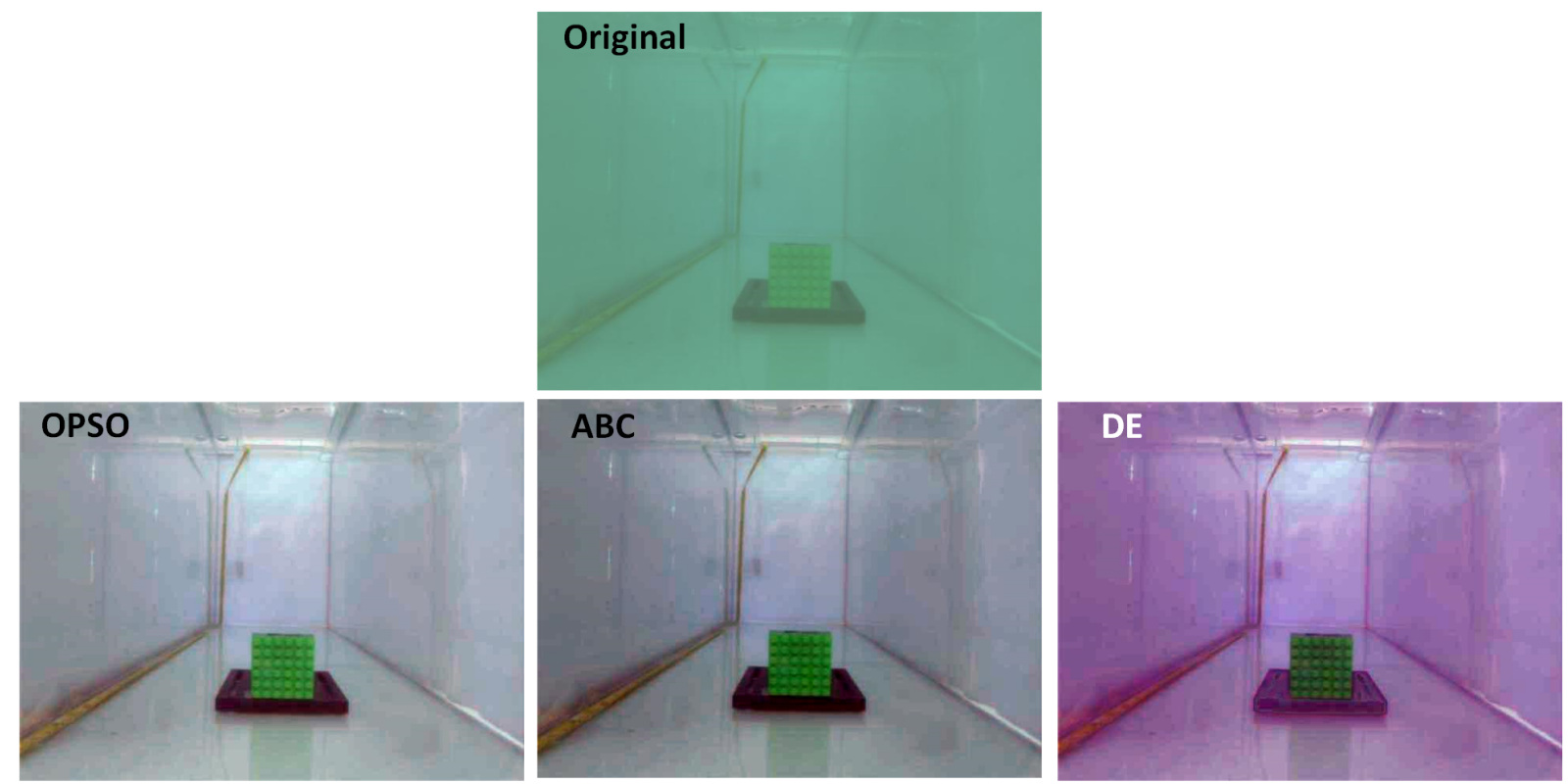

Figura A.8. Teste de restauração para imagem do UID-LEIA. 
Tabela A.15. Valores das variáveis de decisão encontrados pelos algoritmos de otimização bio-inspirada aplicados à restauração da imagem mostrada na Figura A.8.

\begin{tabular}{|c|c|c|c|c|}
\hline Algoritmo & Mediana & $c$ & $K$ & $L_{\infty}$ \\
\hline OPSO & 83,794 & $-0,430$ & 0,431 & $-0,819$ \\
ABC & 83,195 & $-1,147$ & $-0,778$ & $-2,010$ \\
RAPSO & 84,574 & 7,000 & $-4,241$ & 2,880 \\
DE & 84,574 & 7,000 & $-0,113$ & 2,743 \\
OABC & 83,210 & $-1,491$ & $-0,120$ & $-1,843$ \\
\hline
\end{tabular}

Tabela A.16. Estatísticas dos algoritmos de otimização bio-inspirada aplicados à restauração da imagem mostrada na Figura A.8.

\begin{tabular}{|c|c|c|c|c|c|}
\hline Algoritmo & Mediana & Média & Desvio Padrão & Mínimo & Máximo \\
\hline OPSO & 83,794 & 83,716 & 0,1218 & 83,566 & 83,866 \\
ABC & 83,195 & 83,203 & 0,0291 & 83,176 & 83,322 \\
RAPSO & 84,574 & 84,578 & 0,0316 & 84,564 & 84,795 \\
DE & 84,574 & 84,581 & 0,0230 & 84,566 & 84,680 \\
OABC & 83,210 & 83,223 & 0,0420 & 83,180 & 83,393 \\
\hline
\end{tabular}
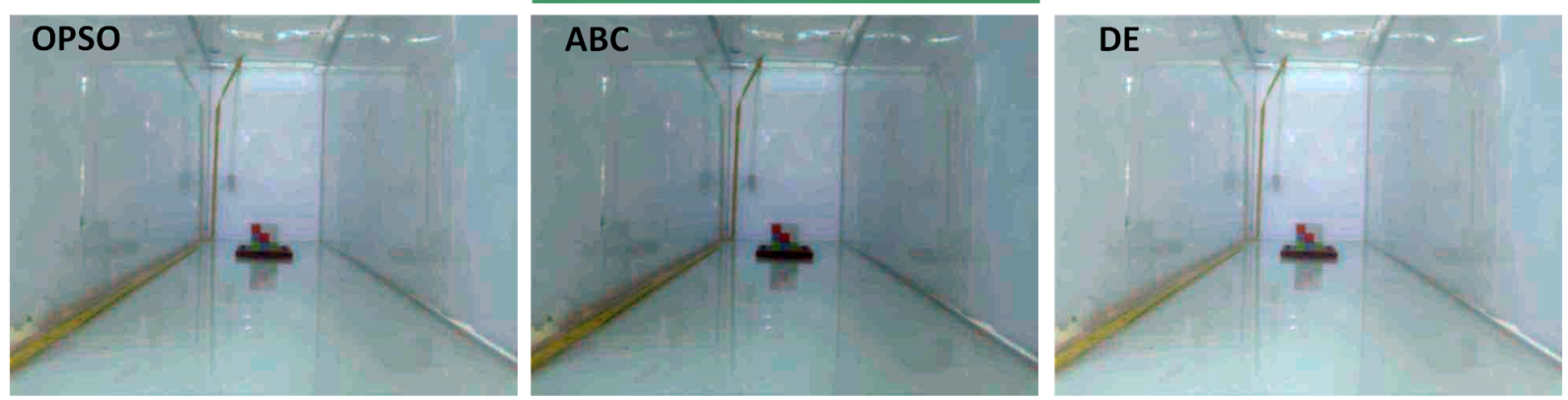

Figura A.9. Teste de restauração para imagem do UID-LEIA. 
Tabela A.17. Valores das variáveis de decisão encontrados pelos algoritmos de otimização bio-inspirada aplicados à restauração da imagem mostrada na Figura A.9.

\begin{tabular}{|c|c|c|c|c|}
\hline Algoritmo & Mediana & $c$ & $K$ & $L_{\infty}$ \\
\hline OPSO & 84,838 & 1,974 & $-0,878$ & 2,230 \\
ABC & 84,780 & 7,000 & $-0,787$ & 0,856 \\
RAPSO & 84,836 & 2,335 & $-0,529$ & 2,095 \\
DE & 84,875 & 1,962 & $-1,289$ & 2,000 \\
OABC & 84,794 & 7,000 & 7,000 & 0,823 \\
\hline
\end{tabular}

Tabela A.18. Estatísticas dos algoritmos de otimização bio-inspirada aplicados à restauração da imagem mostrada na Figura A.9.

\begin{tabular}{|c|c|c|c|c|c|}
\hline Algoritmo & Mediana & Média & Desvio Padrão & Mínimo & Máximo \\
\hline OPSO & 84,838 & 84,874 & 0,0591 & 84,829 & 85,191 \\
ABC & 84,780 & 84,781 & 0,0229 & 84,747 & 84,850 \\
RAPSO & 84,836 & 84,835 & 0,0050 & 84,829 & 84,845 \\
DE & 84,875 & 84,889 & 0,0247 & 84,868 & 84,940 \\
OABC & 84,794 & 84,803 & 0,0333 & 84,744 & 84,885 \\
\hline
\end{tabular}
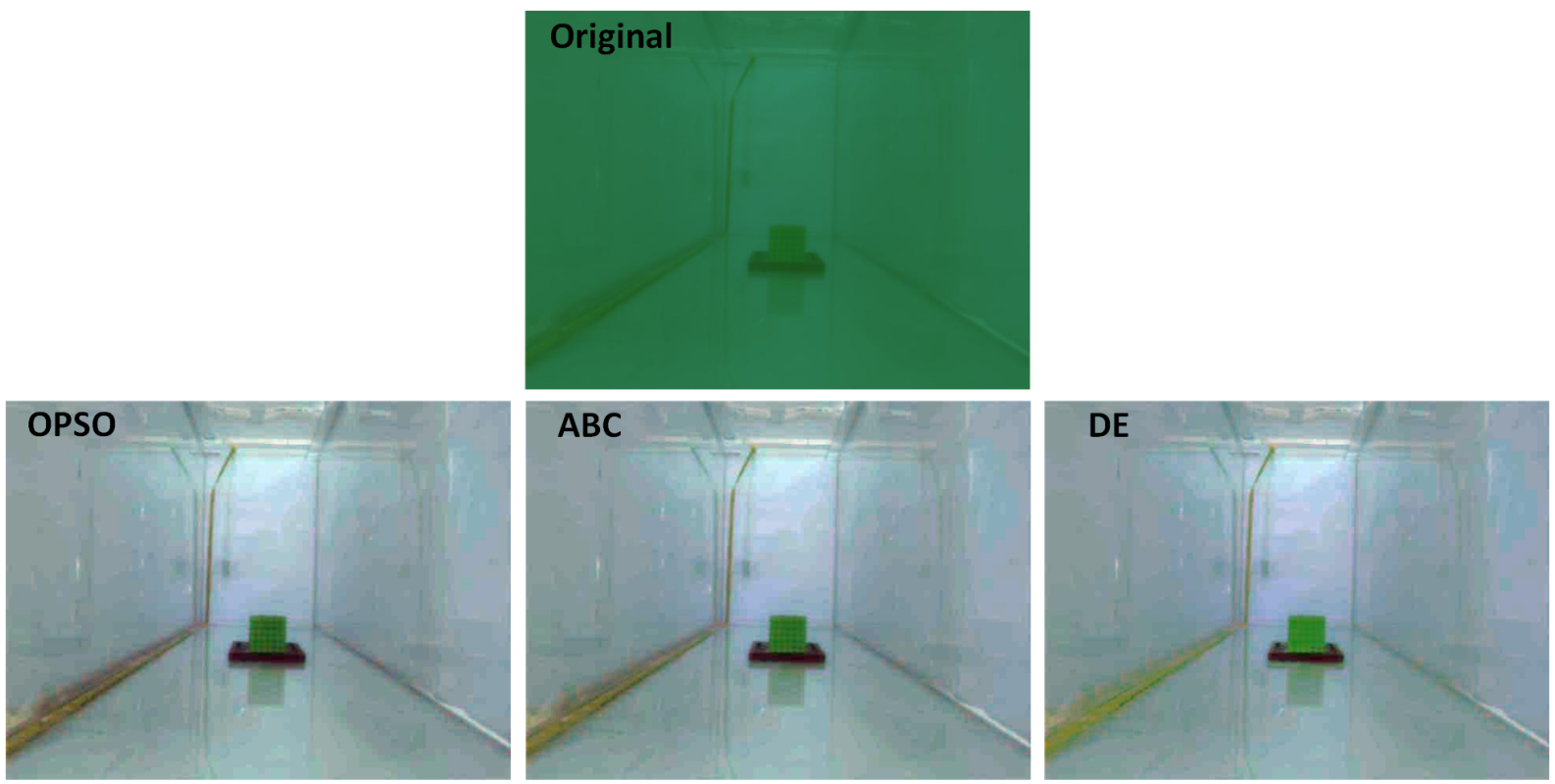

Figura A.10. Teste de restauração para imagem do UID-LEIA. 
Tabela A.19. Valores das variáveis de decisão encontrados pelos algoritmos de otimização bio-inspirada aplicados à restauração da imagem mostrada na Figura A.10.

\begin{tabular}{|c|c|c|c|c|}
\hline Algoritmo & Mediana & $c$ & $K$ & $L_{\infty}$ \\
\hline OPSO & 84,793 & $-0,560$ & $-0,143$ & $-0,138$ \\
ABC & 84,436 & $-2,706$ & $-1,074$ & $-3,212$ \\
RAPSO & 84,442 & $-3,049$ & $-0,761$ & $-2,846$ \\
DE & 85,459 & $-2,000$ & 1,832 & $-2,000$ \\
OABC & 84,438 & $-1,302$ & $-2,520$ & $-7,000$ \\
\hline
\end{tabular}

Tabela A.20. Estatísticas dos algoritmos de otimização bio-inspirada aplicados à restauração da imagem mostrada na Figura A.10

\begin{tabular}{|c|c|c|c|c|c|}
\hline Algoritmo & Mediana & Média & Desvio Padrão & Mínimo & Máximo \\
\hline OPSO & 84,793 & 84,603 & 0,4758 & 83,430 & 84,854 \\
RAPSO & 84,442 & 84,772 & 0,5378 & 84,433 & 85,795 \\
ABC & 84,436 & 84,435 & 0,0071 & 84,422 & 84,452 \\
OABC & 84,438 & 84,437 & 0,0085 & 84,419 & 84,450 \\
DE & 85,459 & 85,471 & 0,0427 & 85,458 & 85,638 \\
\hline
\end{tabular}
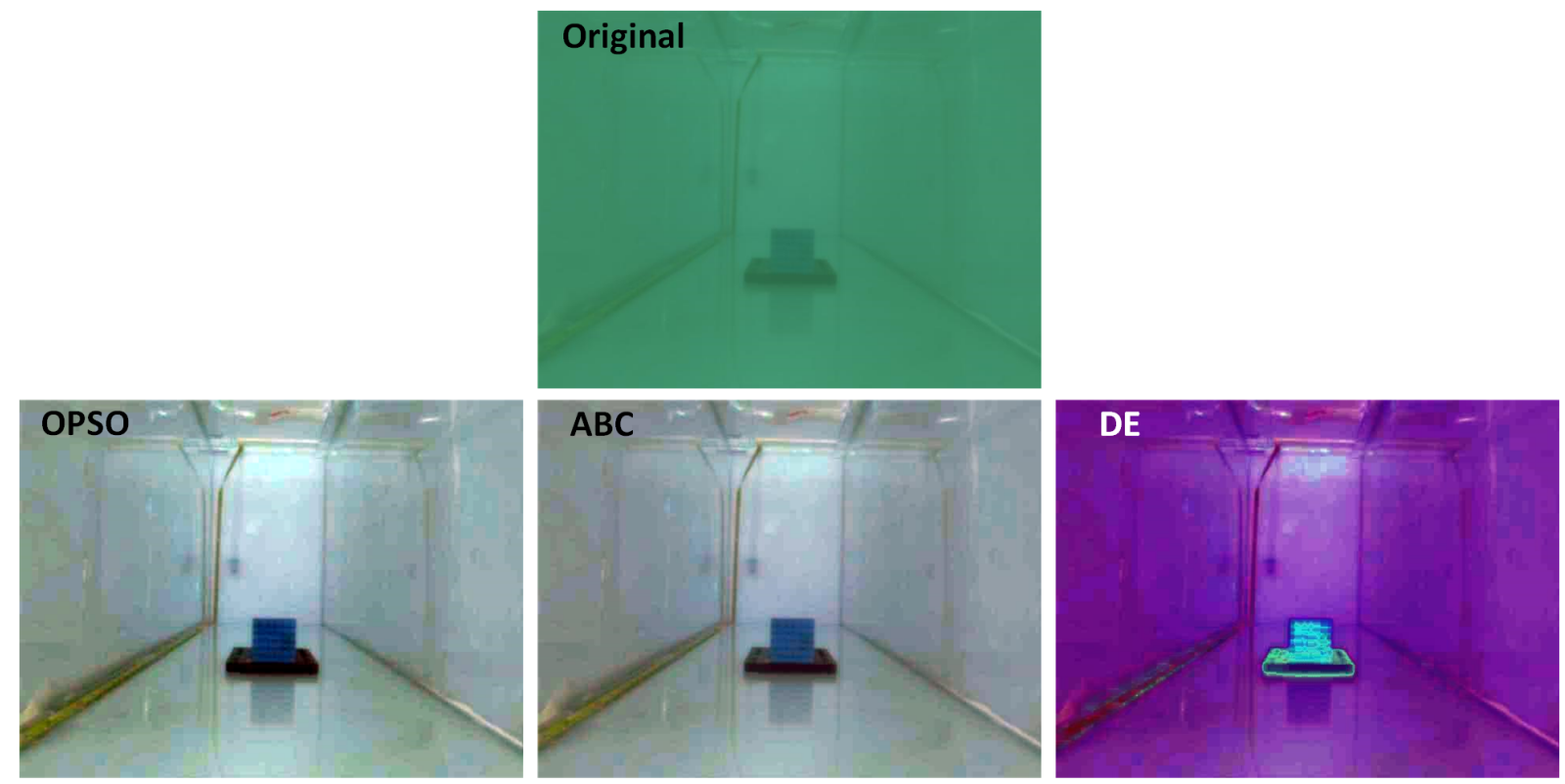

Figura A.11. Teste de restauração para imagem do UID-LEIA. 
Tabela A.21. Valores das variáveis de decisão encontrados pelos algoritmos de otimização bio-inspirada aplicados à restauração da imagem mostrada na Figura A.11

\begin{tabular}{|c|c|c|c|c|}
\hline Algoritmo & Mediana & $c$ & $K$ & $L_{\infty}$ \\
\hline OPSO & 83,258 & $-0,770$ & 0,326 & $-0,462$ \\
ABC & 83,684 & $-3,613$ & $-0,438$ & $-4,013$ \\
RAPSO & 84,919 & $-4,663$ & 3,626 & $-4,202$ \\
DE & 86,891 & $-6,510$ & 1,565 & $-2,948$ \\
OABC & 83,700 & $-1,950$ & $-0,649$ & $-1,960$ \\
\hline
\end{tabular}

Tabela A.22. Estatísticas dos algoritmos de otimização bio-inspirada aplicados à restauração da imagem mostrada na Figura A.11

\begin{tabular}{|c|c|c|c|c|c|}
\hline Algoritmo & Mediana & Média & Desvio Padrão & Mínimo & Máximo \\
\hline OPSO & 83,258 & 83,234 & 0,2676 & 81,414 & 83,350 \\
ABC & 83,684 & 83,686 & 0,0274 & 83,638 & 83,780 \\
RAPSO & 84,919 & 85,087 & 1,3348 & 83,633 & 87,347 \\
DE & 86,891 & 86,947 & 0,1021 & 86,885 & 87,301 \\
OABC & 83,700 & 83,720 & 0,0725 & 83,635 & 83,968 \\
\hline
\end{tabular}
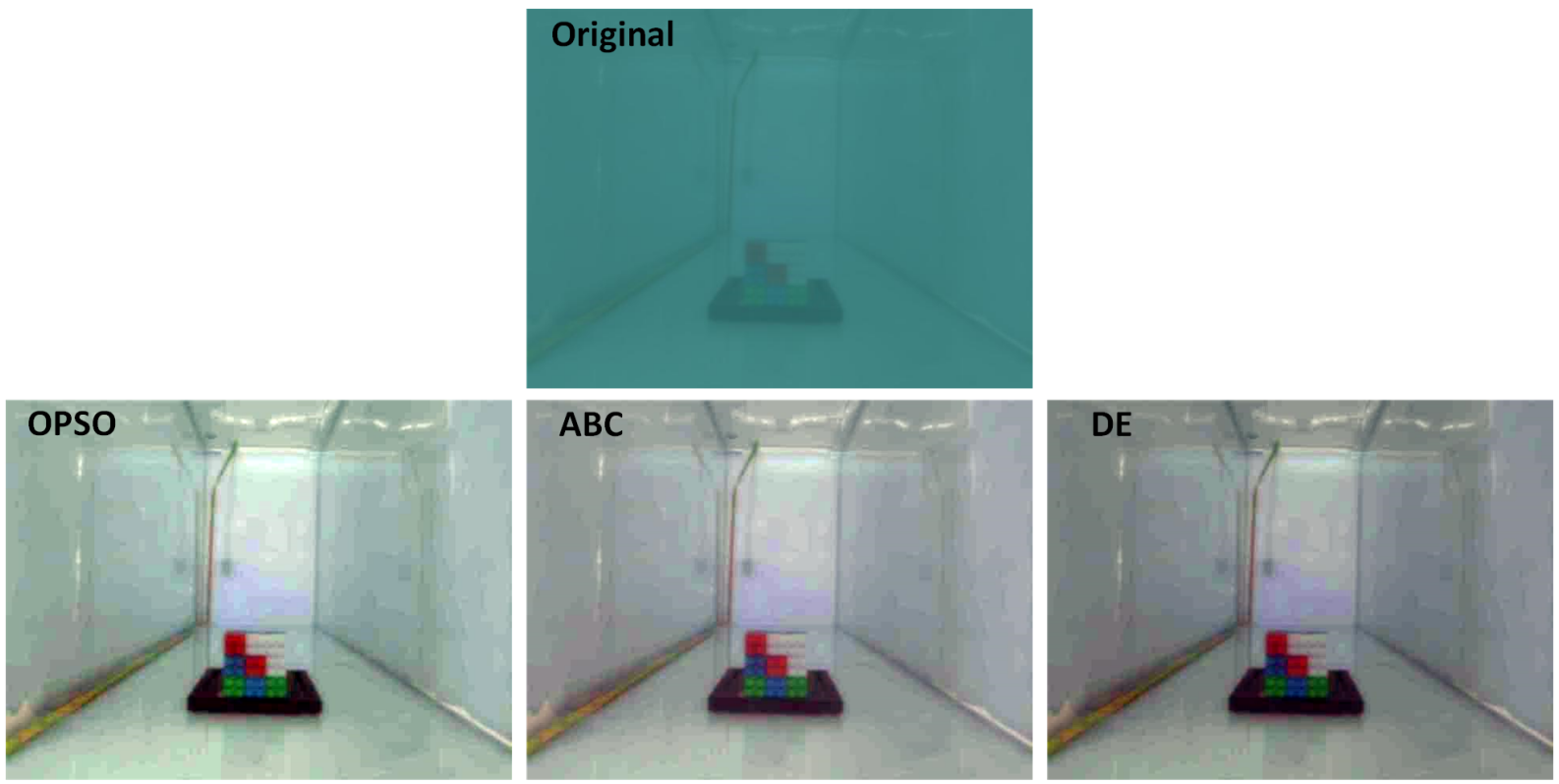

Figura A.12. Teste de restauração para imagem do UID-LEIA. 
Tabela A.23. Valores das variáveis de decisão encontrados pelos algoritmos de otimização bio-inspirada aplicados à restauração da imagem mostrada na Figura A.12

\begin{tabular}{|c|c|c|c|c|}
\hline Algoritmo & Mediana & $c$ & $K$ & $L_{\infty}$ \\
\hline OPSO & 84,542 & 0,125 & $-0,090$ & 0,334 \\
ABC & 84,470 & 7,000 & $-4,184$ & 0,625 \\
RAPSO & 84,536 & 0,375 & $-0,264$ & 0,579 \\
DE & 84,516 & 1,776 & 0,452 & 2,000 \\
OABC & 84,482 & 7,000 & $-6,134$ & 0,772 \\
\hline
\end{tabular}

Tabela A.24. Estatísticas dos algoritmos de otimização bio-inspirada aplicados à restauração da imagem mostrada na Figura A.12

\begin{tabular}{|c|c|c|c|c|c|}
\hline Algoritmo & Mediana & Média & Desvio Padrão & Mínimo & Máximo \\
\hline OPSO & 84,542 & 84,540 & 0,0054 & 84,527 & 84,548 \\
ABC & 84,470 & 84,474 & 0,0132 & 84,456 & 84,505 \\
RAPSO & 84,536 & 84,536 & 0,0050 & 84,527 & 84,549 \\
DE & 84,516 & 84,518 & 0,0073 & 84,494 & 84,544 \\
OABC & 84,482 & 84,482 & 0,0165 & 84,456 & 84,514 \\
\hline
\end{tabular}
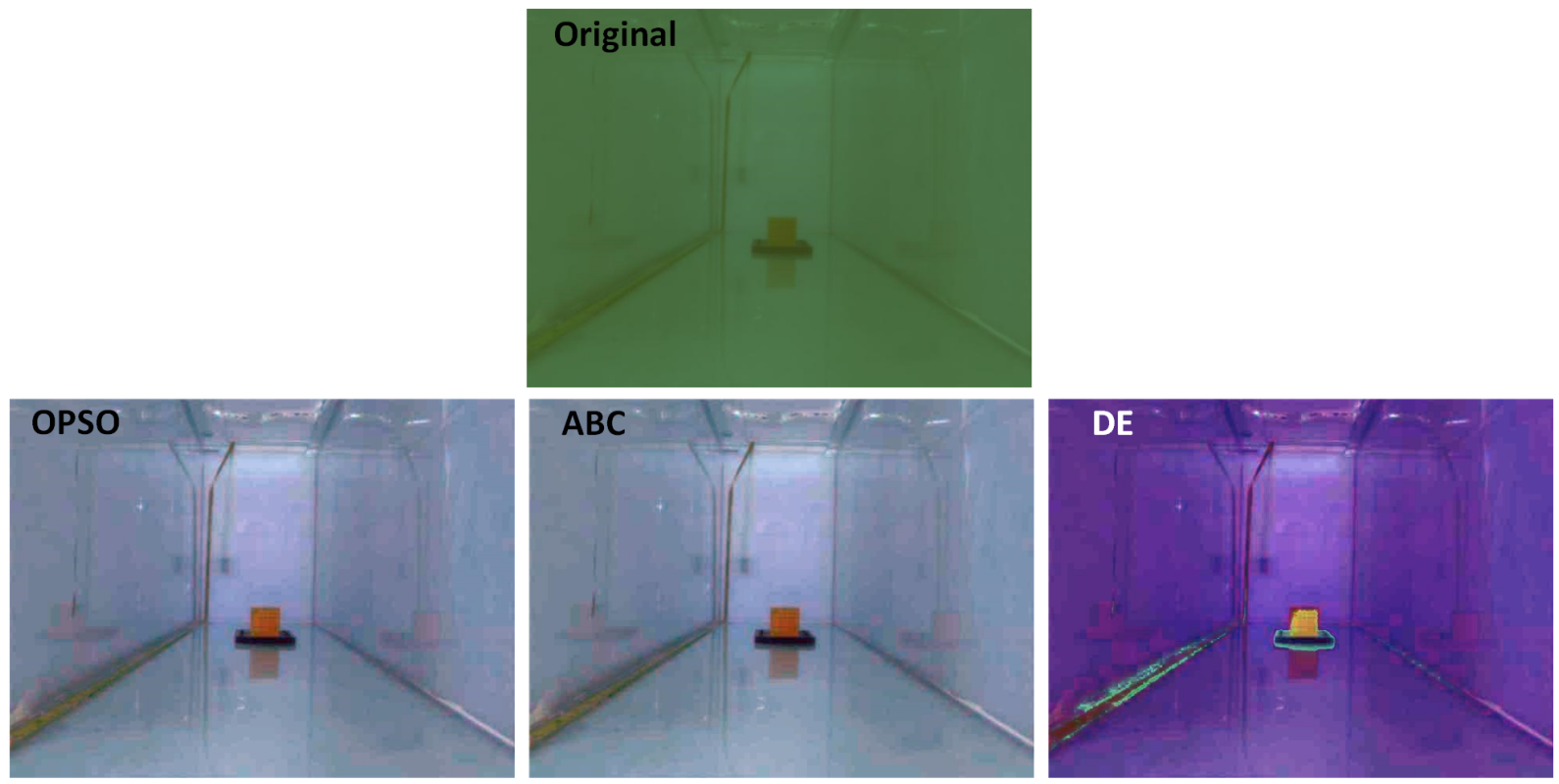

Figura A.13. Teste de restauração para imagem do UID-LEIA. 
Tabela A.25. Valores das variáveis de decisão encontrados pelos algoritmos de otimização bio-inspirada aplicados à restauração da imagem mostrada na Figura A.13

\begin{tabular}{|c|c|c|c|c|}
\hline Algoritmo & Mediana & $c$ & $K$ & $L_{\infty}$ \\
\hline OPSO & 84,821 & $-2,339$ & 1,833 & $-2,282$ \\
ABC & 84,657 & $-3,686$ & $-0,516$ & $-3,312$ \\
RAPSO & 87,329 & 6,996 & 0,517 & 3,300 \\
DE & 87,179 & $-2,969$ & $-0,803$ & $-6,962$ \\
OABC & 84,668 & $-2,000$ & $-0,466$ & $-1,972$ \\
\hline
\end{tabular}

Tabela A.26. Estatísticas dos algoritmos de otimização bio-inspirada aplicados à restauração da imagem mostrada na Figura A.13

\begin{tabular}{|c|c|c|c|c|c|}
\hline Algoritmo & Mediana & Média & Desvio Padrão & Mínimo & Máximo \\
\hline OPSO & 84,821 & 84,821 & 0,0188 & 84,790 & 84,854 \\
ABC & 84,657 & 84,660 & 0,0123 & 84,627 & 84,695 \\
RAPSO & 87,329 & 85,771 & 0,6771 & 84,663 & 86,841 \\
DE & 87,179 & 87,345 & 0,2990 & 87,168 & 88,450 \\
OABC & 84,668 & 84,668 & 0,0118 & 84,640 & 84,692 \\
\hline
\end{tabular}
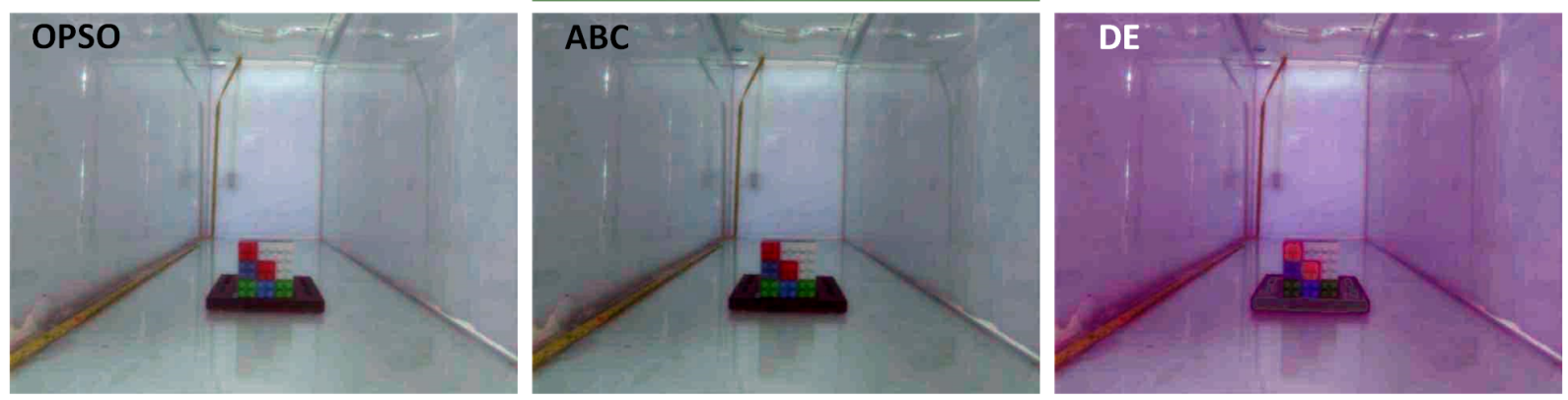

Figura A.14. Teste de restauração para imagem do UID-LEIA. 
Tabela A.27. Valores das variáveis de decisão encontrados pelos algoritmos de otimização bio-inspirada aplicados à restauração da imagem mostrada na Figura A.14.

\begin{tabular}{|c|c|c|c|c|}
\hline Algoritmo & Mediana & $c$ & $K$ & $L_{\infty}$ \\
\hline OPSO & 82,998 & $-3,831$ & $-1,429$ & $-3,894$ \\
ABC & 82,010 & $-3,951$ & 0,129 & $-3,795$ \\
RAPSO & 83,995 & $-2,220$ & $-4,393$ & $-7,000$ \\
DE & 86,141 & $-2,489$ & $-4,002$ & $-6,139$ \\
OABC & 82,014 & $-2,000$ & $-0,093$ & $-2,000$ \\
\hline
\end{tabular}

Tabela A.28. Estatísticas dos algoritmos de otimização bio-inspirada aplicados à restauração da imagem mostrada na Figura A.14

\begin{tabular}{|c|c|c|c|c|c|}
\hline Algoritmo & Mediana & Média & Desvio Padrão & Mínimo & Máximo \\
\hline OPSO & 82,998 & 82,314 & 1,0834 & 81,983 & 83,952 \\
ABC & 82,010 & 83,010 & 0,0121 & 82,988 & 83,064 \\
RAPSO & 83,995 & 83,014 & 0,1272 & 82,985 & 83,895 \\
DE & 86,141 & 86,210 & 0,1395 & 86,129 & 86,573 \\
OABC & 82,014 & 83,016 & 0,0153 & 82,989 & 83,081 \\
\hline
\end{tabular}
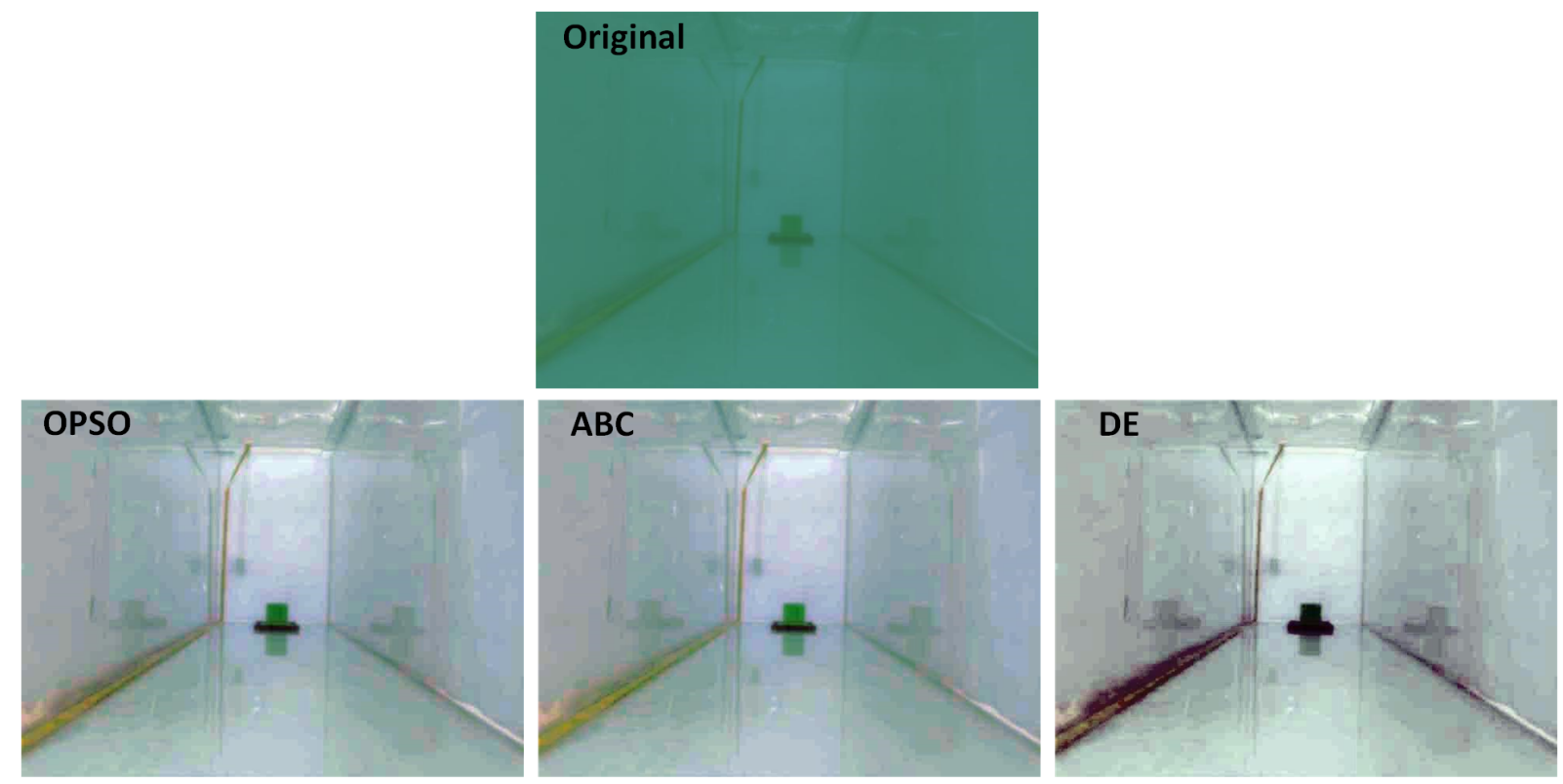

Figura A.15. Teste de restauração para imagem do UID-LEIA. 
Tabela A.29. Valores das variáveis de decisão encontrados pelos algoritmos de otimização bio-inspirada aplicados à restauração da imagem mostrada na Figura A.15

\begin{tabular}{|c|c|c|c|c|}
\hline Algoritmo & Mediana & $c$ & $K$ & $L_{\infty}$ \\
\hline OPSO & 86,043 & $-1,364$ & 0,508 & $-1,681$ \\
ABC & 86,544 & $-1,996$ & 0,495 & $-2,107$ \\
RAPSO & 87,954 & 6,824 & $-0,535$ & $-7,000$ \\
DE & 87,985 & 6,822 & 6,099 & $-7,000$ \\
OABC & 86,551 & $-1,942$ & 1,467 & $-1,862$ \\
\hline
\end{tabular}

Tabela A.30. Estatísticas dos algoritmos de otimização bio-inspirada aplicados à restauração da imagem mostrada na Figura A.15

\begin{tabular}{|c|c|c|c|c|c|}
\hline Algoritmo & Mediana & Média & Desvio Padrão & Mínimo & Máximo \\
\hline OPSO & 86,043 & 86,305 & 0,7114 & 85,927 & 87,083 \\
ABC & 86,544 & 86,547 & 0,0112 & 86,535 & 86,582 \\
RAPSO & 87,954 & 87,913 & 0,2454 & 86,765 & 88,183 \\
DE & 87,985 & 88,026 & 0,1073 & 87,974 & 88,405 \\
OABC & 86,551 & 86,558 & 0,0345 & 86,537 & 86,725 \\
\hline
\end{tabular}
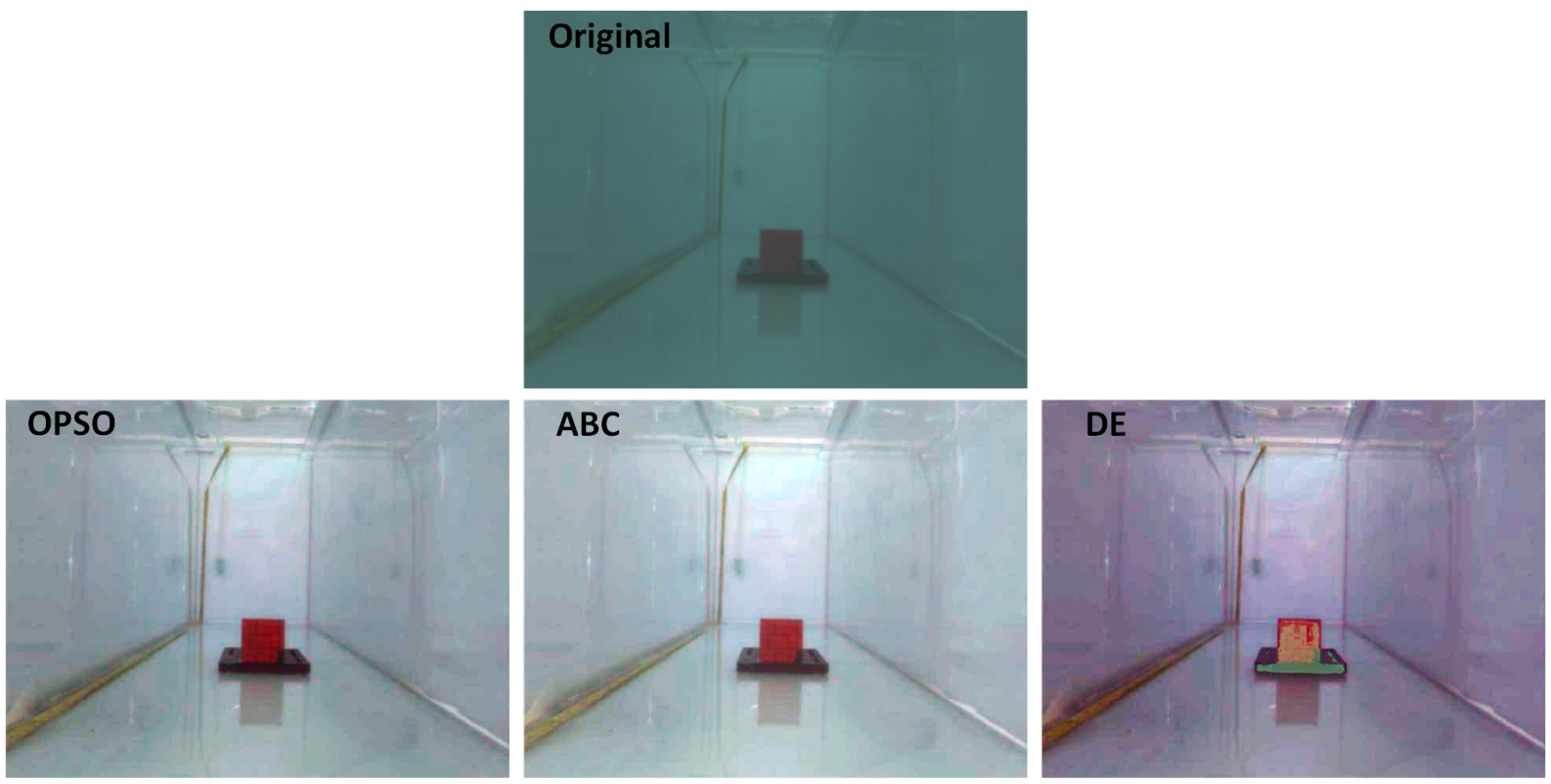

Figura A.16. Teste de restauração para imagem do UID-LEIA. 
Tabela A.31. Valores das variáveis de decisão encontrados pelos algoritmos de otimização bio-inspirada aplicados à restauração da imagem mostrada na Figura A.16

\begin{tabular}{|c|c|c|c|c|}
\hline Algoritmo & Mediana & $c$ & $K$ & $L_{\infty}$ \\
\hline OPSO & 84,297 & $-0,014$ & 0,072 & 0,238 \\
ABC & 84,940 & $-0,661$ & 0,427 & 0,748 \\
RAPSO & 86,256 & $-6,372$ & 7,000 & $-3,235$ \\
DE & 86,106 & 7,000 & $-6,377$ & 3,438 \\
OABC & 84,946 & $-2,000$ & 1,889 & $-2,000$ \\
\hline
\end{tabular}

Tabela A.32. Estatísticas dos algoritmos de otimização bio-inspirada aplicados à restauração da imagem mostrada na Figura A.16

\begin{tabular}{|c|c|c|c|c|c|}
\hline Algoritmo & Mediana & Média & Desvio Padrão & Mínimo & Máximo \\
\hline OPSO & 84,297 & 84,288 & 0,0163 & 84,256 & 84,298 \\
ABC & 84,940 & 84,939 & 0,0071 & 84,924 & 84,954 \\
RAPSO & 86,256 & 86,149 & 0,3002 & 84,942 & 86,298 \\
DE & 86,106 & 86,137 & 0,0467 & 86,105 & 86,233 \\
OABC & 84,946 & 84,946 & 0,0095 & 84,923 & 84,971 \\
\hline
\end{tabular}
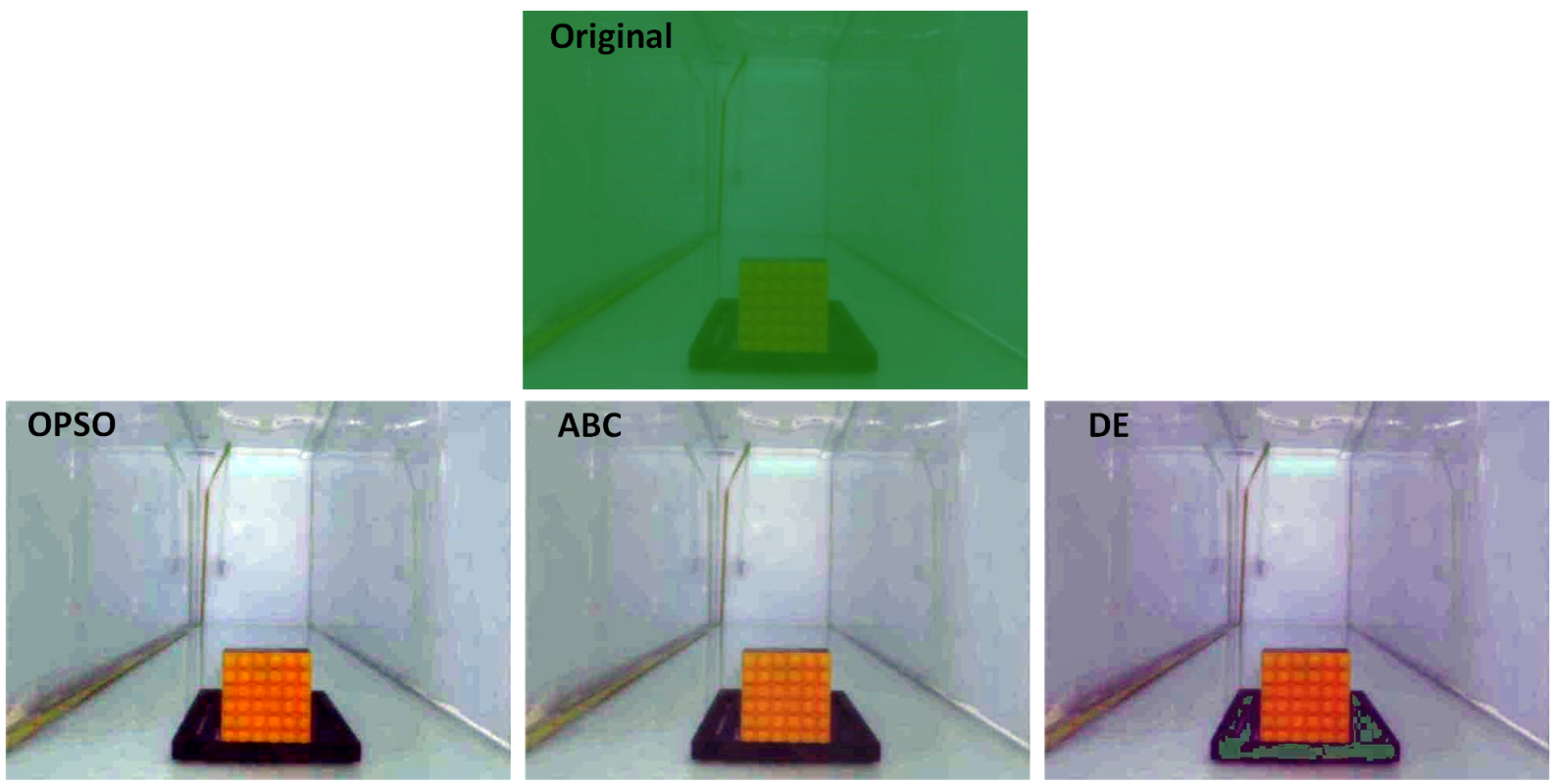

Figura A.17. Teste de restauração para imagem do UID-LEIA. 
Tabela A.33. Valores das variáveis de decisão encontrados pelos algoritmos de otimização bio-inspirada aplicados à restauração da imagem mostrada na Figura A.17.

\begin{tabular}{|c|c|c|c|c|}
\hline Algoritmo & Mediana & $c$ & $K$ & $L_{\infty}$ \\
\hline OPSO & 83,461 & $-1,122$ & $-0,444$ & $-1,273$ \\
ABC & 83,646 & $-0,947$ & 1,288 & $-1,621$ \\
RAPSO & 84,455 & 2,074 & 0,445 & 4,876 \\
DE & 84,435 & 3,862 & 4,959 & 2,740 \\
OABC & 83,654 & $-1,978$ & 1,126 & $-0,803$ \\
\hline
\end{tabular}

Tabela A.34. Estatísticas dos algoritmos de otimização bio-inspirada aplicados à restauração da imagem mostrada na Figura A.17.

\begin{tabular}{|c|c|c|c|c|c|}
\hline Algoritmo & Mediana & Média & Desvio Padrão & Mínimo & Máximo \\
\hline OPSO & 83,461 & 83,489 & 0,0809 & 83,435 & 83,713 \\
ABC & 83,646 & 83,647 & 0,0069 & 83,636 & 83,665 \\
RAPSO & 84,455 & 84,454 & 0,0076 & 84,424 & 84,467 \\
DE & 84,435 & 84,433 & 0,0179 & 84,404 & 84,472 \\
OABC & 83,654 & 83,655 & 0,0111 & 83,636 & 83,689 \\
\hline
\end{tabular}




\section{B. IMAGENS USADAS NA ANÁLISE SUBJETIVA}

Tabela B.1. Imagens usadas como referência no experimento de avaliação subjetiva.

\begin{tabular}{|c|c|c|}
\hline Imagens de Referência ( $\left.R \_1024 \times 768\right)$ & Distância (cm) & Cores no Objeto \\
\hline 0 & 20 & Branco, Vermelho, Azul, Verde \\
\hline 1 & 25 & Branco, Vermelho, Azul, Verde \\
\hline 2 & 30 & Branco, Vermelho, Azul, Verde \\
\hline 3 & 35 & Branco, Vermelho, Azul, Verde \\
\hline 4 & 40 & Branco, Vermelho, Azul, Verde \\
\hline 5 & 45 & Branco, Vermelho, Azul, Verde \\
\hline 6 & 50 & Branco, Vermelho, Azul, Verde \\
\hline 7 & 55 & Branco, Vermelho, Azul, Verde \\
\hline 8 & 60 & Branco, Vermelho, Azul, Verde \\
\hline 9 & 65 & Branco, Vermelho, Azul, Verde \\
\hline 10 & 70 & Branco, Vermelho, Azul, Verde \\
\hline 11 & 75 & Branco, Vermelho, Azul, Verde \\
\hline 12 & 80 & Branco, Vermelho, Azul, Verde \\
\hline 13 & 85 & Branco, Vermelho, Azul, Verde \\
\hline 14 & 90 & Branco, Vermelho, Azul, Verde \\
\hline 15 & 95 & Branco, Vermelho, Azul, Verde \\
\hline 16 & 100 & Branco, Vermelho, Azul, Verde \\
\hline 17 & 20 & Verde \\
\hline 18 & 25 & Verde \\
\hline 19 & 30 & Verde \\
\hline 20 & 35 & Verde \\
\hline 21 & 40 & Verde \\
\hline 22 & 45 & Verde \\
\hline 23 & 50 & Verde \\
\hline 24 & 55 & Verde \\
\hline 25 & 60 & Verde \\
\hline 26 & 65 & Verde \\
\hline 27 & 70 & Verde \\
\hline
\end{tabular}


Tabela B.1 - Continuação da tabela

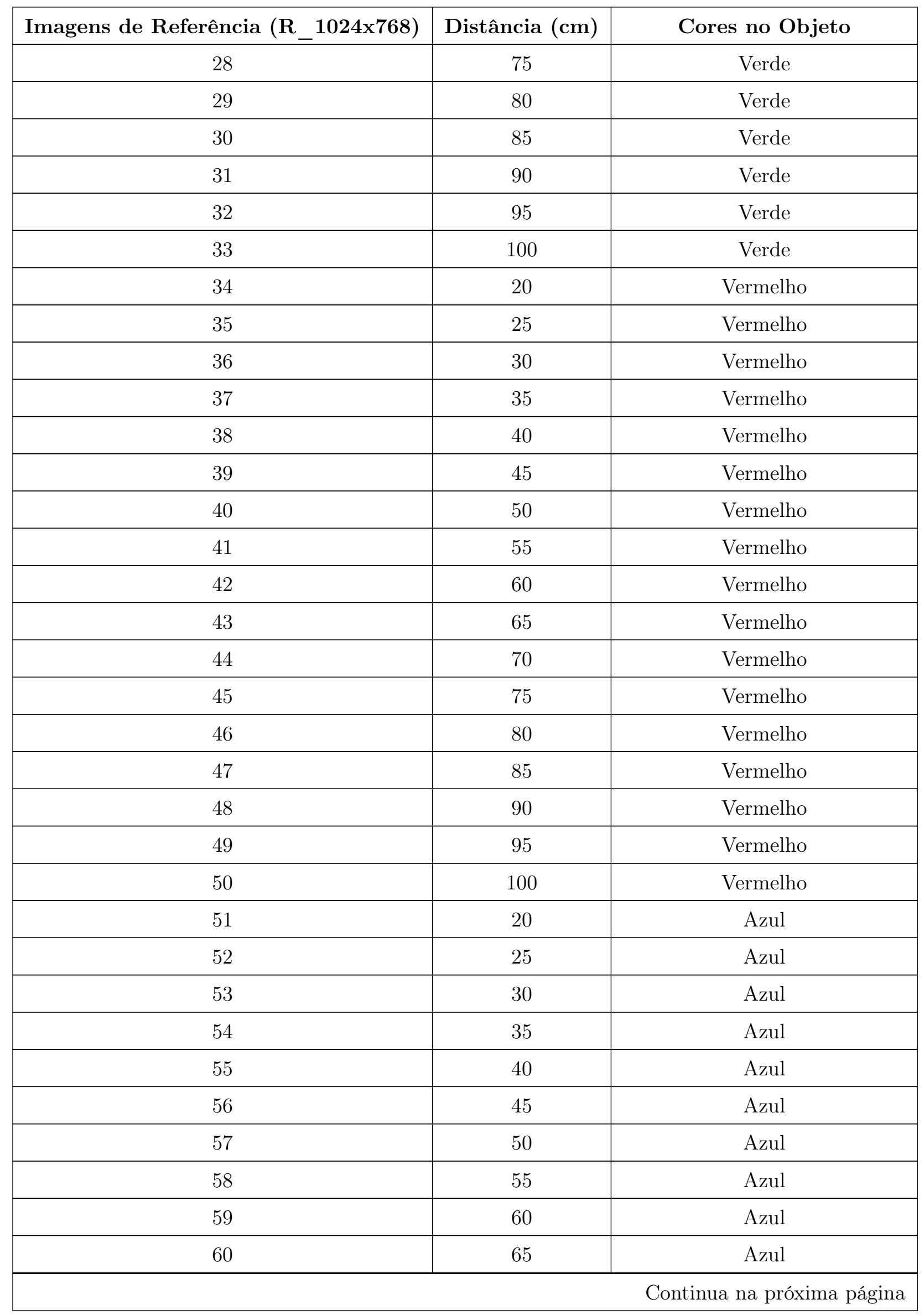


Tabela B.1 - Continuação da tabela

\begin{tabular}{|c|c|c|}
\hline Imagens de Referência $\left(\mathrm{R} \_1024 \times 768\right)$ & Distância (cm) & Cores no Objeto \\
\hline 61 & 70 & Azul \\
\hline 62 & 75 & Azul \\
\hline 63 & 80 & Azul \\
\hline 64 & 85 & Azul \\
\hline 65 & 90 & Azul \\
\hline 66 & 95 & Azul \\
\hline 67 & 100 & Azul \\
\hline 68 & 20 & Laranja \\
\hline 69 & 25 & Laranja \\
\hline 70 & 30 & Laranja \\
\hline 71 & 35 & Laranja \\
\hline 72 & 40 & Laranja \\
\hline 73 & 45 & Laranja \\
\hline 74 & 50 & Laranja \\
\hline 75 & 55 & Laranja \\
\hline 76 & 60 & Laranja \\
\hline 77 & 65 & Laranja \\
\hline 78 & 70 & Laranja \\
\hline 79 & 75 & Laranja \\
\hline 80 & 80 & Laranja \\
\hline 81 & 85 & Laranja \\
\hline 82 & 90 & Laranja \\
\hline 83 & 95 & Laranja \\
\hline 84 & 100 & Laranja \\
\hline
\end{tabular}


Tabela B.2. Imagens usadas para treinamento dos avaliadores no experimento de avaliação subjetiva.

\begin{tabular}{|c|c|c|c|c|}
\hline $\begin{array}{c}\text { Imagens de Treinamento } \\
\left(\mathbf{T} \_\mathbf{1 0 2 4 \times 7 6 8}\right)\end{array}$ & $\begin{array}{c}\text { Distância } \\
(\mathbf{c m})\end{array}$ & $\begin{array}{c}\text { Cores no } \\
\text { Objeto }\end{array}$ & Contraste & Borramento \\
\hline 0 & 55 & Verde & Baixo & Baixo \\
\hline 1 & 95 & Azul & Baixo & Alto \\
\hline 2 & 25 & $\begin{array}{c}\text { Branco, Vermelho, } \\
\text { Azul, Verde }\end{array}$ & Médio & Baixo \\
\hline 3 & 95 & $\begin{array}{c}\text { Branco, Vermelho, } \\
\text { Azul, Verde }\end{array}$ & Baixo & Muito Alto \\
\hline 4 & 25 & Verde & Alto & Muito Baixo \\
\hline 5 & 55 & Laranja & Alto & Médio \\
\hline 6 & 95 & Laranja & Médio & Muito Alto \\
\hline 7 & 25 & Vermelho & Alto & Muito Baixo \\
\hline 8 & 55 & Azul & Médio & Médio \\
\hline
\end{tabular}

Tabela B.3. Imagens avaliadas no experimento de avaliação subjetiva.

\begin{tabular}{|c|c|c|c|c|c|}
\hline $\begin{array}{c}\text { Imagem Avaliada } \\
\left(\mathbf{D} \_\mathbf{1 0 2 4 x 7 6 8}\right)\end{array}$ & $\begin{array}{c}\text { Distância } \\
\mathbf{( \mathbf { c m } )}\end{array}$ & $\begin{array}{c}\text { Cores no } \\
\text { Objeto }\end{array}$ & Contraste & Borramento & MOS \\
\hline 0 & 20 & Verde & Médio & Muito Baixo & 14,50 \\
\hline 1 & 30 & Verde & Baixo & Baixo & 21,57 \\
\hline 2 & 40 & Verde & Baixo & Baixo & 24,40 \\
\hline 3 & 50 & Verde & Baixo & Alto & 36,73 \\
\hline 4 & 60 & Verde & Baixo & Alto & 47,10 \\
\hline 5 & 70 & Verde & Muito Baixo & Muito Alto & 53,17 \\
\hline 6 & 80 & Verde & Muito Baixo & Muito Alto & 63,03 \\
\hline 7 & 90 & Verde & Muito Baixo & Muito Alto & 72,40 \\
\hline 8 & 100 & Verde & Muito Baixo & Muito Alto & 81,37 \\
\hline 9 & 20 & Vermelho & Alto & Baixo & 15,77 \\
\hline 10 & 30 & Vermelho & Médio & Baixo & 25,17 \\
\hline 11 & 40 & Vermelho & Médio & Baixo & 28,70 \\
\hline 12 & 50 & Vermelho & Médio & Médio & 45,10 \\
\hline 13 & 60 & Vermelho & Médio & Alto & 51,90 \\
\hline 14 & 70 & Vermelho & Médio & Alto & 62,97 \\
\hline & & & & Continua na próxima página \\
\hline
\end{tabular}


Tabela B.3 - Continuação da tabela

\begin{tabular}{|c|c|c|c|c|c|}
\hline $\begin{array}{l}\text { Imagem Avaliada } \\
\left(D_{-} 1024 \times 768\right)\end{array}$ & $\begin{array}{l}\text { Distância } \\
\qquad(\mathrm{cm})\end{array}$ & $\begin{array}{l}\text { Cores no } \\
\text { Objeto }\end{array}$ & Contraste & Borramento & MOS \\
\hline 15 & 80 & Vermelho & Baixo & Muito Alto & 72,90 \\
\hline 16 & 90 & Vermelho & Baixo & Muito Alto & 81,67 \\
\hline 17 & 100 & Vermelho & Baixo & Muito Alto & 86,63 \\
\hline 18 & 20 & Azul & Médio & Muito Baixo & 12,57 \\
\hline 19 & 30 & Azul & Médio & Baixo & 20,80 \\
\hline 20 & 40 & Azul & Médio & Baixo & 34,27 \\
\hline 21 & 50 & Azul & Médio & Médio & 51,37 \\
\hline 22 & 60 & Azul & Baixo & Alto & 49,17 \\
\hline 23 & 70 & Azul & Baixo & Alto & 59,40 \\
\hline 24 & 80 & Azul & Muito Baixo & Muito Alto & 70,27 \\
\hline 25 & 90 & Azul & Muito Baixo & Muito Alto & 75,50 \\
\hline 26 & 100 & Azul & Muito Baixo & Muito Alto & 82,93 \\
\hline 27 & 20 & Laranja & Alto & Muito Baixo & 11,13 \\
\hline 28 & 30 & Laranja & Alto & Baixo & 22,13 \\
\hline 29 & 40 & Laranja & Alto & Baixo & 29,43 \\
\hline 30 & 50 & Laranja & Alto & Baixo & 42,73 \\
\hline 31 & 60 & Laranja & Alto & Médio & 42,70 \\
\hline 32 & 70 & Laranja & Médio & Médio & 54,20 \\
\hline 33 & 80 & Laranja & Baixo & Alto & 64,37 \\
\hline 34 & 90 & Laranja & Baixo & Muito Alto & 74,17 \\
\hline 35 & 100 & Laranja & Muito Baixo & Muito Alto & 79,53 \\
\hline 36 & 20 & $\begin{array}{c}\text { Branco, Vermelho, } \\
\text { Azul, Verde }\end{array}$ & Médio & Baixo & 13,13 \\
\hline 37 & 30 & $\begin{array}{c}\text { Branco, Vermelho, } \\
\text { Azul, Verde }\end{array}$ & Médio & Baixo & 24,17 \\
\hline 38 & 40 & $\begin{array}{c}\text { Branco, Vermelho } \\
\text { Azul, Verde }\end{array}$ & Médio & Baixo & 33,43 \\
\hline 39 & 50 & $\begin{array}{c}\text { Branco, Vermelho, } \\
\text { Azul, Verde }\end{array}$ & Baixo & Médio & 40,00 \\
\hline 40 & 60 & $\begin{array}{c}\text { Branco, Vermelho, } \\
\text { Azul, Verde }\end{array}$ & Baixo & Alto & 48,07 \\
\hline 41 & 70 & Branco, Vermelho, & Muito Baixo & Muito Alto & 60,07 \\
\hline \multicolumn{6}{|c|}{ Continua na próxima página } \\
\hline
\end{tabular}


Tabela B.3 - Continuação da tabela

\begin{tabular}{|c|c|c|c|c|c|}
\hline $\begin{array}{l}\text { Imagem Avaliada } \\
\left(D_{-1024 \times 768)}\right.\end{array}$ & $\begin{array}{l}\text { Distância } \\
\qquad(\mathrm{cm})\end{array}$ & $\begin{array}{l}\text { Cores no } \\
\text { Objeto }\end{array}$ & Contraste & Borramento & MOS \\
\hline & & Azul, Verde & & & \\
\hline 42 & 80 & $\begin{array}{c}\text { Branco, Vermelho, } \\
\text { Azul, Verde }\end{array}$ & Muito Baixo & Muito Alto & 70,33 \\
\hline 43 & 90 & $\begin{array}{c}\text { Branco, Vermelho, } \\
\text { Azul, Verde }\end{array}$ & Muito Baixo & Muito Alto & 81,60 \\
\hline 44 & 100 & $\begin{array}{c}\text { Branco, Vermelho, } \\
\text { Azul, Verde }\end{array}$ & Muito Baixo & Muito Alto & 79,50 \\
\hline 45 & 20 & $\begin{array}{c}\text { Branco, Vermelho, } \\
\text { Azul, Verde }\end{array}$ & Alto & Médio & 9,20 \\
\hline 46 & 30 & $\begin{array}{c}\text { Branco, Vermelho, } \\
\text { Azul, Verde }\end{array}$ & Alto & Médio & 20,23 \\
\hline 47 & 40 & $\begin{array}{c}\text { Branco, Vermelho, } \\
\text { Azul, Verde }\end{array}$ & Médio & Alto & 34,13 \\
\hline 48 & 50 & $\begin{array}{c}\text { Branco, Vermelho, } \\
\text { Azul, Verde }\end{array}$ & Médio & Alto & 42,83 \\
\hline 49 & 60 & $\begin{array}{c}\text { Branco, Vermelho, } \\
\text { Azul, Verde }\end{array}$ & Baixo & Alto & 59,07 \\
\hline 50 & 70 & $\begin{array}{c}\text { Branco, Vermelho, } \\
\text { Azul, Verde }\end{array}$ & Baixo & Muito Alto & 66,97 \\
\hline 51 & 80 & $\begin{array}{c}\text { Branco, Vermelho, } \\
\text { Azul, Verde }\end{array}$ & Baixo & Muito Alto & 74,70 \\
\hline 52 & 90 & $\begin{array}{c}\text { Branco, Vermelho, } \\
\text { Azul, Verde }\end{array}$ & Muito Baixo & Muito Alto & 86,20 \\
\hline 53 & 100 & $\begin{array}{c}\text { Branco, Vermelho, } \\
\text { Azul, Verde }\end{array}$ & Muito Baixo & Muito Alto & 91,53 \\
\hline 54 & 20 & Verde & Médio & Médio & 12,90 \\
\hline 55 & 30 & Verde & Médio & Médio & 16,77 \\
\hline 56 & 40 & Verde & Médio & Médio & 27,13 \\
\hline 57 & 50 & Verde & Baixo & Alto & 39,20 \\
\hline 58 & 60 & Verde & Baixo & Alto & 57,33 \\
\hline 59 & 70 & Verde & Muito Baixo & Muito Alto & 67,33 \\
\hline 60 & 80 & Verde & Muito Baixo & Muito Alto & 82,37 \\
\hline
\end{tabular}


Tabela B.3 - Continuação da tabela

\begin{tabular}{|c|c|c|c|c|c|}
\hline $\begin{array}{l}\text { Imagem Avaliada } \\
\left(D_{-} 1024 \times 768\right)\end{array}$ & $\begin{array}{l}\text { Distância } \\
\quad(\mathrm{cm})\end{array}$ & $\begin{array}{c}\text { Cores no } \\
\text { Objeto }\end{array}$ & Contraste & Borramento & MOS \\
\hline 61 & 90 & Verde & Muito Baixo & Muito Alto & 89,33 \\
\hline 62 & 100 & Verde & Muito Baixo & Muito Alto & 92,63 \\
\hline 63 & 20 & Laranja & Alto & Baixo & 14,33 \\
\hline 64 & 30 & Laranja & Alto & Baixo & 19,33 \\
\hline 65 & 40 & Laranja & Alto & Médio & 32,10 \\
\hline 66 & 50 & Laranja & Alto & Médio & 42,37 \\
\hline 67 & 60 & Laranja & Médio & Alto & 56,47 \\
\hline 68 & 70 & Laranja & Médio & Alto & 64,23 \\
\hline 69 & 80 & Laranja & Médio & Muito Alto & 76,57 \\
\hline 70 & 90 & Laranja & Baixo & Muito Alto & 83,33 \\
\hline 71 & 100 & Laranja & Baixo & Muito Alto & 89,67 \\
\hline 72 & 20 & Azul & Alto & Muito Baixo & 10,10 \\
\hline 73 & 30 & Azul & Alto & Baixo & 21,13 \\
\hline 74 & 40 & Azul & Alto & Médio & 32,43 \\
\hline 75 & 50 & Azul & Médio & Médio & 46,90 \\
\hline 76 & 60 & Azul & Baixo & Alto & 62,00 \\
\hline 77 & 70 & Azul & Baixo & Muito Alto & 73,20 \\
\hline 78 & 80 & Azul & Muito Baixo & Muito Alto & 83,23 \\
\hline 79 & 90 & Azul & Muito Baixo & Muito Alto & 91,47 \\
\hline 80 & 100 & Azul & Muito Baixo & Muito Alto & 96,03 \\
\hline 81 & 20 & Vermelho & Alto & Baixo & 15,87 \\
\hline 82 & 30 & Vermelho & Alto & Médio & 20,40 \\
\hline 83 & 40 & Vermelho & Alto & Médio & 36,37 \\
\hline 84 & 50 & Vermelho & Médio & Alto & 55,93 \\
\hline 85 & 60 & Vermelho & Médio & Alto & 64,70 \\
\hline 86 & 70 & Vermelho & Médio & Muito Alto & 78,33 \\
\hline 87 & 80 & Vermelho & Baixo & Muito Alto & 81,03 \\
\hline 88 & 90 & Vermelho & Baixo & Muito Alto & 90,63 \\
\hline 89 & 100 & Vermelho & Muito Baixo & Muito Alto & 96,10 \\
\hline 90 & 20 & Laranja & Alto & Baixo & 13,43 \\
\hline 91 & 30 & Laranja & Alto & Baixo & 17,77 \\
\hline 92 & 40 & Laranja & Alto & Baixo & 27,30 \\
\hline
\end{tabular}


Tabela B.3 - Continuação da tabela

\begin{tabular}{|c|c|c|c|c|c|}
\hline $\begin{array}{l}\text { Imagem Avaliada } \\
\left(D_{-1024 \times 768)}\right.\end{array}$ & $\begin{array}{l}\text { Distância } \\
\qquad(\mathrm{cm})\end{array}$ & $\begin{array}{c}\text { Cores no } \\
\text { Objeto }\end{array}$ & Contraste & Borramento & MOS \\
\hline 93 & 50 & Laranja & Alto & Médio & 35,30 \\
\hline 94 & 60 & Laranja & Alto & Médio & 45,67 \\
\hline 95 & 70 & Laranja & Médio & Alto & 59,87 \\
\hline 96 & 80 & Laranja & Médio & Alto & 61,33 \\
\hline 97 & 90 & Laranja & Médio & Muito Alto & 72,13 \\
\hline 98 & 100 & Laranja & Baixo & Muito Alto & 81,87 \\
\hline 99 & 20 & Verde & Alto & Baixo & 13,30 \\
\hline 100 & 30 & Verde & Alto & Baixo & 14,87 \\
\hline 101 & 40 & Verde & Alto & Baixo & 28,93 \\
\hline 102 & 50 & Verde & Médio & Médio & 40,90 \\
\hline 103 & 60 & Verde & Médio & Médio & 48,87 \\
\hline 104 & 70 & Verde & Médio & Alto & 60,20 \\
\hline 105 & 80 & Verde & Baixo & Alto & 66,57 \\
\hline 106 & 90 & Verde & Muito Baixo & Muito Alto & 74,67 \\
\hline 107 & 100 & Verde & Muito Baixo & Muito Alto & 82,13 \\
\hline 108 & 20 & Vermelho & Alto & Baixo & 15,27 \\
\hline 109 & 30 & Vermelho & Alto & Médio & 24,80 \\
\hline 110 & 40 & Vermelho & Alto & Médio & 33,10 \\
\hline 111 & 50 & Vermelho & Alto & Alto & 49,33 \\
\hline 112 & 60 & Vermelho & Alto & Alto & 56,53 \\
\hline 113 & 70 & Vermelho & Alto & Muito Alto & 67,10 \\
\hline 114 & 80 & Vermelho & Médio & Muito Alto & 76,13 \\
\hline 115 & 90 & Vermelho & Médio & Muito Alto & 80,43 \\
\hline 116 & 100 & Vermelho & Baixo & Muito Alto & 86,57 \\
\hline 117 & 20 & Azul & Alto & Muito Baixo & 10,33 \\
\hline 118 & 30 & Azul & Alto & Baixo & 18,20 \\
\hline 119 & 40 & Azul & Alto & Baixo & 23,00 \\
\hline 120 & 50 & Azul & Médio & Médio & 39,50 \\
\hline 121 & 60 & Azul & Médio & Médio & 56,30 \\
\hline 122 & 70 & Azul & Baixo & Alto & 64,13 \\
\hline 123 & 80 & Azul & Baixo & Muito Alto & 76,37 \\
\hline 124 & 90 & Azul & Muito Baixo & Muito Alto & 81,17 \\
\hline \multicolumn{6}{|c|}{ Continua na próxima página } \\
\hline
\end{tabular}


Tabela B.3 - Continuação da tabela

\begin{tabular}{|c|c|c|c|c|c|}
\hline $\begin{array}{c}\text { Imagem Avaliada } \\
\left(D_{-1024 \times 768)}\right.\end{array}$ & $\begin{array}{l}\text { Distância } \\
\qquad(\mathrm{cm})\end{array}$ & $\begin{array}{c}\text { Cores no } \\
\text { Objeto }\end{array}$ & Contraste & Borramento & MOS \\
\hline 125 & 100 & Azul & Muito Baixo & Muito Alto & 86,97 \\
\hline 126 & 20 & $\begin{array}{c}\text { Branco, Vermelho, } \\
\text { Azul, Verde }\end{array}$ & Alto & Baixo & 12,60 \\
\hline 127 & 30 & $\begin{array}{c}\text { Branco, Vermelho, } \\
\text { Azul, Verde }\end{array}$ & Alto & Baixo & 24,83 \\
\hline 128 & 40 & $\begin{array}{c}\text { Branco, Vermelho, } \\
\text { Azul, Verde }\end{array}$ & Alto & Médio & 34,10 \\
\hline 129 & 50 & $\begin{array}{c}\text { Branco, Vermelho, } \\
\text { Azul, Verde }\end{array}$ & Médio & Médio & 49,43 \\
\hline 130 & 60 & $\begin{array}{c}\text { Branco, Vermelho, } \\
\text { Azul, Verde }\end{array}$ & Médio & Médio & 53,80 \\
\hline 131 & 70 & $\begin{array}{c}\text { Branco, Vermelho, } \\
\text { Azul, Verde }\end{array}$ & Baixo & Alto & 61,27 \\
\hline 132 & 80 & $\begin{array}{c}\text { Branco, Vermelho, } \\
\text { Azul, Verde }\end{array}$ & Baixo & Alto & 67,33 \\
\hline 133 & 90 & $\begin{array}{c}\text { Branco, Vermelho, } \\
\text { Azul, Verde }\end{array}$ & Muito Baixo & Muito Alto & 75,77 \\
\hline 134 & 100 & $\begin{array}{c}\text { Branco, Vermelho, } \\
\text { Azul, Verde }\end{array}$ & Muito Baixo & Muito Alto & 83,77 \\
\hline
\end{tabular}

